\title{
RFID ON THE BOUNDARY BETWEEN THE PUBLIC AND PRIVATE SECTORS: AN ANT/INSTITUTIONAL THEORY INVESTIGATION
}

\section{BY}

MARTA ELIZABETH VOS

\begin{abstract}
A thesis
submitted to the Victoria University of Wellington

in fulfilment of the requirements for the degree of

Doctor of Philosophy
\end{abstract}

Victoria University of Wellington

2014 



\begin{abstract}
Radio frequency identification (RFID) enabled devices are becoming increasingly common in today's world, facilitating many things from supply chain efficiencies to medical equipment tracking. The majority of studies into such systems centre on technical and engineering issues associated with their implementation and operation. Research outside of this scope generally focuses on RFID systems in isolated private sector supply chains. Less common is research on RFID systems within the public sector, and this research generally occurs within the health, defence, or agriculture areas.
\end{abstract}

Using a combination of Actor-Network Theory (ANT) and Institutional Theory, this qualitative study examines how RFID is used within the public sector/private sector RFID network. Interactions across public and private sector RFID networks are examined in order to identify common themes within the network, and to determine where the needs of the two sectors diverge. Twelve themes were identified that acted as ANT mediators within the network, across three dimensions. These mediators differed in activity depending on where within the ANT translation they were strongest. A number of the mediators were also found to exert institutional pressures on organisations within the network, contributing to their strength during translation.

The relationship between the two sectors was also examined. Findings indicated that some mediators were stronger within the public sector, particularly with respect to privacy and legislation. It was further found that the relationship between the two sectors was confused by the multiple different roles taken by the public sector within the translation. This multiplicity at times confused both public and private sector partners, leading to uncertainty within the network.

This study contributes to research by addressing a gap in understanding of RFID systems in the public-private sector context. It also provides practitioners with a guideline as to which mediators should be addressed when contemplating an RFID system within this context, as well as indicating possible reasons the relationship between organisations in the two sectors may be challenging. In addition, the unusual combination of ANT and Institutional Theory contributes to theory by pointing 
towards a possible new way to investigate complex technology systems at the organisational level. 


\section{Acknowledgements}

The course of a PhD is a long one, and along the way, there are many people and organisations without whom the journey would be impossible. Firstly, I would like to thank GS1 New Zealand, for supporting my study with the GS1/EPCGlobal Scholarship, and for providing advice and encouragement beyond the call of duty. I would also like to acknowledge the VUW Post Graduate Students Association for their Excellence Award, which allowed me to attend a conference.

Without the help and guidance of my supervisors, Professor Rowena Cullen and Dr Jocelyn Cranefield this research would not have been possible. Thank you both for keeping me on track through the good times and the rough, and for your sage advice. Similarly, my student colleagues, Rashidah, Namali, Geetha, Diane, Nicole, Balsam, Van, lan and the other students within SIM, you made the journey easier, and far more fun. Thank you all.

To all my participants, human and non-human alike, I would like to say thank you for the gift of your time, and wisdom. I was delighted by how willing the local and international RFID community was to help with this project, and feel this reflects the quality of the individuals within that community.

There were those who helped me technically and administratively who made my life, and study, much easier. Particularly I would like to acknowledge Usha, Jean, Chris, Nicole and Wendy who helped me fill in everything that need to be filled in, and find everything else; Jess Pinker who help with transcriptions, and Louis Schmitt who helped with copy editing.

I would also like to thank Penny, Sarah, Tracey and my other friends, whose encouragement was endless and whose support was invaluable. Finally I would like to thank my husband Grant who supported me without reservation, and encouraged me to pursue the challenge of PhD study, and my father Hank, whose respect for education began this whole journey. This thesis is dedicated to them. 


\section{Contents}

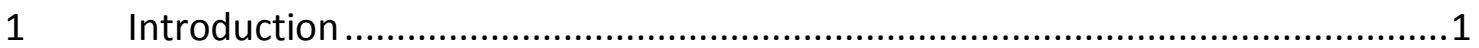

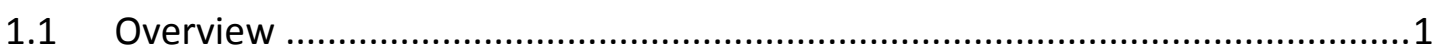

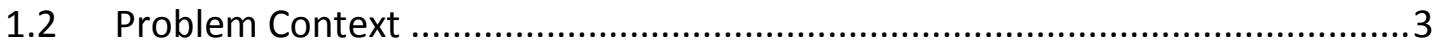

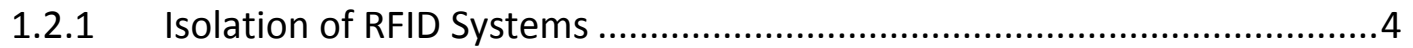

1.2.2 Issues Identified by RFID Research ..........................................................

1.2.3 How are RFID Systems Established? .....................................................

1.2.4 The Need for Broader Research ...........................................................6

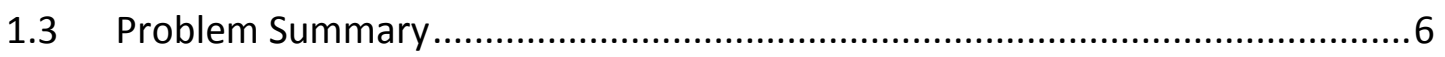

$1.4 \quad$ Research Objectives and Question ............................................................

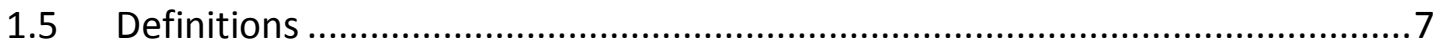

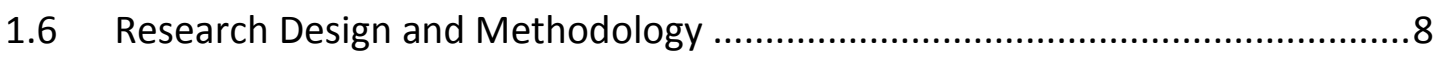

1.6.1 Theoretical Approach to this Research .................................................

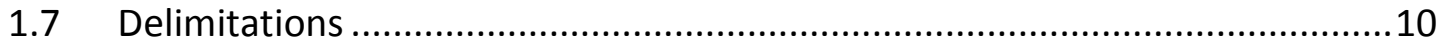

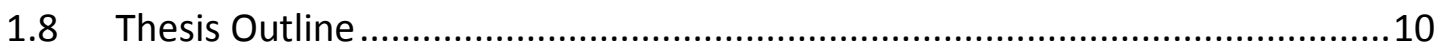

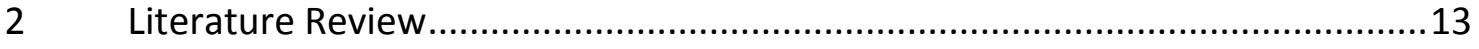

2.1 Radio Frequency Identification - From Identification to Smart Chips.............13

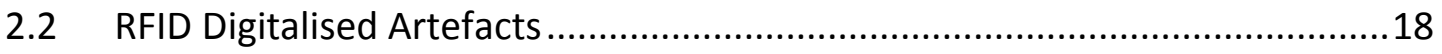

2.3 The Ubiquitous, Pervasive, Disappearing, Invisible, Experiential Internet of

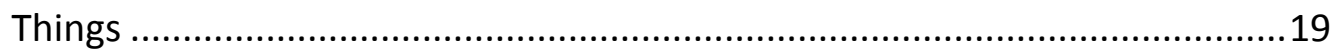

2.4 Technology in Government - e or u-Government.........................................23

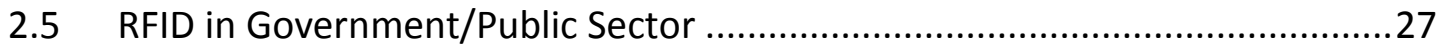

2.6 RFID Research - Themes from Literature .................................................29

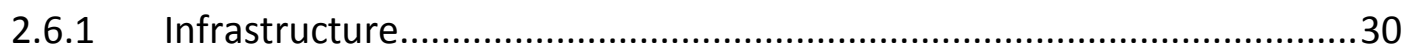

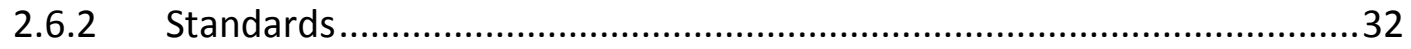

2.6.3 Interoperability and Information Sharing .........................................34

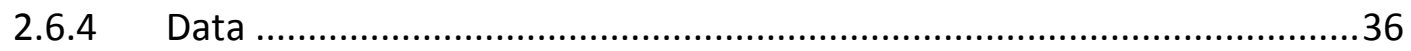

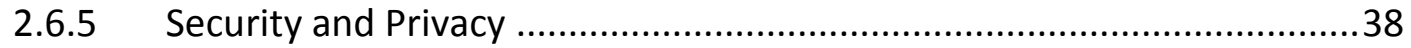

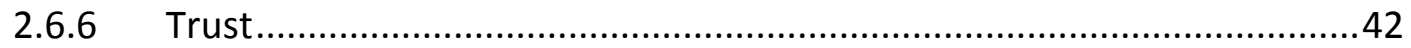

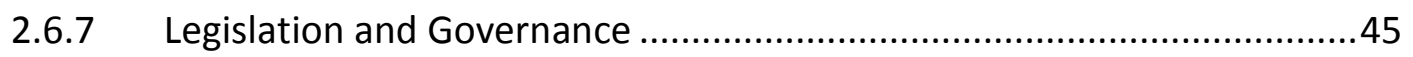

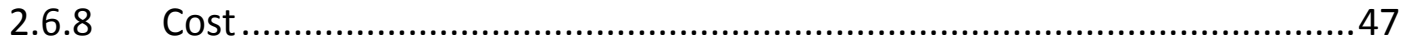

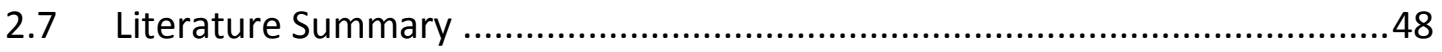


3 Theoretical and Methodological Basis of this Study

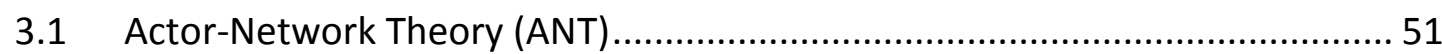

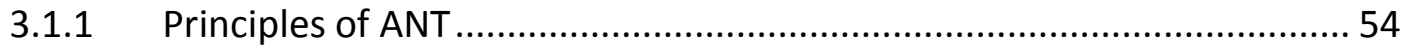

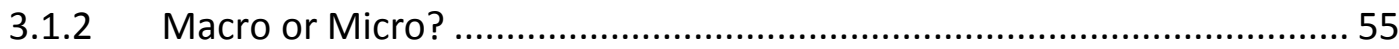

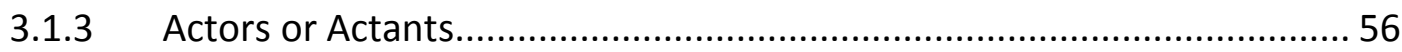

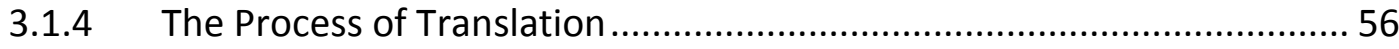

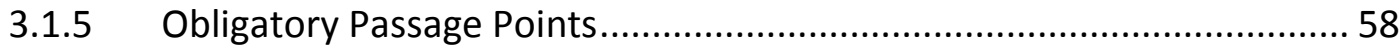

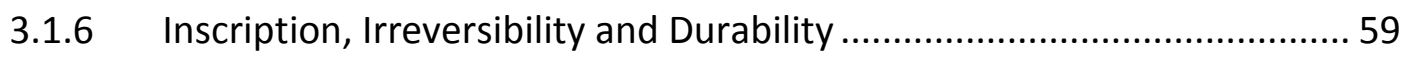

3.1.7 Black Boxes and Immutable Mobiles ...................................................... 61

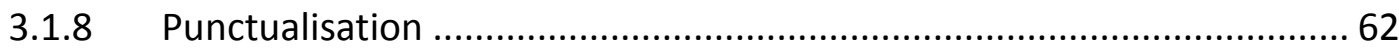

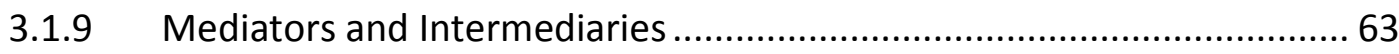

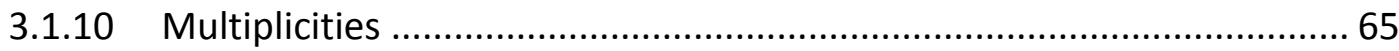

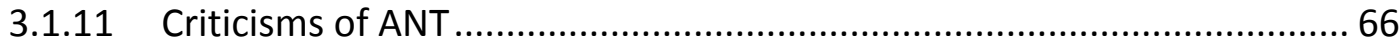

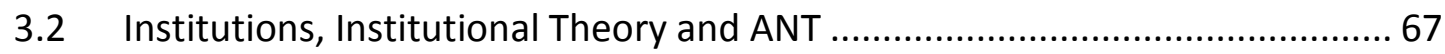

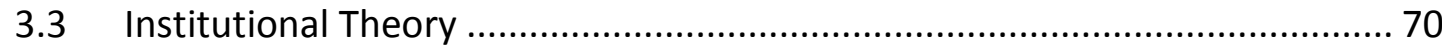

3.4 Summary and Research Questions ............................................................... 74

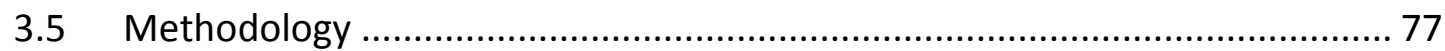

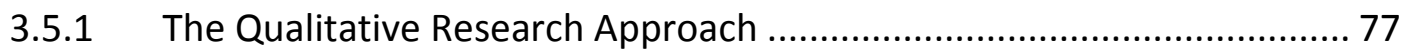

3.5.2 Locating and Following the Actant .................................................. 78

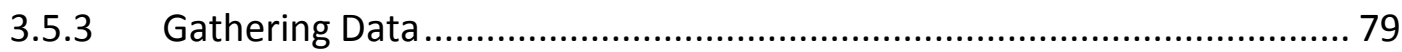

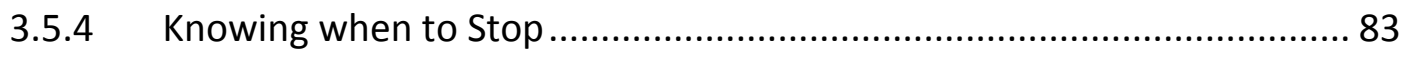

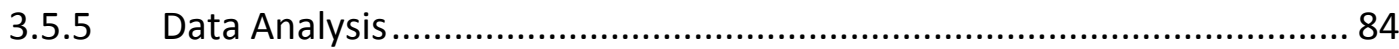

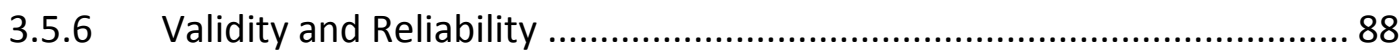

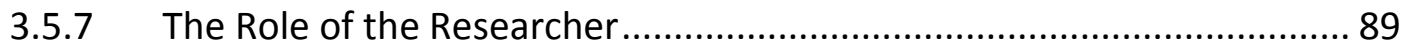

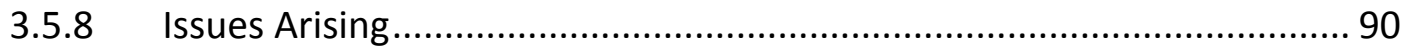

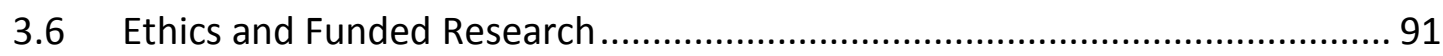

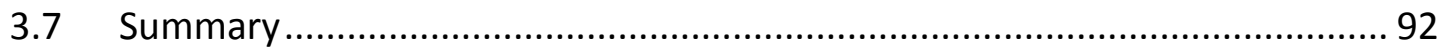

$4 \quad$ Findings: The Translation of the RFID Network ….......................................... 93

4.1 ANT - A Translation View of the RFID Public-Private Network ...................... 94

4.1.1 Understanding the Problem/Problematisation .................................... 94

4.1.2 A Short Journey Through Obligatory Passage Points.............................. 98

4.1.3 Recruiting Others - Interessement................................................ 100 


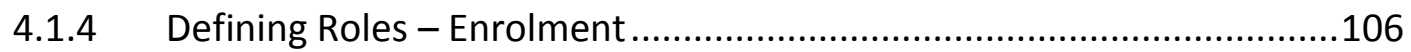

4.1.5 Working Together - Mobilisation .......................................................111

4.1.6 The Future of the Network/ Mobilising the Internet of Things ............113

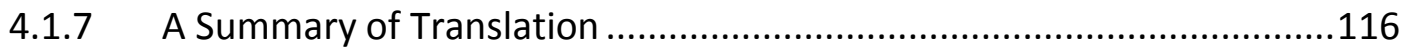

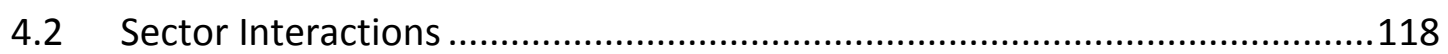

4.2.1 Contrasting Public \& Private ................................................................ 118

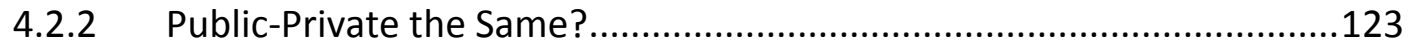

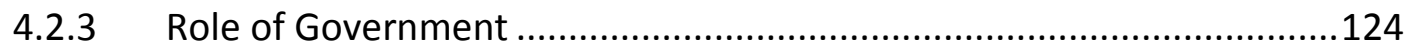

4.2.4 Organisations Working Together …................................................... 125

4.3 An ANT/Institutional Approach to Organisational Interactions.....................129

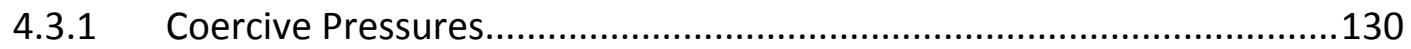

4.3.2 Mimetic Pressures ......................................................................... 132

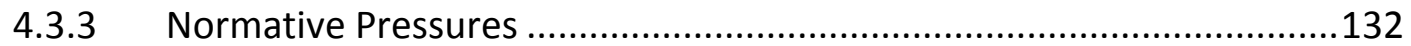

4.3.4 Responses to Institutional Pressures/Enrolment................................133

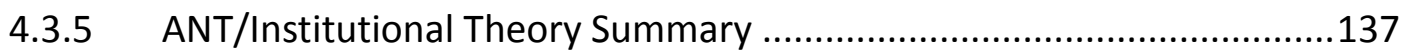

4.4 Summary: Organisational Interactions …..................................................

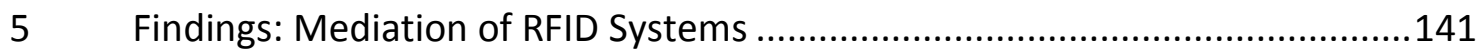

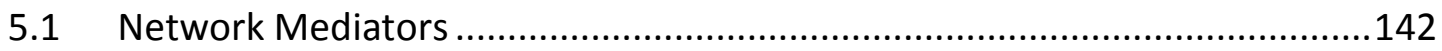

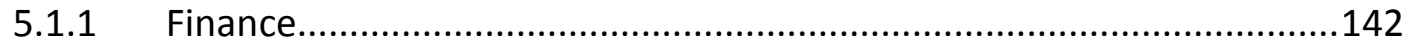

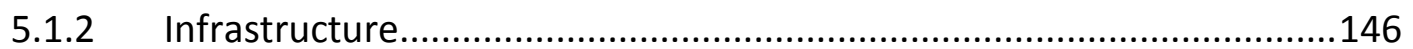

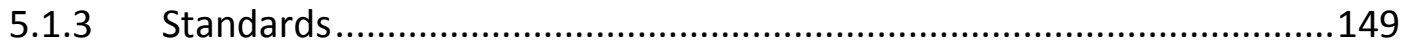

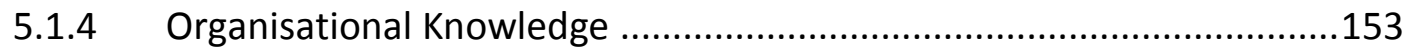

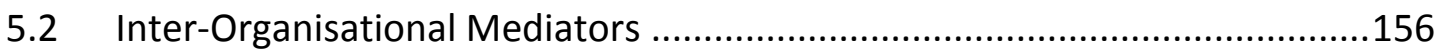

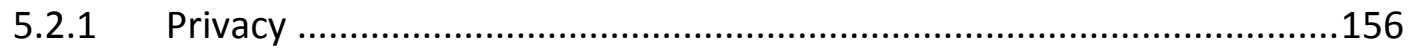

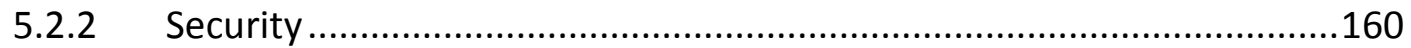

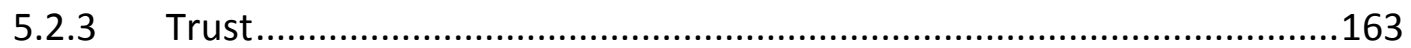

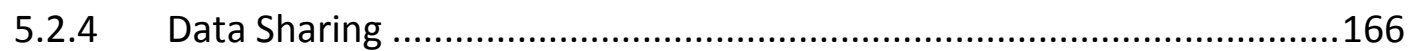

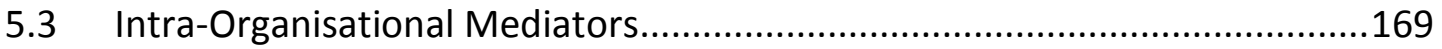

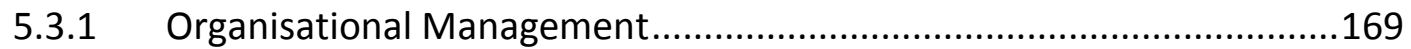

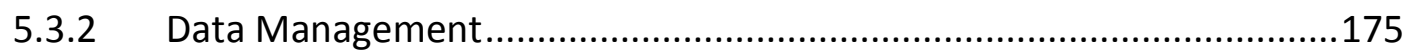

5.3.3 Benefits/Business Case .................................................................177

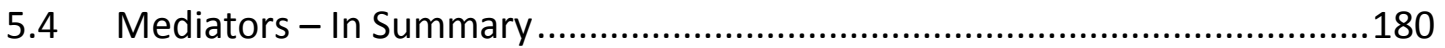


6.1 RQa.: Translating the Network - How the Relationship Between the Actants

Contributes to Establishing and Maintaining the Network 184

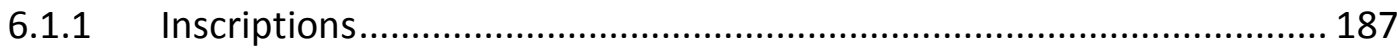

6.1.2 Obligatory Passage Points, Dissenters and Challenges ........................ 188

6.1.3 Micro and Macro-Perspectives and the Internet of Things.................. 190

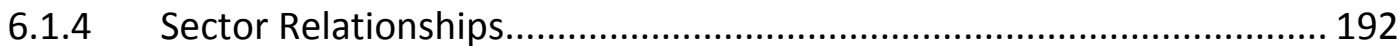

6.1.5 "Public Sector" as a Multiplicity.......................................................... 193

6.2 RQb.: How Mediators Drive the Network .................................................. 195

6.3 RQc.: Macro Perspectives, Sectors and Institutional Theory ........................ 200

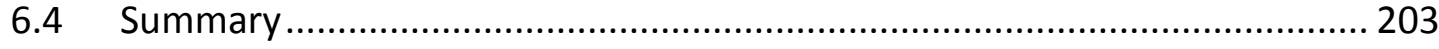

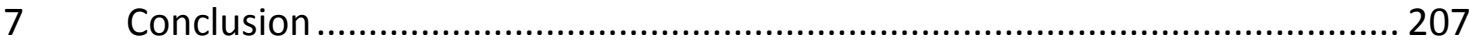

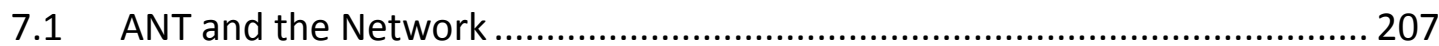

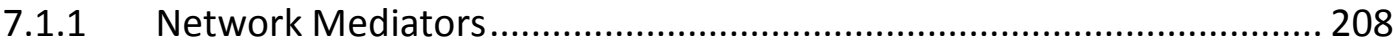

7.1.2 Network Translation ........................................................................ 209

7.1.3 ANT and Institutional Theory ............................................................. 210

7.2 The RFID Network in the Public-Private Sector Context ............................. 212

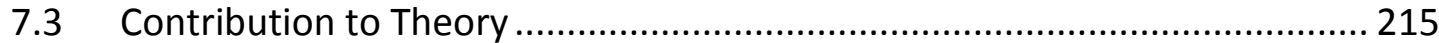

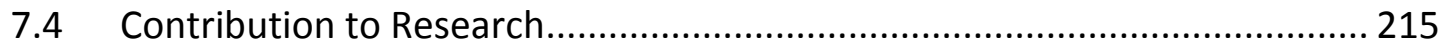

7.5 Contribution/Implications for Practice .......................................................... 216

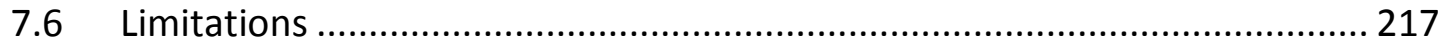

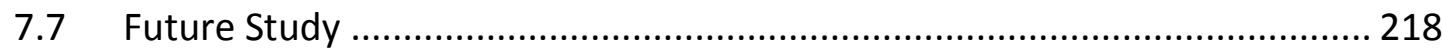

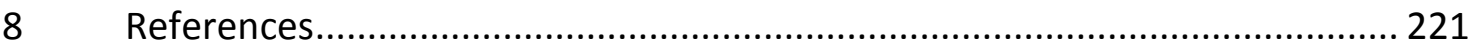

$9 \quad$ Appendix A - Inductive Coding Table ........................................................ 241

10 Appendix B - Deductive Coding Table ..................................................... 247

11 Appendix C - Contact Summary Sheet ....................................................... 249

$12 \quad$ Appendix D - Consent to Participate .......................................................... 251

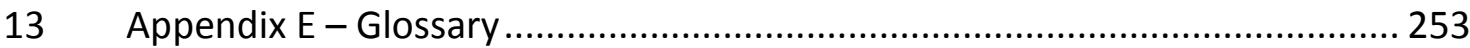




\section{List of Figures}

Figure 1: Early IFF System Tag and Reader Operation .............................................

Figure 2: Summary of Computing Models.................................................................. 19

Figure 3: Government computing models - e, $\mathrm{m}$ or $\mathrm{u}$ ? .............................................26

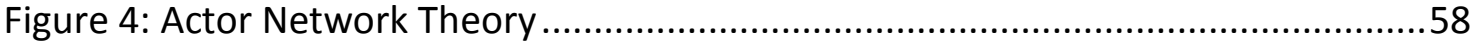

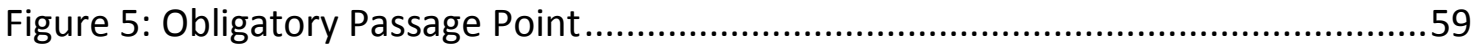

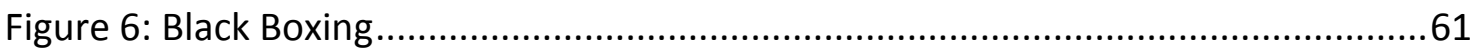

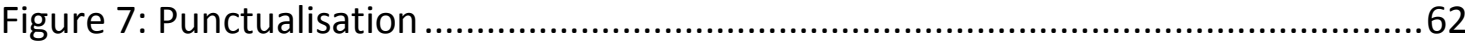

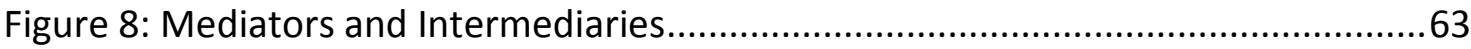

Figure 9: ANT and Institutional Theory Responses .................................................... 74

Figure 10: Stabilisers or De-Stabilisers of Translation ................................................ 75

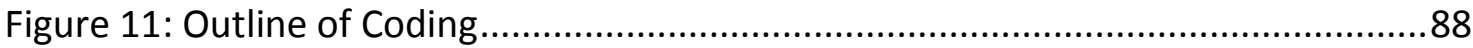

Figure 12: ANT and Institutional Theory Responses ..............................................130

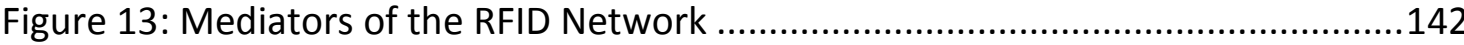

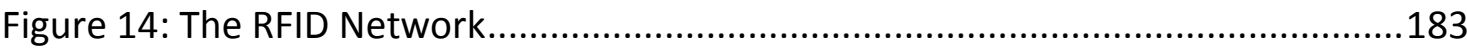

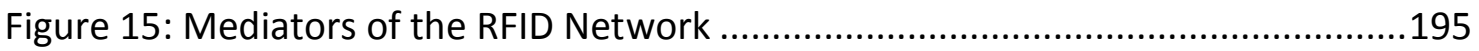

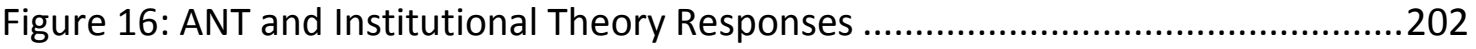




\section{List of Tables}

Table 1: Analysis of non-human actant interests and representatives ........................ 82

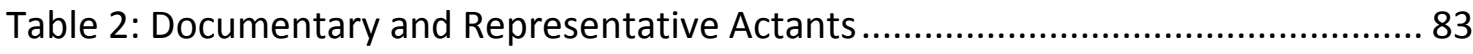

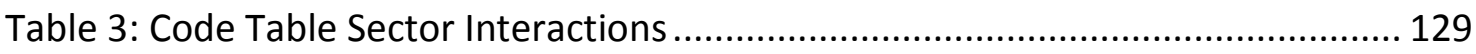

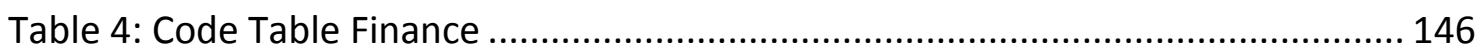

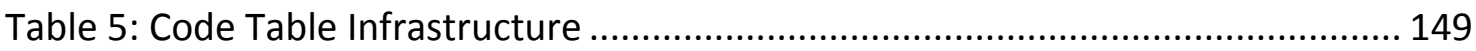

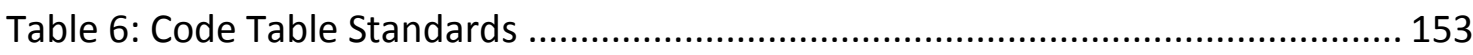

Table 7: Code Table Organisational Knowledge ..................................................... 156

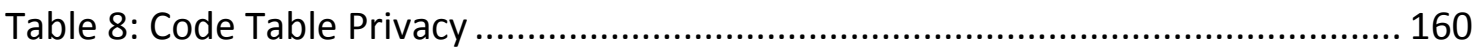

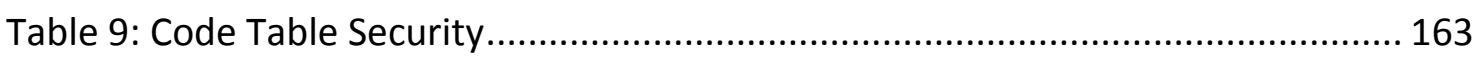

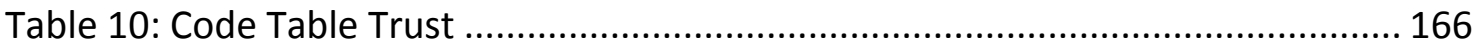

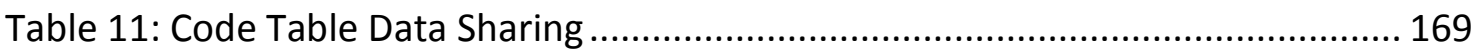

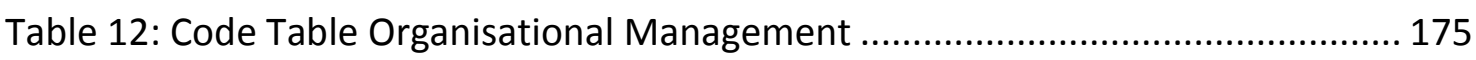

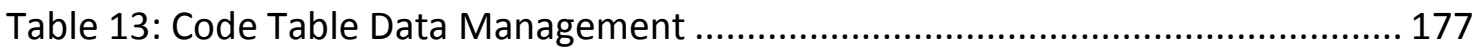

Table 14: Code Table Benefits/Business Case ....................................................... 180

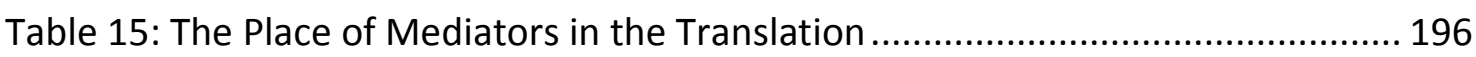




\section{Introduction}

This research was motivated by the desire to investigate how Radio Frequency Identification (RFID) enabled devices are used in applications which are shared between the public and private sector, or where both public and private sector (public-private) entities are involved in one RFID system. Public-private RFID enabled systems might occur in supply chain applications, where both public and private sector organisations use RFID enabled devices to track and trace items along a single supply chain. Applications can also be more complex, such as animal health and traceability systems involving farmers, farming entities, governance bodies, animal health, and public sector agricultural organisations, enabling regulations and RFID sensors.

RFID systems within the public-private context are currently under-researched even though they are becoming broadly implemented. Thus, the implications of such systems need careful consideration and understanding.

This thesis will relate the story of this investigation, and report findings in relation to the operation of RFID enabled technology systems that are shared between the public and private sectors. It will discuss how these systems are established and maintained, primarily using Actor Network Theory (ANT) as a framework for this understanding. This first chapter will present an introduction to the research, and a brief overview of the nature and use of RFID systems in the public-private sector context.

\subsection{Overview}

The story of human interaction with computing devices goes as far back as $2300 \mathrm{BCE}$, with Ifrah (2001) noting the appearance of what is considered to be the first computing device - the abacus. Today the abacus would hardly be considered, or recognised to be a computer as it lacks electronic components. Rosenberg (2004) believes that modern electronic computing has its origins in the ENIAC computer of the early 1940's, the first computer considered to be digital and fully capable of reprogramming. Radio Frequency Identification (RFID) also arose during the early 1940s, as a result of World War II when the British Royal Air Force developed a radar based system to identify incoming aircraft known as the "Identification Friend or Foe 
(IFF)" system (Banks, Pachano, Thompson, \& Hanny, 2007). According to Miles, (2008) this system was based on a radio frequency transponder (or tag) on the aircraft responding correctly to an enquiry from the ground based interrogator (or reader) in order to identify friendly aircraft, this process is demonstrated by Figure 1. Although RFID technology became commonplace in the 1970's, this basic conformation of tag and reader is still in use in current RFID applications (C. M. Roberts, 2006). Today, we exist in a world awash with devices that have computing

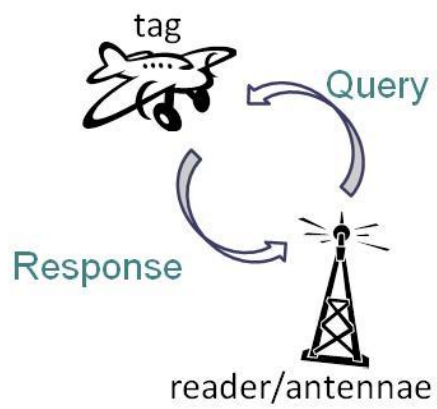

Figure 1: Early IFF System Tag and Reader Operation capabilities. Apart from the easily recognised personal computer, mobile phones and calculators, there are nanotechnology and sensor devices of all sorts, not to mention RFID enabled devices. The nature of human interaction with these less obvious digitalised devices is also changing, as is the way technology is viewed by people and organisations.

Today's RFID technology facilitates a wide range of different processes and actions, from its most common application in smoothing the supply chain, to innovative uses such as tagging bees in order to study their foraging behaviour, related by Swedberg (2011). According to Wyld (2005) the utility of these RFID enabled applications is significantly enhanced by the ability of such systems to identify individual items rather than simply identifying item type, through the use of an Electronic Product Code (EPC). This coding allows for the identification and location of individual items, and is an advance on the familiar barcode type systems, which can identify items only to the item (or product) type (Wyld, 2005).

As well as supply chain uses, RFID facilitates new possibilities for human/computer interaction arising both from different ways a computer can be used, and the increasing commonness of computing devices with the capability to interact with the Internet, and with each other. These new interactions and uses have attracted a range of theories and models to describe them. Terms such as ubiquitous computing, first coined by Weiser (1991), disappearing computing, pervasive, calm, invisible, and 
experiential computing have all been used to describe similar, if not the same, relationships between people and computing devices.

One of the most widely discussed models of the future of human interaction with computers and computing devices is the Internet of Things, a concept of the future where RFID enabled products (things) with unique EPCs communicate with each other, their owners, and the Internet (Slettemeas, 2009; Welbourne et al., 2009). Konomi and Roussos (2007) believe that the ability of objects to connect to each other, and the Internet, is a key to the Internet of Things future, and RFID is the technology through which much of this communication is happening.

Researchers are now looking to extend even further this concept of the RFID enabled Internet of Things. Yoo (2010) suggests that computing will become experiential going beyond human interactions with computers for the purpose of performing tasks, instead focusing on digitally mediated everyday life experiences. Similar to its role in the Internet of Things, RFID plays a central role in this model facilitating the communication of RFID equipped items, known as digitalised artefacts, with each other, people, and organisations, via the Internet.

\subsection{Problem Context}

The spread of RFID technology has attracted the interest of a number of researchers. Irani, Gunasekaran and Dwivedi (2010), analysed 666 peer reviewed academic papers covering 283 journals, finding that the majority were technical in nature with $60 \%$ looking at technology development issues, $9.5 \%$ supply chain management and $8 \%$ adoption issues. The economic, legal, political or social environment was discussed in only $7.5 \%$ of papers. They also found that there was a relative lack of publications in respect of government, ethics or legal issues relating to RFID, and noted that publications in this category were mainly dominated by research into privacy. Ngai et al. (2008) analysed 85 academic papers and came to similar conclusions, finding that papers on RFID technology and hardware made up $36 \%$ of the published literature. They also noted the relative paucity of papers in respect to RFID policy - those published dealt with security and privacy with only two dealing with standardisation, despite recognising the need to standardise networks in order to facilitate data 
sharing and the Internet of Things (Ngai et al., 2008). Wyld (2005) called for further research on the impact of RFID on society, business, law and ethics, and also noted that much of the RFID research available at the time looked at reinventing current processes rather than focusing on new ideas and new ways of doing things. This focus on the technical nature of RFID systems, and calls for research on the social implications of such systems, identifies a gap in the academic literature which this study will address.

\subsubsection{Isolation of RFID Systems}

Despite different computing models describing how the future might look with completely connected technology systems (including RFID) offered by researchers such as Weiser (1991) and Yoo (2010), Santucci (2010) notes that many of the RFID systems in operation today function in isolation either within one organisation alone, or along a single supply chain of manufacturers and consumers. Further adding to this isolation is that these RFID systems seldom cross the boundary between private and public sectors and where they do, they seldom affect core government services, being almost completely limited to supply chain applications. Chatfield, Wamba and Totano (2010) for example, found that the e-government literature contained few references to the use of RFID technology in public safety applications. They also noted the ongoing lack of research regarding RFID policy that had previously been identified by Ngai et al. (2008).

\subsubsection{Issues Identified by RFID Research}

Banks et al. (2007) found that where studies discuss RFID in the public sector, they mainly concentrate on the defence, border control and health sectors where the technology is most widely used. Neuby and Rudin (2008) suggested that identification of individuals and things, individual access control, monitoring, and tracking were general areas in which RFID has uses both in the public and private sectors. They also identified barriers to RFID implementation including cost and privacy. In the agricultural sector, Gogan, Williams and Fedorowicz (2007) examined an RFID system focused on tracking animals from the farm to the table (including the involvement of various public sector agricultural agencies), and noted difficulties in implementation 
that included a lack of uniform data standards and differing levels of collaboration between organisations.

Dawes (2008) noted the importance of information sharing between public and private organisations in achieving success where projects crossed the boundary between the two, also finding that issues of data ownership presented a barrier to successful information sharing. The European Commission (2009) identified policy development and coordination, data protection, and infrastructure management amongst others, as areas in which government has a role in overseeing the spread of the Internet of Things. However, aside from a few specific case studies, some of which are mentioned above, there is little research discussing the use of RFID in the public sector and its use between public and private sectors, or on how RFID systems might change core government systems and processes. In the private sector, similar issues with RFID systems have been identified, including both data and infrastructure standards, privacy and security.

\subsubsection{How are RFID Systems Established?}

Some research has been directed at determining how RFID systems are adopted within various contexts, using a range of technology implementation and adoption models. For example, Wamba and Chatfield (2009) developed a contingency model of RFID adoption based on the Diffusion of Innovation theory proposed by Rogers (2003), and the Venkatraman framework (Venkatraman, 1994). They found that the level of organisational transformation was related to the benefit organisations derived from implementing RFID systems. Kros et al. (2011) studied RFID acceptance using Structural Equation Modelling (SEM), and determined that technology readiness had a positive impact on RFID adoption, while satisfaction with existing organisational technology inhibited RFID adoption. Carr et al. (2010) undertook one of the few studies reported in the public sector, applying the Technology Acceptance Model to RFID systems in the healthcare sector. They determined that risk, change resistance, ease of use, and support from suppliers were indirectly related to each other, while there was no direct relationship between intention to use and perceived ease of use of RFID technology. However, despite these studies no research could be located that addressed how RFID technology was adopted and maintained within systems that 
crossed the boundary between public and private sector. Instead, what research there was focused on either adoption decisions, or those taken during technology implementation.

\subsubsection{The Need for Broader Research}

The limited scope of most research into RFID is inhibiting understanding of the range of issues that need to be addressed before more widespread RFID systems can be considered. In their study of RFID adoption Wamba and Chatfield (2010) found that studies considering the adoption of RFID technology mainly focused on the retail sector. They went on to point out that further research was needed in this area if organisations were to achieve the level of change needed before they could fully utilise their RFID systems. Recognising the need for more broadly based research Yoo (2010) recommended that researchers expand the scope of their enquiries to look at "various issues and opportunities that arise as organisations try to embed various forms of digital technology into their products and services "(Yoo, 2010, p. 244). However, even Yoo does not mention how the public sector might fit into this new, experiential computing model he described, nor how the public and private sectors might combine to deliver innovative products and services using RFID systems.

\subsection{Problem Summary}

Although there is some research available addressing RFID use in the supply chain, and a more limited amount of research focused on the use of RFID in specific public sector applications, there is little general research addressing RFID systems shared between the public and private sectors. Nor could much research be found addressing how such systems are maintained within the public-private sector context. As a result, no satisfactory explanation was found addressing the factors that should be considered when managing such systems. Nor were the wider implications of the various computing models discussed in any detail. This leaves a gap in research in respect of how RFID systems become established and are maintained on an on-going basis where such systems are shared between the public and private sectors. 


\subsection{Research Objectives and Question}

The objective of this research is to examine how RFID based technology systems come to be established in applications which cross the boundary between the public and private sectors. The factors that assist in establishing and maintaining such systems will be identified, and any differences apparent between public and private sectors will be discussed. Thus the overarching research question can be derived as follows:

Research Question: How are public-private RFID systems established and maintained? In this study the term established will be taken to encompass the decisions and actions taken in deciding to use, and bringing into operation, RFID systems within an organisation. Where maintenance is discussed it will be in relation to the on-going support and management required in order to ensure RFID systems continue to operate within the organisation.

Recognising that the term implementation can mean both the establishment of an IT system and the completed system itself, thus leading to confusion, this study will use the term implementation in respect of the installation and establishment of the RFID technology. Otherwise the term system will be used to describe the technology system itself, separate from the act of its implementation.

\subsection{Definitions}

The following definitions of key terms and concepts are used in this thesis, all are discussed in more detail in the Literature Review following, and a glossary is available in Appendix E - Glossary.

- Digitalised Artefacts/Devices are objects or things augmented with digital sensors, RFID tags or similar devices, allowing them to respond to and/or communicate with the Internet or other digital artefacts (Yoo, 2010).

- Electronic Product Code (EPC) is the most widely spread coding scheme used by RFID devices to identify themselves when queried by an RFID reader (EPCglobal, 2010).

- Government, is defined following Shaw and Eichbaum (2011) as the group of individuals and institutions, including the public service, Parliament, and 
government departments, that work together in order to produce government policy.

- The Internet of Things is created by the network of digitalised devices (things) communicating with each other and with computers (and humans) through the Internet (Atzori, lera, \& Morabito, 2010).

- Private Sector can be simply defined following the Oxford Dictionary (2013) as "the part of the national economy that is not under direct state control". However, Parsons (1995) refines this by taking an economic perspective, considering the private sector to be that sector of the economy which produces goods which are purchased by choice, and not under control of the state.

- Public Sectors following the Oxford Dictionary (2013) could be defined as "the part of an economy that is controlled by the government". However, the public sector can be difficult to define according to Lindgren and Jansson (2013). They consider that the public sector consists of those organisations that co-ordinate public administration. Parsons (1995) defines the two sectors economically, in terms of the goods they produce, with the public sector producing goods which are available to all and not necessarily produced in response to the demands of the market.

- Radio Frequency Identification (RFID) is the process by which a device tagged with a transponder, in response to a signal from a reader, identifies itself with a unique response (Lahiri, 2006).

- Supply Chain, is defined by Hatch (2012) as the flow of raw materials, or products, from their origin to their final consumer.

\subsection{Research Design and Methodology}

For this research the qualitative paradigm is considered most appropriate to answer the research questions as the study seeks to find meaning in the reality observed (or constructed) by the organisations and individuals that use and interact with RFID systems. Creswell (2009) finds that qualitative research is best used when not much research has been done on a particular issue. Similarly, Yin (2009) outlines three criteria where qualitative research is indicated - where the research is focused on a 
modern, real life issue; where the researcher does not influence proceedings and/or where the research question is a how or why question. As this study involves a complex, modern, social phenomenon about which little is known, it is considered that a qualitative study is the best approach to answering the research questions.

\subsubsection{Theoretical Approach to this Research}

A number of theories and frameworks are used to address questions in relation to the place of technology in organisations, and society. For example, the Technology Acceptance Model (TAM) developed by Davis (1986), focuses on the intention of users to adopt technology, with particular emphasis on the ease of use and perceived usefulness of the technology itself. Also widely used, Diffusion of Innovations (Dol) Theory, described by Rogers (2003), examines how innovations move through society based on flows of information and social processes. Eze, Duan and Chen (2012) consider these theories to be deterministic, hence failing to account for the range of interactions seen in technology systems. More generally, Structuration Theory formulated by Giddens (1979) emphasises that the relationships between human agents and social structures are based on dual analysis of both agency and structure, thus the social can also take part in the development of technological structures.

However, this research is not bounded by a particular part of the lifecycle of RFID technology. As a result theories examining particular stages in a technology's life cycle (such as TAM and Dol) are not useful in this context. These theories, and others, also force technology to adopt certain roles. For example, Structuration Theory denies technology the ability to act at, all forcing it into a passive role. Given the strong place of RFID technology within this study these theories were also considered to be unsuitable. Therefore an approach that recognises the agency of technology, while not being limited to the use of the technology or a particular phase of its lifecycle was selected.

Actor-Network Theory (ANT), otherwise known as "the sociology of translations" was developed in France in the early 1980's. Arising from the social study of science and technology, ANT focuses on tracing associations and relations between members of a network, be they human or material, in order to determine how the network becomes 
stable over time, if indeed it does (Latour, 2005). Although controversial, the inclusion of material things and concepts within networks, acknowledging the place of technology in the construction of the social, allows the researcher to understand how complex networks of social and technological actors are formed and how they function (Hanseth, Aanestad, \& Berg, 2004). Further, as RFID enabled systems are essentially networks of both human and technological actors, including RFID enabled digital devices, ANT is uniquely placed to offer an in depth understanding of how these networks might be formed, the place of RFID within the network, and what actors - be they human, technological or conceptual - would be involved in its formation. ANT has no detailed methodology in and of itself. However, the majority of ANT studies are presented as qualitative studies; therefore, qualitative methodology will be used to advise this research, as outlined in the following Methodology chapter.

\subsection{Delimitations}

This study examines a small segment of the possible range of worldly experiences. It would not be possible to take an all-encompassing network approach to government/public/organisation interactions as the scope of such a study would be too broad. Nor would it be possible to examine every detail of a network studied using an ANT approach thus it was necessary to place boundaries on the network studied. Understanding how to limit the range of the network will be discussed further in the methods section.

Similarly, this study concentrates on RFID enabled digitalised artefacts using an item identifier. There are simple RFID systems that do not use individual item identifiers, and technology apart from RFID that can be used to digitalise devices, and these will not be discussed.

\subsection{Thesis Outline}

This thesis will be presented in chronological order as far as possible following the sequence in which the research evolved in order to respect both the grounded nature of ANT, and the narrative style of ANT accounts. Therefore, following this Introduction the Literature Review (Chapter 2) will review relevant literature, introduce RFID, and discuss the various technology models that are relevant to the context of this study. 
Chapter 3 will discuss the theoretical basis of this study and justify the use of ANT, as well as the inclusion of Institutional Theory as a further theoretical lens. Institutional Theory is included at this stage as it became apparent during the course of data gathering that some influences on the RFID network arising from organisational and institutional behaviour could not be accounted for within the ANT framework. Observations as to the way the network was formed, and the inclusion of an additional theoretical lens, led to additional research sub-questions which are also outlined in Chapter 3. Chapter 4 will review findings that address the research questions, discussing - how the RFID network is established and maintained; and how institutional forces act on the network. Chapter 5 will then present the mediators of the RFID network, discussing how they influence the ANT process of translation. Consistent with an ANT account, the two findings chapters (Chapters 4 and 5) will focus primarily on reporting the findings and drawing a picture of the network. Chapter 6 will discuss and interpret the findings, and Chapter 7 will conclude this study, discussing how understanding of RFID systems has been extended by this research, as well as describing how ANT and Institutional Theory can be combined to study complex socio-technical systems. 



\section{Literature Review}

This chapter will review the academic literature in respect of RFID, identify the place of RFID within current computing models, and discuss how RFID fits into the new theories of human/computer interaction. It will also explore the interaction of the public and private sector regarding the on-going growth and development of a connected network of RFID devices.

\subsection{Radio Frequency Identification - From Identification to Smart Chips}

Today's RFID systems are far more sophisticated (and much smaller in size) than the initial 1940s Identification Friend or Foe system, but they share the same hardware basis. The core of the RFID technology is still the interrogator, or reader, and transponder, or tag, and this combination has changed little from the origin of RFID. Each radio frequency (RF) tag is coded with a unique identifier, primarily an Electronic Product Code (EPC), although other proprietary coding systems do exist (Konomi \& Roussos, 2007). When the tag comes within range of a reader, the RF energy transmitted by the reader activates the tag and it transmits its identity back to the reader.

The majority of RFID tags are passive - that is they do not contain batteries and rely on the RF energy of the reader in order to transmit. Passive tags often carry and transmit no information other than their identifier. Active tags are more sophisticated and contain a battery, which can power sensors and microchips. These tags can both store and transmit information in response to a reader, depending on their inbuilt capabilities. RF tags can be produced in a huge variety of forms. They can be housed in identity cards, buttons or shoes, and can also be injected into people, or animals (Glover \& Bhatt, 2006).

Of itself, the identifying code transmitted by RF tags has little meaning. The code must be matched with the item it identifies, and processed by RFID middleware systems in order to match the code with the tagged item. Only then can sense be made of the transmitted information. It is possible for one reader to generate a huge amount of information as it may read thousands, or millions, of tags as they move through its 
field. Further, one tag can be read multiple times if it remains stationary within the field of the reader. The RFID middleware is responsible for filtering the information received from readers, removing duplicate reads and otherwise "cleaning" the data. The captured data can then be used in a variety of ways, from tracking the movement of an individual item through the supply chain to determining the total number and location of particular stocked items (Glover \& Bhatt, 2006).

The item identifier is unique to each item and in the case of an EPC is allocated by the EPCglobal Network, a not for profit organisation driven by subscribers including such companies as Wal-Mart, Lockheed and LG Electronics (EPCglobal, 2010). The objective of EPCglobal is to develop standards for both hardware and RFID systems architecture to allow the supply chain to integrate from manufacturers to retailers, and to allow for easy exchange of data across systems (Glover \& Bhatt, 2006). EPCglobal also provides an Object Naming Service (ONS), similar to the domain name system (DNS) used for addressing the internet, which helps connect the EPC code to the appropriate information service. This EPC Information Service (the EPCIS) enables users to share EPC data with each other, mapping an item's EPC code to the relevant item information (for example user manuals, sales information, expiry dates etc.). The EPCIS also controls access to the information it holds, allowing information to be shared according to set permissions between business partners, and between business and the public. For example, business partners would share information regarding the movements of a particular item, while the public would only be able to see its point of origin and user manual (Glover \& Bhatt, 2006; Sarma, 2004).

The most common use of RFID technology today is in supply chain and retail applications where they are used to track either individual items, or pallets. The tags increase inventory visibility allowing for more accurate inventory, location finding and reduction in stock outs. Each item has an electronic product code and can be individually located and tracked (Dutta, Lee, \& Whang, 2007). Osyk, Vijayaraman, Srinivasan and Dey (2012) found that RFID tags were replacing barcodes in supply chain and warehousing applications, with the main benefits being seen to be pallet and item tracking, asset management, loss prevention and security. Stanford (2003) found that advantages of RFID tags compared to barcodes included: 
- the ability to scan an item that is not in the direct line of sight of the scanner;

- the ability to "simultaneously" read many tags at the same time; and

- the ability to uniquely identify individual items.

Similarly, Ilie-Zudor, Kemény, van Blommestein, Monostori, and van der Meulen (2011) noted that RFID identification was more promising than bar coding as a method of automatic identification as it required less manual intervention on the retail side of the supply chain, due to its remote scanning capability.

Roussos (2006) suggested the use of RFID in retail might allow retailers to introduce smart shopping carts where products are scanned once only at check-out. This would allow for the easy identification of products that have exceeded their use by dates or are subject to recalls, and reduce stock outs and item theft. Areas other than supply chain have begun opening up to RFID systems from the commonly used animal tracking applications described by Vlad et al. (2012) to preventing cheating in Mahjong (Tang, 2013). Other conventional uses include controlling building access through the use of RFID enabled cards, and collection of road tolls (Lahiri, 2006).

The value of the RFID market continues to grow annually with Harrop and Das (2013), estimating the value of the RFID market in 2012 to be US \$7.67 billion, compared to US $\$ 6.51$ billion in 2011. For the period 2012 to 2017, ABI Research (2012) estimated that the RFID market would be worth US $\$ 70$ billion over the five years from 2012 to 2017.

Wyld (2005) identifies a number of factors that have driven this broadening of interest in RFID including:

- reductions in the cost of RF tags with passive tags costing around 5 cents US each;

- greater standardisation of technology and product codes allowing interoperability of systems and exchange of data;

- competitive pressures driving a need for better business decision making;

- better data processing capabilities and IT infrastructure allowing for the capture and use of more complex information; and 
- leading organisations (such as Wal-Mart and the US Department of Defense) having mandated the use of RF technology for their suppliers.

As the use of RFID technology has increased, a number of issues have been identified with its use, from the perspective of both the business and the customer. From the point of view of business, Spekman (2006) categorises these barriers as either physical barriers resulting from the deployment of the RFID technology, or interpersonal/institutional barriers that result in a lack of trust and inability to collaborate. Physical barriers include:

- cost (Hossain \& Quaddus, 2011; Ilie-Zudor et al., 2011), a persistent problem although both Wyld (2005) and Hossain and Quaddus (2011) found that the decreasing cost of tags was driving RFID implementation;

- businesses being too small to accrue benefit from implementing the technology (Hossain \& Quaddus, 2011)

- the lack of uniform standards for the radio wavelengths, hardware, and for the product coding leading to concerns regarding interoperability of systems, especially across international boundaries (Hossain \& Quaddus, 2011; IlieZudor et al., 2011; Kopalchick III \& Monk, 2005; Ting, Kwok, Tsang, \& Lee, 2011). The lack of uniform standards was identified (by $60 \%$ of respondents to an Information Week survey), as the biggest challenge to RFID implementations (Bacheldor, 2005);

- complexity of the technology and associated technical issues (Hossain \& Quaddus, 2011; Yao, Chu, \& Li, 2011; Zhou \& Piramuthu, 2010);

- $\quad$ tag reliability (Ilie-Zudor et al., 2011);

- different legislative regimes in different jurisdictions (Ilie-Zudor et al., 2011);

- different standards requirements in different countries (2011);

- unclear ownership of the technology itself, the EPC or coding systems and the data generated by the RF reads (Bose, Ngai, Teo, \& Spiekermann, 2009; Curtin, Kauffman, \& Riggins, 2007; Wyld, 2005); and

- management of large volumes of data produced by RFID reads (Wyld, 2005).

Interpersonal or institutional barriers include: 
- a lack of institutional trust between organisations (Spekman \& Sweeney II, 2006);

- $\quad$ privacy and security concerns (Ting et al., 2011; Van Lieshout \& Kool, 2007; Yao et al., 2011);

- the need for guaranteed accountability between transactions, with incorrect information being occasionally transmitted (Ilie-Zudor et al., 2011);

- management attitude and the lack of readiness of organisations to adopt the technology (Hossain \& Quaddus, 2011);

- the impact of the RFID technology on workers in respect of health concerns as well as potential job downsizing (Curtin et al., 2007; Wyld, 2005); and

- appropriate training for staff in the use of new systems, as well as ensuring the acceptance of these systems (Kopalchick III \& Monk, 2005)

The majority of studies of RFID technology have concentrated on the private sector. However, a number of studies have looked at government/public sector uses, generally focusing on case studies, primarily in the health and defence sectors, or alternatively have discussed how government can encourage the use of RFID technology. Neuby and Rudin (2008) note three interrelated uses in both the private and public sectors, determining:

- what an item is using access control and identification;

- where an item or person is, using location technology; and

- how an item or environment is, in other words monitoring the environment against preset norms, or profiling the environment.

Wyld (2005), suggests a number of ways government can facilitate the use of RFID including promoting best practices and standards, funding research and education and resolving privacy related RFID issues. He also suggests these efforts are best conducted as joint ventures between public and private sectors. Similarly, Hossain and Quaddus (2011) found that government support through funding, training and regulation facilitated the decision of organisations to adopt RFID technology.

Even though the use of RFID systems is steadily increasing in both private and public sectors, the majority of today's RFID systems exist in relative isolation, they do not 
interact with each other. However, this isolation is decreasing as more and more items become tagged (or 'digitalised'), and capable of being part of larger RFID and internet based systems.

\subsection{RFID Digitalised Artefacts}

Any item (or artefact) can be said to be "digitalised" when it has either an RFID chip, two dimensional barcode, and/or sensor installed (Yoo 2010). Differing from the traditional view of artefacts as items stored in museums and libraries, electronic files or digital copies of documents, digitalised artefacts can interact with the user, the environment, each other or the internet, depending on the capability of the chip or sensor. Yoo (2010) identifies seven qualities of digitalised artefacts being:

1. programmability - the artefact can be programmed through embedded software, although in some the programming may not be modified after the initial upload;

2. addressability - the artefact can be identified and responds individually;

3. sensibility - the artefact can respond to the environment, sometimes in complex ways;

4. communicability - the artefact can communicate with other artefacts, the user and the internet;

5. memorisability - the artefact can record and store information, depending on the type of chip or sensor installed;

6. traceability - the artefact can be followed through time and/or space; and

7. associability - the artefact can be related to other artefacts, events and entities.

Even though some passive RFID chips are very simple, having no memory capabilities or ability to be reprogrammed, they can still be considered to be digitalised artefacts as in essence they satisfy the criteria outlined above - they can be communicated with individually using an address, they can be traced and they can be associated with other artefacts.

The low cost and increasing ubiquity of RFID enabled devices are also allowing the emergence of networks of digitalised artefacts especially in the private sector. This 
network is known by a number of different terms with similar meanings, including ubiquitous, pervasive, disappearing or invisible computing as well as the more encompassing term, the Internet of Things (Curtin et al., 2007; Slettemeas, 2009).

\subsection{The Ubiquitous, Pervasive, Disappearing, Invisible, Experiential Internet of Things}

A range of different computing models have been proposed to explain the interaction of computers with society and organisations, each focusing on slightly different aspects of these interactions. Models such as ubiquitous, pervasive, and experiential computing focus more on the social nature of computing interactions. The Internet of Things model focuses more on the interaction of computing devices or things with each other, and organisations, reflecting the uses that the different types of devices have been put to. These relationships are discussed in this section, and are summarised below in Figure 2.

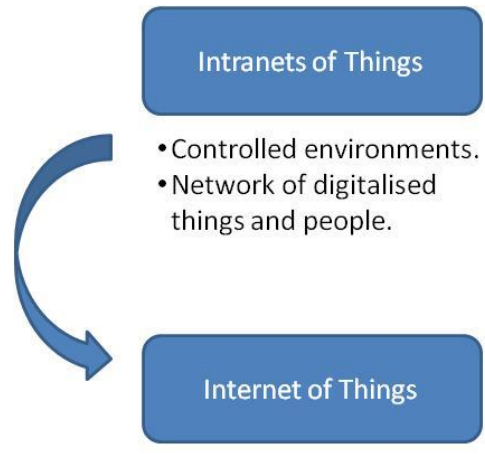

-Wireless network of products.

- Digitalised devices.

- M2M communications.

- Paradigm focuses on devices.

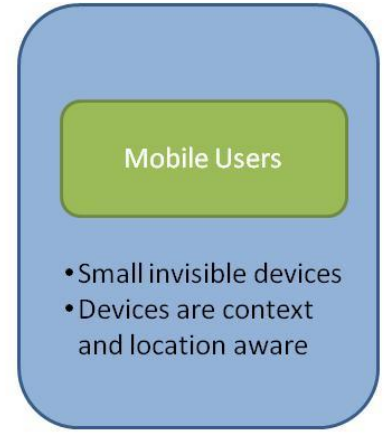

Experiential

Computing

- Non computer digitalised devices (artefacts)

- Part of everyday experience.

- Paradigm focuses on the environment.
Ubiquitous Computing

- Technology merges into the background.

- Paradigm focuses on infrastructure.

\section{Pervasive Computing}

- Technology obtains information

from background devices.

- Implementation of ubiquitous computing.

- Paradigm focuses on services.

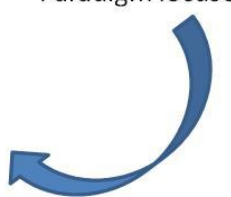

Figure 2: Summary of Computing Models

Weiser (1991) was the first to use the term "ubiquitous computing". In his landmark article, he described a future in which computers would vanish into the background of human existence with both computers and "invisible widgets" fitting into the human environment (Weiser, 1991). Streitz (2008) similarly describes the disappearing computer as a concept, in which the computer itself is invisible to users, but is ubiquitously available for interaction and collaboration. RFID enabled devices fit well 
into such categories as the RFID technology itself is often invisible, or difficult to detect, however, there are other models to consider.

The concept of ubiquitous computing is often confusingly aligned with other computing models, most commonly that of pervasive computing. Lyytinen and Yoo (2002) define pervasive computing as "the capability [of the computer] to obtain information from the environment in which it is embedded" (p. 64). This concept is extended by Kourouthanassis, Giaglis \& Karaiskos (2010) to include an environment with multiple different IT devices. Michelfelder (2010) describes ubiquitous computing (as well as calm technology and the Internet of Things) as an older term, and defines pervasive computing as "the implementation of ubiquitous computing through a constellation of technology" (p. 61). Taylor (2009) directly equates ubiquitous computing with the Internet of Things, and the European Commission (2009) considers the disappearing computer, ubiquitous computing, pervasive, proactive and ambient computing to be the same thing, as do Streitz and Nixon (2005).

The most common distinction between ubiquitous and pervasive computing is subtle and appears to hinge on the difference between the technology infrastructure and its application. This distinction is defined by Ye et al., (2008) who see the difference as ubiquitous computing providing the infrastructure and pervasive computing providing integrated computing services, although they also point out that distinguishing between the two is becoming unnecessary.

Whether defined separately or as the same thing, ubiquitous and/or pervasive computing models share a number of common features:

- they are context and location aware (Chalmers et al., 2006); (Saha \& Mukherjee, 2003);

- they rely on numerous different types of small or invisible devices scattered throughout the environment (Schindler, 2009); (Streitz \& Nixon, 2005); (Agha, 2008); and

- they serve mobile users (Schindler, 2009). 
This view of ubiquitous computing can be broadened to take in the complete network of digitalised things and people, coupled to the internet, and enabled by such devices as RFID. These devices have the capacity to interact not only with humans, but with each other through machine to machine (M2M) communications. This network, first described as the "Internet of Things" by Kevin Ashton in 1999 (Ashton, 2009), is defined by Slettemeas (2009) as a "wireless network of products with unique IDs that communicate with each other through RFID" (p. 226). Miorandi, Sicari, de Pellegrini and Clamtac (2012) suggest three pillars to the Internet of Things being:

- the ability to identify anything;

- the ability to communicate with anything; and

- the ability to interact with anything.

At the moment the vision of the Internet of Things has not reached fruition despite the increasing ubiquity of digitalised things. As Santucci (2010) points out, today's objects that exchange information only within controlled environments he terms "intranets of things" (my emphasis) - he further states that in order to complete the vision of the open and complex Internet of Things, many challenges in design and ethics need to be addressed. Zorzi, Gluhak, Lange and Bassi (2010) describe the current Internet of Things as being "vast mostly unexplored territory, without clear borders, where all current technologies can play a role" (p. 44). They list some of the challenges to integrating devices into an Internet of Things as including governance, standards, connectivity, energy management, privacy, security, connectivity, and the huge number of different devices with different technical specifications (otherwise termed the heterogeneity of devices). A similar list of challenges was produced by Miorandi, Sicari, de Pellegrini and Clamtac (2012) who also included the need to adopt widespread wireless communications as a challenge. Friedewald and Raabe (2011) in discussing the Internet of Things note the importance of solving societal compatibility issues such as ensuring universal access for all, as well as making sure that users understand the nature of the technology they are using. They also note that it is important to ensure individuals are properly served by the technology, instead of the technology being used for the benefit of the technology provider making sure the "house elf... is acting in the interest of its owner" (p. 63). Santucci's (2010) vision of 
the future includes individuals being able to spontaneously document their lives using the highly detailed information that would be provided by digitalised devices. In fact this is already happening today with applications such as Foursquare and Gowalla being used to geo-locate individuals based on their smart phone usage (Wilson, 2012).

The European Commission has produced a number of reports in relation to the Internet of Things. These include in 2009 an Internet of Things action plan, a 2011 Internet of Things conference report, and in 2013 a report covering governance issues. These reports detail policy and concerns surrounding such issues as privacy, security, standards, and governance. However, as the European Commission (2013) report on governance shows, there still appears to be uncertainty around whether one common standard is required, what level of governance the Internet of Things needs, or even around the very definition of the Internet of Things. The report concludes by pointing out the different perspectives of individuals versus industry, with individuals being more concerned about ethical issues while industry was concerned to ensure a minimum of public intervention due to the possibility of stifling economic progress.

Experiential computing takes the ubiquitous computing/Internet of Things model even further. In an experiential computing environment the focus is not on the computer at all, but on the non-computer, but still digitalised, everyday artefacts with which people interact. As such computing is not viewed as a separate activity with its own goals, but instead it is part of our everyday experience (Yoo, 2010). Yoo's focus on integrating digitalised artefacts into everyday existence is similar to the perspective taken by the Internet of Things in that both require devices that communicate with each other, the internet and their users (in this case RFID enables this communication). Ultimately, this digitalisation would allow humans (or their devices) to interact with any and all physical artefacts. Organisationally an experiential computing viewpoint encourages an expansion of the boundaries of inquiry beyond organisational information systems to include not only the Internet of Things but also the organisations or individuals that might connect to it - even when these encompass different types of business or products. Instead of asking the question how do individuals interact experientially with the Internet of Things, this view asks how the organisation provides products and services that add value to the human experience 
and what needs to be done to provide these. Bødker, Gimpel and Hedman (2012) take this concept into the dynamics of interaction between people and devices by suggesting two distinctions, those of time-in and time-out. Time-in devices merge with everyday living (as experiential computing suggests), time-out devices require individuals to interact in an active way with the technology.

While the many and various computing models are interesting, this study is focused on the future Internet of Things, looking beyond a single RFID system and attempting to determine those factors that are required for the integrated Internet of Things to be realised.

\subsection{Technology in Government - e or u-Government}

As this research crosses the boundary between public and private sectors it is also appropriate to review the literature regarding computing models within the public sector. Many of the computing models discussed above have been modified to describe the behaviour of information technology (IT) in the public sector. The use of IT in government has created a broad body of literature covering topics ranging from disaster relief to Government 2.0. The terms Public Management Information Systems (PMIS), mobile government (m-government), ubiquitous government (u-government) and electronic government (e-government) amongst others have been used when describing various aspects of the management of information technology within government.

The most commonly used term among these is e-government. Anttiroiko (2005), notes that the development of e-government has occurred along with the internet revolution since the early 1990s. He defines e-government as the provision of government services through electronic channels. The World Bank (2004) takes a broader definition of e-government considering it to be "about changing how governments work" although this definition alludes more to governance than government. Grönlund and Horan (2005), in a review of e-government find that the term is variously defined, but most commonly focuses on issues of governance rather than government. Sprague (2008) takes the view that e-government is a concept for yesterday and instead discussed "connected government", describing it as 
"a comprehensive approach to building an information infrastructure that facilitates the agency to agency, agency to business and agency to citizen workflows upon which effective, citizen-centric service delivery depends" (p. S6).

The advent of mobile technology has led to theorising about another technological form of government - mobile or m-government. Sharma and Gupta (2004) argue that m-government is a superset of e-government allowing transactions to occur using mobile technology such as PDA's, cell phones and other mobile devices, while defining e-government more restrictively as the "use of information and communication technologies to improve the activities of public sector organisations" (p. 465). Archer (2010) takes a different view arguing that m-government is a subset of e-government, one that supports the use of mobile and wireless devices. Anttiroiko (2005) defines mobile government (m-government) as a subset of u-government, one which allows interaction with government services through mobile devices (with u-government confusingly being a subset itself, of e-government).

The concept of ubiquitous computing has also been extended to government by Bélanger, Carter and Schaupp (2005), as "ubiquitous government" (or u-government). They define u-government as being:

"the use of ubiquitous networks to support personalised and uninterrupted information and services between a government and citizens, employees, organisations, businesses, and among government agencies to provide a level of value over, above and beyond traditional government" (p. 427)

This definition is close to Sprague's (2008) definition of connected government. The ugovernment concept takes m-government one step further in that transactions with government can occur at any time and in any place and on any device, not just the standard computing devices or a mobile telephone (Anttiroiko, 2005). Anttiroiko (2005), also points out that u-government services can be considered as merely another attribute of the fully transformed government, along with "seamless" or "integrated" government. He further suggests that the general development of egovernment and u-government are parallel to each other. Sharma and Gupta (2004) track the evolution path of u-government from information and communication 
services through to interactive and transaction services, the latter allowing for mobile polling, ordering and payments. Almost any device or sensor can transmit over the network, contributing to u-government with many of these devices being enabled by RFID (Anttiroiko, 2005). Yu and Hu (2007) extend the definition of u-government beyond the boundaries of information technology to include any citizen/government transaction regardless of the involvement of electronic means.

Based on the u-commerce constructs of ubiquity, uniqueness, universality and unison, Bélanger, Carter and Schaupp (2005) have identified four parallel characteristics of ugovernment:

- ubiquity - allowing anytime, anywhere access to government information and services.

- uniqueness - allowing for the unique identification of consumers by position, preferences, personal characteristics and actual identity.

- universality - the technology is both multi-functional and universally usable

- unison - u-government integrates data across applications so a consistent view is presented of government information and services across multiple agencies and devices.

Bélanger, Carter and Schaupp (2005) also identify four antecedents of u-government being governmental benevolence, integrity, and competence; and the presence of mediators in the form of the demographics of the citizen and the voluntariness of the transaction. The first three mediators are based on the trust literature and have been shown in many studies to be antecedents of trust.

There are differences between u-commerce and u-government focused on the different relationships people have with companies as opposed to government. Many transactions individuals have with government are mandatory (Warkentin, Gefen, Pavlou, \& Rose, 2001), with both timing and nature of the transactions prescribed (McMillen, 2004). Bélanger, Carter and Schaupp (2005) note that this may lead to concerns with acceptance of u-government, balanced against the advantage of "enabling a citizen to interact directly with embedded technologies in society's infrastructure" (p. 432) without the need for direct contact with a computer. They do 
not describe m-government separately in their model on the basis that u-government includes wireless devices (as opposed to mobile devices alone), and that evolution to multi-platform u-government will likely occur directly from the current e-government model. They also recognise that u-government must occur within the legislative framework of the country in question. Anttiroiko (2005) suggests that to create ugovernment an understanding of how the ubiquity of services is going to change their delivery will be necessary. He goes on to propose that this might be done through fine tuning the current e-government models.

The above discussion shows that, like the discussion of ubiquitous computing, $u$ government suffers from difficulties of definition. This study will take the position that u-government, like ubiquitous computing is a comprehensive term covering the range of electronic transactions with government including computer based internet transactions (e-government), transactions using mobile devices (m-government) and transactions involving other types of devices. The relationship between the various models is demonstrated in Figure 3 below.

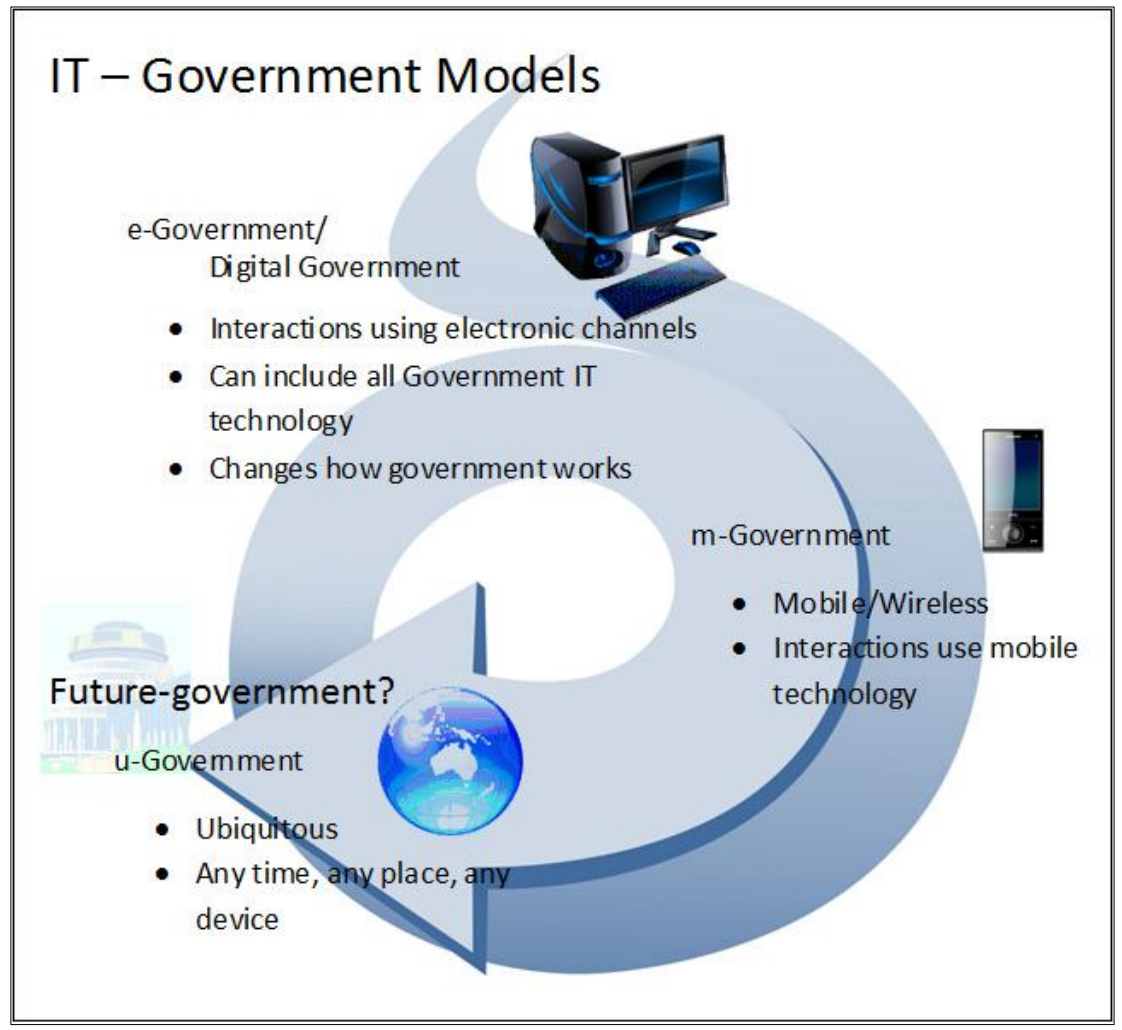

Figure 3: Government computing models - e, $\mathrm{m}$ or $u$ ? 
It remains to be seen how transactions involving the new types of electronic devices, (including RFID) will change the e-government or u-government paradigms. Work has commenced on determining how the RFID enabled Internet of Things might affect governments, mainly based in the European Union. Based on the social changes predicted to result from the on-going spread of the Internet of Things, the European Union (2009) has identified a number of roles for government in managing these changes including:

- co-ordination and development of policy on both the internet itself and the Internet of Things, and ensuring these are compatible and consistent;

- the on-going consultation and regulation of data protection and privacy policy;

- ensuring individuals have the right to opt out of involvement with the Internet of Things;

- open and transparent development of standards; and

- to provide on-going international dialogue in respect of the issues arising with the growth of the Internet of Things (European Union, 2009).

\subsection{RFID in Government/Public Sector}

The use of RFID in the public sector has been primarily focused in the Healthcare, Defence and Border Control areas where the technology is most mature (Banks et al., 2007). For example, in a more usual supply chain type application, the US Department of Defense requires all pallets, cases and individual items of a value greater than US\$5,000 to be RFID tagged (Li, Visich, Khumawala, \& Zhang, 2006; Wyld, 2005). In healthcare a number of studies have suggested uses of RFID ranging from operating room sponges embedded with RFID chips to ensure they are not left inside the patient ("Sponge count," 2006), to tracking all patients, staff and visitors in a hospital so if a person later develops SARS (or a similar infectious disease) everyone they contacted within the hospital can be identified (Xiao et al., 2007).

Further, Ting et al. (2011) found that data management was an issue in RFID systems in the healthcare sector. They particularly highlighted the need to better secure, share and use data from these systems. Wamba (2012) in an analysis of 22 studies in the Journal of Medical Systems (from 1997 to 2011) on RFID in the healthcare sector 
found that the number of articles covering RFID technology increased from two in 2008 to 13 in 2011 . He further found that although the majority of studies dealt with privacy, data management or security, only two discussed financing issues.

Organisationally, Lee and Shim (2007) found that the amount of knowledge an organisation had about RFID, together with the presence of a champion, were determinants of RFID adoption in the healthcare sector.

In the public sector in general authors have found a similar range of issues in RFID systems to those found in the private sector including:

- security (Bhon, Gartner, \& Vogt, 2003; Ting et al., 2011);

- lack of standardisation (C.-P. Lee \& Shim, 2007; Ting et al., 2011);

- cost (Mukerji \& Palanisamy, 2011; Neuby \& Rudin, 2008; Yao et al., 2011);

- legal issues (Mukerji \& Palanisamy, 2011; Yao et al., 2011)

- $\quad$ privacy (Yao et al., 2011; Zhou \& Piramuthu, 2010); and

- technical reasons (Yao et al., 2011, 2011).

Neuby and Rudin (2008) found that a lack of understanding of public understanding of RFID systems was a barrier to its implementation in the public sector. Although the majority of published studies have covered adoption of RFID technology Gogan, Williams and Fedorowicz (2007) found that long term management of an animal tracking system was necessary due to different levels of collaboration between public and private sectors.

Although studies tend to focus on barriers to implementation, a few in the healthcare sector have looked at benefits. Zhou and Piramuthu (2010) in contrasting public and private healthcare, found that benefits to the public sector included the ability to offset efficiencies with public sector resource constraints. This finding was reflected by Yao, Chu and Li (2011) who found that RFID systems benefits included savings in time and cost as well as improvements in healthcare processes. In a Delphi study of the RFID (related to its use in the Internet of Things), Wamba and Ngai (2012) found that the main advantages in the use of RFID for the future were improved asset traceability and inventory management. 
In the broader context RFID appears in a variety of governmental reports ${ }^{1}$ in the context of facilitating the Internet of Things, with which it is inextricably linked (European Commission, 2012). At the time of writing few academic papers could be found taking the approach of studying RFID adoption across the boundary between the government and private sectors, focusing instead on individual government sectors. Nor were any papers found discussing specifically the place of RFID enabled devices in the e (or $\mathrm{u}$ ) government paradigms.

The use of RFID in the public sector could be considered part of the e-government paradigm in that RFID enabled devices work through electronic means. However, their use probably fits best within the concept of u-government as it is a technology that is mobile, pervasive and ubiquitous, extending the boundaries of the relationship between public and private sector by including devices that can communicate between sectors without necessarily requiring human intervention. Following this line of thought, u-government would become experiential by moving beyond the provision of government services making interaction with government both seamless and invisible to the point where the citizen may not even know they were receiving government services and products.

As can be seen from this overview, the themes regarding establishing and maintaining RFID systems in the public-private context are many and entangled. Even the technology model that fits RFID systems best is open to debate, primarily because RFID technology enables many of the current computing models. Nonetheless, there has been a considerable body of research in respect of various RFID systems. The following sections will discuss some of these themes.

\subsection{RFID Research - Themes from Literature}

A number of themes regarding RFID systems can be drawn from literature. Standards for hardware, RFID bandwidths and data management help ensure interoperability between RFID systems locally and internationally, where relevant. Information infrastructure needs to be available for the system to work consistently and seamlessly. Further, organisations need to trust both that the system will work and

\footnotetext{
${ }^{1}$ Especially those arising from the European Union, European Commission and International Telecommunications Union
} 
that their information will be protected before they will feel comfortable using it. Privacy and security are often cited as key issues in the development of any internetbased technology, as they are in the case of RFID systems (Langheinrich, 2001; The European Commission, 2006). The question of both the quality of data generated and its ownership have still to be addressed, and in order to gain full value out of any RFID system this data needs to be both compatible with and shared, broadly, across business partners and individuals. The following sections will discuss these issues in more detail.

\subsubsection{Infrastructure}

The definition of information infrastructure has been extensively debated, though it is also considered essential to the development of any internet-based technology. Borgman (2007) defines information infrastructure simply as "a global framework to facilitate information exchange" (p. 42). In her 2003 book, Borgman notes that the premise of any information infrastructure is the worldwide linking of telecommunication and computer networks brought about by cooperation between individuals and the public and private sectors (Borgman, 2003). Hanseth and Lyytinen (2010), take a more socio-technical approach defining information infrastructure generally as a "shared, open, heterogeneous and evolving socio-technical system of Information Technology capabilities" (p. 1). Although Hanseth, Monteiro and Hatling (1996) note the difficulty of defining the term.

EPCglobal separates hardware and software infrastructures with the readers, tags and middleware components grouped together, and a second group consisting of the EPCIS platform designed to exchange data generated by RFID tags, its data, and interface standards (Bendavid \& Cassivi, 2010). The European Union (2009) in discussing the Internet of Things, notes that its infrastructure should be seen as separate from, while relying on the infrastructure for the internet. The EU also emphasises the importance of providing appropriate infrastructure for the operation of the Internet of Things including power supply and internet connectivity.

Van de Ven (2005) extends the definition of infrastructure to include "political arrangements" such as policies and practices, standards and property rights, all of 
which combine with more traditional information infrastructure in order to facilitate innovation. Interestingly, Yoo (2010) puts the concept of infrastructure into an experiential context by suggesting that it will be necessary to integrate the information infrastructure into other infrastructures including cultural ones - this integration, Yoo notes, will most likely be difficult. He also concludes that a ubiquitous infrastructure will be required to facilitate experiential computing.

The distinction between physical, political and social infrastructure can be a logical one, as it allows for discussion of issues specific to each type of infrastructure. However, it does cause confusion where different authors have different understandings of the term "infrastructure". As a result this thesis will use the term infrastructure more narrowly, following the lead of GS1 and the European Union by defining infrastructure as the technical/hardware and software elements necessary for the functioning of the RFID network and the Internet of Things.

Yoo (2010) discusses the necessity of integrating global IT infrastructure with digitalised devices and sensor networks, and highlights the importance of information infrastructure to the development of the Internet of Things. This integration would allow for seamless communication between, and with digitalised artefacts any time, in any location. Chalmers et al. (2006), point out that the sustainability and permanence of the information infrastructures supporting ubiquitous computing is an issue that needs to be considered when we seek to understand ubiquitous computing systems and their impact on society.

Spekman (2006) finds that the reducing cost of RFID hardware infrastructure is allowing for more widespread adoption of the technology. However, he also notes that this spread is creating difficulties with IT infrastructure expected to be able to cope with the large volumes of data generated by frequent tag reads. The same point is made by Konomi and Roussos (2007), who also emphasise the importance of integrating infrastructure already in place with new infrastructure required by RFID networks so as "not to catastrophically disrupt the capability of the organisation to provide services"(p. 508). 
A number of city sized projects including u-Japan and New Songdo City have emphasised the importance of infrastructure in the development of the "smart cities" of the future. These cities are being built today based on a future where everyone and everything is connected. The design of New Songdo City in Korea considers connectivity in all elements of infrastructure including the more obvious utilities and transport, and less obvious parks and open spaces (Santucci, 2010). U-Japan focuses more on rolling out ubiquitous computing services across Japan, and promoting the importance of broadband technology, network coverage and full utilisation of the current network (Murakami, 2003).

\subsubsection{Standards}

Closely tied to infrastructure development is the need for standardisation, both of hardware and software infrastructure elements. Standards allow a business to be sure that the tag they attach to their product will be readable by trading partners throughout the supply chain, facilitating supply chain interoperability (Rothfeder, 2004). They allow for the automation of information exchange between trading partners, as well as direct data exchange, as data formats would be compatible with all of the business partners' varying information systems (Harrison \& Parlikad, 2006; Konomi \& Roussos, 2007). Standard data formats also make it easier to add or remove partners to the supply chain when necessary without having to reformat any part of the operation (Harrison \& Parlikad, 2006). Finally, standards allow for the interoperability of RFID equipment - tags and readers - from different vendors (Kopalchick III \& Monk, 2005). The global standardisation of the radio frequencies used for communication is also a cause for concern due to different countries and regions allocating different parts of the radio spectrum for RF purposes. The European Commission (2006) note that radio frequency harmonisation is not possible due to these varying national standards.

The need for RFID and EPC standards is one of the most frequently cited barriers to their successful implementation and use. A study by Whitaker, Mithas and Krishnan (2009) found that standards ambiguity was associated with an expectation of delayed return from a firm's investment in RFID. Similarly, Curtin, Kauffman and Riggins (2007) found that industry standards were a key factor in adoption and benefits realisation 
for RFID projects. Wyld (2005) identifies the air interface protocol (the communications of tags and readers), data organisation, standardisation of radio frequency product testing, and how RFID applications are used as four areas where standards are needed. Outside of the need for RFID standards, Dawes (2008) highlights the need for standards in government information, noting that the lack of compatibility between government databases limits the ability to integrate and share information between government departments, and between public and private sectors. Sprague (2008) also makes this point and identifies compatible information infrastructure as a key component in facilitating information sharing and exchange.

EPCglobal/GS1 is the main standards body for RFID in the US and worldwide, aligning with both the ISO (Dutta et al., 2007) and Global Trade Item Number (GTIN) standards (Thiesse, Floerkemeier, Harrison, Michahelles, \& Roduner, 2009). Dobkin (2013) notes that although the EPC standards are not the only standards available for RFID, they are the most widely implemented. He lists two other established organisations producing suites of RFID standards, being ANSI and ISO. Despite the current dominance of these standards Ilie-Zudor et al. (2011) note that given the speed of technological development the current standards could become quickly obsolescent. On top of these general standards, many proprietary standards, working within individual or small groups of RFID applications, also exist (Dobkin, 2013).

Parallels can be drawn between the development of barcode and RFID standards. Barcode standards in the form of the Universal Product Code (UPC) were proposed for use on grocery items in 1969 by a committee of members of the Grocery Manufacturers of America, and the National Association of Food Chains (Brown, 1997). The barcode standards spread rapidly, and today the barcode is one of the world's most recognisable symbols appearing on virtually every manufactured item (Markus, Steinfield, Wigand, \& Minton, 2006). Wu et al. (2006) note that barcodes and RFID will continue to co-exist for the moment, mainly due to the cost of RFID systems and tags, and demands caused by the high volume of data generated by RFID systems on IT system capacity. Gershenfeld, Krikorian and Cohen (2004) also note an interesting similarity between the current state of RFID standards development and the early development of ARPANET where a wide range of differing standards existed, requiring 
special hardware to bridge the differences, eventually becoming one open universal standard allowing worldwide harmonisation of the internet.

\subsubsection{Interoperability and Information Sharing}

As RFID systems become standardised, the opportunity arises to exchange data between different systems, either organisationally or between organisations. Interoperability is the engine that drives the sharing of information. Without interoperability of systems, data cannot be shared as systems cannot talk to each other. Kopalchick and Monk (2005) found that interoperability between readers and tags from different sources was necessary for a high rate of adoption of RFID systems. Thiesse, Al-Kassab and Fleisch (2009), advise that organisations should implement RFID systems based on international standards in order to ensure interoperability between components, even when it is intended that the systems will only function internally.

Interoperability of RFID systems allows for information sharing between the members of the system. The power of an RFID system arises from the ability of organisations to track items, receive information from sensors, to share that information within and between organisations, and to process it into business knowledge. Without the sharing of data between organisations, or even departments in the same organisation, this power cannot be harnessed. This is one area where public and private sector organisations may well differ. Holmes (2001), finds that the primary goals of public sector organisations are to carry out policy and to provide a stable administration, goals which are not seen in the private sector. Bretschneider (1990), notes that there is more interdependence between public sector organisations than that which occurs between private organisations. Focusing on information sharing, Rocheleau and $\mathrm{Wu}$ (2002), discuss the differing views of IT in the public and private sectors with the private sector viewing IT as a way of achieving competitive advantage leading to a reluctance to share information with other entities. They find the opposite applies in public sector organisations enabling the public sector to draw from the experience and lessons learnt by other organisations when implementing their own IT systems. However, they also note that private sector organisations can use IT to identify unprofitable customers, and decide whether to continue doing business with them 
whereas government does not have this option and must continue to transact with all citizens and businesses. As stated by Yu and Hu (2007), "governments cannot choose their customers - they are obliged to serving [sic] all citizens" (p. 4).

Yang and Pardo (2011), also highlight the importance of sharing information across government boundaries in order to efficiently run government operations involving more than one department. They identify four factors necessary for effective information sharing between departments as being:

- trusted social networks;

- shared information;

- integrated data; and

- interoperable technical infrastructure (p. 1).

This is a point echoed by Dawes (2008) who discusses the importance of sharing information not only between public sector organisations, but also between public and private sectors, as the processes of government are now being increasingly shared with the private sector. She also notes that the issues of data ownership can impede the sharing of information, making it difficult to determine who has the right to make decisions regarding the release of information. In an earlier paper, Dawes (1996) lists a range of technical, organisational and political advantages to information sharing between government departments including integration of planning and policy development, as well as more efficient use of resources. Gil-Garcia et al. (2010) report that governments globally are sharing information as part of the response to challenges in the health and justice sectors. A point also reported by the United Nations (2007) who found that increased sharing of information is occurring as managers realise the information they need for decision making is held outside their own organisations. Ilie-Zudor et al. (2011) list a number of issues that might inhibit data sharing in cross border RFID networks including different legislation in different jurisdictions, different languages, and time zones.

Treglia and Park (2009) found that knowledge of, and trust in the other parties in an intelligence system led to greater sharing of information, as did clear policies and regulations - which were made clear to staff. Similarly Gil-Garcia et al. (2010) in their 
study of cross boundary information sharing found that knowledge of partner organisations and alignment of objectives was important in facilitating information sharing as they built trust.

\subsubsection{Data}

Fundamental to information sharing is the generation of data, and its exchange between organisations. The issue of the quantity, quality and ownership of data generated by RFID tags and readers has been identified as a concern by a number of authors. Levinson (2003), predicted that businesses will be swamped by an "ocean of information" generated by RFID tag reads. However, there are alternative views to Levinsons'; Sarma (2004), found that the on-going development of, and research on, RFID systems has addressed the fear of data generated by RFID readers ${ }^{2}$ overloading middleware systems. Businesses are also getting better at understanding how to manage and store the large volumes of data generated by RFID technology, and how to manage reader and tag positioning to ensure that no more data than necessary is collected (McKnight, 2007).

However, many businesses are not making optimal use of the data that is generated by RFID systems. Albright (2005) found that many retailers were not using the data they had available to them to generate any kind of business process improvement. Discussing RFID related data specifically, Albright (2005) emphasises the importance of sharing data between stores and their suppliers, stating that "RFID data is useless unless stores use it effectively and more importantly can share it with their suppliers" (p. 22). Alvarez (2004) also emphasises the importance of using the data generated by RFID, finding that businesses are currently focusing on implementation of the technology rather than using the data generated to improve business decision making. It is the processing and interpretation of the information generated by RFID systems that will create useful knowledge for managers and businesses, on which they can base their decisions (Curtin et al., 2007). Brady, Fellenz and Armstrong (2007), studying how marketing firms use data generated by RFID, found that there was an initial peak of high expectations which could be disappointed as firms struggled to find

\footnotetext{
${ }^{2}$ RFID readers capture many reads, often from the same tag. The result of a reader querying for responses every few seconds can be hundreds or thousands of lines of data (or more), depending on the query rate of the reader. Many of these data points could come from the same tag.
} 
meaning from the information generated by the system. They emphasised the importance of aligning the capability and objectives of the business in order to make the best use of the RFID technology (Brady et al., 2007).

Along with determining how to use the data generated by RFID systems, organisations must also determine who owns the data generated by increasingly distributed systems. For example, where an RFID supply chain system crosses several organisations, who own the data generated within each distinct organisation? The ownership of data generated by RFID systems is complex, and one on which there were few academic papers found. Smith (2006), identifies several areas of concern with tracking data generated by RFID systems including:

- in some cases the data gathered may arise from the actions of others - e.g. tracking data which arises from a customer moving around a store, raises the question of who owns the data, the store that collected it or the customer who generated it;

- copyright is difficult to claim on data sets because the data itself is automatically gathered rather than being the product of a specific intellectual process; and

- the tag that generates the data is likely owned by the customer when the data is gathered, rather than being owned by the organisation that owns the RFID equipment that gathered the data.

Smith comes to the conclusion in the case of tracking data that it would be difficult for a business to claim they owned the data because they did not generate it as such, they only gathered it. Garon (2010), concluded that in the US and some European countries the effort involved in the extraction of data from a large database, and it's processing, would be enough to allow the claiming of copyright on that effort. However, the situation is unclear in respect of the ownership of the initial data set. Garon (2010) also comments on the importance of integrating data management with appropriate data privacy, data policy and standards, in order to provide a comprehensive approach to ensuring data is protected not just within a company but nationally and worldwide. 
A further complication arises when considering where the data is held, as different countries have different laws that can be applied to data management and ownership, both at local and national level. International treaties also impact on ownership of any data (Garon, 2010). Chow et al. (2009), discussing the ownership of data stored in a cloud computing environment, states that "the legal implications of data and applications being held by a third party are complex and not well understood" (p. 86). They also find that the majority of fears in relation to data being held "on the cloud" relate to the potential to lose control of the stored data, some of which can be sensitive.

In general, the issues described above refer exclusively to non-personally identifying information generated within a business supply chain. The problem of personal data (or data that identifies an individual), is an entirely separate issue, and raises privacy and security questions in respect of the data concerned.

\subsubsection{Security and Privacy}

Probably among most frequently cited barriers to the implementation of both RFID and ubiquitous/pervasive computing is the security and privacy of both data collected and individuals and businesses that use the technology. The concepts of privacy and security are inter-related and often confused. The concept of privacy is generally considered to be derived from the Warren and Brandeis (1890) definition of "the right to be let alone" (p. 193). However, this view is insufficient in the modern age where data can be exchanged freely between individuals, organisations and even countries. Thus, Brodie, Karat, Karat and Feng (2005) proposed amending the definition of privacy to become "The right of an individual to control information about themselves, rather than the right to individual isolation" (p. 35).

In the international arena the OECD (1980) has produced a set of guidelines outlining requirements which have been widely implemented in the privacy legislation of various countries, including New Zealand ${ }^{3}$. These guidelines and their associated legislations recognise that without security, privacy can be difficult to achieve. As a result they mandate at least a minimum level of security in relation to systems

\footnotetext{
${ }^{3}$ The OECD guidelines are incorporated as Privacy Principles in the NZ Privacy Act (1993)
} 
containing individuals' information. The European Commission on Internet of Things Governance (2013) considered that the current data protection framework, (including the OECD guidelines) was sufficient, but noted the need for further transparency around what data was collected by organisations. They recommended ensuring that organisational privacy policies were "by default and design" (p. 4), and that adequate security was implemented on Internet of Things systems. The European Union (2009), as well as implementing privacy guidelines which mandate protections for personal data and privacy, also recognises the importance of security, finding that appropriate control over individual and business data plays a role in encouraging the use of technology.

Privacy concerns within an Internet of Things environment can be separated into two streams, one related to the personal information collected by the tags, the second related to the movements of individuals who may be carrying tagged items. Passive RFID tags by their very nature carry little if any inbuilt security, and nor do they have the capability within technical constraints of memory and cost; they simply respond to any reader within range. As such, they are constantly "on", representing a risk in themselves as anyone who can decipher the codes transmitted by the tag can identify the tag. Of greater concern is that anyone can purchase a reader, some of which can read tags over 10 metres away, making it possible to track tagged items, or to intercept tag/reader communications over some distance (United Nations, 2006). This allows for the possibly of covert surveillance of a person carrying a particular tag, or for someone to discover what items are in a particular location by simply reading the embedded RFID tags. Even when a person doesn't carry the same item every day, they likely own many items bearing RFID tags that can be used to track them, from their car keys to their wallet (Cas, 2005). In the future it may be difficult to avoid carrying tagged items (United Nations, 2006). That said, as pointed out by Murphy and Blessinger (2003), the problem of clandestine surveillance is not limited to RFID tags as it can more effectively be carried out through other wireless devices such as those that are Bluetooth enabled, or even cell phones.

The ubiquitous computing environment presents numerous privacy challenges, as many of the features that make an environment ubiquitous are the very features that 
raise privacy concerns. The tags in a ubiquitous environment are not only everywhere but they are invisible, making it difficult to know what items carry tags, what information those tags carry, and if they are being read at any particular time (Krotov \& Junglas, 2008). This increase in computing power of both tags and the ubiquitous environment also makes it possible to not only gather information, but to store it in real time for possibly indefinite periods (Langheinrich, 2001). Michelfelder (2010) argues that these features compromise the right of the individual to decide the criteria under which they relate to information technology, as information can be gathered and dispersed without their knowledge or consent. Responding to this concern, the European Commission (2013) found that individuals should have the right to be invisible to Internet of Things systems, essentially opting out of having data collected from any RFID tags (or other Internet of Things enabled devices) they may be carrying.

As well as the immediate threat of tag interception and individual tracking, there are further privacy concerns raised about the nature of the data collected by tags and readers. The European Commission (2006), draw a distinction between tags identifying goods (or services) and the identification of individuals, finding that the identification of an item per se does not result in a privacy problem. Privacy problems arise when the owner of a tag (or the data collected from it) can be individually identified, or when the aggregation and profiling of data is used in a way that disadvantages an individual. King and Jessen (2010) note a number of privacy harms arising from profiling including the individual being subject to tracking, increased exposure to the risks of identity theft and fraud, not to mention the data being used to generate advertising by marketers. The most well-known example of this type of targeted advertising is Google's AdSense technology which, when applied to email in Google's G-mail service, generates advertising based on keywords in a user's email messages (Chopra \& White, 2007).

Bandyopadhyay and Sen (2011) note two dimensions of privacy in the Internet of Things environment, being individual privacy and business confidentiality. They find that despite a range of security technologies being available "the cloud of things is hard to control" (p. 59). They also consider that privacy and security challenges arise from the nature of the technology itself with tags generally being incapable of carrying 
much security, as well as from the huge variety (heterogeneity) of devices able to interact with the Internet of Things. Miorandi et al. (2012) also discuss the importance of data confidentiality, pointing out not only the individual privacy implications of a data breach, but also that the data held in a business context is an asset to that business which needs to be protected. They define data confidentiality as "the guarantee that only authorised entities can access and modify data" (Miorandi et al., 2012 , p. 1505), and suggest a range of possible technology solutions. Like the European Commission (2013) and others they find that implementing privacy and security in the Internet of Things still presents many challenges, despite the range of technologies currently available supposedly addressing this issue.

A number of solutions have been proposed to answer privacy issues. The most commonly cited is the "kill tag" solution where an RFID tag is deactivated at point of sale. This solution however presents its own problems. Deactivating the tag also disables a number of features that make the use of tags attractive in the first place, features like ease of item return, warranty tracking, advanced waste management and product support (Ohkubo, Suzuki, \& Kinoshita, 2005). Other possible privacy solutions include physically shielding the tag itself, blocking the transmissions from the tags, and encrypting the tag information (United Nations, 2006). All of these solutions face difficulties, not least of which is in a ubiquitous computing environment there will be many more tags than just those individually purchased by, or even discoverable by, individuals.

Another possible solution to the problem of individual privacy and security in an RFID system is identity management. Identity management is generally considered to be the way the identity of the user of a particular system is verified so that the user can be logged on to a computing system, and when logged on, the identity management profile dictates what information that user can access (De Hert, 2008). De Hert (2008) also recognises a second element of identity management, discussing how an individual can manage their own identity through the use of pseudonyms and other techniques which allow for the actual identity of an individual to be obscured online. In respect of RFID systems, especially when considering their contribution to the Internet of Things, it is possible that in the future individuals will be able to dictate 
what information they reveal about themselves (their identities) in specific contexts (Streitz et al., 2005). For example, Cas (2005) suggests that when a person walks through a shop they could choose to suppress any information about their movements that might be collected from any RFID enabled devices they happen to be carrying. This kind of "privacy enhancing technology" may help answer some of the concerns individuals have with future ubiquitous computing environments, and has also been recommended by the European Commission (2013). Debate remains about whether privacy rights need to be regulated, or whether industry can be counted upon to self-regulate. A number of authors argue that privacy solutions cannot be left to industry self-regulation, but that government intervention will be required to ensure the rights of consumers identified in various government and European Union mandates are protected (King \& Jessen, 2010).

\subsubsection{Trust}

Although not always explicitly acknowledged in technology systems, trust is a strong theme within the information systems and supply chain management literature. Rousseau, Sitkin, Burt and Camerer (1998) describe the discipline specific range of trust definitions, from the calculative or institutional views generally taken by economists, to the personal attribute views taken by psychologists. They find two common features of trust across all disciplines being the need for a risk which gives rise to the opportunity to trust, and interdependence where the different parties must rely on each other. They also note, along with many others, that the broader literature on trust is vast. As such this review focuses on that part of the literature relevant to the research topic highlighting some key points.

Trust is a concept that extends beyond the inter-personal and can include trust in technology or institutions. Mahinderjit-Singh and Li (2010) for example, found that the ability to build trust in the supply chain context could turn against infrastructure characteristics of the RFID system itself (such as tag qualities and data communications) as well as the more familiar business characteristics. In the purely technical sense Miorandi, et al. (2012) in discussing trust in the Internet of Things context describe trust as a function of trust negotiation - being "the process of credential exchanges that allows a party requiring a service or a resource from 
another party to provide the necessary credentials in order to obtain the service..." (p. 1508). This concept relates to the identification of individual digitalised artefacts within RFID networks, as tagged artefacts identify themselves to the RFID network, which then processes the information and either reads the tag or ignores it depending on the appropriated responses being provided. When considering the sharing of data, essential to the RFID supply chain, Eurich, Oertel and Boutellier (2010) found that trust between organisations was necessary before data would be shared in any way.

Where the implementation of a technology-based system is successful, trust, both individual and organisational, frequently emerges as having been central to this success, as it does in studies of RFID systems. Lee, Park, Yoon and Yeon (2007) note that trust issues in a RFID based ubiquitous environment are complicated by the various perspectives held by many different stakeholders and the speed of technological change. Their study found that consumer trust became especially important in this environment as the newness of the technology exacerbated consumer concerns. They recommended the use of strong, consistent policies in relation to privacy in particular, in order to increase consumer acceptance of ubiquitous systems. Trust is generally considered to build slowly over time. However, Blomqvist (2005) found that trust could develop quickly between organisations in an environment where managers were involved in intense negotiation and collaboration.

Trust in the relationship between supply chain partners has been examined in a number of studies. Laeequddin, Sahay, Sahay and Waheed (2012) considered that trust wasn't strictly relevant between supply chain partners, as long as they had sufficient information about each others' business practices to ensure there was no risk in their relationship. Similarly, Blomqvist, Hurmelinna-Laukkanen, Nummela and Saarenketo (2008) in studying trust relationships within and between born-global companies suggested that risks were high for such relationships and that the use of contracts assisted in the building of trust. Luhmann (1979) in discussing institutional trust suggested that the use of legislation or regulation was one of the most effective ways to reduce the risk of trusting in business relationships, possibly related to the legislated consequences of trust violation. 
A number of authors have also modelled trust in various contexts. In their study Laeequddin et al. (2012) suggest a conceptual model of trust between supply chain partners that includes three dimensions:

1. Characteristic trust: trust related to personal aspects including benevolence, honesty and reliability;

2. Rational trust: trust related to logical aspects including economics, outcomes and cost/rewards calculations;

3. Institutional trust: trust related to requirements including legislation, contracts and regulation.

These dimensions are consistent with three of the four dimensions of trust suggested by Rousseau et al. (1998) who also noted the importance of deterrence based trust which was based on the presence of sanctions for possible non-performance. These three dimensions also mirror those suggested by Tejpal, Garg and Sachdeva (2013) who include a further four dimensions in their supply chain trust model being:

1. Anticipatory trust: trust related to the expectation of a certain response or action;

2. Responsive trust: trust related to the expectation of trust being both placed (by the trustor) and received (by the trustee);

3. Identification based trust: trust related to the knowledge of what is mutually expected from the various parties involved, often based on shared goals and values; and

4. Calculus based trust: trust related to the knowledge of the consequences of not completing a certain action.

In the public sector, Dawes, Cresswell and Pardo (2009) note that lack of trust can be a barrier to the operation of knowledge networks in the public service. Hudson et al. (1999) while viewing collaboration between government sector organisations as being "self-evident" found that there needs to be a level of trust between organisations before collaboration can be successful. Gil-Garcia, Pardo and Burke (2010) noted the importance of trust in successful cross-boundary initiatives. They found three dimensions of trust in such initiatives being: 
1. defined responsibilities and roles (reducing the complexity of cross boundary programs and facilitating understanding of the roles of each partner);

2. familiarity with the partner organisations (creating realistic expectations); and

3. the proper exercise of authority.

Treglia and Park (2009) similarly found that understanding and knowledge of other partners within a network facilitated trusting relationships, and thus a greater tendency to share information. They also found that consistent policies aid in facilitating information sharing. Across national borders, Navarrete, Mellouli, Pardo and Gil-Garcia (2009) found that collaborative efforts faced challenges based on differing state and national agendas, the number of agencies involved in collaboration, and sociological differences based on language, culture, and resistance to technology.

\subsubsection{Legislation and Governance}

The presence of government regulation or legislation in respect of elements of any IT system, frames both the implementation and functioning of the system. Marche and McNiven (2003) draw a distinction between the business of government and the activity of governance. They define the difference around the relationship between the citizen and government, with government being the "way in which decisions are carried out" (p. 75) and governance as focusing on the way decisions are made.

Any consideration of the role of the public sector in society will need to consider some aspect of governance as this is the basic function of government. Coleman (2008), notes that governance relies on information technology in the broad sense, and specifically on the information generated by IT applications, to provide information and support necessary for the various functions of government. Anttiroiko (2012) considers that the increasing use of technology in society is leading to increasing need for (and consideration of) technology governance. Busch (2010) considers government administered standards to be a form of governance, while Shah and Kesan (2010) conclude that the design of software defaults and configurations can also be considered a form of governance.

In respect of governance in the Internet of Things context the European Commission (2013) report on Internet of Things governance showed a difference of opinion 
between industry/academia and individuals. Industry and academic respondents believed there were already sufficient regulatory protections in place, and did not want to see additional regulation, as they were concerned about stifling innovation and investment. In contrast, individuals along with consumer associations were of the belief that rights to privacy (and other ethical issues) were more important. They were also concerned that users would be locked into technologies due to the market not developing competitively. Zorzi, Gluhak, Lange and Bassi (2010) also discussed the importance of governance in the Internet of Things, noting that at the time of writing there was little governance, which was contradictory at times.

When considering any widespread IT system, especially one that includes the government sector, central to its implementation will be considerations of how legislation could affect the implementation, infrastructure and use of the system. Many countries have some form of privacy legislation mostly based on the OECD (1980) privacy principles, which include expectations of privacy, and the associated security. The European Union also requires member states to comply with its various directives in respect of data protection and privacy (Directives 95/46 and 2002/58). Despite the regulatory protections already in place, Friedewald and Raabe (2011), note that ubiquitous applications still present challenges in the protection of individual data, especially when balanced with the needs of organisations which want to use the data they collect. They further point out that the uncertainty surrounding technological development leads to difficulties in developing appropriate regulatory and legislative protections, and that it is likely that current protections are not adequate. These concerns are especially critical to RFID systems because of their scope, as RFID enabled devices can be easily carried across borders and around the world. A good example of this is RFID enabled passports commonly carried by citizens of many countries including the US and New Zealand (The RFID Reader, 2006).

In the government context, Hovy (2008), claims that any research on e-government should consider a range of perspectives including amongst others, political agendas, legislation and technological perspectives. Jansen (2011), also discusses the importance of linking political priorities and legislation to the objectives of any technology based project in the government, noting that this linkage is necessary for 
any successful IT implementation, along with building the appropriate infrastructure to support any reform necessary. Dawes, Cresswell and Pardo (2009) when discussing the importance of policy in achieving success in government collaborative projects, state that "policy barriers are the greatest obstacles to substantive success in building Public Service Knowledge Networks" (p. 398).

\subsubsection{Cost}

The final challenge to the implementation of any IT system is often consideration of its cost. Where RFID systems are studied, cost is one of the most frequently discussed elements on which the adoption decision is made. Rothfeder (2004) in a study of suppliers' compliance with Wal-Mart's requirement to RFID tag cases and pallets, found that cost was a major inhibitor to suppliers utilising RFID systems beyond the minimum requirement to put a tag on an item (this minimal compliance has come to be known as "slap and ship"). Other cost issues identified by Rothfeder include the cost of the tag relative to the value of the item - with tags costing 20 cents representing a large portion of the value of items worth only a dollar. Chui, Löffler and Roberts (2010) find that both cost and size of tags are falling, although they have not yet fallen far enough to encourage adoption on low margin goods.

When discussing the implementation of Smart Card fare collection systems, Pelletier, Trépanier and Morency (2011) found that while ongoing cost reductions were an incentive for implementation, the actual cost of implementation was a major barrier. Taking a slightly different viewpoint, Riggins and Slaughter (2006), discussing interorganisation supply chains, found that issues around the sharing of both costs and benefits between participating organisations inhibited the adoption of RFID based information systems. Ramanathan, Ramanathan and Ko (2013) in a study of logistics found that cheaper costs would probably increase systems uptake, and interestingly that government support in terms of finance, training or regulation increased the probability of adoption of RFID systems. From a public management perspective, Dawes (2008) recommends a broad approach which includes intangible costs such as managing cultural change and organisational relationships. 
Bunduchi, Weissharr and Smart (2011), examined both benefits and costs of technology systems from a process innovation perspective. Using the spread of RFID technology through industry as an example they found that during the early evolution of RFID systems the costs of systems development, infrastructure and ethical costs (including the cost of complying with privacy requirements) outweighed other costs. As RFID technology became more widespread they argued that initiation costs, cost associated with owning RFID equipment and the cost of business change come to dominate. In respect of benefits, they found that early adopters benefited from being able to accurately track inventory, thus reducing labour and handling costs. As RFID systems became more widespread they saw different benefits in different industries as these industries adopted RFID systems, as would be expected since RFID systems were first used in the supply chain arena, and moved from there into other industries.

\subsection{Literature Summary}

Examination of the RFID literature presents the picture of a simple technology wrapped in a complex network. From the uncomplicated tag and reader infrastructure arises a detailed middleware and data sharing network. Basic issues surrounding standards for both hardware and software remain undecided, and this is inhibiting systems interoperability and information sharing. Further barriers to information sharing include concerns about individual privacy and security of data, and the related issue of whether organisations can be trusted with the data they receive. From an organisational perspective, business practices and governance need to be balanced with knowledge of any legislation that might affect RFID systems.

The context in which systems are based is also important. Various technology models hint at what might become possible, with RFID enabled devices contributing to a ubiquitous Internet of Things style network where all things (devices) could be digitalised with RFID tags and able to interact with each other, organisations and even individuals. The relationship such technology has with organisations, especially where they cross the boundary between public and private is still unclear, with only a few studies in limited application areas looking at this issue. The challenge remains how to study this network in the public-private context in a way that allows a clear picture of 
how it is established and sustained to emerge. This is the question that will be addressed in the next section of this thesis. 



\section{Theoretical and Methodological Basis of this Study}

As the basis of this research is the study of RFID, it is necessary to take a theoretical and methodological approach that will allow the technology itself to take a place within the analysis. This chapter will first discuss the theoretical approach taken in this study then describe the methodology used to gather and analyse data. It will conclude with a discussion of the role of the researcher and the ethics of funded research.

\subsection{Actor-Network Theory (ANT)}

As discussed in the introduction, a number of theoretical frameworks and epistemologies were considered for this study, but ANT's inclusion of technology and devices in its model of society was considered most appropriate for answering the research questions. ANT's use of a symmetrical view of the social, where all things human or non-human are considered to be able to act or have agency, allows the technology of RFID networks to act along with human counterparts. This view allows the network to be traced from place to place, focusing on the technology within the public-private context, rather than having to focus on individuals within single RFID systems. Given the dispersed, pervasive nature of RFID networks this seems particularly appropriate as a way to trace associations between humans and things that would otherwise not be visible within a constricting 'humans only' view of the social. For example, in discussing ANT, Vidgen and McMaster (1996) describe a "parliament of things"(p. 253) in which technology is present within society and represented by its spokespersons, a reasonable parallel to today's Internet of Things. This highlights the value of ANT particularly in its focus on the place of technology in society, as RFID systems are networks themselves - of humans and non-human devices - the very core of ANT based study.

There is little argument that ANT is a qualitative approach used by researchers who are attempting to make the world visible through the collection of the perspectives of many different people and objects - much like the bricolage of Denzin and Lincoln (2005). However, ANT does not fit comfortably into the more usual sociological frameworks. Instead Lewis (2007) and Myers (2009) consider ANT to be a "grand theory", a way of looking at and understanding large and complex social and 
technological structures. More commonly, as noted by Gad and Jensen (2010), ANT is considered to be neither a theory nor a method but more of a lens through which to view the social. Gherardi and Nicolini (2005) also take this point of view, believing that ANT is not a theory in and of itself but better considered to be an 'interpretive sensitivity', following the ideology of ontological performativity, where reality is constructed through the various actions or performances of its members.

Although a research study generally takes the point of view of one of the accepted research paradigms (Bailey, 2007; Myers, 2009), ANT can be difficult to categorise as it has its own ontology, or set of assumptions about the nature of world, largely based on the work of Bruno Latour, John Law and Michael Callon. As pointed out by Law (1992) p 383:

"Actor network theory is analytically radical in part because it treads on a set of ethical, epistemological, and ontological toes. In particular it does not celebrate the idea that there is a difference in kind between people on the one hand, and objects on the other".

He argues that 'the social' is heterogeneous; it is an effect of networks of society, people, organisations and things (technological artefacts). According to Law (1999) none of these elements can exist apart from each other and they are formed by the inter-relationships between them, in other words they have "relational materiality".

Despite, or perhaps because of the difficulty of assigning ANT to a particular social category, it has been associated with a number of paradigms, particularly interpretivism, social constructivism and critical theory. Cordella and Shaikh (2003) find that ANT is most commonly associated with interpretivism, a tradition whereby reality is constructed by humans, according to their values and beliefs, and is therefore subjective (Orlikowski \& Baroudi, 1991). However, Cordella and Shaikh (2003) go on to criticise the way researchers use ANT within an interpretivist paradigm, on the basis that they fail to focus on the ontology of ANT, instead using it as a lens to study information systems rather than allowing the actants to "speak for themselves" (p. 9). They contrast the ontology of the interpretivist tradition, which places emphasis on the construction of reality by the observer; with the ontology of ANT where reality 
emerges through the association of the actors. This view, where reality should not be imposed by the researcher is also taken by Elbanna (2011, p. 138) who states "The role played by the social and the technical, and their effect on each other, is left as a local empirical matter that needs to be explored rather than being a theoretical starting point for research". Elbanna (2011) considers that ANT provides the flexibility to allow the actors in the network to assemble their own form of existence (and politics for that matter), rather than having it imposed on them by the researcher.

Although a number of studies have linked ANT with the social constructivist viewpoint, it is difficult to consider ANT a constructivist approach as in its purest sense social constructivism does not allow for the presence of non-human actors (Cordella \& Shaikh, 2003). Alvesson and Sköldberg (2009), consider ANT to be part of the "second wave" of social construction which does allow non-human actors. Bijker (1993, p. 125), agrees with this view stating that "the technical is socially constructed, and the social is technically constructed - all stable ensembles are bound together as much by the technical as by the social"; although this is considered to be a less common viewpoint. This is the approach taken by Hanseth, Aanestad \& Berg (2004, p. 119) who argue that ANT looks at the "construction of things normally taken for granted". Similarly Aanestad (2003), employs ANT as a way of looking at the relationship between new technology and work practices in a different and more flexible way.

The third paradigm sometimes associated with ANT is the critical paradigm as in the work of Doolin and Lowe (2001). However, as this study does not seek to critique society, nor take a moral stance (both requirements of a critical study according to Myers (2009)), such a critical approach is not considered appropriate.

As this study is more interested in describing the RFID network rather than commenting on society, it is considered more appropriate to follow Elbanna (2011) in neither taking up a particular paradigm approach nor making any a priori assumptions about the nature of reality. Instead, this study focuses on the ontology and principles of ANT in order to advise the research, since "ANT can account for both the social and the technical without losing any thread in favour of the other providing a more balanced view of both" (Elbanna, 2011, p. 138). Thus, following Klein and Myers 
(1999), ANT will also be used as a way of viewing the social that will allow for new associations and perspectives to be recognised.

\subsubsection{Principles of ANT}

ANT focuses on the examination of "the interaction between social and technical systems" (Shin \& Lee, 2011, p. 89). Its basis lies in the relationships between elements (or actors) in a socio-technical network. Anything might be included as an actor in a network, a technological artefact, institution, document, policy, concept or person. The resulting network is termed "heterogeneous", as it is made up of a mixture of elements. According to Doolin and Lowe (Doolin \& Lowe, 2001) this mixture of human and non-human actors stabilises the network and results in its being socio-technical in nature rather than purely social. The technical actants are more than mere placeholders. Law (1992) argues that if we were to exclude any of the non-human materials from our networks, the networks themselves would disappear as the interactions between the humans and non-humans are an essential part of the network. Thus, the actor-network emerges both from the actors that make up the network, and their interactions with each other. As Law (1999) points out, the relationship between the actors is dynamic and changing. It is the dynamic interplay between the actors, how they act together and apart in order to form the network (in a process called "translation") that the actor network researcher finds interesting (M Callon \& Latour, 1981).

Callon and Latour (1981) believe that in order to understand a network, it cannot be assumed that one actor is superior to another, otherwise elements of the network may be lost in attributing importance to one actor over another. Therefore, ANT demands that all actors are treated in the same way - it is agnostic to the position or quality of the actor, human or non-human, famous or mundane, social or technical (Law, 1992). It is also symmetric describing the viewpoints of both human and nonhuman actors in the same neutral language. Callon (1986) considers that this requires a certain sometimes heroic approach to ANT description. For example in Aramis, or, the love of technology, Latour (2002) describes the Aramis project through different perspectives, including that of the technology itself. Aramis is an actor, commentating 
on its own problems and ultimately its demise. Latour's approach does not privilege human actors, he investigates all through the same approach.

Along with the inclusion of non-human actors in the ANT networks, these actors are also treated on an equal symmetrical basis with human. Law (1992) argues that this approach demystifies the powerful by recognising no distinction between the actors in the network, instead it theorises that the difference between actors lies in how they use methods and materials to create themselves. Similarly, Hanseth and Monteiro (1998), state that "a more satisfactory account of the interwoven relationship between IT and organisational transformations is lacking" (p. 92). They believe that ANT provides a way to describe the detailed actions which contribute to the make-up of information technology systems.

\subsubsection{Macro or Micro?}

The symmetrical approach gives rise to the flat ontology of ANT, as outlined by Callon and Latour (1981, p. 280):

"There are of course macro-actors and micro-actors, but the difference between them is brought about by power relations and the constructions of networks that will elude analysis if we presume a priori that macro-actors are bigger than or superior to microactors."

Callon and Latour (1981) assume that all actants are isomorphic - being made up of similar material or in similar ways. Therefore, they argue, each actant and network should be examined using the same methods, as all are made of the same stuff. It is the process of examining how the actants form associations, and black boxes, which leads us to being able to tell the difference between them - not the size of the actant. The ability of a macro actant to assemble and keep together an association of micro actants is what dictates its ability to stay macro. Latour (1988) demonstrates how this process works, describing how Pasteur's process grew in scope through the enrolment of many micro actants from microbes to governments. As Callon and Latour (1986) describe "macro-actors and micro-actors seated on top of many (leaky) black boxes". 


\subsubsection{Actors or Actants}

One of the controversies of ANT, already alluded to above and discussed in detail later in this section, is the inclusion of non-human "actors" in ANT networks. This inclusion leads to difficulties with the use of the term "actor" to describe all members of a particular network as the term actor is normally reserved for humans who are capable of agency, and action. The term 'actant' on the other hand, can be applied to both human and non-human, and is defined by Czarniawska-Joerges and Hernes (2005, p. 9) as "those that act and are acted upon". Because both human and non-human actants are included in this study, it is considered appropriate that the term actant will be applied to both, for the remainder of the study as well as allowing the non-human actants to have something of a "speaking role" in the networks developed, as Latour (2002) did with Aramis.

The use of the term network in ANT is also not the standard usage. In ANT terms the network is heterogeneous - made up of both human and non-human actants, with the presence of the non-human actants helping the network to achieve stability (Elbanna, 2009). ANT is concerned with how this stable network forms, how the actants organise themselves and how they keep the network together (Law, 1992). It is also interested in tracing the relationships between actants in the network, sometimes to "surprising places" (Law, 2007, p. 8). It is the tracing of these associations through the process of translation that is described in ANT accounts.

\subsubsection{The Process of Translation}

The process of translation forms and stabilises the network, and each part of the network - human, non-human or organisation, jostles for position within it. At any time part of the network can become unstable, actants can leave the network and new ones can join, forcing the network to go through further translations. According to Law (2007) actants attract other actants by persuading them that they share a common problem (a process known as problematisation) thus attracting them to join the network. This process of persuasion requires continuing negotiations during which the interests of the actants become aligned. According to Callon and Latour (1981) this process of translating another actant into the network is complete when that actant becomes able to act or speak on behalf of the other members of the network. 
Translation is recognised to have four stages, originally summarised by Callon (1986) as:

1. problematisation, during which an actant or actants begin by defining the problem, possible solutions, and the roles they will play in finding this solution. Some actants may also represent themselves as being essential to solving the problem thus becoming "obligatory passage points" for the solution;

2. interessement, during which the initial focal actants attempt to interest other actants in the problem, aligning them with their own interests - and validating the problem;

3. enrolment occurs when interessement succeeds and the different actants are all working towards a common goal. At this stage the role of each actant in the network is generally defined. Some actants may be delegated to stand in, and speak on behalf of others; and

4. mobilisation involves the initial actants ensuring that the other actants continue supporting the network.

Law (1992) describes four features of translation:

1. it is most stable or durable when it incorporates a range of stable actants - for example books are more stable and durable than thoughts;

2. it includes actants at a distance and therefore also includes the means of communicating with these actants through immutable mobiles;

3. anticipation of future events and reactions to the network lends stability to it; and

4. the scope of the network can be extended beyond the local to include strategies, which are largely implicit. Law (1992) suggests a range of strategies including "enterprise" and "vision" which act to form the typical structure of an organisation.

Latour (1999b) provides simple diagrams in order to assist in understanding the various concepts he discusses. Following his lead Figure 4 below summarises the ANT process of translation. This thesis will use diagrams in the following sections to further demonstrate the ANT concepts discussed. 


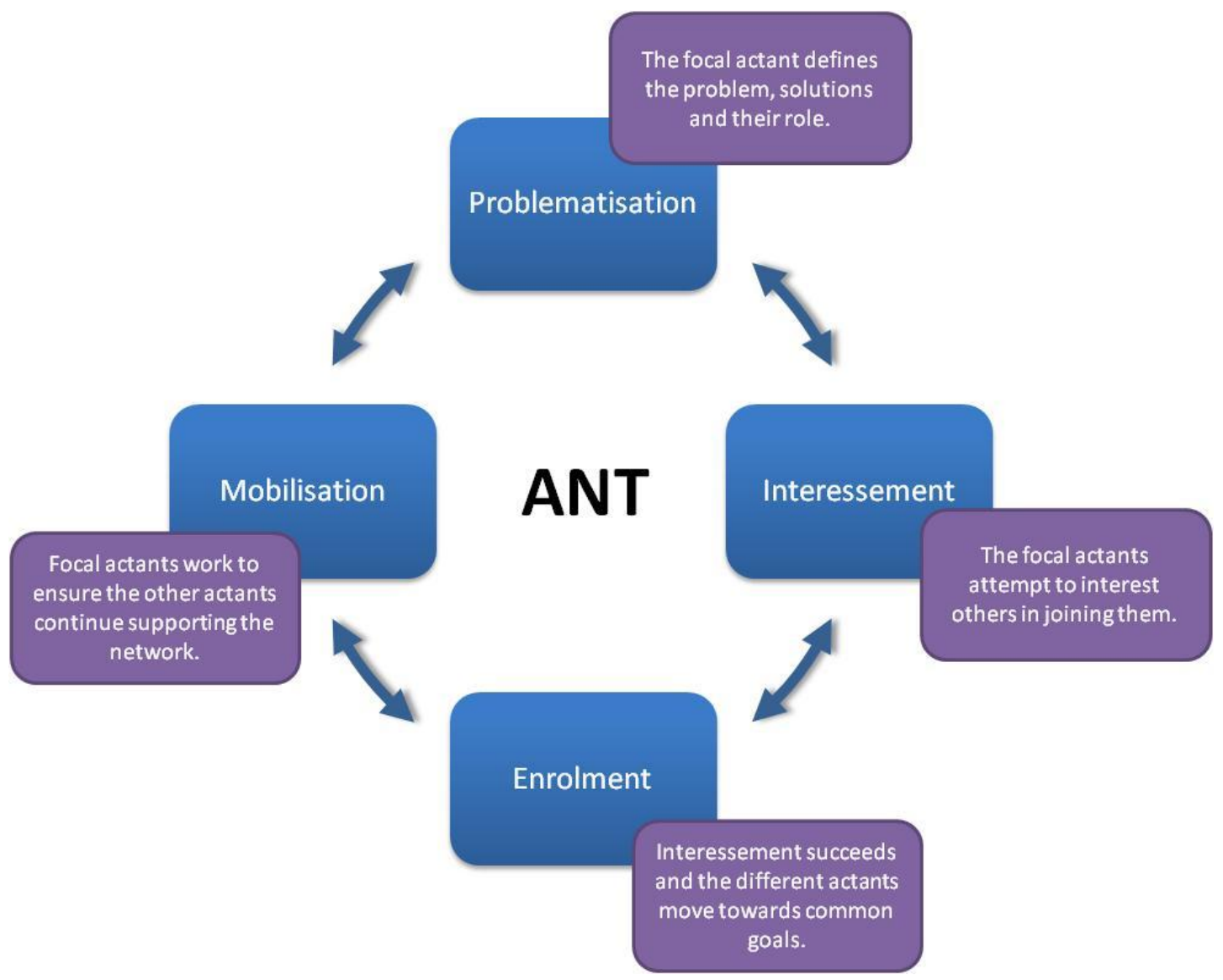

Figure 4: Actor Network Theory

According to Latour (2005) the purpose of translation is to allow for the formation of a stabilised network, where controversies surrounding the network, and between the actants, are settled, or at least at rest. The process theoretically leads to the alignment of the interests of all the actants as they work towards solving the identified problem. However, while the process of translation itself seems relatively straightforward, it is possible for dissidents to de-rail the process of translation forcing actants to return to earlier stages of translation, or to give up on their attempts to align with others. Latour (1987) describes how a network can be challenged by 'unreliable allies' that want to alter the shape of the translation to suit themselves. In order to stabilise translation the actants can use other tools including inscription, punctualisation, immutable mobiles, displacement and black boxing, which will be discussed in the following sections.

\subsubsection{Obligatory Passage Points}

At the end of the problematisation phase of translation, there is an obligatory passage point that must be passed to move through the remaining phases of translation, as 
demonstrated in Figure 5 below. Callon (1986) describes how the obligatory passage point occurs at the moment of problematisation where other actants accept the program set out by the original (focal) actants. Gherardi and Nicolini (2005) used the example of how legislation made a management accounting system an obligatory passage point in Italian local government agencies by requiring its use in the

A

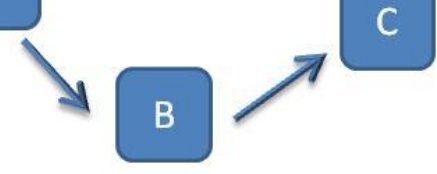

Obligatory Passage Point local body financial systems. However, they also recorded considerable resistance to this legislation with a number of dissidents sabotaging the translations required to integrate the accounting system into their organisations on the basis it would reduce their discretionary powers or increase workloads. There was also resistance from non-humans in the form of difficulties encountered with integrating pre-existing accounting information, changing accounting practices, and even in obtaining data to input into the new systems.

Similarly Backhouse, Hsu and Silva (2006) found that an information security standard became an obligatory passage point "insofar as its prescribed practices and policies are considered valuable and interpreted to be technically sound". This security standard could also be considered to be an inscription as it is an item or artefact with a course of action written into it.

\subsubsection{Inscription, Irreversibility and Durability}

Any translation is advised by, and produces, various inscriptions. When an artefact or a technology has a program or a course of action written into it - it is said to be inscribed. Akrich (1992) believes that the production of inscriptions is the primary occupation of innovators. The innovator's vision of how the world works and the place of their invention in it is inscribed into the construction of the artefact they produce. The artefact then takes its place in the network, its programming dictating how it is used by other actants. When a network contains an inscribed actant, the network usually becomes irreversible as it is impossible, or at least extremely difficult, for the network to return to the same condition it was in before inscription occurred. Callon (1991) describes two features of irreversibility - the difficulty of completely undoing the effects of the translation, and the degree that the translation determines 
subsequent events. An example commonly used is that of a computer program. Without the computer programming (or inscription) a computer is merely a collection of components. Thus the programming inscription is not only necessary it is irreversible, it cannot be undone or the technology will not operate. Latour (1992) argues that inscription also takes place in the formation of the technology itself within the actor-network. He implies that the inscriptions operating within the network bring it into existence, thus the network can act even if it is not fully implemented, through its inscriptions.

According to Hanseth and Monteiro (1997) the strength of an inscription can be related to the complexity of its surrounding networks and how well they are aligned with the inscription. Monteiro and Ciborra (2000) give the example of learning a specific work practice. If the initial attempt to inscribe the process through training is too weak, then the practice could be inscribed into a manual, or if that is unsuccessful then an information system based inscription could be considered. Each inscription increases in strength until it is successful (or translated) into practice. They consider that an information infrastructure is an aligned actor-network as "the constitutive elements of an information infrastructure - the collection of standards and protocols, user expectations and experience, bureaucratic procedures for passing standards inscribe patterns of use" (Monteiro \& Ciborra, 2000, p. 78). Once established these networks are difficult to reverse - or to put it in ANT terms they are more irreversible; this lends the network a degree of strength and according to Monteiro and Ciborra (2000) contributes to the institutionalisation of networks.

Law (1992) argues that translation is strengthened when more durable materials are used, assisting the translation in maintaining relationships. This applies particularly to inscriptions, as he notes "when we start to perform relations - and in particular when we embody them in inanimate materials such as texts and buildings - they may last longer" (p. 387). However, Law (1992) also cautions against being too keen to use the term durable due to its context dependence. He uses the example of a prison where the walls are secure and durable but still dependent on the presence of guards to ensure prisoners stay behind them. Callon (1991) believes that the durability of a network increases as the number of elements/actants, (especially irreversible ones) 
increases. This he says is because it becomes more and more difficult to reverse a network that contains many actants as a redefinition of any part of that network causes it to re-translate - or to fail. Thus, these tightly wound networks also resist attempts to change or alter them. Such a network can then be said to be predictable in its output - or black boxed.

\subsubsection{Black Boxes and Immutable Mobiles}

Where parts of the network are considered no longer interesting, or where they are simply accepted as they stand, are thought to be

reliable and unchanging, they are considered to be black boxes, as

Black Boxing depicted in Figure 6. According to Latour (1987) the term black box Figure 6: Black Boxing arises from cybernetics where commands that are too complicated are viewed entirely as their input and their output, surrounded by a black box. A black box is part of a network that "no longer needs to be reconsidered, those things whose contents have become a matter of indifference" (M Callon \& Latour, 1981, p. 285); such things as habits, or policies could be considered to be black boxes. This differs from the concept of punctualisation (which will be discussed in full later). While a punctualisation can be considered to be where part of the network acts as if it is a single block, a black box can be set aside as its contents can be considered fixed - for the particular moment it is being observed.

Latour (1987), suggests a number of ways in which other actants can be enrolled into a black box:

- appealing to the interests of others or persuading others to take up the interests of the actant;

- suggesting other actants take a detour through the black box;

- rearranging the interests and goals of others in order to divert them through the black box; and,

- making themselves invaluable to others.

Once an actant has been enrolled, it becomes part of the black box with predictable outcomes. 
Black boxes also vary in stability. For example, Latour (1991) considers that the more difficult it is to open a black box, the more stable it is. He also believes that the more black boxes occurring in a "chain of associations" (p. 123), the more predictable the network is, and also more powerful as the black boxes limit the performance of actants to the one they dictate. However, Latour (1987) also believes that black boxes are not fixed, they can be re-opened and re-negotiated. The many different parts of a black box can also come apart as readily as they can be assembled, and a network gains durability when the various actants no longer feel the need to open up the black boxes to examine their contents.

Durability itself is something that is open to question. Latour (2005) discusses how the different things that make up a network, or black box, differ in durability. He considers that "social stuff" (p. 66) cannot make up a durable network, instead networks are constructed of social skills and things. From this the instruction to "follow the actors" becomes instead "follow the actors in their weaving through things they have added to social skills so as to render more durable the constantly shifting interactions" (p. 68). Where an element of the network is mobile and durable - for example a manual or a map - it can become an immutable mobile, able to travel through both space and time. Law and Singleton (2005) relate that the concept of immutable mobiles arose as a way to understand control exerted over a distance. They give the example of ships used during the era of European Imperialism. The ships were mobile and held their shape, allowing sailors to travel around the world exerting European control, thus stabilising the European Colonial network. Other commonly given ANT examples of immutable mobiles include "letters of credit, military orders or cannon balls" (Law, 1992, p. 387), as all of these elements can have effect over a distance - although the effects are clearly different.

\subsubsection{Punctualisation}

Differing slightly from black boxing, punctualisation occurs when part of the network can be simplified and assumed to act in the same way consistently. It can then be incorporated into another network,

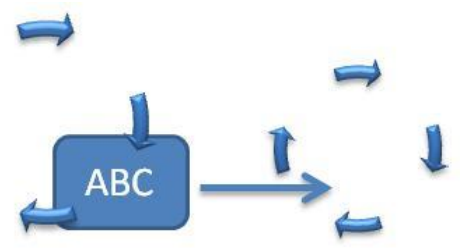

Punctualisation 
as depicted in Figure7. Returning to the example of a computer, Callon (1991) describes how a computer, the product of a translation, is used in another network as a punctualised device. It can be assumed to work in a consistent way in the network in which it is placed, but is actually the product of another separate network. Further examples of this might be a strategy, a habit, or a device. Law (1992) describes how patterns within the network that are often repeated can be considered punctualised, primarily as a way of dealing with the complexity of networks. In the case of this study an RFID transmitter is a punctualised device, it is expected to work in the same way the majority of the time, and is the black boxed product of another translation punctualised into the network we are observing.

The 'punctualised' actant is what we perceive in our network -a group of actants held together for the time being, by the process of translation, which Callon (1987) allows us to treat as a single point or actant. However, as Law (1992) notes it is not taken for granted that the punctualisation will work all the time (nor can we guarantee our transmitters will work all the time) as it can be challenged. When this happens, irreversibility decreases, and actants start to drift apart, as Callon (1991) states "markets collapse, industrial sectors are dislocated, and scientific specialities tear themselves apart. The macro-social is no different in kind from the micro social..." (p. 153). So, to summarise, a fully translated network can become a black box, which can then be used in another network as a punctualised device (or actant).

\subsubsection{Mediators and Intermediaries}

Apart from describing those elements that lend stability to the network such as inscriptions or immutable mobiles, or arise from it such as black boxes, there are other influences on ANT networks. Mediators and intermediaries act within the network to either change or stabilise the translation. The most widely cited definition of a mediator in the ANT sense comes from Latour (2005, p. 39) who states "their input is never a good predictor of their output. Mediators transform, translate, distort and modify the meaning of

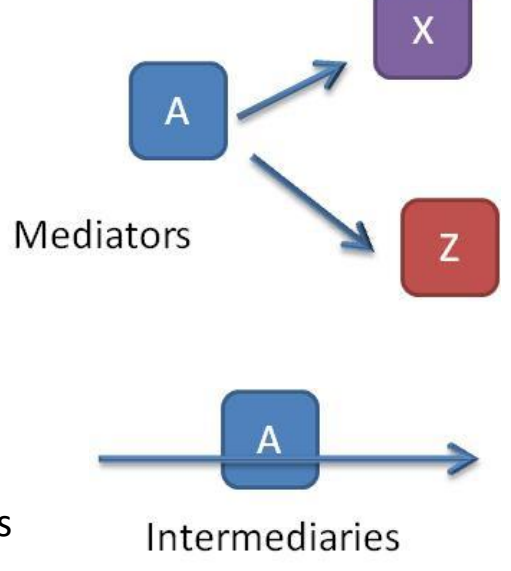

Figure 8: Mediators and Intermediaries 
the elements they are supposed to carry", as demonstrated at the top of Figure 8. Because technology can mediate change in relationships (between actants) it becomes part of the translation, a "quasi-object" according to Latour (1993, p. 136), able to participate in events within a given network. One frequently cited example of a mediator is given by Latour (1999b), who describes the action of a speed bump as mediating the behaviour of drivers - forcing them to slow down when their plan was to continue driving at the same speed. Even processes can be considered mediators. Bryson, Crosby and Bryson (2009) argued that strategic planning was a mediator of the planning of a geospatial information system, as strategic planning was a set of processes the outcome of which was not predictable.

Intermediaries on the other hand have a predictable output whereby they may "count for just one, or even for nothing at all because [they] can be easily forgotten" (Latour, 2005, p. 39).This throughput is demonstrated above in Figure 8. In fact Latour (2005) views intermediaries as being black boxes. Callon (1991) considers that intermediaries can be categorised into four groups, texts (or literary inscriptions), technical artefacts, humans (with their associated skills and knowledge), and money. Aside from this grouping he acknowledges that many intermediaries are actually hybrids, constructed of both things and humans, giving the simple example of a man mashing potatoes with his fork - the predictable outcome of this action being mashed potatoes. Similarly, in Aramis Latour (2002) describes the transportation system "VAL" as an intermediary. When travelling on VAL users hardly notices the technology, it is simply a way of travelling from one station to another without thought (Latour, 2002).

However, mediators are not fixed, they can become intermediaries, and vice versa, and where an intermediary becomes a mediator according to Latour (2005), a network can become destabilised as its output is suddenly unpredictable. Pollack, Costello and Sankaran (2013) describe mediating relationships in the implementation of a project management information system (PMIS). They found that the PMIS initially acted as a mediator in project development as its introduction did not lead to predicted outcomes. However, as the users of the PMIS became more familiar with it, its nature changed from being a mediator to that of an intermediary. As an intermediary the PMIS stabilised the process of project management while not changing its outcome. 
Interestingly, they also found that the nature of a mediator/intermediary changed depending on the perspective of the actant. From the perspective of the PMIS the provision of training was an intermediary - it was "stabilised with repeatable outcomes from the inputs to the outputs of the translation" (p. 8). However, from the perspective of the new user the process was mediating in that they did not understand how they would be changing their work processes when they first encountered the PMIS, thus the output of the process was uncertain. Similarly Doganova (2013) describes how academic spin-offs ${ }^{4}$ can be seen as both intermediaries - simply transferring knowledge to the general public, and mediators, engaging with others outside the academic community to develop new knowledge and innovations.

\subsubsection{Multiplicities}

Because ANT acknowledges many different actants, and because the interpretation of the state of those actants (micro/macro, black boxed etc.) is variable depending on circumstances, it is possible for ANT to accommodate multiple different views of reality or multiplicities. Cresswell, Worth and Sheikh (2010) suggest that this multiplicity can help in interpreting the ANT network as it can accommodate the different characteristics of each actant, assisting in understanding their different roles and forms.

Mol (1999) discusses how reality is performed in different ways and how these different performances lead to multiple views of reality, suggesting that reality, rather than being observed is instead "done and enacted" (p. 77). She gives the example of anaemia having three different performances. The first is the clinical performance where a doctor diagnoses a patient based on their symptoms. The second is the laboratory performance, where lab tests determine the presence (or absence) of anaemia. The third is the patho-physiological performance, or the differentiation between normal and abnormal haemoglobin levels. Understanding these performances allows Mol to understand why things happen in certain ways depending on the perspective taken, and how the different versions of reality might conflict.

\footnotetext{
${ }^{4}$ Products or businesses that arise from the result of research done in academic institutions.
} 
Latour (2002) lists 21 different versions of the state of the Aramis transportation system, from "Aramis has been perfected..." to "No piece of Aramis has been perfected..." (p. 277), displaying a complete range of realities from the implemented to the impossible. Ironically, Gad and Jensen (2010) view ANT itself as being multiple with different versions addressing the different ways it is applied in practice, something they regard as unsurprising given the flexibility of the ANT approach.

\subsubsection{Criticisms of ANT}

Although the logic of the ANT approach can be seen through the above discussion and examples, ANT has been criticised in a number of ways. There are four main points of contention:

- lack of a political dimension (Alcadipani \& Hassard, 2009);

- focusing on the local rather than society (Walsham, 1997);

- inclusion of non-humans as agents (Alcadipani \& Hassard, 2009; Walsham, 1997); and

- agnosticism (Walsham, 1997).

The lack of a politics of ANT is addressed in more recent publications considered to be part of the ANT and After literature. Law (2007) discusses this issue, noting that the "politics" of ANT focus on describing how different realities could be constructed, how those realities might otherwise appear, and emphasising that each reality is not the only one possible. Latour (1993) addresses politics in ANT by pointing out that both the local and societal structures are made up of the same actants, and operate in similar ways. The same tools can be used to analyse both types of structure and it is possible to move between examining them both, depending on the nature of the study being undertaken.

Hanseth and Monteiro (1997), do not consider politics to be a problem, with movement between macro and micro structures being a matter of choosing which black box to open, with the choice of box being a matter of convenience. Thus, the different layers of society can be navigated without regard for whether the actant is macro or micro, local or social. 
Those that criticise ANT for including non-human actants generally do so on the basis that it abrogates human responsibility. This criticism is answered by Law $(1992$, p. 383) "We need, I think, to distinguish between ethics and sociology. The one may - indeed should - inform the other, but they are not identical. To say that there is no fundamental difference between people and objects is an analytical stance, not an ethical position. And to say this does not mean that we have to treat the people in our lives as machines".

As well as in his 1992 article quoted above, Law (2007) addresses the criticism that ANT is agnostic by noting that both good and bad arise from, and are identified in networks. This does not mean that ANT is agnostic; merely that it identifies both the good and the bad done within the network. In any case, it is the network examined and its implications that determine whether or not a particular study is either agnostic or overly privileging of technology compared to humans. As pointed out by Walsham (1997, p. 475) "moral and political issues should be debated from a solid empirical base, and actor-network theory offers a contribution to the latter if not directly to the former".

Taking the above issues under advisement, ANT is considered a suitable framework for this research, both because of its inclusion of technology actants, and because moral issues are not the primary focus of this research. However, the presence of large organisations within the network leads to the question, is ANT the most appropriate framework for the study of organisational behaviour especially at the more macro level? ANT has been coupled with a number of other theoretical approaches in the study of organisations, most commonly Structuration theory (Greenhalgh \& Stones, 2010), and Institutional Theory (Lounsbury, 2008). The following section will consider whether the addition of a second theoretical approach is appropriate in this study of the RFID network.

\subsection{Institutions, Institutional Theory and ANT}

While the discussion has so far focused on ANT as the most appropriate theoretical lens for this study, there are other perspectives that could add richness to the data analysis and assist in understanding some of the interactions between organisations 
and actants that emerge in the findings. Okhuysen and Bonardi (2011) challenge the assumption that only one theoretical lens should be used to examine data. They argue that the management field is complex, lending itself to multi-theory explanations in preference to the narrow account that a single theory can provide. Similarly, Vosselman (2012) argues for multi-paradigm research. Utilising a combination of ANT and Transaction Cost Economics, he argues that "contrasting the two perspectives sharpens the assumptions of each of them, while connecting them brings interaction effects into focus" (p. 7). Orlikowski and Barley (2001) also favour combining approaches from organisational studies and information technology fields. Pointing towards the advantages to be gained from combining the strengths of both they argue that:

"Technologies are simultaneously social and physical artefacts. Consequently, neither a strictly constructionist nor a strictly materialist stance is adequate for studying technologies..." (p. 149).

They find that most organisational theories take a deterministic view of technology and its interaction with people, and believe that combining epistemologies would assist in enhancing understanding of socio/technical systems. They go on to also suggest that information technology researchers could gain insight from the inclusion of institutional perspectives. Fredriksson, Pallas and Wehmeier (2013) also accuse Institutional Theory of over-determinism in respect of institutions, while it ignores social actants. They suggest the ANT concept of translation may be of assistance in combating this tendency as it is non-deterministic and focuses on the role of actants in translating meaning into organisational contexts. In his study combining ANT and Institutional Theory, Waldorff (2013) examines how health innovations were adopted in a Danish healthcare setting. He used Institutional Theory to describe the institutional logics that actants used to legitimise their actions, while ANT described how these logics were translated into practice.

In respect of ANT specifically, Cresswell, Worth and Sheikh (2010) suggest combining ANT with other theoretical approaches, as they believe a combination approach can "help to focus data collection and inform strategic decisions throughout the conduct 
of the research" (p. 6). Although ANT has been combined with Structuration Theory, Clegg (2010) does not favour this approach as he believes Structuration Theory is one directional, describing only structuration without taking account of the possibility of de-structuration, a criticism he also levels at Institutional Theory. Instead, he prefers a combination of Institutional Theory with ANT on the basis that ANT helps explain power relationships, as well as including technology within its scope of analysis. Greenhalgh and Stones (2010) combine ANT with Strong Structuration Theory, which they argue allows for the inclusion of technology within the study framework, something that Structuration Theory would normally deny. However, the presence of large organisations (and institutions such as governments) within the scope of this research would tend to favour the addition of Institutional Theory along with ANT to explain the RFID network.

Although it is not common to combine theoretical approaches, ANT has been combined with Institutional Theory by a number of authors such as CzarniawskaJoerges \& Hernes (2005) or Justesen \& Mouritsen (2011), primarily from the Scandinavian countries. This approach has come to be known as the Scandinavian School of Institutional Theory according to Boxenbaum and Strandgaard-Pedersen (2009). They point out that Scandinavian Institutionalism emphasises the variation between organisations, rather than institutional isomorphism (the tendency for organisations to be driven towards standardisation by institutional pressures), with the ANT concept of translation being incorporated in order to explain how organisations change. They also note a newer trend to using the concept of translation within Institutional Theory to explain how actants attempt to align ideas or practices with their own interests.

A major difference between ANT and Institutional Theory is that ANT describes the micro detail of the formation of networks that could (or did) become institutions. An example of this is Latour's (1988) work describing how the expanding networks surrounding the pasteurisation process led to its global adoption, acknowledging along the way the place of technology within this formation. Institutional Theory on the other hand emphasises isomorphism or similarity, while not approaching how technology or other more micro actors may influence this process. Institutional Theory 
assumes that institutions are driven to become more similar by isomorphic pressures, and moves away from the variation or heterogeneity seen in ANT descriptions. It is this drive towards isomorphism that the Scandinavian institutionalists and authors such as Lounsbury (2008) see as a weakness in the pure version of Institutional Theory. Although Lounsbury (2008) does note that even Meyer and Rowan (1977) (two of the originators of modern Institutional Theory) acknowledged that Institutional Theory was "decoupled from the buzzing conformity of everyday life" (Lounsbury, 2008, p. 356).

Lounsbury (2008) also focuses on how ANT can help explain variations in institutional practice, noting that an ANT perspective can assist in explaining lower level organisational relationships. This research takes the opposite orientation to Lounsbury (2008), utilising Institutional Theory to assist in explaining gaps in the ANT account, describing how institutional organisations and institutions (as actants) are influenced to act in certain ways by institutional pressures, an explanation that is not possible within the ANT framework.

\subsection{Institutional Theory}

As this study examines the interactions of organisations, and institutions, it is important to have an understanding of what the terms mean, especially as they tend to be used interchangeably but are not necessarily synonymous. According to Currie and Swanson (2009) the definition of institution is open to some debate with a number of recognised interpretations. Likewise, DiMaggio and Powell (1991) note that researchers have been lax in defining the term. However, among a number of definitions is that of Jepperson (1991) who defines an institution as "a social order or pattern that has attained a certain state or property" (p. 145), and institutionalisation as "the process of such attainment" (p. 152). Ostrom (2005) defines an institution as "the prescriptions that humans use to organise all forms of repetitive and structured interactions including those within families, neighbourhoods, markets, firms, sports, leagues, churches, private associations, and governments at all scales" (pg. 3). Scott (2001) is more precise in his definitions outlining five dimensions of the concept of institution, resilience, jurisdictional spread, a degree of stability, the elements that 
make up institutions, and the carrier of the institution's meaning. By these definitions, both government and motherhood could be considered to be institutions.

The definition of organisation on the other hand is equally debated but somewhat narrower. Hatch (2012) views organisations as being "instruments for producing products and/or services in demand within the environment" (p. 57). Robbins takes a broader view defining an organisation as "a consciously coordinated social unit composed of two or more people, that functions on a relatively continuous basis to achieve a common goal or set of goals" Whereas authors such as Pindyck and Rubinfeld (2009) take an economic perspective, defining organisations through the negotiation of purchasers for products. These definitions highlight the main difference between the definition of institution and organisation. An institution can include a social construct (such as motherhood) whereas the definition of organisation is based around economic/market concepts excluding such a social concept. However, government, for example, can be considered both an institution and an organisation, as can the organisations within this study (Pindyck \& Rubinfeld, 2009). Feldman and Pentland (2005) take a slightly different view noting that organisations are a collection of routines such as HR, or finance, with each routine being its own black box.

Institutional Theory itself is seen to arise primarily from the work of Meyer and Rowan (1977), and DiMaggio and Powell (1983). Meyer and Rowan (1977) laid down the basis of the theory, suggesting that organisations develop as a result of institutionalised rules. These rules work as myths or stories within organisations, outlining how institutions (and individuals) should act, and reinforcing and legitimising behaviour. For example, Hatch (2012) suggests the concept some banks were 'too big to fail' that arose during the 2008 financial crisis was an excellent example of an institutional myth, which was untested simply because it was taken to be true at the time.

According to Choi and Bhakoo (2013), the work of Meyer and Rowan (1977) concentrates on the internal structures of organisations. DiMaggio and Powell (1983) on the other hand, discuss how institutions react to the various pressures that surround them, and drive them to become more homogeneous, an effect they call isomorphism. They recognise three pressures acting on institutions: 
- Coercive pressure arising from formal or informal requirements or regulation;

- Normative pressure arising from professional organisations and the similarity of backgrounds of many organisational members; and

- Mimetic pressure where organisations seek to model what others are doing.

DiMaggio and Powell (1983) believe that coercive pressures arise within organisations, from organisations on which they rely, and can be manifest as persuasion or force, and sometimes as regulation. The legislative environment and the requirements imposed on organisations for reporting to various government and non-government entities also tends to drive organisations towards becoming more similar. A point that is also made by Meyer and Rowan (1977) who found that as government and large organisations increasingly move into areas of social life, their requirements are increasingly reflected in the social arena. Barratt and Choi (2007) describe how the US Department of Defense mandate to include RFID tags on items over a prescribed value forces other organisations to act in certain uniform ways.

Normative pressures on the other hand, arise from professionalisation, which DiMaggio and Powell (1983) define as "the collective struggle of members of an occupation to define the conditions and methods of their work" (p. 70). The origin of this pressure is twofold. Firstly, the formal education required by most professions tends to be somewhat similar, and secondly membership of professional bodies or trade associations generally requires a level of conformity with association norms. An example of this within the RFID network is the pressure facing organisations to conform with RFID technology standards. While organisations could choose not to conform, it would be difficult for them to interact with other supply chain members.

Mimetic pressures occur when organisations look to other organisations as benchmarks for success, or for solutions to problems. This behaviour can yield solutions with little expense according to DiMaggio and Powell (1983), as copying already established, and apparently successful behaviour can be reasonably inexpensive. They see mimetic pressures as having a ritual characteristic, attempting to prove the legitimacy of the organisation by copying the already legitimised actions of others (whether or not they want to be copied). They also point out that the 
amount of variation within organisational structures is low; that larger organisations tend to consult with a limited number of other companies, and that most organisations are built on older organisational models already in place.

A broad example of the effect of these pressures is provided by Choi and Bhakoo (2013) in their study of hospital supply chains. They found that the three institutional pressures do not act uniformly across the supply chain. Instead, normative pressures were seen throughout the supply chain. This was due to the strong networks apparent in the health sector, and the work of professional bodies to drive high IT standards across healthcare institutions. Coercive pressures were more apparent upstream of healthcare institutions, as government saw this part of the supply chain as limiting potential integration. Mimetic pressures meanwhile were more apparent downstream of the healthcare institutions. This was seen as being due to the hospitals sharing information and best practices, thus they tended to become more similar through mimetic behaviour.

When institutional pressure comes to bear on organisations, they can respond in a number of ways. Oliver (1991b) combining Institutional Theory with Resource Dependence Theory suggested there were five ways organisations could respond to institutional pressure:

- Acquiescence - where organisations comply with the pressure for their own perceived good, following regulation and norms;

- Compromise - where organisations engage in negotiation and bargaining;

- Avoidance - where organisations steer clear of the pressure;

- Defiance - where organisations ignore, dismiss or repel the pressure; and

- Manipulation - where organisations attempt to control or influence the pressure into a more acceptable form.

Mignerat and Rivard (2009) see organisational structures as being fully institutionalised "when they are considered taken for granted" (pg. 372), or as Latour might say, black boxed. Similarly, Latour (1987) suggests three possible responses of actants that have been offered enrolment. Actants could: 
- Accept - thereby submitting themselves to the problematisation;

- Dispute - and seek another problematisation/translation (or anti-program);

- Disregard - simply walk away without engaging with the translation.

These three ANT responses can be mapped with the responses suggested by institutional theory as shown by the Figure 9 . From this figure it can be seen that the acquiescence and compromise of institutional theory can be considered forms of acceptance of a given institutional pressure, where organisations agree to the solution offered by the
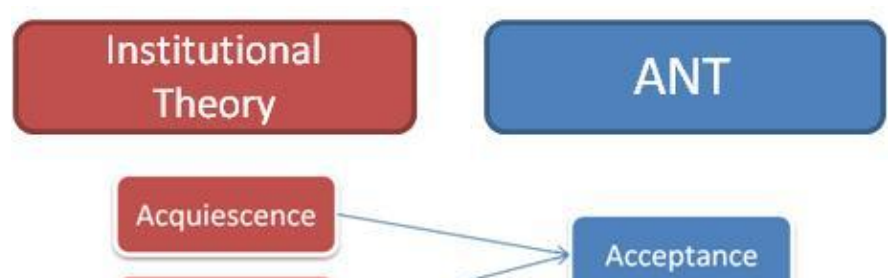

Compromise

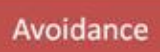

Disregard

problematisation, and work with the translation as a member of the network (perhaps attempting to change the form of the problematisation through negotiation). Similarly, the defiance and manipulation of institutional theory can be mapped to the disputation of ANT, where organisations go out of their way to disrupt the translation, or to aggressively defy the solutions offered by problematisation. Finally avoidance maps easily to disregarding, where in Institutional terms an organisation avoids the pressure. In ANT terms an organisation disregards an offer of enrolment. This similarity between the two theories provides a useful overlap, helping to explain the responses of organisations to problematisation and offers of enrolment.

\subsection{Summary and Research Questions}

Doolin and Lowe (2001) believe that the principal aim of ANT is to reveal associations between human and non-human actants in a network, uncovering the influences that drive the structure of this network. When looking at an ANT network, Latour (1993) argues that a device can represent a network - allowing it to move through time while repeating the actions inscribed into it. This insight allows us to focus on RFID as the particular device in question, how it operates within a network and how that network is influenced by the associations between its actants. However, ANT accounts tend to 
concentrate on the micro level of everyday existence rather than at the higher level of the public-private sector context, leading us to wonder how to best describe organisations and institutional actants, and the affect they have on the network

Powell and Colyvas (2008) point out that institutional arrangements have their origins in the actions of individuals, and the technologies and tools they use in their actions. Yet, they say, these are not truly represented within Institutional Theory. They also resist the tendency to view organisations as actors - the very flat ontology suggested by ANT. Their concern that the roles assigned to macro factors causing institutional change are too prescriptive, leads them to call for more research on the microfoundations of Institutional Theory or "the genesis of organisational practices and the resulting meanings that are attached to these routines" (p. 295). ANT assists in answering this call by describing the very factors (or actants) not included within the Institutional Theory context, while Institutional Theory can assist in explaining the actions of Institutional actants. Thus, the two theories can be conceptualised together as in Figure 10 below:

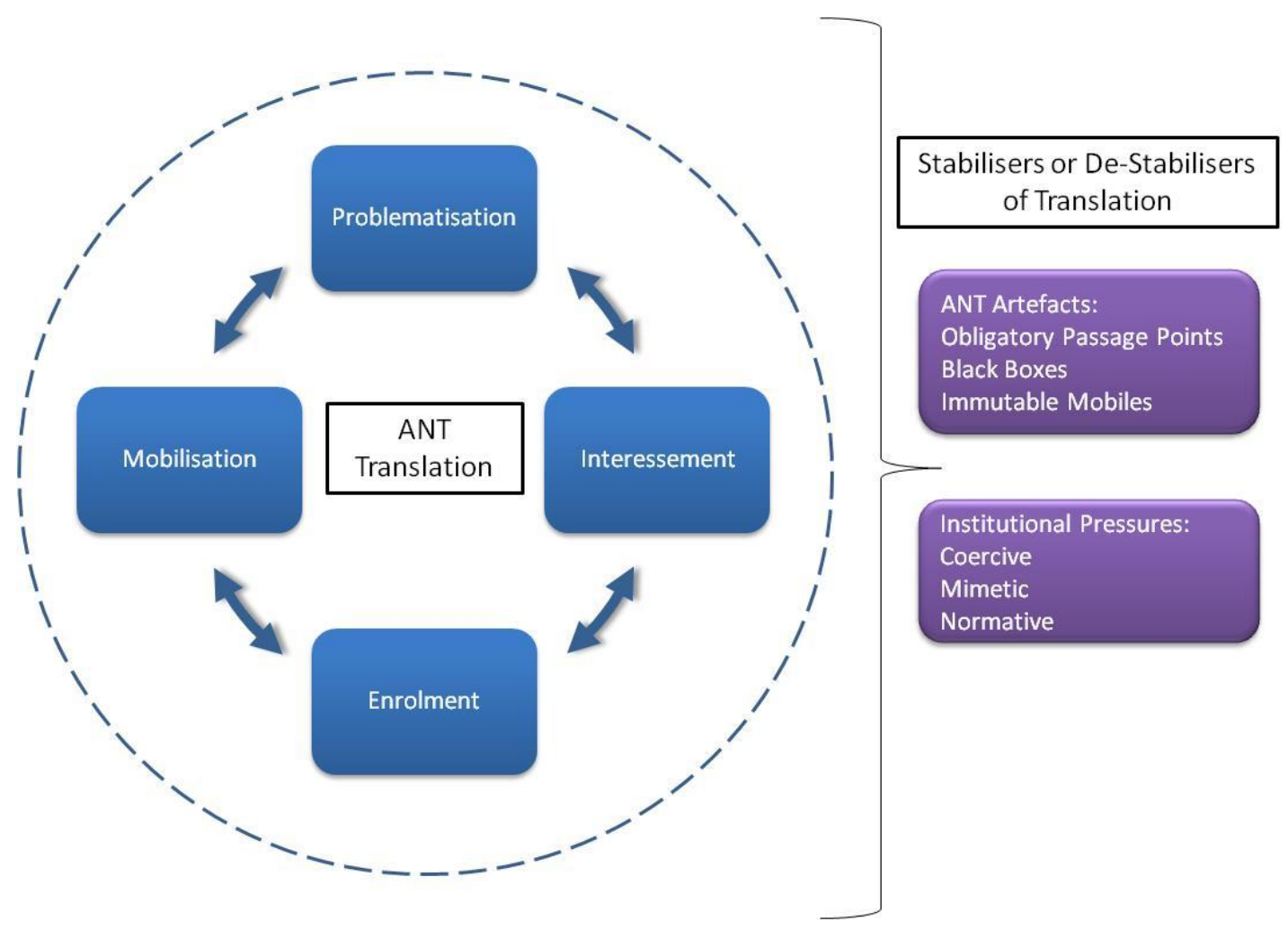

Figure 10: Stabilisers or De-Stabilisers of Translation 
The two theories together provide a sound theoretical basis for this research. ANT and the additional tool of Institutional Theory can assist in explaining institutional behaviour, as well as illuminating the behaviour of the other human and non-human actants. However, the inclusion of Institutional Theory is not reflected in the research questions. Nor for that matter is the recognition of the importance of mediators in driving the network. Therefore, in order to focus the research question and to recognise the extra level of understanding brought by ANT and Institutional Theory, a supplementary research questions can be added as follows:

RQ: How are public-private RFID systems established and maintained?

RQa: How does the relationship between actants contribute to this?

RQb: What mediators affect this process and how are they manifested?

RQc. What role does institutional behaviour play in the process?

The next section will describe the methodology used to address these questions, discuss how the data collected was analysed and consider the role of the researcher in the process of data analysis. 


\subsection{Methodology}

The primary aim of this research is to describe how the RFID network is established and maintained within the public-private sector context. Thus, it is necessary to follow a methodology directed at this aim, which is compatible with the theoretical basis of the research. As ANT is a descriptive approach, qualitative research was considered most appropriate to answer the research questions.

\subsubsection{The Qualitative Research Approach}

From the point of view of the researcher, one of the main difficulties of ANT is translating the theory into practice. Gad and Jensen (2010) note that ANT does not have any explicit methodology even though it might "ally with specific methods" ( $p$. 73), consistent with Lewis' (2007) view of ANT as a grand theory. Thus, ANT resists the tendency to say how a study must be done, just as it resists the tendency to say how, or of what, society must be formed. Instead as noted by Gad and Jensen (2010), ANT encourages the researcher to leave behind any preconceived notion of methodology and to use their training and study to understand, and translate, the construction of networks. Therefore, ANT studies must be advised by the qualitative approach.

Thomas (2006), finds that a number of authors reporting qualitative studies take a "general inductive approach" (p. 238) to data gathering and analysis in ANT studies. Similarly Barbour (2008, p. 31), discussing qualitative research methods states "the main thing is to be able to justify your rationale".

Despite the lack of an explicit methodology for the conduct of ANT studies, there is still some guidance offered by the literature. Law (1992) proposes a number of questions that can advise any ANT analysis (discussed later in Section 3.5.5 Data Analysis), and Bonner and Chiasson (2009), identified three ways ANT could guide a study:

1. by tracing the makeup of networks by following the actants involved in them;

2. by focusing on black boxes employed by actants, and their effects on the network being studied;

3. by recognising that actants at a distance can also influence networks. 
ANT also provides its own vocabulary and ontology to use in ANT based studies. Each network is described in the language of translation allowing the researcher, and reader, to gain a greater understanding of how the different actants work together. Latour (2005) recommends using the simplest and most "banal" of language to describe the network, with the objective of allowing the voices of the actants to be strongest, rather than the voice of the researcher, although interestingly the recommendation for the use of simple language is one Latour himself seldom adheres to. Latour (2005) cautions against following only those terms currently used by researchers. Instead, he recommends the researcher follow up on the "queerest, baroque and most idiosyncratic terms offered by the actants" (p. 47).

This context based language focusing as it does on the words of the actants, allows the voices of the actants to be dominant within any ANT discussion. Further, as the discourse focuses on the way the actants speak, neither humans nor non-humans are privileged in the ANT accounts as ANT makes no distinction between them (Elbanna, 2009). The language of ANT and the guidelines above is used, along with qualitative methodology, when conducting this research.

\subsubsection{Locating and Following the Actant}

Although, there is relatively little advice offered by ANT researchers as to the specifics of an ANT method, there is, one point of agreement amongst ANT researchers which is to adhere to the advice of Latour (2002) and Callon (1991), to "follow the actants (sic)". The actants and their associations are everything in the ANT study. Latour (1999a) considers that ANT is not a theory but a way to give voice to the actants in a network; "one learns not to take the characteristics of any actant (sic) for granted" (p. 62). Creswell, Worth and Sheikh (2010) consider ANT to be a roadmap to understanding a particular network, a way to trace and make sense of the connections between the actors, and to locate the different parts of the network.

This research commenced with two human actants located outside of New Zealand, who were known to the researcher, and very experienced within the context of RFID systems that crossed the boundary between the public and private sectors. These actants were interviewed and pointed towards other actants, both human and 
documentary. Thus, the following of the actants began. Throughout the course of the research, actants were asked to refer the researcher to others who may be of assistance, in a process referred to by Yin (2009), and others, as snowballing. However, actants also tacitly referred to other actants (human and non-human) during the course of the interview, and these actants were located (or representatives were found), separate from the process of snowballing. In total 40 human actants were interviewed, representing both their own RFID systems and various non-human actants, and 24 documentary actants were consulted (aside from the literature review). Non-human actants are discussed in more detail in Section 3.5.3.1 below. Following the advice of Latour (2005) on ensuring that actants could speak on behalf of the network, there was a requirement maintained that human actants must have knowledge of RFID systems within the public-private context, and that they must have participated in such systems. A number of human actants were identified through the need to find representatives for technology actants, especially such actants as RFID hardware. Therefore, where a representative was needed for RFID tags, an expert in RFID hardware was sought. Human representatives were also sought when mediators arose and were not represented within those actants already recruited. For example, where privacy and security issues experts were recruited within these areas, they were also knowledgeable about RFID in the public-private context. In this manner a complex network was found, linking together several RFID systems across a number of countries, industries and organisations as demonstrated in Figure 11 above. No attempt was made to remain within certain areas, sub-sectors, or cases; instead the network was allowed to develop entirely through the directions of the actants themselves. Thus, the network developed much in the same way the Internet of Things develops with members joining throughout the process in order to contribute to the whole, but without limitation on the possible scope of the network.

\subsubsection{Gathering Data}

In gathering data throughout the course of this study, the researcher kept in mind the necessity to follow the actants wherever they led, no matter whether they were human or non-human. Generally, in qualitative research, Richards and Morse (2007) recognise a number of sources of qualitative data aside from the literature review. 
These include interviews, photographs, maps, documents and diaries. This research used in-depth interviews to collect information from human actants, as well as allowing the literature review (above), documents, policies and other relevant nonhuman actants to participate.

As the aim of this research is to provide a rich account of the networks, the interviews were in-depth rather than focus group based (Yin, 2009). As noted by lyamu and Tatnall (2011), this allowed the flexibility to follow actants as they were identified by the actants, and to gather a rich picture of the network. Where necessary, the interviews were followed up by email or by phone. As well as following actants that were identified during the interview process, the actants were asked to recommend others within and outside their organisations who have knowledge of their RFID system - this process, common in ANT and qualitative research, is generally termed "snowballing" (Bryman, 2012).

Interviews were focused on the use of RFID in organisations, where the RFID system was shared between public and private sectors, in order to develop a picture of the actor-network in the public-private context. Interviews addressed the actants' relationships with others, how relationships were built and maintained, and how they change, as advised by Tilson (2008). Each interview was digitally recorded and transcribed as soon as possible. Actants received a copy of the transcript and were able to make corrections and clarifications as necessary.

Some interviews were conducted over Skype. Although this is not ideal, Rubin and Rubin (2012) discussed the use of phone interviews, and concluded that they are a good method for gathering data from participants who might otherwise not be interviewed due to distance constraints. Although they do point out that it is helpful to have previously met the interviewee. Similarly, Bryman (2012) notes a number of benefits of telephone interviewing including cost savings, and he suggests that phone interviews might be of advantage in removing bias arising from the presence of the interviewer. In respect of telephone surveys used in social research, Denscombe (2007) finds that "people are as honest in telephone interviews as they are with face-to-face 
type interviews" (p. 11), and that researchers still retain the ability to interact with the respondent one-on-one.

Of the 40 human actants interviewed, 17 were interviewed by Skype; 14 were in the US, two in Hong Kong, and one in Australia. Respondents were broadly involved in health, defence, primary industries, and general supply chain type activities. Seven of the participants interviewed by Skype had previously met the researcher, predominantly at RFID industry events. All interviews were digitally recorded; Skype interviews were recorded using EasyVOIP Recorder software, and transcribed by the researcher. The last 6 interviews were transcribed by a professional transcribe. All transcripts were double-checked by the researcher against the original recording.

As the interviews were in-depth there was no formal questionnaire. Interviews commenced with the general question "Please tell me about your RFID system...."; and finished with the question "Is there anything else you would like to tell me about RFID systems in the public-private sector context"? However, no other questions were pre-supposed. The actants led the discussion as recommended by Latour and others, with direction provided by the researcher only when required to keep the interview focused. The final question in particular was valuable as it allowed actants to summarise any thoughts they may have had regarding their experiences, and in some cases led to further lines of enquiry. Interviews lasted between 60 and 120 minutes with most being between 60 and 80 minutes in length. The researcher took notes during interviews, as well as the recording, and these notes were included with the transcript. In accordance with the advice of Miles, Huberman and Saldana (2013) a contact summary sheet such as that in Appendix $C$ was used to record information in respect of each interview, or document examined, in order to assist with identification of concepts raised during data gathering. This also assisted with reflecting on each interview and document examined.

\subsubsection{Non-Human Actants}

An ANT study typically has a number of non-human actants. In the case of documents, although they are non-human they can speak for themselves to a certain extent in that they can be read and analysed in a similar way to interview transcripts. The study 
took this approach, analysing documentary actants as if they were interview transcripts. Documentary input was coded into HyperResearch, and included in the analysis that followed as if the documents were human.

To assist with gathering data from non-human and non-documentary actants the approach of Vidgen and McMaster (1996) was followed whereby potential representatives of non-human actants were identified. Also identified were the various components of the actant, along with their potential interests. A demonstration of how this worked is presented in Table 2 below, using RFID tags as an example.

\begin{tabular}{|l|l|l|l|}
\hline Actant & Components & Interests & $\begin{array}{l}\text { Potential } \\
\text { Representatives }\end{array}$ \\
\hline RFID tag & Antennae/Transmitter & To be used and maintained & Suppliers \\
& Battery & To transmit EPC & Users \\
& Memory (in active tags) & To collect and transmit & Developers \\
& Sensor & sensor information & Manufacturers \\
& EPC (or similar) & & Technicians \\
\hline
\end{tabular}

Table 1: Analysis of non-human actant interests and representatives

Vidgen and McMaster (1996) found that the advantage of this approach was that it allowed for the identification of human and non-human actants that might not otherwise have been identified, as well as allowing a view of the interests of the nonhuman actants. The various documentary and human representatives identified and by this study are detailed in Table 2 following: 


\begin{tabular}{|l|l|}
\hline Documentary Actant Type & No. \\
\hline Books & 1 \\
\hline Business Cases & 4 \\
\hline Legislation & 5 \\
\hline Other Documents & 6 \\
\hline Reports & 5 \\
\hline Standards & 3 \\
\hline Total Documentary Actants & 24 \\
\hline Human Representatives & \\
\hline Industry Advocacy & 1 \\
\hline Privacy & 1 \\
\hline RFID Systems Implementation & 2 \\
\hline RFID Tags/Antennae & 2 \\
\hline Security & 2 \\
\hline Technology Design/Research & 3 \\
\hline Total Representative Humans & 11 \\
\hline Table 2:Documentayand Representive Actats
\end{tabular}

Table 2: Documentary and Representative Actants

This approach is similar to that of Bryson, Crosby and Bryson (2009). In their study of strategic planning they treated such terms as stakeholder analysis, plans, strategic visions, and goals, as artefacts/non-human actants that need to be understood. They concentrated on discovering how the artefacts were performed (or how they came into being) - in order to understand how they influence organisational performance.

Following the ANT principle of symmetry, non-human actants are reported in the findings in the same way as human actants. Only where it is relevant are they noted as being non-human, or are mentioned specifically ${ }^{5}$. This is especially true of actants such as legislation where even the mention appeared sufficient to indicate their action, as they were such strong intermediaries their course of action was obvious.

\subsubsection{Knowing when to Stop}

Theoretically, an ANT approach could allow for the following of actants, with no boundaries of any type, through black boxes, to any possible destination. As Callon (1987) emphasises, each network is made up of actants but is also an actant in and of

\footnotetext{
${ }^{5}$ This is most obvious where literature is referred to as all literature is cited according to convention.
} 
itself. Thus, actor-networks are theoretically boundless as each actor is also a network, and following of the network could continue ad infinitum. This is not, however, a very practical approach as the decision needs to be made about where the boundaries of the study should lie. Different researchers have taken different approaches to solving this problem. Akrich and Latour (1992) argue that the ANT researcher must limit the network by studying how a specific set of actants interact with each other. Cordella and Shaikh (2003) note that the only way to limit an ANT network is to arbitrarily close it. Most researchers work within the constraints of case studies to limit their ANT networks. Given the aim of this research is to examine the RFID network in the publicprivate context, this is considered to be the boundary of the network, rather than specific organisations, cases, or RFID systems.

Within this boundary there still needs to be a point at which the study should stop. Bonner and Chiasson (2005) in their study of privacy legislation, followed actants through interviews, documentation, statements, and publications, until no new actants emerged, a point similar to that of "saturation" defined by Corbin and Strauss (2008, p. 143) as the point "when no new data are emerging". In studying telecommunications strategy formation in China, Gao (2005) ceased looking for further actants when the actants identified could explain the change seen in China's telecommunications market. Gad and Jensen (2010) suggest taking into account what the research is hoping to achieve - the research question - in deciding when to cease studying the network. They also note that practical considerations play a part in deciding when to stop studying the network, and that knowing when this point is reached is part of "good" research.

This research followed Bonner and Chiasson (2005), stopping where any new actants that emerged could be punctualised ${ }^{6}$, or where the actants that emerged knew nothing about RFID systems, and/or were not involved in the network.

\subsubsection{Data Analysis}

The analysis of data is the cornerstone of any research project, without appropriate analysis the results are meaningless. Thomas (2006) notes that many qualitative

\footnotetext{
${ }^{6}$ Treated as a black box for the purposes of the network being studied, following Law (1992)
} 
researchers use what he calls a "general inductive approach" (p. 238) in order to derive themes and understanding from collected data. The purpose of such an inductive analysis is to allow findings to emerge from the data without enforcing the constraints of a particular methodology, or in ANT words, the analysis allows the network to emerge from a collection of data. As such it fits well with the ANT approach which has no specified analytical framework although Law (1992) suggests five questions to assist in an ANT based analysis:

- what different types of actants are present and how are they organised in order to generate organisational effects?

- how is resistance to the network overcome?

- what (if any) strategies are being used to ensure the network is durable and, where necessary, mobile?

- how far do these strategies spread and how do they interact?

- how does one part of an organisation come to speak for another part?

These questions were kept in mind during data analysis.

In general, where ANT studies analyse qualitative data beyond presenting narrative accounts, standard qualitative data analysis is used. Miles et al. (2013) present a detailed account of data analysis which is consistent with the inductive approach, including three phases - data condensation ${ }^{7}$, data display, and conclusion drawing/verification. Data condensation consists of the on-going process of data selection, simplification, focusing, and abstraction for the purpose of organising and strengthening the data. This process leads to the production of memos, themes, categorising, and coding, and continues throughout the course of the research project.

Thomas (2006) offers further advice on the process of data condensation ${ }^{8}$. His findings arise from multiple passes through the raw data, developing categories, and from these a model framework. He also notes that the pattern coding approach of Miles et al. (2013) is more able to identify connections between people (or actants) as well as

\footnotetext{
${ }^{7}$ In previous editions of their book, including Miles and Huberman (1994), data condensation was referred to as data reduction.

${ }^{8}$ Thomas (2006) also refers to data condensation as data reduction.
} 
providing explanations of the data. Both Miles et al. (2013), and Thomas (2006) focus on the development of categories to describe raw data, and assist in drawing conclusions based on that data. In order to ensure both methodological rigour, and the finding of relationships between actants, this research follows both Thomas (2006), and Miles et al. (2013).

Data display is the process of organising the data in various ways for the purpose of deriving meaning from the different perspectives presented. Miles et al. (2013), recommend a variety of approaches apart from the usual lengthy text, including matrices and network displays. However, ANT accounts are commonly related in narrative form and this approach is the predominant one used in this study.

Conclusion drawing/verification is the process of not only coming to conclusions based on the data gathered, but of verifying those conclusions based on how easily they can be confirmed, together with their strength and plausibility. In this research, conclusions have been drawn based on the presence of mediators in the network, as well as the narrative description of the network translation.

\subsubsection{Data Condensation/Reduction}

Data was coded using the Hyper Research analysis program. Categories arose through considered, detailed and repeated reading of the text (of documents and interviews), in order to derive meanings within it. Themes and categories were identified, and these were constantly revised as new data was analysed. Following Thomas (2006) each category was defined by means of a detailed memo which included information in respect of the origin of the code, possible meanings, contradictions, and implications. Human and non-human actants were coded in the same way. To ensure consistency and rigour in coding, portions of the coded transcripts were checked and discussed with the researchers' supervisors, and all codes were discussed and reviewed with them. Coding also assisted in identifying the stages of translation, actants' relationships, obligatory passage points and other elements of both ANT and Institutional Theory.

Coding proceeded in the two cycles described by Miles et al. (2013). In the first cycle codes were assigned to portions of the data through an inductive coding process. For 
this process the codes were based on "elemental methods" (Miles et al., 2013, p. 74) of in-vivo coding, descriptive coding and process coding. In-vivo coding uses the participants own words to form the codes, and allows for the emergence of words or phrases particular to the actants being studied. Descriptive codes are, as the name implies, summarising particular parts of a transcript. They are particularly useful for providing a source for later indexing. In this research they described various parts of the RFID systems studied, hardware and software and details of technology. Some deductive codes were also used in this first coding cycle, derived from the elements of the RFID system, the hardware and software; and the ontology of ANT and Institutional Theory. The theory based codes highlighted particular aspects of the theory relevant to the study and these developed over time as new features of the RFID network became apparent. These deductive codes are listed in Appendix B.

Process codes focus on determining action especially where things change, arise or are involved in action. These codes included those related to the mediation of the RFID network, detailing the various elements that affected the RFID systems studied. The inductive codes derived in this process are listed in Appendix A, and are further included within the findings, in brackets following the various quotes.

The second cycle or pattern coding involves grouping the initial first cycle codes, and is sometimes known as axial coding. These codes act as higher level summary groupings of the first cycle codes, and assist in identifying themes or concepts within data. Miles et al. (2013) suggest the pattern codes not only assist in condensing the data, but they also help the researcher better understand the range and scope of the data, and in drawing a "cognitive map" (p. 86). Pattern codes highlight categories, associations, causes, and constructs.

These cycles of coding assisted the researcher in identifying mediators of the RFID network, as well as the various phases of translation, and associations relating to institutional behaviour. First cycle codes assisted the researcher in developing the narrative story of the RFID network as they allowed for identifying and retrieving relevant passages relating to elements of the network. Second cycle codes assisted particularly in identifying mediators of the network by allowing for the aggregation of 
network elements into larger groups from which mediators emerged. The coding process is summarised in the diagram below:

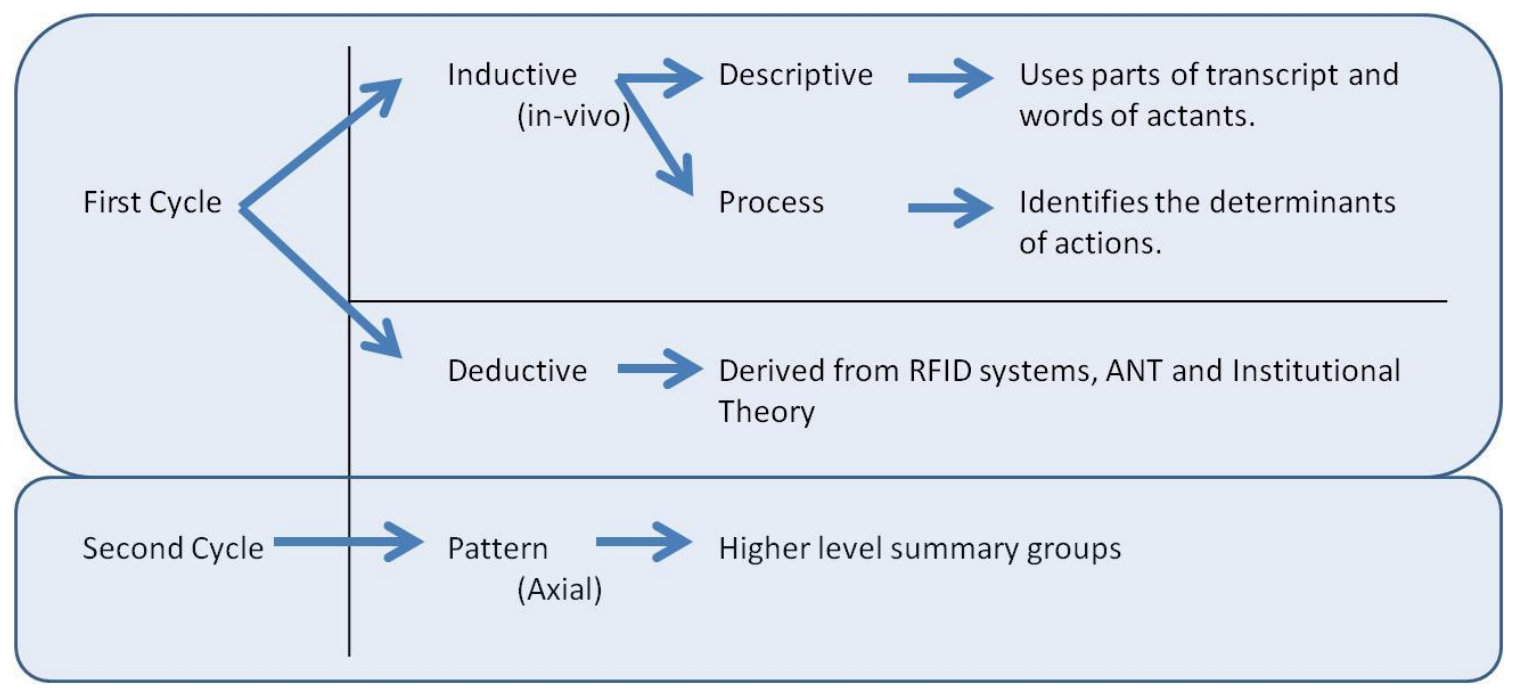

Figure 11: Outline of Coding

\subsubsection{Validity and Reliability}

Questions of validity and reliability arise frequently with qualitative studies such as those undertaken by ANT researchers. As in most qualitative research with ANT, reality is partially constructed by the researcher who participates in the network and it can be difficult to replicate studies of this nature in order to produce the same results each time. Some authors contend that the terms validity and reliability cannot be applied to qualitative research as it is too reliant on context and the interpretation of the researcher (Guba \& Lincoln, 2005). Others (for example Lincoln and Guba (1985) or Bryman (2012)) suggest the use of other criteria to ensure the quality of the research, such as trustworthiness and credibility. Richards and Morse (2007), see no reason why qualitative research cannot be both valid and reliable, and suggest the following principles as ways of ensuring research has these qualities:

- being rigorous in the design of the project including preparing well, and thoroughly reviewing the literature, using it as a basis for the research;

- being explicit about the theory and method used;

- ensuring the method and sampling techniques suit the design of the study;

- coding reliably and keeping track of decisions made throughout the coding process; 
- keeping an appropriate research diary; and,

- comparing findings with the literature.

Using the literature review as a basis for research presents the ANT researcher with some difficulties. As noted by Law (1992) "If we wish to understand the mechanics of power and organisation it is important not to start out assuming whatever we wish to explain..." (p. 380). Although he is talking about the importance of symmetry in treatment of the social and the technical, the point is clear that it would be outside the boundaries of what little ANT method there is to commence study with a model of potential results already in mind. Thus the literature review is considered more of an actant, advising the research, rather than the source of a model to which the remainder of the analysis must adhere.

However, the remainder of the principles are consistent with an ANT approach, and have been followed in this research. In the case of each interview, the interviewee had the chance to read and correct a copy of the transcript produced, and was also able to read and correct references made to their contribution in the text. According to Brown (1997), and Stake (2005), these 'member checks' add to the trustworthiness of the data as they ensure the conclusions drawn by the researcher align with the perspective of the interviewee - or actant.

Richards and Morse (2007), also recommend using the technique of bracketing in order to ensure the researcher does not find out what they already know, rather than recognising what is before them. Bracketing requires that the researcher put aside, as much as possible, knowledge already gained from the literature review and other studies. This is done by making the knowledge overt through writing it down - either in the form of a literature review or as a research diary which includes the personal assumptions of the researcher. Once this is done, the researcher can learn from the information being collected - in ANT terms, to learn from the actants.

\subsubsection{The Role of the Researcher}

When discussing research methodology, the role of the researcher in the study needs to be considered. According to Lewis (2007) the researcher is also part of the network being studied. Similarly, Bonner and Chiasson (2005) recognised the importance of 
following the network without imposing their own rationales on that being studied. It is also important within ANT to recognise that the researcher is part of the research; this reflexive understanding recognises that the researcher cannot be completely objective; instead becoming part of the network under study almost as if an actant (Latour, 1993).

Callon (1986) describes three principles of method for the ANT researcher which follows the foundation ANT principles. First, the researcher should be agnostic towards everything the actant says, and should extend no judgement on or censor anything of the actants words. Secondly the researcher should take a symmetrical approach to describing the network, not varying between the descriptions of the social and the natural. Finally, the researcher is advised to make no distinction between the social and natural, instead the researcher should "follow the actors in order to identify the manner in which these define and associate the different elements by which they build and explain their world..." (p. 201). These principles were followed as much as possible in this research. The interviews were in depth and no attempt was made to guide the actants. The language of translation was used in the data analysis, and as much as possible the words of the actants were used in the findings, in order to reflect their voices and the voice of the network. Non-human (documentary) actants in the data analysis were treated in the same manner as human actants, and have not been indicated separately in the findings, unless it was relevant to do so.

\subsubsection{Issues Arising}

A number of issues arose with the data gathering and analysis stages, which had to be dealt with appropriately.

Firstly, it was not always simple to locate study participants. This was either because of the small number of easily accessible RFID systems that crossed the boundary between public and private sector, or because it was difficult to locate representatives for the various non-human actants. This problem was dealt with by the researcher who actively sought out participants at the RFID Live industry event, and partly through the process of snowballing. 
Second, deciding when to cease studying the network was problematic as the second interview participant referred back to the first, thus rendering the criteria to cease looking for participants when they started referring to other's moot. This happened a number of times with four participants being referred to by at least two other participants. The final decision to stop studying the network came when the researcher simply ran out of suitable willing participants, and the majority of nonhuman actants were considered to be appropriately represented.

Finally, maintaining the flat ontology of ANT was also a challenge. The researcher had to deliberately remain agnostic to the position of the actant, be they human or nonhuman. Similarly, the researcher had consciously put aside any tendencies to direct the participants, instead strictly following the actant where they pointed, not where the researcher thought they should go.

\subsection{Ethics and Funded Research}

Generally published guidelines for conducting ethical research are very similar amongst most authors according to Denscombe (2007) and can be summarised as respecting the human research participants, ensuring no-one is harmed by being involved in the research and the researcher conducting herself honestly. As this research is also funded, extra care was taken to ensure participants understood who the research sponsor is, and that the researcher retains academic independence.

In order to ensure the research was conducted in an ethical manner it was preapproved by the Victoria University Human Ethics Committee (HEC). Each participant was asked to give consent to participating in the research, and to specific terms and conditions related to it. They were also provided with a summary of the research and a consent form, which they signed. An example of the consent form can be seen in Appendix D.. Every effort was made to ensure that the participants understood the basis of the research, and they were given the opportunity to correct and approve any reference made to their contribution. Each participant received a transcript of their interview and was given to opportunity to make corrections, clarifications or withdrawals. Further, where quotes were used in this thesis the participants were consulted a second time to ensure they were comfortable with their comments. 
Names of participants and their organisations are kept confidential and concealed in this thesis, as Cheek (2005) points out, it can be difficult to ensure complete anonymity. No participant contribution was included without their approval (Denscombe, 2007).

\subsection{Summary}

Richards and Morse (2007, p. 193) believe that "The golden rule of methodological cohesiveness - of ensuring the best fit of the research question with the assumptions, strategies, types of data, and analysis techniques - ensures maximal validity". This research has addressed the golden rule of Richards and Morse (2007) by taking a qualitative approach to answering the research questions. ANT, accompanied by Institutional Theory was used to guide the research, and advise the data analysis. Inductive data analysis was used to develop meaning from the data collected by in depth interviews, and reading of documentary actants. This coding was then used to develop conclusions, and assist in the narrative description of the RFID network.

Care was taken to follow the actants through the network, ensuring that their voices were heard, and that the researcher stayed agnostic to the status of the actant. As such, the voice of the actant is always to the forefront of any ANT account. The next chapter will present the description of the network derived from the data analysis, as well as the mediators identified in the network. 


\section{Findings: The Translation of the RFID Network}

This chapter report's findings based on the 40 in-depth interviews with human actants involved in the RFID network. Input is also included from a number of non-human documentary actants such as legislation, reports, books, and project documents ${ }^{9}$. Based on analysis of the interviews, and the input from non-human actants, it was apparent there were three major themes or stories running through the study. The first was the story of the RFID network told through the lens of ANT. The ANT process of translation describes how the RFID network is formed, how the various actants struggle for power and position, and how the cycle of translation is broken and reformed as the actants jostle for position. The second story relates to the individual items, actions, and negotiations that mediate the process of translation. These mediators describe the things that drive decision making around RFID systems, and the everyday actions that individuals and organisations take around the installation, operation and maintenance of such systems. The third story is told through the framework of Institutional Theory. It relates to the organisations involved in the RFID network and how they are influenced, or attempt to influence others, in order to gain power within the RFID network. This story joins with the ANT story as it describes the forces that act on an organisation, and how these forces encourage or compel organisations to take actions which affect the process of translation. These three stories align with the research questions:

RQ: How are public-private RFID systems established and maintained?

RQa: How does the relationship between actants contribute to this?

RQb: What mediators affect this and how are they manifested?

RQc. What role does institutional behaviour play in the process?

\footnotetext{
${ }^{9}$ In order to maintain the flat ontology of ANT, the nature of the actant is only reported when relevant. This means that where sources are referred to at all, they are referred to as actants. Sector of the actant is indicated by superscript - "PU" for public sector, "PR" for private sector. Also, where the nature of the actant may be important it is also described - for example the documentary actant legislation is sometimes referred to directly.
} 
The following chapter focuses on the organisational stories, first describing how organisations and other actants move through the ANT process of translation, and how this process forms the RFID network. A brief consideration of the future of the RFID network and the Internet of Things follows, although this question is addressed more fully in the Discussion chapter. The second part of this chapter takes the sector viewpoint, describing how the organisations in the public and private sector interact. Finally, the chapter discusses RQb., outlining the role of institutional processes in the formation of the network, through the lens of both ANT and Institutional Theory. Consistent with the ANT approach, the voices of the actants are used to tell as much of the story as possible and their voices are indicated by quotation marks. Thus, any words enclosed with quotation marks have come from an actant ${ }^{10}$.

\subsection{ANT - A Translation View of the RFID Public-Private Network}

The ANT translation view first requires the definition of a problem, design of a solution, and allocation of roles to the various actants in the process of 'problematisation'. This seems at first glance to be straightforward in the public-private sector context. From the view of RFID as a technological actant the problem is basic, how to get used in the public-private context. However, the other actants have their own ways of expressing (or enacting) the problem depending on their needs and perspectives. They also have their own organisations to consider, thus they jostle with each other to define the problem in a way that suits them.

\subsubsection{Understanding the Problem/Problematisation}

The problematisation stage of translation is characterised by the recognition and framing of the problem. In all of the RFID systems studied, the problem was defined around a recognised business need or imperative. One system had commenced because a biosecurity incident led the industry involved to the realisation that they needed to be able to locate items accurately. "In response to that [incident], the Chairs and CEOs and senior policy people of every [industry] group in the country came and met", ${ }^{P R}$ deciding to create an "identification and traceability program" ${ }^{P R}$ which would meet the needs of the industry sector. A working group was formed

\footnotetext{
${ }^{10}$ In order to preserve the continuity of the story the coding is not included in this section. It can be assumed that all quotes within specific headings, such as problematisation, have been coded that way. Likewise, references to mediators have been coded to that mediator.
} 
which considered a range of options available focused on "an improved traceability system as providing more protection... more of a story, which would perhaps enable us to provide some market assurances and [reduce] the risk" ${ }^{\mathrm{PR}}$ in the event of further bio-security incidents.

Debate continued for some time around a number of issues framing the bio-security problem. Requirements for the RFID tags the system was going to use needed to be "sat in the happy place between so rigid only one operator could ever provide those tags, to so loose that it was meaningless". ${ }^{\text {PR }}$ The system chosen also needed to fit the "requirements" ${ }^{\mathrm{PR}}$ of the industry members, as well as considering "[are] the governance arrangements OK? Are the funding things - do they make sense... who's going to run it?"PR This initial process was primarily industry driven, and the preference was for an industry operated system, possibly based on an already existing traceability system. However difficulties with the existing system which was barcode based, included the cost imposed by the owners of the barcode based system, as it was felt "they were charging too much" ${ }^{P R}$ and questions around how data collected by the system was being used. These concerns led to this barcode system being rejected as a possible solution to the problematisation. The eventual decision to use RFID to address the traceability problem, was based not only on its attractiveness as a traceability solution, but on global best practice "... because everyone else around the world was kind of moving towards RFID it made sense for us to do that as well” ${ }^{\text {PR }}$. Alternatives were viewed as either "way too expensive, not entirely proven and [looking] too weird against what everyone else was doing". PR

However, even the emergence of a general consensus on the nature of the problem from the industry perspective wasn't sufficient. During this process it became apparent that the system proposed would be most effective if all the industry members participated. This recognition occurred as it became apparent that "this won't work voluntarily (sic) ${ }^{\mathrm{PR}}$, and that any traceability solution would be rendered useless by an incident involving untraceable product. Therefore, some level of partnership with government was deemed necessary and "... the industry went to government and said, you've got to do this, or you've got to help us do it, and there's no way it's going to happen unless it's mandatory, it will never work voluntarily 
(sic)... “. ${ }^{P R}$ Despite the initial framing of the problem, and the inclusion of the government as part of the solution, the problematisation in this instance still faced challenges, on the basis of cost, particularly as the system was to be mandated by government, as "the system was a biosecurity insurance policy for the good of [our country]. Therefore, in my view, [our country] should pay for it, not just those implementing it". ${ }^{\text {PR }}$

A further challenge to the problematisation in this instance was aimed specifically at whether or not the solution developed could solve the perceived biosecurity problem at which it was directed. As one actant explained:

“...if we all sort of understood what bio security means, what we are actually afraid of, how this technology can mitigate those risks, or not, if we had any sort of agreement on that, I'm not entirely convinced that we would even be going ahead with these type of solutions". ${ }^{\mathrm{PR}}$

This actant saw the social/political and technological issues as being disparate "running side by side... each on their own paths". ${ }^{\text {PR }}$ Similarly, an actant speaking on behalf of systems implementation described how it was important to "[spend] some time working with [clients] to find out what their expectations are, and what they will do. Everybody we try and work with always wants more than they are going to be able to have". ${ }^{\text {PR }}$ The actant had also found that barcode systems were attractive alternatives to RFID technology. At times he had "talked someone out of an RFID project, and tried to convince them that they don't need RFID to do what they want to do and they'd be better off using barcode". ${ }^{\text {PR }}$ Particularly the actant focused on determining what the customers really wanted from a solution, noting that "we all end up playing these games in an effort to get what we hope is the thing for the customer, but it can be very difficult sometimes to identify what they really want". ${ }^{\text {PR }}$

The view that RFID was being presented as a solution to a problem that had not been carefully considered was echoed in another system. The design of RFID tags developed as part of a traceability solution was challenged by one actant as "they seemed to be the answer to the question, but the real question was what was the question that they were actually purporting to answer"? ${ }^{\mathrm{PU}}$ The actant went on to describe the solution 
proposed in his system as "not $100 \%$ of [the] solution... not sufficiently robust to achieve the objectives of the organisation". ${ }^{\mathrm{PU}}$ In this particular instance resistance to the tag design, and its application had been sufficient that the solution had not been developed further, and the problematisation had failed. A second attempt had been made to develop a solution involving similar tags which was still being investigated, and initially seemed "really impressive if it can be achieved...". ${ }^{\text {PU }}$ However, this second proposed tag was competing against a similar barcode system that was already in place, and being used successfully. The actant considered if the RFID technology could reach the "reliability and ubiquity" $\mathrm{PU}$ of barcodes then the RFID solution proposed "could be quite compelling". PU

In a similar RFID system, public and private sector teams worked together as "joint owners, and subject matter experts working side by side to develop the requirements" $^{\mathrm{PU}}$ for an RFID system the two were going to share. The initial process was commenced by the public sector in order to meet government requirements to "achieve value for money, collaboration and co-ordinated agencies". ${ }^{\text {PU }}$ However, the private sector was eager to join in the development of the problematisation as they were "sick of providing the same information to multiple agencies, and sometimes manually, when there was already an electronic system that [could] take it". ${ }^{\mathrm{PU}}$ This system was in the later stages of problematisation when the actants were interviewed, and debates were continuing around privacy - particularly how the organisations were going to "make sure that each [public sector] officer only sees what they should now that it's electronic...". ${ }^{\mathrm{PU}}$ The public sector agency in particular was debating how to share their information, and how to manage the resultant database. In terms of sharing the data a public sector actant had noted that it was "difficult to give away control" ${ }^{\mathrm{PU}}$, as part of the data-sharing agreement. These issues were slowing the problematisation as organisations needed to have data sharing arrangements in place before the business case (OPP) could be completed.

In another biosecurity based pilot RFID system, government legislation was already in place, and framed the problematisation. The legislation dictated requirements for data collected by the RFID system, in order to provide "a set of data that identifies the shipper and origin of the shipment". ${ }^{\mathrm{PR}}$ One actant described how the organisation was 
keen to participate in this pilot as "recognising all the kind of changes that were occurring in... law as well as just industry requirements, with regard to all of these issues, we thought than when this opportunity came up that we would like to participate in it". PR This pilot system had faced challenges to framing the problematisation from "cutbacks in personnel" ${ }^{\mathrm{PR}}$ as well as in obtaining funding. One of the project managers from the public sector had "some [government] dollars that he could utilise for something like this, but without that he would not have won the support of his director, and the pilot would not have gone anywhere" ${ }^{\mathrm{PR}}$ However, when "the recession kind of hit, and funding was finalised" ${ }^{\mathrm{PR}}$, the pilot implementation had stalled. This lack of funding had stalled the translation as well, despite the program being in use, further development and wider system implementation was not possible without funding from government sources.

\subsubsection{A Short Journey Through Obligatory Passage Points}

In the instances discussed above once problematisation had been determined, the development of a business (or use) case anchored the problem and outlined the solution. These business cases then became an Obligatory Passage Point (OPP) for each of the problematisations, as they provided a "strategy... [what we] promised we

would deliver when the industry agreed to the business case". ${ }^{\mathrm{PU}}$ Business cases, strategies and similar documents are also considered to be documentary actants as they influence action within the network. Similarly, if they are transported, and act over distance - by email for example - they could also be considered to be immutable mobiles as they influence action at a distance.

It was also apparent that the standards mediator was an additional obligatory passage point. A basic level of standardisation was necessary for every RFID system in terms of hardware, given the necessity to ensure RFID tags and readers were compatible within a single RFID system at least. Further than that, a number of strategies encouraging the possibility of interoperability outside the initial system were apparent. These included attempts by actants speaking on behalf of standards, as well as documentary actants such as standards publications, to persuade organisations that any RFID systems should be interoperable, and "vendor agnostic". ${ }^{\mathrm{PR}}$ These arguments were not always popular with RFID systems vendors as "it means vendors have to compete on 
capabilities other than hardware, so it really levels the playing field" ${ }^{\prime P R}$, as interoperability between all available RFID software would remove a point of difference for those vendors who were not standards compliant. One actant felt that vendors could consider a push for universal standardisation to be a "threat". ${ }^{\text {PR }}$

From the software perspective, the need for standardised item identification and tracking was emphasised by one actant speaking on behalf of standards who noted:

"...if you are trying to do traceability for any reason then you have a vested interest in having a standardised language to exchange information from upstream suppliers, [as well as] downstream consumers that actually wish to be able to find out information in a standardised way". ${ }^{P R}$

However, not every organisation was interested in implementing standards that could reach outside their own RFID system, as this actant had found some organisations did not want to implement RFID standards at all because of risks to "competitive advantage $\mathrm{e}^{\mathrm{PR}}$, or because competing systems offered data mapping services which "did not require a standardised approach". ${ }^{P R}$ Nonetheless, this organisation speaking on behalf of standards had achieved some success in strengthening the place of standards as an additional OPP through working with organisations on RFID business cases especially where the organisations did not have "the understanding or internal capability, or the wherewithal to do a business case to support the use of RFID in their operations". ${ }^{\text {PR }}$ Another organisation working on behalf of standards had sought "missionaries... from within the industry who we work really closely with, who get it, and are seen as influential within [every] sector we are engaging with to actually help us evangelise the [RFID standards] message". ${ }^{\text {PR }}$ These missionaries represented the importance of standards to other organisations.

At the global level the standards organisations were struggling to get agreement on global standards especially as countries were reluctant to have "just the [one country's] standards". ${ }^{\mathrm{PU}}$ This reluctance was making it difficult to get general agreements as to which standards should be accepted in different jurisdictions. Where jurisdictions had decided to implement different standards, whilst resisting others, it was see to "[force] whoever is selling, other countries, to take a tariff"PR in order to 
trade with that country. This reduced the attractiveness of admitting the country imposing the de facto tariff to the network.

There were also differences between different standards organisations in terms of charges imposed for the use of data services. The imposition of charges was seen to be an inhibitor of standards by one actant who was of the opinion that:

“...unless it's an open, essentially free architecture I don't think it will be adopted. (Paying) for information is just not going to happen in this age. I think they went down the wrong path and I understand they are essentially a commercial organisation but they ought to stay in the non-profit (sector) handling and helping develop the trading partner information". ${ }^{P R}$

Another actant saw the future of traceability as enabling someone to "type a [standardised number] in and it gives you a whole history of where it was and where it has been" ${ }^{\mathrm{PR}}$ however he acknowledged "we need to be there, but it is not like that at all at the moment". ${ }^{P R}$

\subsubsection{Recruiting Others - Interessement}

Once the problem has been defined and a solution proposed, the translation moves on to recruiting or interesting supporters. So the question must be asked - how does RFID interest other actants in joining the network?

With the biosecurity system discussed at the beginning of problematisation, a number of strategies were apparent. First and importantly, the problematisation had identified the need for legislation, so the government needed to be recruited as:

“...they had to get legislation, so therefore the government's got to be convinced, and then you've got to do a business case, and it's got to be able to be stacked up and demonstrated and proven [that] it's not just a crazy idea...". ${ }^{\mathrm{PR}}$

Apart from the business case, other methods that private sector actants used to persuade the public sector to get involved included attempting to "convince government that it will create and maintain jobs and profit that can be funnelled back 
into the nation's economy... whether it's true or not people tend to push that". ${ }^{\mathrm{PR}}$ Further, one actant had spent time:

“...persuading officials that they weren't going to be left holding the baby which essentially was their fear. It was that we would go ahead with a hiss and a roar, [some organisations] would throw their toys, there would be mutiny, and they would be left trying to administer a scheme which was a disaster area because we would all walk away... I guess we had to assure them that we were kind of deadly serious about it." ${ }^{\mathrm{PR}}$

Other actants were also recruited into the translation over time, as the structure of the organisation running the system:

"evolved over the years from a small group of industry stakeholders to more formal structures, to more stakeholder consultation, to more meetings, more expectations... and then you start to really get some muscle... [when] you get to that level of momentum". ${ }^{P R}$

The momentum gained through the work put into persuading stakeholders to join the problematisation assisted in interesting other actants "to want to" ${ }^{\mathrm{PR}}$ join, as well as in "getting the [associated government] Minister's attention" ${ }^{\mathrm{PR}}$, which helped in forming the legislation that was required. Despite this work persuading other actants, there was ongoing debate within the industry about the proposed problematisation. This debate had been "aggressive and accusatory in ton ${ }^{\text {"PR }}$ at times, although many members felt "well represented by their industry [while] others didn' $t$ ". ${ }^{\text {RR }}$ While there was considerable interest in this system, there were also industry members who were opposed, and a number of questions arose including:

"...exactly [what] sort of entity is [this] going to be? How is it actually going to be governed? What rights are different people/organisations going to have? And who sets import stuff like cost recovery, and all of that kind of thing? Who has to pay [and how] much? That's where things started to fracture a bit in the sector being entirely unified". ${ }^{P R}$ 
One organisation originally supportive of the problematisation appeared to defect at the interessement stage because "the impetus behind [their] involvement changed over time". ${ }^{\text {PR }}$ This was mainly due to governance changes as “... every few years we refresh our governance, and depending on who's in what role for which group... it changes. In terms of the overarching views we express it has been affected largely by the governance coming through...". ${ }^{\mathrm{PR}}$ Although this organisation had eventually arrived at the view that "it's coming in, so let's make the best of it and best prepare our people and make sure it works for them the best it can ${ }^{\prime \mathrm{PR}}$, some resistance was still apparent. This resistance was expected to continue until "the risk profile changed and the costs changed, and... where it [makes] sense" ${ }^{P R}$ However, despite the public resistance the organisation still maintained support for the RFID system within the organisation. As described by one actant:

“[our] involvement in [the system] didn't change from what it was throughout that whole time, and there was general acceptance by the others that [we] needed to be... angry and do [our] public thing, and they were cool with that because privately we were still doing the constructive, collaborative, helping shape the thing so it worked better". ${ }^{\mathrm{PR}}$

While debate continued within this organisation, other supporters were working to strengthen the system. Another actant from a different organisation (in the public sector) related difficulties his organisation had in deciding to get involved with the RFID system, and commented "it didn't really get good traction until [my organisation], and the industry funders decided to front with money, decided to share dollars, share resources and enter into an agreement to actually do it". ${ }^{\mathrm{PU}}$ He was also conscious of the need to ensure there was a good understanding of how the data collected was going to be used, pointing out that "industry had concerns about what the data might be being used for and had a suspicion, and paranoia about it being used for other things." ${ }^{\mathrm{PU}}$ However, this actant was sanguine about the resistance described above, noting that:

“...it's about playing that game I just referred to, about building trust, and giving people the space that they need to get acceptance, and so industry 
players and bodies need the space to say they're adding value to their membership, and so there would be the ability to say they are in control. [This] is very powerful for them when they go and talk to their members, but trying to say to them we're in a partnership with government is not an easy sell if you are going to go talk to a [member]. So, you'll see quite carefully crafted wording around those relationships when an industry [is] talking with their members, depending on circumstance." ${ }^{\mathrm{PU}}$

The industries involved in this system spent a lot of time promoting the problematisation:

“...because it was really up to our industries to promote the idea so we obviously spent a lot of time talking to companies, and to groups of [members] etc about what it was all about, and dealing with their issues, whether it be about the technology or the need for such a system". ${ }^{P R}$

The industry ran a "technical working group" ${ }^{\mathrm{PR}}$ which discussed "about the practicalities, and about the types of rules that might be applied in a traceability system" ${ }^{P R}$ They had found the best method to persuade others, especially where details had not yet been worked out, was to "be straight up and say look, we don't know just yet, we are trying to work through all of that stuff... we want to make sure that it works and that it is as cost efficient as possible, and that means we need to work through all of these things". ${ }^{P R}$ Further, there was still resistance in industry meetings despite the presence of a legislated requirement. When in such meetings, one actant focused on discussing:

"...what the system would be like, not having an argument about whether or not it should exist. But we want you, or need you, to be involved in all of that so that when a decision is made one way or another you are at least up with the play and we don't have to go back over all of this sort of stuff just to satisfy you guys. That raised some issues. People sometimes play nicely and sometimes they don' $t$ ". PR 
The process resulting from the ongoing meetings was "cross party, non-political"PR according to a different actant, but had also taken quite a few years due to "industry politics more than government... they all want to own it, and run it, and share in it, and be in charge". ${ }^{\mathrm{PR}}$ However, despite these challenges there had been "sufficient support within our community... that we want this sort of thing. So, there's basic support on that level and there always has been." ${ }^{\mathrm{PR}}$

Issues seen in this system were also echoed in others. Challenges to the proposed problematisation in another public-private system had arisen due to its "voluntary" $\mathrm{PU}$ nature, making the associated cost of implementation a "highly relevant" ${ }^{\mathrm{PU}}$ consideration. A point echoed by a public sector actant who noted that to attract interest an RFID system his department was considering, the system would need to "offer value beyond just our agencies". ${ }^{\mathrm{PU}}$ This, along with the lower cost of barcode systems, was providing a considerable challenge to interessement in RFID. As one public sector actant commented: "as a commercial provider, I [would] have a free of charge bar coding system, internationally recognised, now accepted as part of conventional contract packaging, [so] what's the benefit in RFID, and what's the cost of the benefit?"PU This particular system was also facing difficulties associated with different levels of security required by public and private sector users as related by one public sector actant:

“...[It] offers no benefit to government because once it's completely available then in fact what happens is that every criminal can get hold of it, so its actual value as a security solution vanishes immediately, and so the challenge for RFID or anything else in this space is to be sufficiently unique and carry sufficient data that people in compliance roles absolutely understand what they are dealing with and know that it is a legitimate consignment". PU

Related to this were difficulties with establishing a "common international view about where privacy begins and where it finishes" ${ }^{\mathrm{PU}}$, although this public sector actant felt that solving the privacy problem would allow "the data and price questions [to] become more easily answered, because it's much easier to talk about what the real value of the data internationally is when you overcome the issue of how we manage 
privacy". PU Difficulties had also been encountered in this system with infrastructure, particularly tags not being "sufficiently robust for their intended use". ${ }^{\text {PU }}$ However, there was interest surrounding the ability of RFID to identify items at the item level rather than at the box or pallet level, and if this identification could be done with “certainty and assurance" ${ }^{\mathrm{PU}}$, it was seen as a "compelling"PU argument for RFID.

In a different system, interest in cross sector collaboration was being fuelled by a governmental drive to provide "coordinated agencies" ${ }^{\mathrm{PU}}$, as the government "didn't want to be duplicating IT infrastructure that was largely the same thing" ${ }^{\mathrm{PU}}$, according to one public sector actant. This actant went on to discuss how relationships had been difficult within one industry, suggesting that problems had arisen as the industry management was "a little bit slow,... I think they need a much more informed and IT aware governing body to help have those conversations". ${ }^{\mathrm{PU}} \mathrm{He}$ also related the importance of "talking to people, and getting ten people in a room that can solve a problem" ${ }^{\mathrm{PU}}$, as well as the use of various cross sector forums to bring together "everyone in the chain" ${ }^{\mathrm{PU}}$ to discuss issues.

RFID technology also had a range of straightforward and easily identified features that organisations found attractive which assisted with the interessement. One public sector actant had found "no resistance to the technology" ${ }^{\mathrm{PU}}$ as the private sector organisations involved in his RFID system had quickly recognised that labour savings were going to "add extra value" $\mathrm{PU}$ to their business. Similarly, a public sector actant had found that the novelty of using an RFID system created interest for customers, describing their response as "very supportive, they liked it and to be fair it was a little bit of fun for them having a little bit of automation...". ${ }^{\mathrm{PU}}$ One private sector actant related that the term "RFID" itself generated a level of "buzz" ${ }^{P R}$ that attracted interest. Although, this actant also found that many organisations had "no real understanding of their problem in many cases, and they certainly have no understanding of the methods to solve their problem". ${ }^{\text {PR }}$ The actant had found that the best way to maintain interest in RFID was to get "the decision makers involved early on to make sure they understand where we're going and we like to start bringing in the people doing the work, getting them to buy in to doing this." ${ }^{\mathrm{PR}}$ The actant went on to describe: 
“...there's kind of [a] two sided problem, and the first is if we don't have the decision makers and the money holders involved it can't happen to start with. Then if we don't have the people actually doing it on board with the program it gets sabotaged or for another bunch of reasons it doesn't happen". ${ }^{\text {PR }}$

Another challenge to interessement was also seen arising from allies of a non-human actant SpyChips (2006) a book often cited by those opposing RFID technology. This actant believed that "RFID is a disturbing technology with frightening implications" ${ }^{\text {PR }}$ (p. 232), and further that RFID technology was "something that looks surprisingly similar to the mark of the beast". ${ }^{\text {PR }}$ Counter to this belief another actant discussed how it was:

"very frustrating every day I see somebody is talking about how RFID is the mark of the devil, how here in the US new healthcare the plan is going to require everybody to have an RIFD chip embedded in them, and it goes on and on and on and it's all wrong". ${ }^{\text {PR }}$

This actant went on to discuss the value of industry conferences and events in interesting and educating others as to the value of the technology, as well as noting that government mandates would also play a role in "increasing the use of RFID systems". PR

\subsubsection{Defining Roles - Enrolment}

Once the necessary actants have become interested in the network, the next stage of translation is the definition and delegation of roles within the network. In the first system discussed in both the problematisation and interessement sections, enrolment proved difficult, despite both the government agreeing to come on board and providing legislation that would frame the nature of the RFID system, and the acquiescence of actants that had initially resisted the problematisation. The struggle for control of this system still persisted as one actant observed "they all want to own it, and run it, and share it, and be in charge". ${ }^{P R}$ This point was echoed by another, who also saw the different places organisations had within the market as causing "constant tension between the [organisations] because of their relatively different fortunes and market power, and how they see themselves, and the pressures they face". ${ }^{\text {PR }}$ The 
relationship between government and industry was also complex as industry and government jostled for control, with one private sector actant describing how industry struggled at times to retain control of the problematisation:

“...so when the government's finally convinced and then it starts putting its resources into establishing legislation that will reflect the outcomes that industry want. That's when you lose a bit of the, the tail starts wagging the dog, because they then know best and all the policy wonks get involved and it grows a life of its own. So then you got to [sic] go and grab them all and bring them all back, and that's where it's taken a lot of time... So, industry, government, industry partnerships aren't without issues." ${ }^{\mathrm{PR}}$

There were also difficulties with industry members accepting the regulated system, especially as communication was not always clear enough. One actant speaking on behalf of the industry felt that industry members "were told about [our system] in such a way that they were hearing about the policy part of it at the same time as the fact that they [had] to do it, and it wasn't well explained, so they got the wrong story". ${ }^{\mathrm{PR}}$

The members of the organisation that had tried to defect from this system also continued to display a breadth of opinion as their actant explained:

"At one end you have got those that will resign from [our organisation] because we are not orchestrating national disobedience to compliance with [the system] and there are those at the other end that are quite p...ed off at us generally because we are not, we're failing to see the opportunities that come from the use of RFID tags". ${ }^{\text {PR }}$

A different actant took a more direct approach, observing that in his organisation "one way of dealing with [members who don't agree] is saying "well it's a bit late now because it is the law". ${ }^{\mathrm{PR}}$ In terms of the relationship between the two sectors using this system, a public sector actant explained the organisation's approach was to collaborate with industry, relating "we are an equal player with the other parties, so we are actually partnered. You've got a partnered structure as opposed to two entities 
trying to work together". PU His organisation also used a memorandum of understanding to give shape to the "complexities of relationship" ${ }^{\mathrm{PU}}$ between government and industry bodies.

Political support had been consistent for this application as "[the politicians] are in agreement. They can't not be [as both parties] were pushing for it". ${ }^{\text {PU }}$ Further the industry bodies had left the political parties in no doubt as to their preference for the system, and "...the politicians understood that the industry push was there, then they were buying into it". PU However, debate was ongoing around one aspect of the system that had not been legislated initially, and this point had required "compromise all over the place around that element to keep people at the table". ${ }^{\mathrm{PU}}$ This had resulted in the contentious point not being included in the legislation until "...the industry bodies felt they would be in a place to be able to have, to be able to have the discussion with their members, which really comes once it's proven with [those aspects] currently legislated". ${ }^{\text {PU }}$ A delay in the actual passing of legislation for this system had also changed the tone of the debate somewhat, improving enrolment, as another actant discussed:

"... the thing that got picked up in a lot of... newspapers was that "[instance $A$ is] now optional", so you have [some time] to pick it up voluntarily before they now force you to. It changed the tone of the public discourse, nothing changed really, it's still going to be mandatory, but by telling people that they don't have to do it right now it switched from you have to do it now, to you can, if you want to, do it now." ${ }^{\text {PR }}$

Some mediation had also been needed around the issue of privacy in this system, as one public sector actant found "there were some differing views, and so, unsurprisingly, our policy guys would be at the cautious end, and the [industry] guys will be at the more bullish end". ${ }^{\text {PR }}$ Obtaining clarity on how data was going to be used assisted enrolment as it provided comfort for those who had a "level of paranoia about [data] being used for other things". ${ }^{\text {PR }}$ 
In a different system where participation was governed by guidelines rather than regulation, a public sector actant described how the organisation encouraged vendors to participate in their RFID system as they:

“...[paid] vendors faster if they used the RFID system... and if they didn't use the RFID system it would take a lot longer, and we put that in our contracts. Now all of a sudden our system had the information we wanted, and it was always available, all we had to do was give an incentive to the vendors". PU

This incentive encouraged enrolment in the system. Another private sector actant took a pragmatic approach noting that most government contracts required adherence to a "set process for tendering for supply" ${ }^{\mathrm{PR}}$ and that in order to "sell to government then you have to meet those conditions" ${ }^{P R}$ In these instances, tender or bid documentary actants clearly set out conditions for enrolment.

In a similar system one private sector actant had found that being involved in a pilot RFID project had helped with "inclusion of the various partners" ${ }^{\mathrm{PR}}$, encouraging them to come on board and see the value of RFID. This actant also found that organisations could be encouraged to work together by "having everybody work together and they can understand what this is going to be about from their highest level, so that it can be filtered down, and that it will be supported by the leadership of the company or each government entity or whatever it is." ${ }^{\mathrm{PR}}$ However despite the pilot project encouraging enrolment this system had difficulties politically as one public sector actant observed "it's just another project [for the politicians], and they always think they have bigger problems, they are more concerned about their bigger problems like where to put a new softball field". PU Although, in a separate RFID system, another public sector actant had found that relationships were more "a product of its individuals... if you have good people at the time then you get good results". ${ }^{\text {PU }}$

A number of the RFID systems studied were subject to legislation, in others this had not yet happened. In one non-mandatory RFID system the actants were working hard to prevent the government legislating, instead attempting to convince the government that industry could self-regulate, as one private sector actant describes: 
"... and we, the industry itself, the manufacture's [sic] the distributors the [payers], and in some cases the [organisations] have done what we call lean in and lean out in making progress towards agreement... saying, we will serialise the product, we will do it using this identifier, we will do it using a barcode, we will do that, we will exchange that information in the following way. They have genuinely attempted to demonstrate to government that they are able to do it in a responsible way so that there isn't a necessary regulation passed in addition to that which is already out there that says you will do it exactly like this." ${ }^{P R}$

In general, one of the most difficult issues faced at the enrolment stage was determining roles, and changing organisations to wholly adopt the RFID technology as outlined by the problematisation. As one actant found "there needs to be some process changes, different ways of doing a job to make allowances for the technologies". ${ }^{\mathrm{PR}}$ It was also challenging to enrol those at the non-strategic level, and ensure they understood what they were supposed to be doing. A different actant had found at times that it was unclear "if people at the [non-strategic] level clearly understood the significance of the tags and what they were doing..., and therefore I think the communications could have been a lot more [clear]...". PR Contention between different departments about funding and control led to the failure of a project in a case related by one private sector actant. This actant had been involved in an implementation with a military organisation where "each group wanted control, and then not control at different times, and so it became, if you like, lost". ${ }^{\text {PR }}$ Changes in staffing, especially in the case of those involved in the military, where there were staff rotated regularly, also caused enrolment problems as it was necessary to persuade and enrol the incoming staff members. In the military project just discussed another element contributing to the eventual failure of the project was "the [officer] who wanted it, saw it as a great tool that [he] was going to be able to use, but in the end [he] was busy doing other things... By the time we actually came down to the point [he] was about ready to rotate out into another job". ${ }^{P R}$

Many of organisations felt as one private sector actant did when dealing with the public sector organisations "almost all government suppliers... have to follow a set 
process for tendering for supply and the government normally will put out basic requirements that they have to meet". ${ }^{\mathrm{PR}}$ These requirements, sometimes framed as legislation, strictly shaped the problematisation and enrolment, setting out the roles required by organisations that wished to participate. The ability to dictate roles was also seen in the largest private sector organisations, as detailed by one actant "WalMart has money and they have the clout. They are the biggest retailer, they wag the dog, and they influence the market versus being influenced by the market". ${ }^{\text {PR }}$ Discussing a failed implementation, another private sector actant observed when dealing with complex organisations it was an advantage to have "people whose job it is purely to deal with the process of doing business, and I think we fell apart because we didn't have any of that. Not only did we not have the people to do it, we didn't necessarily have the knowledge to do it either". ${ }^{\mathrm{PR}}$

\subsubsection{Working Together - Mobilisation}

Once all the actants have been enrolled to support the problematisation, the original actants (those involved in forming the problematisation) work to ensure the other actants remain enrolled, and that the shape of the problematisation is maintained, through the stage of translation referred to as 'mobilisation'.

The biosecurity system discussed first in the problematisation section had reached mobilisation and could be considered reasonably stable. One public sector actant, and the heads of the other organisations involved had become fairly comfortable delegating for each other, as he described:

"So... the CE,... the chair, myself, ... [and others], we keep very close, and so we are always talking... Just came away from a meeting where some of the members of the industry bodies were asking questions around the amount of capital and how much, why is [the government] charging that sort of interest on the depreciation and whatever, so, in that sort of circumstance it's great when [the CE] or [other industry members], they can stand up and say well, here's the deal, here's why we have this relationship, and here's why it is this way. It's a lot more powerful than if I stood up and tried to defend something 
around a, really what's a [government] position. So the personal relationships, they are fundamental, and if they are not strong you're in trouble."PU

The organisation that was initially reluctant to enrol was participating in the network as legislated, and was described by their representing actant as "... working to ensure that the system works for [our members] as best it can, as efficient, and minimising the cost to [members]". ${ }^{\text {PR }}$ Although he was finding his organisation's members found the "terms and conditions that they are being asked to accept" ${ }^{\text {PR }}$ irritating. In another private sector actant's organisation, the initial stages of this translation had been "relatively hand to mouth..." ${ }^{\mathrm{PR}}$ in that not a lot of funding had been available to support work on the system. However, after a couple of years "formality gradually increased"PR , and more support became available. The final mobilisation saw each of the participating organisations becoming "shareholders" ${ }^{\mathrm{PR}}$ with each organisation appointing representatives to the board of the organisation running the traceability program. This controlling organisation had a "completely separate operation with its own board"PR , and had been allowed to "basically get on with" ${ }^{\mathrm{PR}}$ the running of the traceability program. Each organisation also had "control over how the whole thing operates, and accountability for that ${ }^{\prime \mathrm{PU}}$, and in general the private sector actant felt his organisation was satisfied with the resultant program.

Where legislation was in place requiring participation before the RFID system had commenced, the resulting solution fitted closely to the requirements of the legislation. However, the presence of legislation was no guarantee of stable mobilisation. A number of challenges to mobilisation were observed in organisations where a cross sector RFID system had been implemented. Not accurately forming the problematisation led to difficulties at the mobilisation stage, as one private sector actant had found "there's frustration all round because we think we've delivered what they wanted, and they are telling us that it isn't what they wanted, but then we never really knew what it is they really did want". ${ }^{P R}$ The actant also considered the inability or unwillingness of an organisation to change their processes to be a "concern". ${ }^{\mathrm{PR}}$ In a different system, a lack of training and communication was causing participation to lag, as the actant speaking on behalf of the system felt that workers didn't "have an appreciation for the [organisation's] participation in something like this". PR 
Organisations also sometimes failed to see the immediate benefits of their RFID systems, with one actant explaining "my particular feeling is that a lot of the best benefits of a technology turn out to be [serendipitous], it's the stuff that we didn't necessarily think of". ${ }^{\mathrm{PR}}$ This was of particular concern to the RFID network as the mobilisations that appeared most stable were focused on the benefits gained from the RFID systems, and clearly anchored by legislation.

A number of strategies were in use to maintain these more stable translations. One public sector actant found that "socialising the concept" ${ }^{\mathrm{PU}}$ of the system with workers at various levels of the organisation was successful (in a non-legislated system). Combined with ensuring simplicity of design and front end use, this had allowed the users of his system to "go from 'whoops I feel all at sea because this is new' to 'hey this is cool'. [It took] very few days once they got going, and away they went". ${ }^{\mathrm{PU}}$ Similarly, a public sector actant had found that once his organisation's RFID system was implemented those using it had quickly adapted to its use and found it natural and easy to use. The actant observed that "...once you get [the RFID system] rolling and [the staff] see success, and they see their vision coming alive... it's kind of second nature to them... so it kind of becomes the mode of operating, and you've reached your goal because you've made the change."PU

This actant had also found that RFID was "better than barcode because you can read the tags from a distance, you can read, 20 tags at a time, so it's less interference in the daily operations especially if you have like a portal" ${ }^{\mathrm{PU}}$, and this had encouraged utilisation of his system. One actant believed that while RFID technology might be expensive "today" ${ }^{\mathrm{PR}}$, it would be much cheaper "tomorrow" ${ }^{\mathrm{PR}}$, and that this was going to facilitate much wider acceptance and adoption of RFID systems.

\subsubsection{The Future of the Network/ Mobilising the Internet of Things}

The RFID systems discussed in this study are shared between public and private sector organisations. However, while there is interoperability within each individual system, they do not connect with each other, and nor are they likely to in the near future. If these networks could interconnect, they would be far closer to the Internet of Things concept envisioned by such authors as Slettemeas (2009) and Miorandi et al. (2012). 
From the current position, further translation would be required to form an integrated Internet of Things. The majority of human actants did not mention the term Internet of Things, and when human actants were asked directly about the Internet of Things, after the conclusion of the interview, most had not heard of the term, or the concept. Those actants that mentioned the Internet of Things saw RFID being intimately connected to, and facilitating it. As a result they did not see the current RFID network as being the end state for RFID, either in the public-private sector context, or the global context. As one actant explained:

"...what we are doing now is only the beginning, I certainly believe there is much more to RFID because very often RFID gives the impression that it is only the tag and the reader. In fact, what we are trying to do now is the beginning, it is really the Internet of Things that is using... the EPC standards of Internet data exchange to create end to end visibility. Then we will be able to track identify and ship objects anywhere in the world". ${ }^{\mathrm{R}}$

Similarly another actant was of the opinion that "we have not conceived of all the power that the Internet of Things is going to bring us", mainly because the actant felt "we're still in a time where technology development is going very, very fast". ${ }^{\text {PR }} \mathrm{A}$ different actant, representing systems integration, discussed how rapidly evolving technology was allowing RFID systems to change:

“...previous to about now the last year or so, I would suggest that (people) saw RFID as the solution as opposed to a part of the solution, and this includes the data systems like ERPs, human readable barcodes, being able to do parents and children, privacy issues. We're are all at that cusp right now where all those are coming together. I can see it in the next year or so really hitting the top of the curve". ${ }^{\text {PR }}$

The observation that many actants had not heard of the Internet of Things was supported by one actant who noted “most people don't know what it is, they don't have a clue... it's way too early". PR Similarly, within government it was observed that "they are getting more of that vision but I don't think that the vision of everything 
being connected to everything else was really well understood, certainly at government levels...". ${ }^{\text {PR }}$

The mediators of the Internet of Things were seen to be the same as those for the RFID systems that enable it. For example, the necessity to fund systems was foremost among the barriers mentioned to Internet of Things systems, as noted by one actant:

"New technology always costs money. Even when we look at RFID, the cost of RFID has come down particularly over the last ten years. But, does that mean that in order to be able to do some of the work we've got to do with sensors to enable loT we should be looking at another 10 years before we are really getting to the cost point we can afford it?"PR

Other mediators of the Internet of Things were considered to be the "data handling that we use... so that we can share information...". ${ }^{P R}$ The governance of such systems was also considered to be problematic, as one actant stated "how do we govern it I think is a much harder question to answer and one that I don't really have a good idea for". ${ }^{P R}$

However, more than any other mediator, where Internet of Things related issues were discussed by actants they mentioned the importance of ensuring that organisations understood the concept. As one actant speaking on behalf of systems implementation observed: "I think education is a major barrier. When I talk to companies, large ones in some cases, and it becomes pretty obvious they don't even understand what the Internet of Things is and could do. I think that we've got a long way to go yet." ${ }^{\text {PR }}$ The main drive for implementation of the Internet of Things was seen to come from the private sector, rather than from government or individuals. One actant discussing Internet of Things implementation stated, "we will start to see the industry pushing it. I think that eventually government will start to help. I don't see the consumer being a part of the drive until industry is able to show them the benefits". PR This focus on benefits as an avenue to implementation mirrored that seen in RFID systems implementation, and was emphasised by another actant who observed "if you go to a CEO and you say do you want Internet of Things can help your business you are going 
to get blank stares. If you go in and say I'm going to improve your inventory accuracy from $65 \%$ to $99 \%$ are you interested [then the answer is] "yes"..PR

\subsubsection{A Summary of Translation}

The ANT translation view allows for the description of how the RFID network is formed in the public-private sector context. In the problematisation phase, organisations focused on constructing business cases and ensuring they met any obligations put on them through such obligatory passage points as legislation and industry self-regulation. Funding was crucial at all stages in determining whether a system could continue. Standards for both hardware and software were also very important in the problematisation phase with organisations needing to decide if they were going to accept a common standard such as the EPC, which would allow them interoperability with the RFID systems of other organisations, or if they were going to use proprietary standards. Once decided, these standards also became obligatory passage points. During the problematisation stage, barcode tracking systems provided a strong challenge to RFID systems by presenting an alternative tracking technology that was perceived as being cheaper, but not offering all the benefits of an RFID system. In a number of instances it was apparent that the greatest benefit to implementing the RFID system would be seen if participation in the system was mandatory.

Where legislation had been identified as a requirement in a particular RFID system the private sector actants had to persuade government to become involved in order to pass the needed legislation. This happened during the interessement stage of translation, with the resultant legislation becoming an OPP for the remainder of the translation. Interessement was focused on persuading other actants to join in the problematisation, not always successfully. Some organisations rejected the problematisation due to changes in the governance (where they had already accepted it), cost, and privacy concerns. Trust also appeared to be important at this stage especially when negotiating between organisations. Where organisations could recognise benefits to them in joining the problematisation they were more easily interested, with cost and labour savings being foremost among the benefits identified. Even the nature of the technology itself attracted some organisations, generating a 'buzz'. However, some organisations and individuals were afraid of RFID technology 
due to health and privacy concerns, as well as the actions of organisations opposing RFID implementations.

The enrolment stage of translation was characterised by organisations jostling for control within their RFID systems. Because more than one organisation was involved in all the systems there was a considerable range of reactions to offers of enrolment from those affected. In some organisations individual actants continued to dispute the enrolment while others in the same organisation wanted to move more quickly on implementation. Privacy still appeared to be a concern at this stage with debate continuing on how data collected by RFID systems would be used. Where involvement in RFID systems was not mandatory, enrolment was assisted by the provision of incentives to other actants. Piloting RFID systems was also found to assist organisations to understand how such systems could be of benefit to them, and encourage enrolment. Where legislation was in place, or a large organisation had mandated involvement to its suppliers, the requirements of these obligatory passage points forced certain roles on participating organisations, with which they had to comply at least to a minimum standard. The biggest challenge organisations faced at the enrolment phase was changing their organisational structures to accommodate RFID systems. This was seen to require strong organisational management and direction.

The final stage of translation, namely mobilisation, was characterised by the number of intermediaries compared with previous stages. Standards, infrastructure and privacy in particular were not mentioned as being of concern at this stage.

Mobilisation was characterised by increased formality of RFID systems, and the ability of actants in one system to delegate for each other. However, not all mobilisations were stable, especially where problematisation had not been carefully formed, resulting in dissatisfaction with the outcome of the translation. A lack of training and communication of systems requirements was also seen to cause difficulties. Furthermore, mobilisation was also the stage where the benefits of implementing RFID systems became apparent, even if the benefits were not the same as those identified at the problematisation stage. 
Despite the apparently stable mobilisation stages observed, not all actants saw the current state of RFID systems as being its final state. Those actants that understood the concept of the Internet of Things believed that in the future RFID systems would be far more connected than they are today, moving more and more towards the theorised Internet of Things. The mediators (or barriers) to the Internet of Things were seen to be the same as those for the RFID systems that would constitute it. However, far more emphasis was placed on education as a mediator, primarily because of the number of individuals and organisations with no understanding of this concept.

\subsection{Sector Interactions}

The interaction that occurs between sectors is part of the story of the RFID network. This relationship is complex and there are differences apparent in the way the two sectors act, and perceive each other. These differences become visible around the mediators, as some act differently in the different sectors. They are also evident in the way the two sectors perceive each other, and the roles they play in the ANT translation process that forms the RFID network.

This section discusses the details of the inter-organisational relationship as described by the participants in the network, on a day to day basis, as well as describing how each sector views the other, how they work together and the perceived role of government in the network.

\subsubsection{Contrasting Public \& Private}

The relationship between the public and private sectors apparent in the RFID network is complicated. In some instances legislation or regulation required actants in both sectors to undertake certain actions and activities, although predominantly legislation forced courses of action on private sector actants. In other cases the sector relationships were framed by the perceptions each sector had of the other, and the perceptions reported by both sectors were largely negative.

The private sector for example viewed the public sector as being more bound by procedures and requirements and thus "less flexible" ${ }^{\mathrm{PR}}$ and "slow" ${ }^{\mathrm{PR}}$ in action as they were required to "undertake due diligence". ${ }^{\mathrm{PR}}$ In the case of the privacy mediator, it was perceived that it was necessary for public sector entities to "more carefully 
understand the privacy implications than private sector companies that sell to other businesses (as opposed to consumers)". ${ }^{\text {PR }}$ This was linked to the lack of voluntariness when dealing with the public sector as "people have a right to choose what private sector companies they work with, whereas in the public sector you're kind of stuck with the government" (Sector Interaction - Perception of Public Sector). ${ }^{\text {PR }}$

This need to secure public information brought a greater focus on security in public sector entities, with one private sector actant noting:

“... for the users that I know in the public sector, they've always automatically asked for security, 2005/2006 even 2004, in those years you could not for your life find a proposal out of the private sector that had security written into it." (Sector Interaction - Public-Private Comparison) $^{P R}$

In terms of willingness to share information, the public sector was perceived as being less willing with one private sector actant observing that "government keeps their data internally and do not give it out. Data is kept on the government servers where government considers it more secure". ${ }^{\mathrm{PR}}$ Though where data could be shared it was perceived by another private sector actant that "[in] government and academia there is this ethos of sharing and free information flows in the public sector". ${ }^{\text {PR }}$ This actant also felt the private sector response to sharing data in RFID systems was "oh s..t, yeah competitive advantage, I want to implement it a different way ${ }^{\mathrm{PR} \prime}$, pointing to a reluctance to share information (Sector Interaction - Public-Private Comparison).

The public sector was generally seen as being short of funds and not particularly cohesive with a private sector actant feeling that:

"It's the government, you know. It really, let's be honest, it has to do with funding, vision, authority. They don't have the funds, [and] they don't have someone with a cohesive vision across the enterprise..." (Sector Interaction Perception of Public Sector) ${ }^{\mathrm{PR}}$

Conversely, the public sector was also seen as not being "very cost conscious" ${ }^{\mathrm{PR}}$ particularly when the application being considered was critical to security or national policy. It was also suggested that this lack of cost consciousness related to the job 
security, and lack of accountability within the public sector, as one private sector actant observed:

"[in] the private sector you are often rewarded... that does not happen in the public sector, and therefore, people in [the] public sector look down upon those who work hard as though "you are trying to make me look bad, and you are trying to win brownie points". ${ }^{P R}$

This actant felt that this behaviour led to "bureaucracy becoming stagnant" ${ }^{\mathrm{PR}}$ as there was a lower drive to change processes or innovate (Sector Interaction - Perception of Public Sector). In contrast, it was also reported that greater public sector job security led to a willingness to take risks with technology innovation, with a different private sector actant being of the view that "public sector institutions are innovative and they are risk takers, where private sector is not". ${ }^{\mathrm{PR}}$ Further where a particular RFID system was considered to be critical, the public sector was seen as being active in pursuing solutions by this actant who observed the public sector "[was] not sleeping" on security (Sector Interaction - Perception of Public Sector). ${ }^{P R}$

Where contract tendering, or bidding processes were discussed the public sector was seen as requiring more "due diligence" ${ }^{\mathrm{PR}}$ than the private sector according to one private sector actant. Another actant discussed how public sector organisations were less willing to negotiate the details of bids saying there was "very little opportunity for an integrator or solutions provider to influence [a] set of [bid] requirements". ${ }^{\mathrm{PR}}$ It was suggested that this lack of willingness may be related to the public sector "looking after everybody's money, so to speak, so they want to get the best deal that they can..." (Sector Interaction - Public-Private Comparison). ${ }^{P R}$ In addition, the public sector at times called in private sector organisations to assist in the bid process. This led to situations where "by the time the proposal gets around [to organisations that might want to compete for it] it's pretty much a done deal, so if you have a different solution [to that proposed] you will have an extremely hard time to win the project" (Sector Interaction - Perception of Public Sector). ${ }^{P R}$

At times it was perceived that the public sector, particularly politicians, were doing things - including getting involved in RFID systems - because it was a good idea to be 
seen to be doing them, rather than because the RFID systems themselves were a good idea. As described by one private sector actant:

“... the traceability issues were kind of secondary too, and RFID; they couldn't care less whether it was an RFID initiative or not other than when there was a newspaper [reporter]. They would show up and make sure their picture was taken. But in terms of supporting any bills or really helping you, they... like I said they're more concerned about a new softball field, because a lot of people like that." (Sector Interaction - Perception of Public Sector) ${ }^{\text {PR }}$

Many of the above findings were generally viewed as the "government way" ${ }^{\mathrm{PR}}$ of doing things with one private sector actant commenting "of course, you know government has its proper way that government tends to like it" (Sector Interaction Perception of Public Sector). ${ }^{\text {PR }}$

The views expressed about the private sector were much simpler than those directed towards the public sector. In general the private sector was seen as focusing on short term quick returns. One private sector actant described his sector as "looking for a very quick return on investment versus more of a long term plan". ${ }^{\mathrm{PR}} \mathrm{He}$ tied this to the need to provide value to private sector shareholders (or organisation members). This was a view shared by a public sector actant who perceived in his system that "industry players and bodies need the space to say they're adding value to their membership". ${ }^{\mathrm{PU}}$ The private sector was also seen as being less willing to engage in cross organisational RFID systems because they were "nervous about working within that bigger system in the same way [as the public sector] because it risks giving away what they perceive as their advantage" (Sector Interaction - Perception of Private Sector). ${ }^{\text {PR }}$

From the public sector side, private sector organisations were seen by one public sector actant as being variable in their responses to the public sector. In contrast he considered his organisation, which was governed by legislation and policy guidelines, was more "constant because we are the same [organisation]... What really drives the differences is how the industries chose to interact [with us]" (Sector Interaction Perception of Private Sector). ${ }^{\text {PU }}$ 
Organisational strategy was considered to give rise to differences between the two sectors with a private sector actant discussing the three or four year political cycle on the public sector side, and contrasting it with the theoretically longer strategic cycle on the private sector side:

"...there is a changeover [of political] administration potentially every four years, and just as you're getting used to the rules of the game by this administration the next one comes in and there's a new group you have to contend with. So this is in the leadership arena of course, but still it is frustrating because sometimes the rules of the game change and it's hard." (Sector Interaction - Public-Private Comparison) $^{\mathrm{PR}}$

It was noted by another private sector actant that private sector strategy also changed when leadership of the organisations changed. In the actants organisation in particular changing board membership had led to the views the organisation expressed being "affected largely by the governance coming through". ${ }^{\text {PR }}$ The lack of a CEO to direct public sector strategy was also seen as a barrier to strategic management. One private sector actant considered that "in the private sector you have a CEO saying "this is important to our business and we are going to do this "there is no CEO of the government... every government agency is a unique conversation" (Sector Interaction - Public-Private Comparison). ${ }^{P R}$

The type of services provided by the two sectors was seen by one public sector actant to influence how the sectors interacted, with private sector targeting their services towards individuals, while public sector organisations provided service at a higher level targeted at populations:

"From my experience the private sector are much more driven by the market and that includes [customer] preferences and things like that. So they are much more a service industry than the public sector is. So a service industry, you give the customer what they want and you are constantly worried about what they want. Whereas in the public sector they are much more focused on [general approaches], generally we should provide this for the country." (Sector Interaction - Public-Private Comparison) $^{\mathrm{PU}}$ 
This actant also saw the public sector as being unable to refuse to provide service. This led to public sector costs being higher than in the private sector where private sector organisations could "offload everything they don't like so they don't have to provide services to people who can't pay, they don't have to provide services when it's not convenient for them... and that's a lot of the costs of any organisation" (Sector Interaction - Public-Private Comparison). ${ }^{\mathrm{PU}}$

\subsubsection{Public-Private the Same?}

A number of actants also discussed similarities between the two sectors. These similarities were seen as turning on the nature of the individuals who were part of the inter-sector relationship, rather than the nature of the organisations. One private sector actant was of the opinion that "it is really how educated a person is, and how much research they've done"PR ${ }^{\mathrm{PR}}$ ather than the nature of the organisation, that dictated what kind of reception an RFID system might get (Sector Interaction Individual Based).

One public sector actant discussed how the views of individuals in both sectors tended to be presumed to be the views of their organisations as well. The actant noted that the organisation was often viewed as "the bad guys" ${ }^{\mathrm{PU}}$ by many in industry. However, this actant also acknowledged that that the organisation tended to "react and say, 'there goes that industry again saying that, what on earth are they doing,' and we miss the point that well, that's just actually one individual and that individual has a view within the context of the industry". (Sector Interaction - Public-Private the Same). ${ }^{\mathrm{PU}}$

The view that interaction between public and private sectors was similar was more often expressed where actants were familiar with the individuals they were interacting with, having worked on the same RFID system for some time. A private sector actant for example described working with the public sector from the early days of implementation and found that "since then we've been working on the [implementation] through thick and thin all those years... our dealings with [government] on [implementation] stuff happen exactly the same way as our dealings with...the other industry guys on the [implementation] stuff" (Sector Interaction Individual Based). ${ }^{\text {PR }}$ 
A number of actants believed that both sectors faced the same challenges in implementing RFID systems, as explained by a private sector actant:

"In the long term, as RFID systems proliferate, the challenges for governmentto-private sector interactions are the same as government-to-government, and private sector company-to-private sector company interactions. You need hardware standards and you need software standards that enable data to be shared. The systems must be secure." (Sector Interaction - Public-Private the Same). ${ }^{P R}$

\subsubsection{Role of Government}

'Government' and/or the public sector was seen as having a variety of roles to play in the RFID network. One public sector actant saw the public sector as having a role in encouraging "confidence to be established and maintained by [a] wide section of the trading community". PU Although jurisdictions provided varying levels of support for RFID systems, as one private sector actant explained "in Europe, the European Commission has spent millions and millions of dollars funding projects for industry for RFID... [in] Asia, Pacific Asia, they fund a great deal... All of those countries [are] very very industry friendly". ${ }^{\mathrm{PR}}$ At times, this friendliness towards their own industry was manifested through the government creation of artificial trade barriers. These worked by requiring importers to comply with local RFID regulations. For example one public sector actant explained "if your [RFID] numbering scheme is different then it forces whoever is selling, other countries, to take a tariff. That's the effect. You can't just resell stuff in that country, you have to remake it for that country so it makes import/export to [some countries] a little more onerous" (Sector Interaction - Role of Government). ${ }^{\mathrm{PU}}$ There was also a role seen for the public sector in educating industry, and the public as to the usefulness and safety of RFID systems. One private sector actant believed "government has a major obligation to educate, and this is something that I'm not sure that many governments do a very good job [at]" (Sector Interaction Role of Government). ${ }^{\text {PR }}$

The public sector was also seen as providing 'government' services as outlined by a private sector actant, "to get regulation or to get regulations changed... So there's an 
instance where you go to the government to try to help, to set up the right conditions for you to compete". ${ }^{P R}$ Although the actant saw the role of government as necessarily limited stating, "why would industry want government to become involved? If you think about it, if it's not something industry is doing for government there are very few visions where government acts as a supplier or providing a service or so on". ${ }^{P R}$ Expanding on this, a private sector actant related how organisations the actant was involved with had "genuinely attempted to demonstrate to government that they are able to [implement product tracing] in a responsible way so that there isn't a necessary regulation passed in addition to that which is already out there, that says you will do it exactly like this." ${ }^{\text {PR }}$ Where legislation was deemed necessary the involvement of the public sector was viewed as a "cost" ${ }^{\mathrm{PR}}$ of getting the legislation enacted by one private sector actant. The importance of ensuring any policy or regulation was matched to actual need was explained by one public sector actant who considered there was a "profound disconnect between government policy, industry desire, and technological development" ${ }^{\text {PU }}$ which was leading to unnecessary and poorly thought out legislation in the RFID system in which he was involved (Sector Interaction - Role of Government).

\subsubsection{Organisations Working Together}

There were a number of factors seen to facilitate public and private sector organisations working together. The ability to get all the interested parties together was seen as enhancing cooperation by a public sector actant. This actant explained how in one system "there was essentially this pan industry government group made up of representatives from [our department]... at senior official level and at a technical level; and then representatives from the industries in various parts, some of which were going to be funders, and others weren't...". ${ }^{\mathrm{PU}}$ Another public sector actant explained how an important element of success in getting this cross sector system going was when the public sector organisations "and the industry funders decided to front with money, decided to share dollars, share resources and enter into an agreement to actually do it..." (Sector Interaction - Working Together). ${ }^{\mathrm{PU}}$

Further issues that needed to be solved before organisations could work together included determining which organisation was going to be controlling the system. As a 
private sector actant found "they all want to own it and run it and share it and be in charge and so, it's taken a while to get there". PR Problems also arose with the sharing of benefits as they were seldom shared equally between organisations, requiring careful negotiation as a private sector actant explained:

"If I said to my supplier 'well I want you to just add that cost and I'm not going to pay more and I'll have all these wonderful benefits and screw you', well you might actually get cooperation but you're not really getting cooperation. What you are actually getting is compliance and there's a big difference between the two. Compliance doesn't enhance the relationship, cooperation does. So go back to that supplier and say 'look, we figure out that we are going to probably save 40 cents a unit, we will share it with you', and people are much more inclined to work that way. If you pay people peanuts don't be surprised if they act like monkeys." (Sector Interaction - Working Together). ${ }^{P R}$

It was also suggested by a private sector actant that the inclusion of a neutral third party was of assistance in this negotiation process. The actants organisation had found that where "a [neutral] organisation works to facilitate work groups and groups of organisations to move forward... it seems to work and work well..." (Sector Interaction - Third Parties). ${ }^{\text {PR }}$

Disagreements were seen to arise from arguments about who will supply technology, and support the cost of implementation "along the lines of who's going to be the supplier, what particular kind of RFID is going to be used, what's it going to cost"PU according to a public sector actant. Similarly a private sector actant discussed the place of the public sector in subsidising or funding RFID systems. Where public funding was not available the actant noted "in countries where there is government funding available, it's much easier to move industry forward in collaboration with government" (Sector Interaction - Public Funding). ${ }^{\mathrm{PR}}$ This actant also outlined difficulties surrounded the location, and organisation, of data storage with:

"Different folks have different points of view... distributors for example, who have acted as information brokers [in the past], and they are more accustomed to saying 'oh we'll handle all the data for you just send it all to us and we will 
take care of it'. Whereas some are advocating 'no no no, this data is more accurate if it stays where it was created and we just need a mechanism to bring it all together' ${ }^{\prime \prime .}{ }^{\mathrm{PR}}$

On occasions the private sector was seen to provide services to the public sector, as a way of promoting their products. One public sector actant explained how in one system "any money which came in was [from a private sector company], which was a technology company. [They] wanted to promote their product" (Sector Interaction Private Funding). ${ }^{\mathrm{PU}}$

It was also found that getting agreement to implement RFID systems required persistence on the part of the various organisations, as one private sector actant related "that's a lot of... door knocking and a lot of meetings and a lot of discussions, and it isn't always obvious... Sort of like the invention of the flywheel, you keep pushing it and pushing and eventually it spins all by itself" (Sector Interaction - Getting Agreement). ${ }^{P R}$

The way the two sectors interacted was contrasted by a private sector actant who pointed out that the "way the government interacts with industry is regulation, and the way industry interacts with government is politics". ${ }^{\mathrm{PR}}$ This actant went on to explain how the private sector was resisting politically mandated RFID systems in a particular instance and had:

"Lobbied very hard to have no such mandates on them, because should the government pass such a law or create this regulation the implications are huge. In the private industry it is hard to do the same because private companies don't have the same clout. Private companies can create regulations in a couple of ways, one is self-regulation, and one of the aims of that is companies coming together and creating a regulation that they will adhere to. They do that to pre-empt government action." (Sector Interaction - Organisations Working Together) ${ }^{P R}$

Where the private sector managed to gain momentum on an issue, one private sector actant working to get legislation in respect of one system had found that you were 
"more likely... to get the Minister's attention or somewhere in that level" (Sector Interaction). ${ }^{\mathrm{PR}}$

However, in one instance the public sector was reluctant to become involved because of concern that the private sector would walk away from the RFID system, as one private sector actant explained:

"There has always been support at the political level and then it really just became a matter of persuading officials that they weren't going to be left holding the baby which essentially was their fear. It was that we would go ahead with a hiss and a roar, [the industry group] would throw their toys, there would be mutiny, and they would be left trying to administer a scheme which was a disaster area because we would all walk away." (Sector Interaction). ${ }^{P R}$

In summary, the interaction between public and private sector was complex with a number of different aspects apparent. At a superficial level, the perception of organisations was mostly negative on both sides, with the public sector seen as being slow, short of funds and bound by procedure. The private sector on the other hand was seen as being more concerned with competitive advantage and less willing to collaborate for this reason. Differences were perceived to arise as a result of the political cycle and the different organisational focus of the two sectors. Similarities arose in the nature of individuals working for the different sectors with familiarity increasing this sense. Comments were also made as to the role of government, which was seen primarily as a regulatory one, although suggestions were made in respect of the provision of education and funding for RFID systems. Despite the tension between the two sectors a number of successful RFID implementations gave rise to some guidelines for success in implementation, including getting all parties together to negotiate agreement, and the sharing of resources. However, the need for both sectors to collaborate more around RFID systems was also emphasised. 


\begin{tabular}{|l|l|}
\hline Code & Description \\
\hline Sector Interaction & $\begin{array}{l}\text { Observations about the interaction of organisations in } \\
\text { the RFID network. }\end{array}$ \\
\hline $\begin{array}{l}\text { Sector Interaction - Getting } \\
\text { Agreement }\end{array}$ & Organisations work together to get agreement. \\
\hline $\begin{array}{l}\text { Sector Interaction - Individual } \\
\text { Based }\end{array}$ & $\begin{array}{l}\text { Where individuals are seen to represent } \\
\text { organisations. }\end{array}$ \\
\hline $\begin{array}{l}\text { Sector Interaction - Perception } \\
\text { of Public Sector }\end{array}$ & $\begin{array}{l}\text { How the public sector is seen or perceived, either by } \\
\text { the private sector, or within the public sector. }\end{array}$ \\
\hline $\begin{array}{l}\text { Sector Interaction - Perception } \\
\text { of Private Sector }\end{array}$ & $\begin{array}{l}\text { How the private sector is seen or perceived, either by } \\
\text { the public sector, or within the private sector. }\end{array}$ \\
\hline $\begin{array}{l}\text { Sector Interaction - Public } \\
\text { Funding }\end{array}$ & $\begin{array}{l}\text { How organisations pursue or obtain public sector } \\
\text { funding for RFID implementations. }\end{array}$ \\
\hline $\begin{array}{l}\text { Sector Interaction - Public- } \\
\text { Private Comparison }\end{array}$ & $\begin{array}{l}\text { Comparison of public and private sector } \\
\text { organisations. }\end{array}$ \\
\hline $\begin{array}{l}\text { Sector Interaction - Public- } \\
\text { Private the Same }\end{array}$ & $\begin{array}{l}\text { Where public and private sector organisations act or } \\
\text { are perceived to act in the same way. }\end{array}$ \\
\hline $\begin{array}{l}\text { Sector Interaction - Role of } \\
\text { Government }\end{array}$ & $\begin{array}{l}\text { The perceived or stated role of government within the } \\
\text { RFID network. }\end{array}$ \\
\hline $\begin{array}{l}\text { Sector Interaction - Third } \\
\text { Parties }\end{array}$ & $\begin{array}{l}\text { How the implementations or systems work with third } \\
\text { parties (parties that might not normally be involved } \\
\text { with the network) }\end{array}$ \\
\hline $\begin{array}{l}\text { Sector Interaction - Working } \\
\text { Together }\end{array}$ & How the organisations work together. \\
\hline Tab 3:Code Tabe Sect Intertions & \\
\hline
\end{tabular}

Table 3: Code Table Sector Interactions

\subsection{An ANT/Institutional Approach to Organisational Interactions}

As the focus of this study is at the organisational, or institutional level, it is appropriate to consider the behaviour of organisations as actants. To facilitate this understanding Institutional Theory has been added as an additional lens through which to assist in interpreting the findings, as outlined in Sections 3.2 Institutions, Institutional Theory and ANT; and 3.3 Institutional Theory. This section will discuss the findings in terms of a combination of ANT and Institutional Theory, focusing both on the institutional pressures apparent in the network, and on the responses organisations have in respect of institutional pressures ${ }^{11}$. These responses, outlined by Oliver (1991b), have been mapped with the ANT responses to problematisation suggested by Latour (1987),

\footnotetext{
${ }^{11}$ As with the ANT discussion, coding will not be detailed in this section. It can be assumed that quotes under each heading are coded to that heading.
} 
and the diagram thus produced in Section 3.3 (page 72 ) is reproduced below for convenience: This figure

demonstrates the close

relationship between the ANT

actant responses to an offer of

enrolment and the Institutional

Theory responses to institutional

pressures. As this section is less
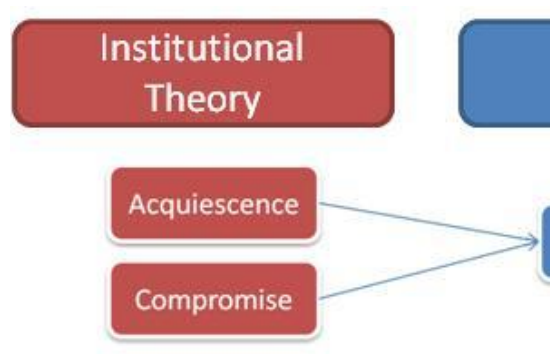

Avoidance

Acceptance

Avoidance

\section{Defiance}

Manipulation

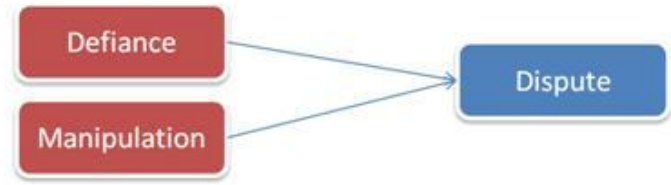

Figure 12: ANT and Institutional Theory Responses

each quote is coded to its associated table.

\subsubsection{Coercive Pressures}

The most obvious, and strongest, institutional pressure evident in the RFID network was that of coercive pressure. It was mainly apparent around the various legislative and regulatory requirements placed on RFID systems in this context. Where an RFID system had been implemented, and legislation was already in place, the coercive effect of the legislation was seen in the problematisation where it framed the shape of the proposed solution. When this happened legislation became an obligatory passage point to the ANT translation, as discussed in Section 4.1.2 above. In a number of systems studied, legislation was brought to bear because it was felt that compliance at a national level was necessary for system effectiveness. As one actant observed “there's absolutely no point in creating something like this [system] if you don't have compliance". ${ }^{P R}$ Coercive pressures were also exerted at the request of industry. In one of the systems studied it was "industry [which] went to government and said, you've got to do this, or you've got to help us do it... it will never work voluntary” ${ }^{\text {PR }}$, although it was perceived that "the cost of doing that was to have the government involved"PR, where the organisations would otherwise have preferred to have voluntary participation. 
A range of legislation exerted coercive pressures on RFID systems not only that which directly mandated involvement in RFID based implementation. Examples included privacy legislation, which varied by jurisdiction although it was felt that privacy concerns were likely to give rise to "more controls"12PR than those already in place. Food safety laws also affected RFID systems where "new food safety laws... [have] put some fairly heavy requirements on transportation of food, and protecting food safety". PU One actant related how "truckers and truck fleet owners are getting more and more concerned... about the cargo" ${ }^{\mathrm{PR}}$ due to food safety and liability regulations, and this was driving implementation of RFID sensor systems. Similarly, requirements to be able to provide Customs data "such as who manufacture it, or grew it, who's shipping it, who's it shipped to..." ${ }^{\mathrm{PU}}$ were driving implementation of RFID container and pallet tracking systems in some jurisdictions. Although legislation mainly acted at the problematisation stage, where legislation changed, or new legislation was introduced, existing RFID systems could also be affected, causing changes to RFID systems in place.

Other non-legislative coercive pressures were seen to be applied, in the form of larger organisations setting mandated requirements to use RFID tags within their supply chains. As related by one actant, an organisation had instituted:

"... a mandate, we had to tell vendors to do it. This was not a 'would you like to put RFID tags on', we worked with the vendor community to come up with the formats and the technologies and stuff, but let there be no doubt that there was a mandate...". ${ }^{\mathrm{PU}}$

Self-regulation was also seen in the network, as an attempt to avoid government legislation. As one actant related, “... what will happen is the industry will try and fight this regulation until they think it is inevitable then they will try and staunch or stem the flow, or they will try and pre-empt it by passing some self-regulation...". ${ }^{P R}$

In other systems coercive pressures were applied to supply chain partners in the form of "incentives"PU to use the RFID system. In one system this was seen through the ability of suppliers "to get paid faster" ${ }^{\mathrm{PU}}$ if they used RFID technology. Despite such

${ }^{12}$ Privacy and RFID systems has been discussed from the literature in Section 2.6.5 
incentives, using non-legislative coercive means to obtain compliance was not always perceived as being positive. Some vendors were inclined to simply "slap the label on so that they can get paid" ${ }^{\mathrm{PU}}$ which was seen to lead to organisations "approaching RFID as just something I've got to do to get a tag on this..." ${ }^{\mathrm{PU}}$ rather than gaining business value from the technology.

\subsubsection{Mimetic Pressures}

Mimetic pressures were most obvious in the problematisation phase where organisations were seeking to decide the form their RFID systems would take. In these cases organisations would seek to discover what others were doing. In one instance RFID was chosen over bar-code systems "because everyone else around the world was kind of moving towards RFID it made sense for us to do that as well...". ${ }^{\text {PR }}$ Apart from following perceived industry best practice, the need for interoperability was cited as a reason for replicating RFID systems as "it is a lot easier if what you've got looks similar to what they've got, because then you don't have to explain quite so much about how the intricacies and technical stuff is slightly different to theirs...". ${ }^{\mathrm{PR}}$ This drive towards interoperability was also seen in the application of normative pressure, discussed below.

Organisations also kept a "watch on what is working well overseas, and is it translatable to [our environment]?" ${ }^{\mathrm{PU}}$ Not only in order to acquire ideas that might work well in their own organisations, but also to take note of technologies that were not working as "they can't make it work cost benefit wise over there, then we are unlikely to here...". PU

\subsubsection{Normative Pressures}

Although not common, there were some normative pressures apparent in the RFID network, particularly centred around attempts by industry to self-regulate through various professional organisations. Of particular interest is a recent initiative to create an RFID certification which will "provide comprehensive coverage of the fundamental information needed to understand the characteristics, proper usage, and implementation considerations for the primary types of RFID in use" (RFID Institute, 2013b). This certificate is supported by the RFID Institute which has the specific goal of promoting the "public good that comes from having industry and professionals 
achieve high levels of professionalism through the research, education, and development of the RFID science and knowledge-base; and validation of that knowledge obtained through professional certification." (RFID Institute, 2013a).

Normative pressures are also seen in other forms of self-regulation, either through membership of various professional organisations associated with RFID - such as standards organisations or the RFID Institute mentioned above; or through industry based self-regulation. These industry based regulations are seen to arise mainly from the desire to "pre-empt"PR coercive government regulation, although they can also be described as coercive pressure. Like mimetic and coercive pressures, normative pressure was mainly apparent in the problematisation phase of the translation, as it affected the form of the business case through industry requirements.

\subsubsection{Responses to Institutional Pressures/Enrolment}

As discussed in above sections both ANT and Institutional Theory recognise a range of actions that organisations/actants can take when confronted with either institutional pressures, or offers of enrolment to the network translation. These responses are similar enough that they can be mapped, and discussed together. They are considered separately from the public-private sector discussion as this section focuses on the response of the organisation rather than sector differences, or perception of sector. Because of the size of many of the RFID systems in which both public and private sector are involved (especially where involvement in RFID systems was legislated), there was often a wide range of different responses to institutional pressures and offers of enrolment, from "no" to "OK whatever" to "should have been doing it years ago", and these are discussed below.

\subsubsection{Acceptance/Acquiescence/Compromise}

In ANT terms when actants agree to the problematisation they are said to have accepted it. Similarly, in Institutional Theory when organisations agree to the institutional pressure they are said to acquiesce, although they may also engage in compromise through negotiation before they do so. These behaviours were clearly evident within the RFID network studied. 
The easiest way to achieve acceptance/acquiescence within the systems studied was through presenting the RFID system as being of benefit to the other organisations. One actant had related that in the case of his system the business case was so persuasive that it "did not need selling. People were going 'great! Let's get on with it'...". ${ }^{P R}$ As a result, the system was easily accepted. In another system involving an entry card system “...people were experiencing too many hours wait time... and you had a choice if you wanted to wait for two and a half hours [you could use the old system], or get in another lane which was 15 minutes [using an RFID card] with a tag in it...". ${ }^{\text {PR }}$ Again this system had proven popular due to the reduced wait time. This strategy of encouraging other organisations or individuals to join in the RFID systems was described by one actant as "the only strategy that ever works in those situations it's called mutual benefit". ${ }^{\text {PR }}$ Another organisation had encouraged supply chain partners to accept their RFID system by incentivising them through an offer to "pay the vendors faster if they used [our system]... now all of a sudden [our system] had the information that we wanted... all we had to do was give an incentive to the vendors". PU

Sharing of benefits was also seen as a way to gain acceptance of RFID systems, as explained by one actant:

"If I said to my supplier 'well I want you to just add that cost and I'm not going to pay more and I'll have all these wonderful benefits and screw you', well you might actually get cooperation but you're not really getting cooperation, what you are actually getting is compliance and there's a big difference between the two. Compliance doesn't enhance the relationship, cooperation does. So go back to that supplier and say "look, we figure out that we are going to probably save 40 cents a unit, we will share it with you", and people are much more inclined to work that way." ${ }^{\mathrm{PR}}$

A range of compromises were also used within the RFID systems studied. Compromise was seen to be facilitated by:

"being able to genuinely... sit in the seat of the other player and know what's driving, what's going on in their mind, and what's affecting them... then you'll 
be able to understand how you will interact with them, and it's about being able to accommodate compromise or a bit of give and take, and not being obstructive." ${ }^{\mathrm{PU}}$

In one instance standards had been negotiated through "topic specific working groups, and they participate through... a community room interaction, document sharing, Internet sharing, meetings, online meetings... and we all agree that this is a best practice...". ${ }^{\text {PR }}$ Maturity of the organisations involved was also mentioned as a facilitator of cooperation with one actant relating how after initial tensions, competing organisations in the system "buried the hatchet"PR and decided to "get mature on this, that really working together was the only way forward.."PR

\subsubsection{Disregard/Avoidance}

Despite the involvement of the public sector in the RFID systems, and the presence of legislation in a number of instances, there were still some individuals and organisations that attempted to avoid or disregard the RFID network. As noted by one actant "... there's a percentage that [are] just going to go no...". PR In fact, the presence of legislation in most cases arose from the recognition that there was "...no point in creating something like this [RFID system] if you don't have compliance...". ${ }^{\text {R }}$ Such legislation was designed to reduce the number of organisations refusing to participate in the legislated system. The necessity and value of legislation in promoting compliance was noted by a number of actants, as was the need "to make sure the act is complied with through effective enforcement...". ${ }^{\mathrm{PU}}$

Even in non-legislated systems, the large organisations promoting them had mechanisms to ensure participation, as was noted in one system "... they [the private sector organisation] are driving mandates with penalties, and they are holding people accountable, which is something that the Federal government doesn't do a good job of...". PR In another case, incentives in the form of earlier payment encouraged vendors to agree to applying RFID tags to their items, reducing the amount of vendor avoidance.

At a staffing level it was apparent that some organisations were also having difficulties with individuals who were afraid of the RFID technology for a number of reasons. One 
actant related how it was "a juggling act as to who do we get involved, when do we get them involved. [Be]cause it's great if the CEO says go ahead and do it, but then [someone] on the shop floor won't pick up a reader for some reason because he's frightened of it...". PU Health and privacy concerns also caused individuals, and organisations to be reluctant to adopt RFID systems.

\subsubsection{Dispute/Defiance/Manipulation}

As with the tendency to disregard or avoid institutional pressures, or the invitation to enrolment, many organisations had limited capacity to dispute, defy or manipulate circumstances around their involvement in public-private RFID systems, due to the legislated requirement for them to be involved. This did not mean that organisational involvement was enthusiastic, as observed by one actant "... the companies only do it [participate in the RFID system] to the extent that they are liable from a law point of view, and so the government regulates and the companies try to fight it until they realise they are liable...". PR

The form that the attempted manipulation, or disputes, often took was that of lobbying. This occurred especially "when [organisations] don't see the value, they are pushing back" ${ }^{\prime \mathrm{PU}}$ in order to prevent RFID related legislation. In one instance an actant observed "the [government department]... they have contemplated RFID mandates, and the industry is very worried about it so they have lobbied very hard to have no such mandates on them...". ${ }^{\mathrm{PR}}$ In this instance some organisations already had proprietary systems in place, which also strengthened resistance to legislation as "those who have got the proprietary system that's in there are now going to have their livelihood threatened... and tell the government first it shouldn't be interfering...". ${ }^{P R}$

Where legislation was not in place, or in instances where legislation was being debated organisations were very active in attempting to manipulate the final form of the legislation, or in trying to ensure legislation was not enacted. As one actant who had been involved in legislating an RFID system noted, another organisation was set on "derailing [the system]... because they just saw this as a cost to [their members]". ${ }^{P R}$ In another instance an organisation had "objected to the death that the minister had 
[a particular] power..." ${ }^{\mathrm{PR}}$, which was opposed because it could cause the organisation to change its business processes.

Others recognised that legislation in some cases was inevitable even though they did not agree with it. As one actant related "I think [what] we are facing now today in regard to RFID is certainly the privacy issue, and I think that... we're going to get regulated in some way... I'm pretty certain that I don't think it's the right thing, but it's going to happen...". ${ }^{P R}$ In one RFID system studied, industry "were also starting to push back because they were sick of providing the same information to multiple agencies..." ${ }^{\mathrm{PU}}$, and wanted changes to include RFID legislation.

In one instance, an organisation had been heavily involved in attempting to manipulate the final outcome of RFID based legislation. As one actant recalled "...we were in the odd position of having to talk the government out of being involved in it in terms of being an industry based scheme, and then having to talk them back in to being involved in it for the funding...". ${ }^{\text {PR }}$ However, despite the organisation's involvement they still had some members who did not want to be involved in the RFID system at all and took the view that "... no you can't do that...", defying any attempt at enrolment. $^{P R}$

\subsubsection{ANT/Institutional Theory Summary}

In summary, Institutional Theory provides an additional understanding of what is happening within the RFID network, by focusing on the way organisations respond to pressures applied to them.

Coercive pressures were apparent in the presence of both legislation, and industry self-regulation. Self-regulation also presents as a normative pressure, especially when regulation arises from RFID standards bodies. Mimetic pressures appear as a result of organisations looking to others to determine best practice, and to determine what not to do.

The responses of organisations to institutional pressures were aligned with the ANT responses that actants display as a result of an offer of enrolment. Again, all the responses proposed by Latour (1987), and Brown (1997) were evident in the RFID network. Where organisations had accepted the offer of enrolment, or had acquiesced 
to institutional pressure, it was apparent that the benefits of RFID systems had been identified, and most parties were seen to be able to benefit from them. Often this position had been arrived at through compromise. Alternatively where legislation mandated involvement, organisations accepted this, but some chose to do the bare minimum towards compliance, often because they could not recognise any benefit in the RFID system proposed.

At times organisations resisted or defied attempts to get them to enrol in RFID systems, especially where they were not mandated. Individuals also objected to RFID systems, generally on the grounds of fear, or health concerns.

Some organisations were also involved in actively disputing/defying or attempting to manipulate the problematisation offered, or the institutional pressure applied. This behaviour was most obvious where legislation was being proposed, but had not been enacted, and was directed at either preventing or amending the legislation.

\subsection{Summary: Organisational Interactions}

This chapter has focused on answering the research question How are public-private RFID systems established and maintained?, and RQb: What role does institutional behaviour play in the process?

ANT allows this study to answer the first research question by viewing RFID systems in the public-private sector context through the ANT process of translation. ANT views the establishment of the RFID network as moving from defining the problem in the problematisation stage (to which the use of an RFID system is the answer), through the interessement of other actants and their enrolment, to mobilisation and stability of the resulting RFID network. During this process, mediators, discussed in the Findings chapter advised, influenced, and at times destroyed the actants' attempts at translation.

Problematisation was characterised by actants debating various aspects of the problem including standards, infrastructure, cost, and whether or not their particular RFID systems needed to be legislated. These debates led to the problematisation being framed in the form of a business case, which then became an obligatory passage point (OPP) for the remainder of the translation. Standards and legislation were also 
seen to act as obligatory passage points for the RFID systems studied. Where legislation was deemed necessary by the problematisation, interessement included the industry actants involving government in order to have this legislation enacted. Other features of interessement included the original focal actants attempting to persuade others to join the translation. They mainly used the perceived benefits of joining as inducements, with concerns around cost, privacy and trust being seen to be challenges to persuading others to join the translation. During enrolment debates continued around how the different actants were going to work together, and who was going to control various aspects of the RFID system. Because of the size of most of the systems studied these debates were on-going, and represented the complete spectrum from total agreement with the problematisation, to total opposition. Where systems involvement was legislated the requirements of the regulation framed the shape of the enrolment. Process changes, and the organisational management required to implement RFID systems, were seen as major organisational challenges. The final mobilisation saw actants being able to delegate for each other, and the realisation of benefits. Some of the benefits were those promised in the original problematisation, whereas others had not been originally envisaged. Not all mobilisations were stable, particularly where RFID systems were not legislated, or where the problematisation had not been well considered.

Overlying the story of translation is the way the two sectors act towards each other. Their relationship is complicated, and driven initially by preconceptions each sector holds about the other. The public sector is generally viewed by the private sector as being slow and unwieldy, and the private sector is viewed as being focused on competitive advantage. However, as the organisations worked together through the process of translation, their attitudes changed and sector differences became less important. Nonetheless, there were still differences apparent. This was particularly evident around sensitivity within the public sector to legislation already in place, mainly in respect of privacy legislation.

Interactions between organisations, apart from those arising as a result of different sector requirements, can be best viewed through the lens of Institutional Theory, thus addressing research question $1 \mathrm{~b}$. All three institutional pressures are apparent, with 
coercive pressures in the form of legislation (and mandates in non-regulated RFID systems), being the most commonly seen. Mimetic pressure is particularly apparent when organisations are looking to determine the solution they will adopt, as are normative pressures which appear to be exerted mainly by standards organisations. All three Institutional Theory pressures are most apparent during problematisation, though coercive pressures particularly, persist throughout translation.

The responses of organisations on being offered enrolment in the ANT process of translation, and the responses of organisations to institutional pressures can be considered to be congruent. All three ANT responses (accept, disregard, and dispute), and five Institutional Theory responses (acquiescence, compromise, avoidance, defiance, manipulation) are seen in this study. Acceptance/acquiescence/compromise were seen to be most associated with those actants who could see the benefits of the RFID system, or where involvement was legislated. Disregard/avoidance/ behaviour was apparent in RFID systems, even when the systems were legislated. Some actants simply refused to participate. This was particularly apparent with some individual actants who were reluctant to participate in RFID systems due to concerns about health and privacy implications. Actants also attempted to dispute/defy or manipulate translations from the private sector side, primarily in the form of lobbying in order to have legislation changed. A certain amount of dispute was also apparent through minimal compliance with legislation or mandates, where organisations would merely add tags to the requisite items, and not attempt to gain any other benefit from RFID systems. 


\section{Findings: Mediation of RFID Systems}

Within the RFID network a number of mediators were apparent, influencing the way the actants behaved, affecting network stability. Mediators were the common themes that were seen to influence the network in sometimes unexpected and disruptive ways. They were also the most frequently discussed issues seen in RFID systems, or they arose most often when describing change or influencing decisions. Mediators could suddenly alter the course of an RFID system, change, or even destroy it. Some mediators were obvious and strong, such as financial considerations. Others were subtle but still important within the public-private context.

The mediators were sorted into the three dimensions listed below, depending on where in the network they were most influential, and/or most frequently seen:

- Network mediators acted across the entire RFID network and were identified as finance, infrastructure, standards and organisational knowledge. They were seen both within and between organisations and were the most commonly discussed mediators;

- Inter-organisational mediators acted primarily between organisations, and were identified as privacy, security, trust and data sharing. These mediators were discussed in connection to relationships and actions taken between organisations, and where it was necessary to secure inter-organisational agreement or action; and

- Intra-organisational mediators were most influential within organisations, and were identified as organisational management, data management, and benefits/business case. These mediators advised organisational decision making around the RFID network, and forming the basis of network success or failure.

Figure14 below shows a summary model of these mediators, illustrating how they fit together within the RFID network: 


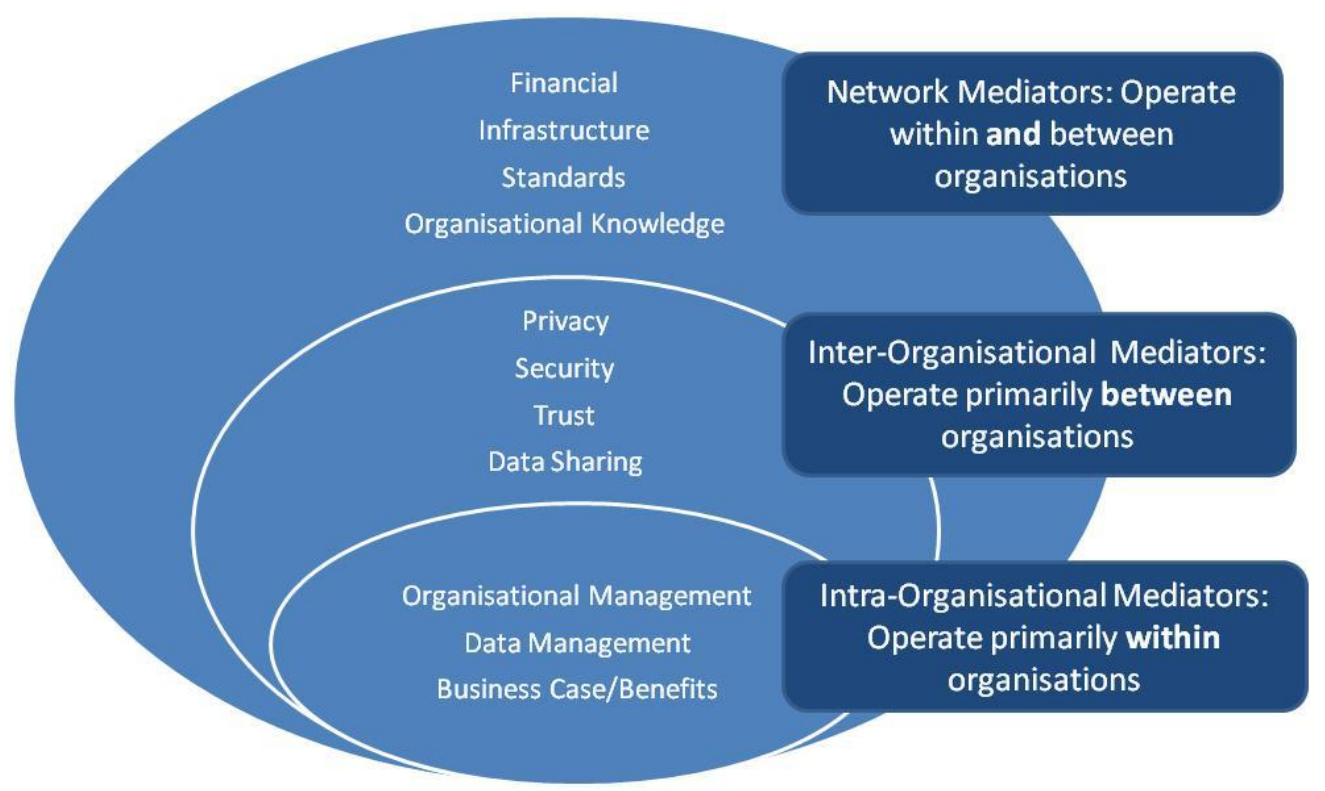

Figure 13: Mediators of the RFID Network

This section of findings will be discussed in the three dimensions outlined above. The mediators seen within each dimension will be considered separately, along with a breakdown of the descriptive, in-vivo, and process codes which were grouped to form the mediator. Each quote will be followed by the code it was assigned, and each section will end with a table summarising and describing the codes. Some quotes appear more than once, as they have been coded to more than one group. This is especially true of cost, where cost is relevant across a wide range of different mediators, as well as being a mediator itself. Thus cost of infrastructure, for example, may be discussed in both the cost sections and the infrastructure section. Differences in the way the mediators work in the two sectors are also touched upon, and are discussed in full at the end of the mediator's section under Organisational Interaction.

\subsection{Network Mediators}

Network mediators operated across the entire RFID network. They were present both within organisations, between organisational sections or departments, and between organisations. These mediators were active participants in either driving the entire network forward, or as primary causes of its failure.

\subsubsection{Finance}

Central to every RFID system studied was discussion surrounding finance. This was mainly manifest as the cost of RFID systems, or in the case of documentary actants, as 
financial spreadsheets, breakdowns and cost analysis. By far the most widely and frequently discussed of all the mediators, finance, and cost, was mentioned by almost all actants and was important to both public and private sectors. A number of different aspects of finance were apparent including the cost of RFID infrastructure, and systems compliance. There was also discussion of the allocation of costs between organisations, as well as the imposition of cost caused by legislated RFID systems.

The cost of RFID infrastructure, especially of RFID tags, was recognised across the whole network. "There's cost involved as soon as you start asking people to put stuff on [objects] then they will probably want them back unless they are at a price that can be thrown away" (Finance - Cost) ${ }^{\mathrm{PU}}$. It was apparent that persuading customers to accept the cost of tags was difficult, even when that cost represented a minimal investment relative to the price of the item being tagged. One actant related that he dealt with organisations that owned costly assets yet still took the position that "I'm not going to put a $\$ 20$ tag on, that's wasteful" (Finance - Cost) ${ }^{P R}$.

This struggle to have the cost of RFID tags accepted became especially apparent when comparing the cost of RFID tagging against the older established bar coding systems. Bar coding was largely seen as being "free" as barcodes "cost... nothing or almost nothing, and you can print the label on the can... But, RFID tags cost a lot more even if you're doing huge volumes you are still a few cents versus a fraction of a cent or less..." (Finance-Cost/Barcode Comparison) ${ }^{P R}$.

Outside organisational boundaries, the allocation of the cost of RFID implementations between participating organisations was of concern to those attempting to extend the scope of their RFID systems. "If cost wasn't an issue, of course everyone would do it" (Finance - Cost-Sharing) ${ }^{\mathrm{PU}}$. This was often highlighted as cost was seldom spread evenly among organisational participants in an RFID system. In one instance participation in an implementation was limited as "there are other companies that were interested in participating but could not, or would not, have the funds..." (Finance-Cost Sharing) ${ }^{\mathrm{PR}}$.

The allocation of cost was of concern to the public sector, especially where compliance costs were imposed on organisations by the necessity to comply with RFID 
based legislation. The importance of aligning costs with benefits gained by the use of RFID systems was highlighted by one public service actant who noted that his organisation was "very careful about imposing a compliance cost without really proving the benefit" (Finance Cost Imposition) ${ }^{\mathrm{PU}}$.

From the point of view of the private sector, these compliance costs were not always seen as justified. One private sector actant summarised the views of those involved in a legislated RFID system by pointing out that the system struggled because "the benefits were not focused on [private sector] benefits, but they [the public sector] expected the [private sector] to take a lot of the cost" ${ }^{\mathrm{PR}}$. In these cases the private sector looked to the public sector to provide funding for RFID systems that were being mandated as described by one private sector actant:

"...the industry wanted the ID system, and the industry wanted the government to legislate for it so it was mandatory. The system was a biosecurity insurance policy for the good of [our country]. Therefore, in my view, [our country] should pay for it, not just those implementing it". (Finance Cost Imposition) $)^{P R}$

In one legislated asset tracking example studied, some of the cost had been borne by the public sector. This cost sharing was considered to "make everybody more willing to come to the table" (Finance - Cost Sharing) ${ }^{\mathrm{PU}}$. As a result the system had progressed more smoothly than had been expected.

Criticality of the RFID system was also a factor in obtaining public sector funding for RFID systems. The level of importance of the system involved was seen to influence whether the public sector would contribute to, or even care about, the cost of the application:

“...where the government is after RFID [it] usually goes after things, applications, that are extremely related to national security, and so to some extent this lack of sensitivity to cost is justified." (Finance - Criticality) ${ }^{\mathrm{PR}}$

While finance seemed to be less of an issue for nationally critical applications, in other areas the public sector was attempting to be more cost efficient. This was seen to be 
linked to the recent economic recession with one actant noting that "funding just kind of disappeared" ${ }^{\mathrm{PU}}$ on his RFID system when the recession hit (Finance - Funding)

Further, the private sector perceived the public sector as being unwilling to finance RFID systems even when the business case was persuasive. In one instance a private sector system implementer related a case where he had sought public sector funding on a project where "...payback is one year, a one year payback. But it means investing 3 to 5 billion dollars in order to get 3 to 5 billion dollars [in the first year], and oh by the way you get 3 to 5 billion every year in payback. You make a onetime investment with a minor operating [cost], and they are not going to do it" (Finance - Funding) ${ }^{P R}$. However, reluctance to spend on RFID implementation was not limited to the public sector. A private sector actant related the difficulties of balancing systems costs with the capability provided, and found that at times "we can inevitably solve the problem. [But], either it is going to cost some more money than what they want to spend; or the compromises we are going to put into effect are going to hurt them in other ways" (Finance - Funding) ${ }^{\mathrm{PR}}$. Despite all of the discussion about cost, it was recognised that costs of RFID systems would decrease over time, as they had with other IT based technologies:

“... the tags are too much, the tags don't work well enough and the readers are far too expensive... with decades of watching how electronics develop my projection was, yes readers might be expensive today, they won't be tomorrow..." (Finance - Cost Infrastructure) ${ }^{P R}$

In summary, concerns about finance underpinned the entire RFID network through both public and private sectors. Where applications were perceived as critical, finance while still important was less of a factor. Strained economic times limited spending on both critical and more commonly, non-critical applications. More generally, the allocation of costs between organisations was also of concern with cost seldom being shared equally. The public sector was conscious of costs incurred where regulation or legislation led to the mandating of RFID applications. In many instances private sector organisations felt this cost should be borne by the public sector. 


\begin{tabular}{|l|l|}
\hline Code & Description \\
\hline Finance - Cost & Cost associated with the RFID network. \\
\hline $\begin{array}{l}\text { Finance Cost /Barcode } \\
\text { Comparison }\end{array}$ & Comparison of the cost of RFID and Barcode systems. \\
\hline Finance - Cost Imposition & $\begin{array}{l}\text { How cost is imposed on one sector or organisation by } \\
\text { another. }\end{array}$ \\
\hline Finance - Criticality & $\begin{array}{l}\text { Cost of RFID systems and willingness to pay, related to } \\
\text { the criticality or otherwise of the system. }\end{array}$ \\
\hline Finance - Funding & Funding/financing of RFID systems. \\
\hline Finance - Cost Infrastructure & $\begin{array}{l}\text { Cost of RFID related infrastructure including tags, } \\
\text { readers, data storage etc. }\end{array}$ \\
\hline Finance - Cost Sharing & $\begin{array}{l}\text { Sharing and/or allocation of costs between members } \\
\text { of the RFID system. }\end{array}$ \\
\hline
\end{tabular}

Table 4: Code Table Finance

\subsubsection{Infrastructure}

Infrastructure was seen as fundamental to the RFID network, with the combination of RFID tags, readers, transmitters and data architecture providing the basis of network functionality. The effectiveness and efficiency of the network's infrastructure affects the usefulness of the individual RFID systems as well influencing how users perceive the systems, even though users don't always think about RFID infrastructure or realise its complexity.

From the point of view of users, the importance of ease of use of RFID infrastructure was highlighted in a number of instances. Being able to "[easily] affix [a tag] without cost or training or anything else, and the tag will work $100 \%$ of the time ${ }^{\prime \mathrm{PU}}$ was considered highly desirable (Infrastructure - Tag). Simplicity of systems design was also valued:

“... you have got to keep it absolutely as simple as possible. If you start trying to get clever with writing stuff and reading stuff then you put a lot more pressure on your physical layout, your processes, your speed and all the other things that come into it." (Infrastructure - Design) ${ }^{\mathrm{PU}}$

Further barriers were related to configuration of various parts of the infrastructure including readers. In one public sector system the organisation struggled with "can it reach... does orientation matter" (Infrastructure-Design) ${ }^{\mathrm{PU}}$. Difficulties were also encountered where systems were expected to operate in challenging environments 
including "[around] metal and a lot of moisture laden environments, cold environments, environments where there might be a lot of machinery..." (Infrastructure-Environment) ${ }^{\mathrm{PR}}$.

Where the design of the RFID infrastructure was perceived as being poor, the organisations involved struggled to persuade employees to use systems. In a health care system, where multiple passwords were required to access asset information, difficulties were encountered with persuading employees to use the systems. Instead the project manager changed the hardware interface ensuring there was a "touch screen on every floor, so they can easily locate where [the asset] is and go there"

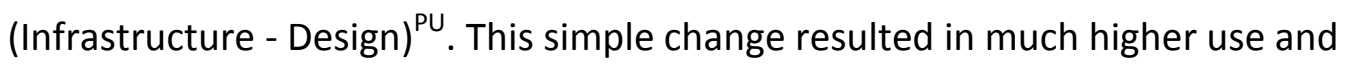
acceptance of the asset tracking system.

Another important dimension of infrastructure ease of use was compatibility with partner systems. The use of infrastructure standards was seen to "make it a lot easier if what you've got looks similar to what they've got" (Infrastructure - Standards) ${ }^{\mathrm{PR}}$. The standards used by other organisations also influenced infrastructure choice as other organisations were "moving towards RFID it made sense for us to do that as well..." (Infrastructure - Standards) ${ }^{\mathrm{PR}}$.

Cost of infrastructure was also of concern, as has been previously reported, although it was recognised that infrastructure costs would drop as the technology became more common, in a similar way to that seen with Internet infrastructure:

"You harken back to the days before you could affordably put in a network. It was very expensive to put in a switch and a router and data was slow. I can still remember dial-up days. I think RFID is at that point where it is dial-up mode still for most users." (Cost - Infrastructure) $)^{P R}$

Problems also arose with the integration of RFID based data into existing enterprise systems, with “legacy systems that don't provide for [data integration because] the data structures don't comply or integrate easily with the systems or the solutions that they are looking for" (Infrastructure - Design) ${ }^{\mathrm{PR}}$. The very nature of RFID data, and its high level of detail caused difficulties. As one organisation found: 
"The technology is a lot more complicated, it is a bit more expensive initially. There are the issues... particularly around item level, 'crickey I have got to capture that data, this is a level of granularity which I have never dealt with before. My ERP doesn't support it...'" (Infrastructure - Design) ${ }^{P R}$

Beyond issues arising with the implementation and operation of the technology itself, concerns were also expressed by individuals regarding possible health consequences from exposure to RF radiation. This was cited as a possible barrier to acceptance of RFID systems by an actant speaking on behalf of systems implementation, although solutions were proposed including "RFID gear could listen before talking..." ${ }^{\text {PR }}$, where the readers would not turn on and query tags until they were triggered (Infrastructure - Health Concerns).

However, despite the issues outlined above, in general RFID based infrastructure was considered reliable to the point where one actant observed "RFID is yesterday's news. It just happens to be RFID because it's so well known, proven, reliable off the shelf stuff that works." (Infrastructure) ${ }^{\text {PR. }}$

In summary, infrastructure forms the framework of the RFID network. Although it is considered largely reliable, problems still occur with existing systems especially during systems implementation or in challenging environments. The importance of keeping the infrastructure design simple, and of standardising components as much as possible, was emphasised. This standardisation was seen as ensuring interoperability between organisational systems. In some ways, RFID networks were considered to be early in their development and parallels were drawn with the Internet where costs and technical problems experienced with Internet architecture eased over time. Infrastructure coding table follows: 


\begin{tabular}{|l|l|}
\hline Code & Description \\
\hline Infrastructure & Infrastructure associated with the RFID network. \\
\hline Infrastructure - Design & $\begin{array}{l}\text { Covers the design of the RFID system infrastructure, } \\
\text { placement of equipment and simplicity. }\end{array}$ \\
\hline Infrastructure - Environment & $\begin{array}{l}\text { Environment in which the RFID infrastructure is } \\
\text { operating, includes humidity, presence of metals, } \\
\text { location etc. }\end{array}$ \\
\hline Infrastructure - Health Concerns & $\begin{array}{l}\text { Health concerns associated with human exposure to } \\
\text { RFID systems. }\end{array}$ \\
\hline Infrastructure - Standards & $\begin{array}{l}\text { Standards related specifically to RFID infrastructure } \\
\text { tags, readers, transmission spectrum. Does not } \\
\text { include data. }\end{array}$ \\
\hline Infrastructure - Tag & $\begin{array}{l}\text { Infrastructure comments related specifically to RFID } \\
\text { tags. }\end{array}$ \\
\hline
\end{tabular}

Table 5: Code Table Infrastructure

\subsubsection{Standards}

"It's hugely complex, just standards setting alone." ${ }^{\mathrm{PR}}$

As discussed in the literature review, there is a significant body of research dedicated to the importance of standards in RFID systems, and indeed to standards in IT systems where integration across applications and platforms is required. The picture seen in the RFID network studied is also complex, as might be expected from the literature review.

Standardisation of both software and hardware infrastructure was discussed.

Hardware standards were seen to be important in ensuring interoperability of systems:

"If you are part of the supply chain [and] they have a different reader, and different tags that it's using, and yet I have to read every tag that comes in, with my reader. Therefore I need interoperability which is what the standard's world was for." (Standards - Hardware) ${ }^{\mathrm{PR}}$

Hardware standards were also seen as being important to ensure a minimum quality of hardware being used in RFID systems, mainly to ensure that systems worked with a "minimum standard of device..." (Standards - Hardware) ${ }^{\mathrm{PU}}$.

As with most elements of the RFID network, cost was also a factor driving the desire for common standardised infrastructure. Especially in the large systems where: 
“The [organisation] doesn't want to have to use different infrastructure for RFID in the same place. It doesn't make sense at all, it is too expensive and difficult to maintain and so on. So it wants a standard and a consistent standard." (Standards - Cost) ${ }^{\mathrm{PR}}$

Though it was noted by one actant that the standard needed to be flexible enough to make sure competition between suppliers was still possible ensuring "competitive pricing but not so much that the tags that [our members] ended up buying were worthless or didn't work or they were told they had the wrong ones" (Standards Cost) ${ }^{\mathrm{PR}}$.

Decisions surrounding standards setting were complex and contentious. Vendor organisations were perceived as not:

"[caring] about standards. They care about the standards at the hardware level, that is are your tags compliant, and is your reader compliant... The vendor community don't care about the data, they only care about does my tag work and can I read your tag with my readers" (Standards - Hardware) ${ }^{\mathrm{PR}}$.

Although this was not always the case with one actant being more concerned about data standards and sharing than hardware, pointing out that "it doesn't matter if the RFID tags that my refrigerator reads are completely different from the ones my car reads, that doesn't matter. What matters is that the communications techniques, [and the] data handling that we use becomes compatible at some point so that we can share information (Standards - Hardware) ${ }^{P R}$.

At the international level standards were seen by one public sector actant as being "great if you could just pick one"PU. The actant also observed that compliance with standards "is not always very strong... as they are generally voluntary anyway" (Standards-Compliance) $)^{\mathrm{PU}}$.

In order to solve the problem of participation in particular RFID systems, the public sector had legislated involvement in some instances, dictating standards in order to ensure interoperability between systems, and mandating participation. In cases where legislation was passed, non-human documentary actants became essential to the 
network as they formed the framework to which RFID systems had to comply. In respect of pressure brought to bear on the government to legislate in the case of RFID standards in health systems, one private sector actant observed that:

“... they're smart to say 'government you have to cough [up] some kind of standard here' because one corporation will have one, another corporation will have another etc, etc. So, when you have all those standards what you have is no standard." (Standards - Compliance) ${ }^{\mathrm{PR}}$

The criticality of the system was seen to be a driver of public sector legislation and standards setting, as one actant, speaking on behalf of security observed "I see the government highly involved, they are proposing cryptographic standards and whatever, they are not sleeping on this one" (Standards - Criticality) ${ }^{P R}$.

However, the public sector outside of the few public-private RFID systems, was seen as having "a general lack of understanding about any sort of standards" ${ }^{\mathrm{PR}}$. This was also discussed by others, and connected to the lack of interoperability between different departments by a one actant who observed that government departments in the actant's country had "standardised [department] ways of doing it, but they don't standardise across [departments]" (Standards - Public Sector) ${ }^{\mathrm{PR}}$.

At a high level, political manoeuvring between countries was seen as being a barrier to standards setting with some countries reluctant to use standards set in other countries, even though the need for standards at the international level was recognised:

"They know they need standards. No one wants just the [country 1] standards across [our association of countries]. You are never going to have [all our countries] agreeing to the [country 1] standards. They have got to find a way; so actually global standards [are] what everybody can agree to." (Standards International) $^{\mathrm{PU}}$.

In some cases standards had been mandated by default through what were described as "trade requirements" ${ }^{\mathrm{PU}}$. In these cases the use of particular systems or technologies was required before participation in the RFID system was permitted leading to a de 
facto standard being in operation (Standards - Setting). This was seen across both public and private sector organisations, with well-publicised examples including the United States Department of Defense, and Wal-Mart systems.

However, not all saw the need for standardisation. In the case of public sector departmental standards, the drive for single RFID data standards was seen as unnecessary "to install a one size fits all would sub-optimise what it is the [departments] are doing ${ }^{\prime \mathrm{PU}}$. Similarly in the private sector it was considered by one actant that some systems "don't need to adhere to anybody else's system. It's an in house closed loop thing and you can do whatever you like ${ }^{\prime P R}$. The internal nature of some private sector RFID systems was also considered to protect a certain amount of competitive advantage as private organisations did not want to run the risk of exposing proprietary information. When it came to supply chains in the private sector one actant speaking on behalf of standards discussed a number of instances where the actants organisation had "lost some customers that wanted to use [standards] because they suddenly realised that they are not committed to an open supply chain. They think that a proprietary approach is preferable because of the competitive risks around doing it in a standardised way ${ }^{\prime P R}$. The actant went on to outline the frustration felt with organisations that took this approach in their supply chains, pointing out that:

"If you are trying to do traceability for any reason then you have a vested interest in having a standardised language to exchange information from upstream suppliers. Or what about downstream consumers that actually wish to be able to find out information in a standardised way?" (Standards Proprietary) ${ }^{\mathrm{PR}}$

Similarly, in some public sector organisations proprietary systems were seen as being more secure with an actant pointing out that non-standard systems were less well known. This lack of familiarity meant "there's virtually no known attacks that are around for this [system] $]^{\prime P R}$. Consequently organisations that wished to breach security on their proprietary system would have had to spend "hundreds of thousands if not a million dollars to just develop a requisite set of (attacks)" (Standards - Proprietary) ${ }^{P R}$. 
In summary, standards were seen as extremely important within the RFID network and were seen to ensure interoperability, quality and lower costs. However, the need for standardisation was controversial to some extent, with parts of the network in the private sector preferring closed systems in order to gain competitive advantage. In the public sector some parts of the network liked proprietary systems as they felt they enhanced security. The selection of standards was also seen as being difficult with the number of standards available, and different partners preferring different standards being cited as problematic. Compliance with standards was variable, and the public sector had legislated standards in some instances to ensure compliance. In other cases, the standard was not legislated but was de facto mandatory as the standard had to be complied with before participation was possible in the RFID system.

\begin{tabular}{|l|l|}
\hline Code & Description \\
\hline Standards - Compliance & $\begin{array}{l}\text { Why and how organisations comply or decide to } \\
\text { comply with standards. }\end{array}$ \\
\hline Standards - Cost & Cost of implementing standards specifically. \\
\hline Standards - Criticality & $\begin{array}{l}\text { The need for standards related to the criticality of the } \\
\text { application. }\end{array}$ \\
\hline Standards - Hardware & $\begin{array}{l}\text { Standards, standards setting etc related to RFID } \\
\text { systems hardware. }\end{array}$ \\
\hline Standards - International & $\begin{array}{l}\text { Standards at the international level, including } \\
\text { international organisations. }\end{array}$ \\
\hline Standards - Proprietary & $\begin{array}{l}\text { Standards specific to a particular system, not } \\
\text { designed or intended to be shared outside that } \\
\text { system. }\end{array}$ \\
\hline Standards - Private Sector & $\begin{array}{l}\text { Standards related specifically to private sector } \\
\text { attitudes, systems and knowledge }\end{array}$ \\
\hline Standards - Public Sector & $\begin{array}{l}\text { Standards related specifically to public sector } \\
\text { attitudes, systems and knowledge }\end{array}$ \\
\hline Standards - Setting & $\begin{array}{l}\text { Setting of standards, including those shared between } \\
\text { public and private sectors. }\end{array}$ \\
\hline
\end{tabular}

Table 6: Code Table Standards

\subsubsection{Organisational Knowledge}

During the course of this study, it became apparent in the RFID network studied that the level of knowledge an organisation, and individuals, had about RFID systems was important. Although not every interviewee talked about the amount of knowledge an organisation had of RFID systems, and the literature only barely discusses it, the need 
for organisational knowledge was especially apparent when implementing, or looking to implement RFID systems. The need for organisational knowledge was shown in several ways from the necessity to ensure every level of the organisation understood their RFID system, to the need to educate clients and users to achieve this.

From the point of view of systems implementation, there was a need to ensure that systems owners understood and appreciated what they were installing, as well as having an understanding of the limitations of a particular system:

"We always make sure our customers understand the technologies that they are getting into...what it's going to provide you, what it's not going to provide, and by the way all we are really doing is collecting data, we are not solving a problem. So in order to solve a problem we have to change some processes. That's the kind of education that has to go ahead up front otherwise you're going to end up doing it much later and then there's going to be disappointment." (Organisational Knowledge) ${ }^{P R}$

The requirement for organisational knowledge was seen in both private (as above) and public sectors, as one actant observed "as with all things governmental we are spending a lot of our time just educating them on what that means, and how industry is using standardised identification for products today" ${ }^{P R}$. Even in organisations where there was some knowledge of RFID it was often necessary to educate higher level managers so they could "drive their systems in the same directions, and coordinate between them ${ }^{\mathrm{PR}}$. There was also a requirement to train those that were going to use the system in order to ensure "getting the data in right" (Organisational Knowledge Training) ${ }^{\mathrm{PU}}$.

The need to educate regarding the data entry was coupled with a feeling that organisations on the whole didn't "understand the effectiveness of the data and working with supply chain partners" (Organisational Knowledge) ${ }^{\mathrm{PR}}$.

Overall, the effort put into education had positive benefits especially in promoting involvement within the network as one actant found "I find you need to hand select who is going to participate and that they need to be educated in some sense, one to 
understand the project and its implications, but also to have something to encourage participation." (Organisational Knowledge) ${ }^{\mathrm{PR}}$.

Outside of the organisational use of RFID systems, there was also a recognised need to educate the general public about RFID technology and its use, to encourage acceptance and counter misinformation. Similar to the issue of the effect of RFID radiation on people, there was a reported perception amongst some individuals that RFID technology was going to be used to track individuals. One actant reported "every day I see somebody is talking about how RFID is the mark of the devil, how here in the US, new healthcare plan is going to require everybody to have [an] RFID chip embedded in them, and it goes on and on, and it's all wrong. So, how do I help educate people, on the benefits of this?" (Organisational Knowledge - Public Perception $)^{P R}$. This actant related how he countered misinformation with an effort to educate about the benefits of RFID:

"I start asking questions like 'how many of you have got frequent shopper cards in your wallet?' 'Do you realise they are tracking you with those frequent shopper cards?' 'How many of you have got a cell phone in your pocked - do you realise that you could be tracked with that?'; and in every case there will be people who go 'oh I didn't know that'. My answer is and it doesn't matter does it because they're not tracking you for bad reasons, it's things that are being done to help you achieve what you want to achieve..." (Organisational Knowledge - Public Perception) ${ }^{P R}$

In summary, the amount of knowledge an organisation had of RFID was found to reduce confusion around the implementation process. More knowledge also led to better outcomes for the RFID network in the form of understanding of the system, and better use of the data generated. Also an understanding of the business process change involved in the RFID systems assisted organisations with gaining full benefit from their implementation. From an individual point of view, education regarding RFID systems and capabilities was seen as necessary to counter negative perceptions regarding the technology. 


\begin{tabular}{|l|l|}
\hline Code & Description \\
\hline Organisational Knowledge & $\begin{array}{l}\text { The amount of knowledge an organisation has related } \\
\text { to RFID. }\end{array}$ \\
\hline $\begin{array}{l}\text { Organisational Knowledge - } \\
\text { Public Perception }\end{array}$ & $\begin{array}{l}\text { Perception the public has of RFID systems, and how } \\
\text { organisations respond to that perception. Includes } \\
\text { negative perceptions. }\end{array}$ \\
\hline $\begin{array}{l}\text { Organisational Knowledge - } \\
\text { Training }\end{array}$ & $\begin{array}{l}\text { Training provide to, or needed by, organisations in } \\
\text { order to understand or use their RFID systems. }\end{array}$ \\
\hline
\end{tabular}

Table 7: Code Table Organisational Knowledge

\subsection{Inter-Organisational Mediators}

Inter-organisational mediators were found influencing events between organisations. Although, like all mediators they could also act across the entire network, in many contexts, they acted predominantly in interactions between organisations or between organisations and other actants.

\subsubsection{Privacy}

Privacy was a multi-faceted mediator. It appeared across many aspects of the network from consideration of the privacy of individuals, to data and organisational privacy, or confidentiality. Despite these many aspects, privacy is still considered an interorganisational mediator as it was mainly active between organisations (or between organisations and individuals), rather than being considered of much concern within organisations.

The need for understanding of the level of privacy protection required for data collected by RFID systems, and the purpose of collecting that data, were extensively discussed. A level of uncertainty about how to handle collected data was apparent even though all the countries covered by the network had privacy legislation of some description in place. However, the level of protection offered by the privacy legislation, and the requirements on organisations to protect the privacy of their customers was variable.

This variable approach to privacy was seen to present difficulties where international borders were crossed by RFID networks:

“We don't really have a common international view or common legislation regarding the release of information provided for a particular purpose, or privacy constraints, and because we don't have a common international view, 
in the end most conversations around trade facilitation actually pivot on privacy as opposed to being facilitated by meeting privacy requirements." (Privacy - International) $^{\mathrm{PU}}$

Solutions to difficulties created by privacy concerns were considered to arise from having "a clear understanding of the purpose for which the information was collected" (Privacy - Purpose of Collection) $^{\mathrm{PU}}$. If a solution to the confusion surrounding international views on privacy definitions was to be found, it was seen to provide a platform on which other issues surrounding data and cost could be based:

“Once you've solved the privacy question then you would think the data and price questions become more easily answered, because it's much easier to talk about what the real value of the data is internationally when you overcome the issue of how we manage privacy."

As well as clearly understanding the purpose for which data was collected, the nature of the data being collected was also important. Data that could be connected to individuals or organisations was seen to require a degree of protection. Whereas, data that pertained merely to things was seen to be less sensitive. As pointed out by one actant "mangoes have no privacy, they are a vegetable or fruit... why would their privacy be infringed?" (Privacy - Nature of Data). ${ }^{\text {PU }}$

The ability to understand the data being collected, and to design privacy solutions, was seen to rest on understanding "what the technology can do, what it can't do, what it is designed to do, what it is designed not to do" ${ }^{\text {PR }}$. Although it was commonly recognised that this understanding was lacking in many organisations as one actant discussed "for most of [my customers] they don't really know what's going to happen and they don't really know the implications of what they are doing ${ }^{\prime P R}$. The actant went on to outline how it "usually ends up in discussions about how [the data] is being used, have you thought about any privacy aspects for what you're doing if that is even applicable" (Privacy). ${ }^{\text {PR }}$

Once data had been collected, tailored access, limited to only those who needed to access it for work related purposes was also identified as a component of good 
privacy. As a actant speaking on behalf of privacy explained "...if you have a database of all your customers you want to have that database only accessible by the people that need to access it for their jobs, you don't want it to be completely open so that anyone in the [organisation] can dip in and out" (Privacy-Access) ${ }^{\mathrm{PU}}$.

Different issues arose where data collected by RFID systems was stored out of the country where it was collected, in cloud based or distributed databases, with the organisation collecting the information being seen as being accountable for the privacy of that information:

"Just because they've stored it overseas, the [home] company is the one that collected it off the customers here, so the [home] company is the one that's responsible for that information." (Privacy - Data Storage) ${ }^{\mathrm{PU}}$

Privacy legislation was also a strong actant in this sense, with various legislations setting out the rights and expectations of individuals in relation to their personal information, where it was collected by IT systems including RFID systems. These various privacy and enabling acts were important participants, and immutable mobiles in the network, as were guidelines produced by organisations themselves as to how to handle customer information.

The sector of the organisation also played a part in the organisations approach to privacy. The public sector was seen to be more sensitive to privacy concerns than the private sector, "...the public sector may have issues around privacy whereas in the private sector issues of privacy while they are known, they are not so much of an issue" (Privacy - Sector Differences) ${ }^{P R}$. In part this difference was considered to occur because of the nature of the information being held by public agencies as "governments need to more carefully understand the privacy implications than private sector companies that sell to other businesses (as opposed to consumers)." ${ }^{\mathrm{PR}}$ This understanding clearly ties back to the need to understand the nature of the data that is being collected by RFID systems (Privacy - Nature of Data).

The lack of choice (or voluntariness) individuals face in the provision of information to public agencies was also seen as a reason for the increased sensitivity of public sector 
agencies towards privacy. Individuals were able to choose whether to interact with a private organisation whereas there was no choice with the public sector organisations, "if [the government] muck up how they handle your information, you've still got to keep handing them information..." (Privacy - Voluntariness). ${ }^{P R}$ This also applied to RFID systems where involvement was legislated. Public agencies within the network were careful to ensure the nature and types of information collected were separated and defined by the enabling act:

"Under the [enabling] legislation it is very clear in the purposes of the Act what exactly information collected can be used for, and it is very narrow... There is an entire section within it around rights of access to information and it quite clearly separates the personal from the impersonal, non-personal." (PrivacyLegislation $^{\mathrm{PU}}$

However, from the private sector point of view, industry generally preferred to selfregulate privacy, with one actant being of the opinion that "an important thing for us for the next probably two years is ensuring that governments don't step in and legislate or mandate [privacy] things that are not necessarily in the best interests...". ${ }^{P R}$ This self-regulation, coupled with data sharing agreements between partners was seen to facilitate information sharing as "you can get around the privacy concerns and everything else around the use of data because [organisations] should be in arrangements with their suppliers that [sharing of data] is okay to happen" (Privacy Self-regulation). ${ }^{\mathrm{PR}}$

In summary privacy was seen as an issue that is still to be resolved, especially in an international context. The different views various countries and organisations have about privacy was seen as an inhibitor to trade. However, some solutions were apparent within the network, especially where systems were based on data that was well understood, and procedures controlling access were in place. The public sector was found to be more sensitive to privacy issues than the private sector, possibly because of the nature of the data collected or the lack of voluntariness in its provision. Industry on the other hand preferred to self-regulate, maintaining confidence through partner agreements. 


\begin{tabular}{|c|c|}
\hline Code & Description \\
\hline Privacy & $\begin{array}{l}\text { General discussion of privacy associated with the RFID } \\
\text { network. }\end{array}$ \\
\hline Privacy - Access & Access to information or data, in the privacy context. \\
\hline Privacy - Data Sharing & $\begin{array}{l}\text { Relates to the privacy issues surrounding the sharing } \\
\text { of data and information between organisations or } \\
\text { individuals. }\end{array}$ \\
\hline Privacy - International & International privacy related issues. \\
\hline Privacy - Data Storage & $\begin{array}{l}\text { Privacy issues surrounding the storage of data, } \\
\text { including jurisdiction. }\end{array}$ \\
\hline Privacy - Legislation & Privacy Legislation, development and application. \\
\hline Privacy - Nature of Data & $\begin{array}{l}\text { The nature of data being collected or stored in RFID } \\
\text { systems. Its origin and sensitivity. }\end{array}$ \\
\hline Privacy - Private Sector & Privacy in the private sector context. \\
\hline Privacy - Public Sector & Privacy in the public sector context. \\
\hline Privacy - Purpose of Collection & $\begin{array}{l}\text { The purpose for which data was collected, or about } \\
\text { the relevance of purpose of collection. }\end{array}$ \\
\hline Privacy - Sector Differences & $\begin{array}{l}\text { Highlights the differences between sectors in their } \\
\text { treatment of privacy related issues. }\end{array}$ \\
\hline Privacy - Self-regulation & $\begin{array}{l}\text { Self-regulation of privacy matters, as opposed to } \\
\text { legislated regulation. }\end{array}$ \\
\hline Privacy - Voluntariness & $\begin{array}{l}\text { Covers the voluntariness of interaction with the public } \\
\text { sector. }\end{array}$ \\
\hline
\end{tabular}

Table 8: Code Table Privacy

\subsubsection{Security}

Security is considered to be a network mediator because of the different levels of the network at which security appears as a concern. From the consumer worrying about whether they will be tracked via an embedded RFID device, to the network security manager concerned about possible hacker intrusions, security appears as central to the RFID network.

Security displayed a number of different aspects depending on which layer of the RFID network was concerned. At the tag layer the necessity to ensure that "tag information is not available for everyone..." ${ }^{\text {PR }}$ was of concern. From the database perspective it was important to balance information availability with "...how tightly do you have to lock [information] down" ${ }^{\mathrm{PR}}$ as well as appreciating the different approaches to 
database location asking the question "do you centralise a database so that is better protected than using a distributed data approach?". ${ }^{\text {PR }}$ In any event the necessity to address each layer of the network individually was emphasised by an actant speaking on behalf of security, who pointed out "...it's quite important that you secure for each of those layers in a way that's appropriate to that layer." (Security) $)^{\mathrm{PR}}$

However, an in-depth understanding of the use of tags and data was seen as being integral to understanding the level of security required. In some instances it was considered un-necessary to secure information. In the case of an organisational vehicle identification program one actant observed that the actant's organisation "don't really care if our tags get used for somebody else's entry point". PU

Nor was security considered necessary in the case of information that was already publicly available, although security of the systems holding that information still needed consideration:

"Agencies are required to protect Official Information as well as any other information they hold. In practical terms this means protecting the confidentiality, integrity and availability of the information and supporting systems. Where published information and public websites are concerned the confidentiality principle is less relevant to the information itself but will still apply to the systems and systems management." (Security - Necessity) ${ }^{\mathrm{PU}}$

The nature of the asset being protected was also important in the consideration of security with one actant pointing out that "nobody has asked us to secure library books", PR although it is worth noting that RFID is commonly used in library applications. (Security - Necessity)

The public sector was generally seen as being more sensitive to the need for security, especially when interaction was required between non-secure and secure systems. One private sector actant described a project worked on where the public sector unsecured system would have been required to communicate with a secured system, and that RFID system failed as the organisation "balked because there was a need to communicate data upward from an unsecured to a secured environment, and they 
didn't want the two touching" (Security - Public Sector). ${ }^{P R}$ Although it was generally observed that public sector entities were more sensitive to privacy, some private sector entities were also security conscious. This largely depended on the nature of the private sector organisation, the type of data they dealt with, and the use of the RFID system they had installed, "I have some financial services customers in the private sector, and medical sector, they are highly sensitive to security" (Security Private Sector). ${ }^{P R}$

Further, from the public sector side in terms of using RFID systems for secure identification and compliance "The challenge for RFID or anything else in this space is to be sufficiently unique and carry sufficient data that people in compliance roles absolutely understand what they are dealing with and know that it is a legitimate consignment" (Security - Necessity). ${ }^{\text {PU }}$

However, the overall importance of at least some level of security was emphasised even where the application might not be thought to be particularly sensitive, as an attack on an organisations' computer network could disable their systems. One actant discussed the various ways RFID systems could be compromised and pointed out "I can actually bring your warehouse down if I send stuff that you've seen two weeks ago, your SAP system is going to cough that up real quick" (Security - Necessity). ${ }^{P R}$ The actant went on to discuss future use of RFID systems, particularly the Internet of Things model, where the actant warned that even home owners would have to think about how RFID systems worked, and how various elements of their households interacted:

"With the Internet of Things it's going to be a lot more complicated, and you also now have to think about how your appliances are going to interact with other people in your home, visitors, guests and so on, or maybe your cleaning services or your plumber... if your plumber is alone in the house and your fridge opens, or your jewellery box, you would want to monitor that very strictly." (Security - Internet of Things)

Despite security being seen as critical by those that discussed it, not every interviewee mentioned security, or the security of their systems. This may not be too surprising 
given that it was also recognised that security was not always central to every RFID system, "this is true for most information technologies that I know, that security is always an afterthought." (Security). ${ }^{P R}$

In summary, security was seen as being essential to some RFID systems, depending on the sensitivity of the data being held. The public sector was perceived as being more security conscious, although where data would be considered sensitive, both sectors were aware of security concerns. The perceived need for security very much turned on the nature of data being held, and the items being secured. However, the need to secure apparently non critical items was not always understood as the organisational effects of security threats were not always appreciated. Nor was the need to secure systems in order to ensure data integrity where the RFID generated data might be expected to play a part in authenticating the item being tagged.

\begin{tabular}{|l|l|}
\hline Code & Description \\
\hline Security & Security of or associated with the RFID network. \\
\hline Security - Internet of Things & $\begin{array}{l}\text { Security related specifically to the RFID in the Internet } \\
\text { of Things context. }\end{array}$ \\
\hline Security - Necessity & The necessity of security in particular RFID systems. \\
\hline Security - Private Sector & Security in the private sector context. \\
\hline Security - Public Sector & Security in the public sector context. \\
\hline
\end{tabular}

Table 9: Code Table Security

\subsubsection{Trust}

Trust was seen as necessary both between individuals and organisations, and between human and non-human actants in the form of infrastructure and data. Although trust is often seen as being connected with privacy and security, it is treated separately in this analysis as this is largely the way it was discussed by the various human actants.

Trust was perceived as the foundation of RFID based automatic identification with the view that "... we will only automate to the degree that we trust" ${ }^{\text {PR }}$ was expressed (Trust). Trust in the accuracy, timeliness and comprehensiveness of data produced by RFID systems was necessary before either organisations, or individuals, found the data useful. One actant advised customers to: 
"...focus on the data rather than on individuals or organisations. If you can show that the data has been collected in a manner that is more timely, more accurate and more complete than before, then this will generate overall trust in the RFID supported environment" (Trust - Accuracy). ${ }^{P R}$

Where data was inaccurate trust could be lost, as was described in relation to a weight based application "...the worst case is that it comes back showing that our site was inaccurate which is just going to really hurt us in terms of them in the future believing us" (Trust - Accuracy). ${ }^{\mathrm{PU}}$ It was also noted that when RFID based data revealed process problems trust could be lost as the data was considered to be inaccurate, even if it actually wasn't. One actant related experiences where "implementing an RFID system into processes often reveals flaws, sometimes serious ones, with the existing processes. The owners of those flawed processes don't generally react very favourably to this and will often proclaim that the RFID data is wrong and can't be trusted" (Trust - Accuracy). ${ }^{P R}$

Even between two non-human actants, a loss of trust in the form of authenticated accurate data (generally due to security breakdowns) led to problems within the network as "...it doesn't take more than defeating one or two percent of the global tracking before the whole system shuts down simply because it doesn't know which [data] to trust and which not to trust any longer" (Trust - Loss). ${ }^{P R}$

It was also necessary at times to prove the reliability of infrastructure through independent checking. In a cold chain application the need to prove "with independent data that you are maintaining controls over the transportation process, so we know you are not reducing shelf life or causing other types of problems in our shipments..." ${ }^{\text {PR }}$ was seen as essential (Trust). However, once trust was established there were clear benefits. In a trade based application, trusted data allowed an organisation to "trust that's where [the item] came from and just let it go." (Trust) Relationships between the various actants was seen to turn on the amount of trust between them, "whether it's a government or an SME, the fact is that making things work between those entities really does depend on that trustful relationship" (Trust). ${ }^{\mathrm{PU}}$ 
In terms of the relationship between sectors, in one instance where a large application covering many different private sector entities (as well as the public sector) needed to be developed, the public sector was approached to build the application as it was perceived as being more trustworthy. One actant in this system observed "... industry is always concerned about it being well run and the information not being misused, so they always look to government agencies to do it" (Trust - Between Sectors). ${ }^{\mathrm{PU}}$ This trust was fostered by organisations being clear about the data being collected, and protected by the various privacy acts, as "public trust is quite important and it's the perception of trust as well, it's not just ticking the boxes in the Act, it's being able to keep people happy" (Trust Building). ${ }^{\text {PU }}$

Familiarity between actants was also seen as building trust, with a number of actants mentioning their previous experience with partner organisations as being an important element of building trusted relationships. For example a public sector actant observed that the actant had "an advantage in a sense in my role because I came out of industry,... so, having that familiarity makes a big difference around building trust too". ${ }^{\mathrm{PU}}$ As was being involved in the process of forming and running the network, and being able to "talk amongst each other a lot and participate in joint initiatives a lot, and network a lot, and have a lot of industry stakeholder groups that talk with each other" (Trust - Building). ${ }^{\mathrm{PU}}$

Organisationally, willingness to behave in a collaborative manner was seen to be important. One actant compared some of the organisations he dealt with and noted that:

“...some other [organisations] around town are quite adversarial antagonistic and unhelpful and obstructive and we don't know how to trust them. Another body will be completely different and we feel a level of trust." (Trust Building) ${ }^{\mathrm{PU}}$

The actant saw this as being partly linked to the "maturity of the organisation again, and the players". ${ }^{\mathrm{PU}}$ Interestingly, the actant also reflected that in a particular instance where the network formation was critical trust was able to form immediately: 
"...l guess the obvious thing there is the 'you're at war' kind of thing, so a sense of urgency. Sense of urgency can create trust, whereas in peacetime, you don't have that sense of urgency so everybody wants to play and it takes a lot of time to build the trust around being able to know that you're getting the honest discussions." (Trust - Building) ${ }^{\mathrm{PU}}$

In the long term a lack of trust, especially by public agencies, was seen as inhibiting the formation of a more expansive Internet of Things RFID network. Discussing the need for trust between organisations and sectors to enable the kind of data sharing that formation of the Internet of Things would require, an actant suggested:

"While the Internet of Things might be seen as a no brainer someone's got to operate this global system and be trusted... This is a global responsibility and maybe that is a bridge too far for some people or organisations especially within the context of government." (Trust - Internet of Things) ${ }^{P R}$

In summary, trust was seen as necessary for the RFID network to form, and to be useful. Trust displayed three aspects, trust in data, trust in infrastructure, and trust in and between organisations (and/or individuals). This trust was fostered by familiarity as well as 'trusting behaviours' such as honesty, collaboration and being involved in the network. The presence of clear guidelines, and legislation, was also seen to engender trust. On the other hand, lack of honesty and poor behaviour diminished trust.

\begin{tabular}{|l|l|}
\hline Code & Description \\
\hline Trust & $\begin{array}{l}\text { General discussion of trust associated with the RFID } \\
\text { network. }\end{array}$ \\
\hline Trust - Between Sectors & Trust between public and private sector entities. \\
\hline Trust - Building & $\begin{array}{l}\text { The building of trust between organisations and } \\
\text { individuals. }\end{array}$ \\
\hline Trust - Internet of Things & Trust in the context of the Internet of Things. \\
\hline Trust - Loss & Loss of trust between organisations and individuals. \\
\hline
\end{tabular}

Table 10: Code Table Trust

\subsubsection{Data Sharing}

The RFID network studied fell short of the idealised Internet of Things model discussed in the literature review. Data was not shared across the network, instead data sharing 
was limited to individual RFID systems operating between public and private sector organisations, or even to individual organisations within a system. A number of reasons for this were apparent. A lack of willingness to share data was observed. Between public and private organisations data flowed predominantly in one direction:

“...if the government uses commercial data it's for referenced data feeds not for action type data feeds... I can't think of any circumstances where the government provides out, in the things that I deal with I cannot think of any times where they feedback data to a commercial system." (Data Sharing Cross Sector $)^{P R}$

Within the public sector context there was also a reluctance to share data between secure and non-secure data sets as was observed in one application where there was "a need to communicate data upward from an unsecured to a secured environment and [the organisation] didn't want the two touching" (Data Sharing - Secure to NonSecure). ${ }^{\text {PR }}$

Despite this reluctance to share data, a number of successful systems in which some data was shared were observed within the network. A number of factors were noted that facilitated the sharing of data within RFID systems, including the use of the nonhuman actant of legislation by the public sector to outline the boundaries of information sharing. Further, public sector organisations were conscious of privacy legislation affecting how data could be collected, used and shared. A public sector actant discussed how data needed to be treated within an agency pointing out:

"If you have a database of all your customers you want to have that database only accessible by the people that need to access it for their jobs. You don't want it to be completely open and anyone in the agency can dip in and out" (Data Sharing - Privacy). ${ }^{\mathrm{PU}}$

A number of strategies to facilitate data sharing were used, or suggested, within the network. These included the use of standardised data formats in order to lessen the cost of data sharing, and increase interoperability of organisational systems. This was seen within organisations where there was a need to "exchange data and the only way 
to do it is via industry standards, where we exchange information at the lowest possible cost" (Data Sharing). ${ }^{\text {PR }}$

Between jurisdictions one actant explained that the "focus at the moment is actually on data, so the problem is [ensuring] compliance with international standards on types of information that are declared to [authorities]". ${ }^{\mathrm{PU}}$ Where different jurisdictions were involved in exchanging data, the lack of commonality around a definition of privacy presented a challenge to data sharing as has previously been discussed in the privacy section. One public sector actant suggested "if you are going to create those business to business relationships there have to be some accepted rules around how the data will be managed and how the owners understand it will be managed. If you don't have those then in effect the value proposition starts to vanish pretty quickly" (Data Sharing). ${ }^{\text {PU }}$

In the private sector the use of linked data, which could be shared based on permissions, was seen as a source of competitive advantage by one actant whose organisation "want[s] to link whole supply chains and make the data available to anyone with appropriate permissions, based on the originator of the data" (Data Sharing - Cross Jurisdiction). ${ }^{\mathrm{PR}}$

Despite this, not all actants were seen by others as caring about using standards to facilitate data sharing, either in the private sector where one actant stated "...there are a lot of vendors out there that don't give a rat's about standards" (Data Sharing Private Sector) ${ }^{P R}$; nor in the public sector where a private sector actant contracting to the public sector observed "six different solutions and six different protocols. But because the data stays within their vertical pipeline, we don't care what their protocol is... All we care about is what the data looks like when it shows up on our door" (Data Sharing - Public Sector). ${ }^{\mathrm{PR}}$

In less specific application areas, anonymisation of data was suggested so it could still be shared without identifying organisations or individuals as:

"You have got none of those benefits that come from data shared, but you could find a way of doing it so that there isn't the risk that your direct 
competitor can find out what you're doing....anonymised across all of the manufacturers in [our country]." (Data Sharing - Anonymisation) ${ }^{\mathrm{PR}}$

In summary, there were a number of inhibitors to data sharing within RFID systems. These included an unwillingness in both public and private sectors to share data. This lack of willingness was seen to be related to concerns about security and privacy in the public sector, while the private sector was concerned about competitive advantage. The need for common rules and definitions was highlighted, especially where different jurisdictions were involved. The lack of these guidelines was seen to hinder data sharing. Apart from the establishment of standards, careful access to datasets based on profiles, or even anonymisation of data were seen as ways to maintain data sharing without breaching privacy or confidentiality requirements.

\begin{tabular}{|l|l|}
\hline Code & Description \\
\hline Data Sharing & Data sharing associated with the RFID network. \\
\hline Data Sharing - Anonymisation & $\begin{array}{l}\text { Anonymisation of data could lead to increased data } \\
\text { sharing. }\end{array}$ \\
\hline Data Sharing - Cross Sector & Data sharing across sectors. \\
\hline Data Sharing - Privacy & $\begin{array}{l}\text { Privacy issues related specifically to the sharing of } \\
\text { data and information. }\end{array}$ \\
\hline $\begin{array}{l}\text { Data Sharing - Secure to Non } \\
\text { Secure }\end{array}$ & $\begin{array}{l}\text { Sharing of data and information between secure and } \\
\text { non secure environments. }\end{array}$ \\
\hline Data Sharing - Cross Jurisdiction & Privacy Legislation, development and application. \\
\hline
\end{tabular}

Table 11: Code Table Data Sharing

\subsection{Intra-Organisational Mediators}

Intra-organisational mediators were found predominantly in interactions within organisations, where they influenced the internal organisational action around RFID networks. Again like the other mediators they could also act at inter-organisational or network level, and they were most commonly found within organisations.

\subsubsection{Organisational Management}

Within organisations there is a significant amount of work done to plan for, implement and manage RFID systems. The organisational management mediator covers those aspects of the management of individual organisations that can affect the organisation itself, rather than the whole RFID system, or RFID network at a higher level. This mediator covers a broad spectrum of organisational management from leadership, 
change management, organisational culture, and personnel management to features of the organisation such as size, which affect its performance.

The most critical aspect of organisational management was identified as being the right leadership for RFID projects, implementations and systems. Top management support was considered essential to achieving good outcomes with one actant describing systems in which the actant was involved "...where we have had success there has been an individual who had their head screwed on the right way at the top of the project, and knew what they wanted and..., we gained their confidence" ${ }^{\text {PR }}$ Where he was involved with a less supportive management structure, he noted that the project became difficult to deliver and was of the opinion that "you get better and better at going 'I think we should just walk away from this 'cause we are going to waste our time with this..."' (Organisational Management - Management Support). ${ }^{P R}$

Thus it was recognised as important to get management and staff on board at the beginning of an RFID project as outlined by one actant speaking on behalf of systems implementation:

"I like to have the decision makers involved early on to make sure they understand where we're going and we like to start bringing in the people doing the work, getting them to buy in to doing this. There's kind of [a] two sided problem and the first is if we don't have the decision makers and the money holders involved it can't happen to start with. Then if we don't have the people actually doing it on board with the program it gets sabotaged or from another bunch of reasons it doesn't happen." (Organisational Management Management Support) $)^{\mathrm{PR}}$

The benefits ${ }^{13}$ of RFID systems made good selling points as was "trying to just articulate simple wins for people $\mathrm{e}^{\mathrm{PU}}$ as one actant found in his asset tracking system. When the RFID system was clearly explained so those having to use the system saw it as a "win", or where they perceived their jobs were getting easier, acceptance of the system by staff was higher. At the lower level an actant had emphasised to staff how

\footnotetext{
${ }^{13}$ Benefits as a mediator are discussed in the Benefits/Business case section.
} 
"their lives were getting better" ${ }^{\mathrm{PU}}$ and their jobs easier as a result of the system, in order to encourage staff buy in (Organisational Management - Staff).

However, at times it was necessary to compromise in order to keep people "at the table". One actant discussed the complexity of dealing with multiple organisations and trying to get agreement, the actant had found that if some issues were:

"...pushed too hard too early it all would have fallen over into disarray. So some things were just taken off the agenda until those [organisational] bodies felt they would be in a place to be able to have... the discussion with their members" (Organisational Management - Agreement). ${ }^{\mathrm{PU}}$

In some organisations governance changed regularly. In these instances the level of interest in RFID systems, and the business strategy around them, also varied as one actant had found in his organisation "the reasons for our interest have changed largely because every few years we refresh our governance...". ${ }^{P R}$ At times change in governance also led to the re-visiting of previous decisions, with the result that "without the continuity of funding, and more particularly lack of continuity of personnel, we would sort of start going round re-litigating things which had been previously decided". ${ }^{\text {PR }}$ Change in governance was also identified as a particular problem in the public sector as "there is a political landscape that you need to have consideration of and a three year cycle that sits within that. So that can obviously impact a lot of different priorities" (Organisational Management - Governance). ${ }^{P R}$ At the project management level the lack of "clear project management" ${ }^{\mathrm{PU}}$ was seen to cause one project to have "a lot of false starts with the ability of the people involved". ${ }^{\mathrm{PU}}$ In one instance where an organisation was "unable to find a program manager to manage it" ${ }^{\mathrm{PR}}$ the RFID system failed. Retaining experienced staff that worked on RFID systems was also identified as problematic. Where key staff or management left, systems were seen to "stall" or even fail, with one actant relating an instance where "the guy [who was managing the implementation] left and that stalled [the project] for two years". PU Bad documentation was seen to exacerbate this problem as "somebody leaves and nobody knows what they were doing, so that's where the main drive for documentation is [coming from]" (Organisational 
Management - Staff). ${ }^{\mathrm{PU}}$ One actant also described how RFID systems were rejected at times because managers were scared of the technology noting "if they are frightened of it enough they will find a reason why it's not the right thing" (Organisational Management - Management Support). ${ }^{\mathrm{PR}}$

It was widely recognised in the network that implementation of RFID systems resulted in organisations having to undertake what was described as "some process changes, different ways of doing a job, to make allowances for the technologies" ${ }^{\text {PR }}$ This change wasn't always viewed positively by organisations with one actant citing examples where:

“I've had people tell me point blank we can't change our processes, and my answer is then, then you cannot do this with this, nearly always, because it's really hard to implement our kinds of systems without changing their processes...If you come up against someone who says 'oh no, I can't change the way we do business' then I can tell pretty much from the start that this is not going to be a good project to be involved in."PR

Another actant, also discussing the amount of change an organisation was required to undertake, noted the importance of:

"keeping it simple, not getting carried away with any kind of strange ideas, [asking] how do we keep it simple, how does this go to the lowest common denominator of people who need to issue it, who don't need to think hard, how do you use existing process without too much change..." (Organisational Management - Change). ${ }^{\mathrm{PU}}$

It was also noted that organisations seldom appreciated the management problems they had before their RFID systems were implemented. The implementation of RFID systems assisted with both the highlighting of, and development of, solutions to these problems. One actant speaking on behalf of systems implementation was of the opinion that "I think most companies, certainly that I see, have a problem, they have no real understanding of their problem in many cases, and they certainly have no 
understanding of the methods to solve their problem" (Organisational Management). ${ }^{\mathrm{PR}}$

The need to get more than just the technology side of an RFID implementation correct was emphasised by a number of respondents, with one actant summarising challenges faced by the actants system which included "getting the technology to work, getting the breeding right, getting the harvest right, getting the shipping cold chain management right, getting the marketing right". ${ }^{\text {PR }}$ Even so, RFID systems were found to be only a part, but not all of, the solution to these business problems as one actant found "we are still in this [way of] thinking that RFID was going to solve it all. [We] have not understood or embraced that it is just part of a solution, it is not the solution." (Organisational Management). ${ }^{\mathrm{PR}}$

Size of organisations was also seen to present challenges to RFID systems. Larger organisations, especially in the public sector, needed to produce solid business cases to support any change to business processes. One public sector actant described the difficulties of implementing RFID in "massive" organisations and noted that, "bringing about change in one of those supply chains, you have to have a very compelling use case and it's just very difficult pretty much, unlike in the private sector". ${ }^{\mathrm{PU}}$ One private sector actant saw larger organisations as having an advantage as they could have "people whose job it is purely to deal with the process of doing business". ${ }^{P R}$ In the public sector smaller public sector organisations were seen by a public sector actant as being more "agile", whilst at the same time having to "try to do things once well and make [them] serve many purposes" (Organisational Management). ${ }^{\mathrm{PU}}$

Many actants also discussed the impact of organisational policies on staff. It was noted by a private sector actant that public sector staff:

“...do not have the career pressure of 'if this goes wrong I'll be fired' and I think that makes a big difference in implementing technology, and you see the public sector also is in a way an early adopter in innovation, in most categories". PR 
Although another private sector actant saw the opposite, with public sector staff being less hard working and unlikely to innovate as the rewards that occur in the private sector “[do] not happen in the public sector and... it's not looked upon as a good thing if they are proactive or initiate new things or whatever, which is why much of the bureaucracy becomes stagnant" (Organisational Management - Staff). ${ }^{\text {PR }}$

In contrast, the hire and fire mentality of the private sector was seen as making long term decisions around RFID systems difficult with one private sector actant observing:

"people are really, especially in [my country] are really afraid of being fired. The hire and fire mentality certainly makes for a very difficult culture when it comes to making long term type decisions, or even risky decisions and knowingly doing so". ${ }^{\mathrm{PR}}$

Differences in work habits of staff between public and private sector organisations was further contrasted by a private sector actant who considered that "in the private sector and dealing with private companies, even on just this project alone the speed with which the private partners can move, make decisions and changes, is just lightning speed compared to government" (Organisational Management - Staff). ${ }^{P R}$ In summary, the importance of leadership was emphasised in the network, with strong leadership being associated with success. It was necessary to get top management on board at the start of any implementation, and to be aware that as governance changed so did management attitudes towards RFID systems. The willingness of an organisation to change processes affected the outcome of RFID implementations, with those that were unprepared to change either finding implementation difficult, or not reaping full benefits from their RFID system. The way staff were treated within an organisation was also of influence, with the hire and fire attitude of the private sector seen to inhibit innovation. Contrastingly, the job security perceived to be enjoyed by the public sector was seen to slow organisational processes and lead to 'bureaucracy'. 


\begin{tabular}{|l|l|}
\hline Code & Description \\
\hline Organisational Management & $\begin{array}{l}\text { Organisational management associated with the RFID } \\
\text { network. }\end{array}$ \\
\hline $\begin{array}{l}\text { Organisational Management - } \\
\text { Agreement }\end{array}$ & $\begin{array}{l}\text { Organisational management involved in getting } \\
\text { agreement. }\end{array}$ \\
\hline $\begin{array}{l}\text { Organisational Management - } \\
\text { Change }\end{array}$ & $\begin{array}{l}\text { How organisations deal with the issues and } \\
\text { complexities surrounding the changes required by } \\
\text { RFID implementation. }\end{array}$ \\
\hline $\begin{array}{l}\text { Organisational Management - } \\
\text { Governance }\end{array}$ & How governance affects RFID systems. \\
\hline $\begin{array}{l}\text { Organisational Management - } \\
\text { Management Support }\end{array}$ & $\begin{array}{l}\text { How support from various management layers affects } \\
\text { RFID implementation and system. }\end{array}$ \\
\hline $\begin{array}{l}\text { Organisational Management - } \\
\text { Staff }\end{array}$ & $\begin{array}{l}\text { How the treatment and attitudes of staff affect RFID } \\
\text { networks. }\end{array}$ \\
\hline
\end{tabular}

Table 12: Code Table Organisational Management

\subsubsection{Data Management}

Although decisions regarding data standards, sharing and privacy are made at the inter-organisational level, data management is still a significant mediator within the RFID network, and thus is treated as separate from the data sharing decisions. This mediator is intra-organisational as decisions regarding management of organisation specific data, or decisions made as a result of data reporting occur within the organisation and largely do not appear to impact on other parts of the network. Conversely, decisions regarding data privacy or sharing have implications for other organisations within the RFID network.

Underlying the usefulness of any data to an organisation is the appropriateness of that data. It is important to have the right data, as "[it] is becoming very obvious that RFID doesn't work without having the right data..." (Data Management - Data Quality). ${ }^{P R}$ The importance of understanding the data received was also emphasised as "it comes back to what does the data mean? What are you actually capturing and what are you going to do with it, and not focusing solely on the technology. ${ }^{\text {PR }}$ This was a point made by a number of actants who saw that there was significant value in understanding data generated by RFID systems, as one actant found "The industry is recognising that the accumulation of data over time will be an extraordinarily valuable asset, and potentially industry wide has lots of other uses..." (Data Management). ${ }^{P R}$ 
The importance of aligning RFID generated data with business process in order to turn data into "business intelligence" was noted by one actant, who also highlighted that "all you have is an expensive data carrier" if the data is not used properly by organisations". ${ }^{\text {R }}$ Similarly, the ability to actually use RFID data, "connecting the dots... about [how] we can read data coming off a tag, can we align it with a process and then start making better business decisions about that process ${ }^{\text {"PR }}$ was also seen as being crucial to the utility of systems. RFID data was also seen to be important in highlighting organisational risk, in order to "see what's successful and start to exclude the things that they find weren't a risk, and more and more sharpen that tool towards what is a risk." (Data Management - Using Data)

It was the more reliable collection of data that was seen as being the major advantage of an RFID system by one actant, "so most people think technology solves problems, in fact it very rarely does, what solves the problem is the more reliable collection of data that goes on." ${ }^{\mathrm{PR}}$

Despite the advantages, there were still difficulties recognised in using RFID data, notably an unwillingness by organisations to accept data that was interpreted as negative. One actant outlined his experience where RFID systems highlighted flaws in business processes "the owners of those flawed processes don't generally react very favourably to this and will often proclaim that the RFID data is wrong and can't be trusted" (Data Management - Negative Data). ${ }^{\mathrm{PR}}$

In summary, although data management was closely tied to data sharing it was seen to be more aligned with internal business processes and practices. It was found that the data generated by RFID systems was not always put to good use, and that organisations struggled to know how to deal with the data as opposed to the technology itself. In order to gain maximum benefit from data, it was necessary to have high quality and accurate data, which was then useful in directing business processes.

Data management coding table follows: 


\begin{tabular}{|l|l|}
\hline Code & Description \\
\hline Data Management & Data management associated with the RFID network. \\
\hline $\begin{array}{l}\text { Data Management - Data } \\
\text { Appropriateness }\end{array}$ & $\begin{array}{l}\text { How the nature of the data being gathered and its } \\
\text { appropriateness to the task for which it is being used. }\end{array}$ \\
\hline $\begin{array}{l}\text { Data Management - Negative } \\
\text { Data }\end{array}$ & $\begin{array}{l}\text { How data that is perceived to be negative is received } \\
\text { by the organisation. }\end{array}$ \\
\hline Data Management - Using Data & The specifics of using data generated by RFID systems. \\
\hline
\end{tabular}

Table 13: Code Table Data Management

\subsubsection{Benefits/Business Case}

While benefits realisation might be considered part of the finance mediator, it was quite clear that the RFID network separated the costs of RFID systems from the benefits they derived, and that the benefits of RFID systems were generally realised within organisations rather than at the network level. Although benefits were outlined in the business cases produced by organisations, they were not always the same as the benefits derived by organisations, thus the separate discussion of business case and benefits which follows.

The reported benefits of an RFID system were numerous and included (but were not limited to):

- Better supply chain control, as outlined by one actant who found that the biggest benefit from his organisation's RFID system was the ability to "maintain quality" $^{\mathrm{PR}}$, achieved through the "supply chain insight" ${ }^{\mathrm{PR}}$ offered by RFID.

- More efficient industrial processing, and the ability to "build more correct things and less things that are not correct". ${ }^{P R}$

- Determination of business risk as "being able to efficiently capture information to then determine risk profiles..." ${ }^{\mathrm{PU}}$ was a major advantage of RFID systems (Benefits).

Although more efficient and effective internal organisational processes were found to be one of the benefits of RFID implementation, where organisations were unwilling to change processes they often failed to realise the benefits of their RFID systems. As one actant related "if you just change out the data capture mechanism and you don't 
change those internal processes, and you don't change what you are sharing, the business benefits get lost..." ${ }^{\mathrm{PR}}$

It was also apparent that many organisations discovered these benefits over time, rather than benefits being apparent when the system was planned, or even when the planned RFID system became operational. As one actant explained:

"My personal feeling is that a lot of the best benefits of a technology turn out to be serendipitous, it's the stuff that we didn't necessarily think of. Even the barcode... was only ever sold as offset to the cost of labour in marking/remarking stuff on the shelf - That was the return on investment. The biggest savings to the barcode today come from inventory management, not labour." (Benefits - Discovery/Realisation). ${ }^{P R}$

This apparent delay appeared to be related to organisations not clearly linking the issues they were attempting to address with appropriate solutions, RFID based or not, with one actant discussing how the:

“...social, political issues are remaining unresolved just as the technological issues are, and they're not coming together they are just trucking on in parallel. So, maybe disconnected isn't the right word but, they are not reinforcing each other they are running side by side. So they, they're each on their own paths." ${ }^{\mathrm{PR}}$

This actant went on to discuss the issue of how an organisation derived benefit and which organisation in the RFID network derived it, stating "what will become interesting is who benefits when and how, and who doesn't. Who's given the capacity to benefit, who's given the capacity to gain something from it, and what they gain being relative to what somebody else gains" (Benefits - Discovery/Realisation). ${ }^{\mathrm{PR}}$ Although as one actant acknowledged, it was difficult to calculate benefit as "... it's the classic sort of situation where if you don't have any sort of benefit idea of the value of something, then you won't do anything because it's just purely a cost, it's just a way to spend more money" (Benefits). ${ }^{\mathrm{PU}}$ 
The delay in realising benefits, and the difficulty in connecting benefit and cost tied to an apparent lack of enthusiasm for RFID solutions were seen in organisations that had not researched the business case for RFID implementation as:

"In the early days of EPC the technology was not robust... and there was price points and probably looking back over the years, the one variable that we probably overlooked was a clear cut business case. And if you don't have that, then the technology it's a solution looking for a problem. You say look at this technology you can read a thousand tags per second and dense reader mode, and all these things that we sorted out, but until you have 'that something' that the senior executives in these companies can relate to and resonates with them you just really have a really cool technology." (Business Case) ${ }^{\mathrm{PR}}$

There was also evidence that the public sector was conscious of the need to connect the cost of legislated compliance with benefits for participating organisations. As one public sector actant explained "you have to be very careful about imposing a compliance cost without really proving the benefit, and so we can't quite do that yet in the whole RFID space". PU

The initial benefits expected on implementation of any of the RFID systems were outlined by a business case, written to support organisational arguments for such systems. Both sectors recognised the importance of "a solid business case, and in making sure that stacks up for bidding, funds, and investment". ${ }^{\text {PR }}$ This need to prove the benefit of RFID systems was emphasised where government was imposing the system on the private sector through legislation. As observed by one public sector actant "you have to be very careful about imposing a compliance cost without really proving the benefit" (Business Case). ${ }^{\mathrm{PU}}$

Where systems had been successful they were based on "a business case, and it's got to be able to be able to be stacked up and demonstrated and proven, it's not just a crazy idea" (Business Case). ${ }^{\mathrm{PR}}$ Developing such business cases took considerable time and collaboration by all organisations concerned, with one actant describing "a lot of door knocking and a lot of meetings and a lot of discussions... a lot of engagement 
through lots of different stakeholders". ${ }^{\mathrm{PR}}$ Where there was a lack of clear planning the systems struggled, or failed as one actant related:

"...and I often say to them, "well, have you done the business case? Or have you done any discovery on understanding both technologies, what they can and can't do, and not so much the cost of what it will cost you but the benefit that you will derive as a consequence of the technologies, and have you actually done that due process?" Almost invariably ten times out of ten the answer is "no", and so poor RFID gets relegated to the too expensive form of AIDC technology." (Benefits) ${ }^{P R}$

In summary, there was shown to be a link between clear business case, system benefits and project implementation. Where benefits were unclear, or business cases were not written or clearly linked to the business problem, implementations either struggled or were not commenced. Despite this, it was commonly found that further benefits were discovered after implementation.

\begin{tabular}{|l|l|}
\hline Code & Description \\
\hline Benefits & $\begin{array}{l}\text { Description of actual benefit derived from } \\
\text { implementation of RFID system. }\end{array}$ \\
\hline Business Case & $\begin{array}{l}\text { Case written to support the implementation of RFID } \\
\text { system. }\end{array}$ \\
\hline Benefits - Discovery/Realisation & $\begin{array}{l}\text { How the organisation found the benefits, or how } \\
\text { benefits arose, as a result of RFID systems } \\
\text { implementation. }\end{array}$ \\
\hline
\end{tabular}

Table 14: Code Table Benefits/Business Case

\subsection{Mediators - In Summary}

This chapter has focused on answering RQa. What mediators affect (the process of establishing and maintain public-private RFID systems) and how are they manifested? The mediators identified were found to operate at three different levels, with some operating generally between organisations (inter-organisational mediators), some within organisations (intra-organisational mediators), and other across the whole network (network mediators). This does not mean that mediators operated only at those levels, more that these were the levels at which they predominantly operated. 
Network mediators include financial considerations, network infrastructure, standards, security, and the knowledge that organisations have about RFID systems. Three of these mediators are very strong, financial concerns were mentioned by nearly all actants. The loss of financing or the cost of systems could cause an RFID implementation or system to fail at any point. Standards needed to be resolved before systems could even be implemented, as they allowed for interoperability of RFID infrastructure. Similarly questions surrounding infrastructure design and choice needed to be resolved before RFID systems could be implemented. Standards were also important here as not all RFID devices were interoperable, as was the varying cost of infrastructure options, non-human actants were also strong here in the form of published guidelines surrounding industry standards. Surprisingly the amount of knowledge an organisation had about RFID systems also occurred as a network mediator. This was seen to be the result of the amount of effort actants had to put into educating others when they wanted them to join into their RFID networks, thus highlighting a relative lack of widespread knowledge of RFID technology.

Inter-organisational mediators operated primarily between organisations, or between organisations and individuals. They included privacy, security, trust and data sharing. Privacy was another very frequently discussed mediator, but despite the level of discussion questions still remained about how to resolve privacy issues. This was especially apparent when discussing privacy in an international context, where different levels of the supply chain were involved, or where one part of the RFID system required more or different privacy to another. Again, non-human actants were strong here with some legislation surrounding privacy playing a part in how personal information was treated within the network. The public sector was seen to be more sensitive to privacy concerns, and this was linked to the nature of the information being held by this sector, and the need for the public sector to comply with legislation and regulation. Security was much less frequently discussed than privacy but was perceived as being critical by those that discussed it, although a number of actants viewed security as being an afterthought in RFID systems. Where security was discussed it was related to the nature of the data being held by RFID systems, and to the various layers of RFID systems, with each layer requiring a tailored security 
approach. Trust is frequently discussed in relation to privacy and security, and this connection was also apparent within the RFID network. Trust had three aspects related to trusting RFID infrastructure, data and organisations. Familiarity was seen to encourage trust, as was the presence of non-human actants in the form of strong legislation or guidelines. Finally, data sharing was considered to be an interorganisational mediator as it is necessary to share data across organisations in order to fully utilise RFID systems. Without the sharing of data, the utility of RFID systems was seen to be much reduced, as was the potential of any Internet of Things type system. The lack of agreed guidelines, and an unwillingness to share data for reasons of privacy and competitive advantage, were both seen to be inhibitors of data sharing.

Within organisations, intra-organisational mediators included organisational management, data management and business case/benefits. These mediators were most active within organisations themselves, driving decisions to implement RFID systems and influencing how the systems operated once implemented. Organisational management had several critical aspects, the most important of which was the quality and consistency of leadership. A lack of leadership, or sudden change in leadership was seen to cause RFID systems to stall or even fail. Other important factors included staff management, and the willingness of the organisation to implement change associated with RFID systems. Data management might normally be thought of as part of organisational management. However, in the RFID network it was important enough to appear as a separate mediator. The way data was managed within the various RFID systems dictated its usefulness. In a number of instances the alignment of data with business processes, and even the way data was used within organisations, was seen to be lacking. Associated with this was business case and benefits realisation. Again these might be considered part of organisational management but they appear separately here as they also mediate the RFID network. Business cases were important non-human actants as they framed any RFID system. However, the business case often did not fully realise the benefits that could be gained from RFID systems, and some of these benefits were tied to the management of RFID related data. Interestingly benefits derived from RFID systems were often discovered after business cases were written, and sometimes after systems implementation. 


\section{Discussion}

The findings reveal a complex RFID network encompassing countries, organisations, industries and sectors. Individual RFID systems operating across a number of organisations link to other RFID systems through standards organisations, and other similar organisations. Furthermore, when humans speak on behalf of the technology actants within an RFID system, The RFID Network even more associations are observed both within, and exterior to, the RFID system in question. Figure 15 (repeated from Section 3.5.2) attempts to demonstrate the complexity of this relationship, where actants (human, nonhuman, or organisational) link

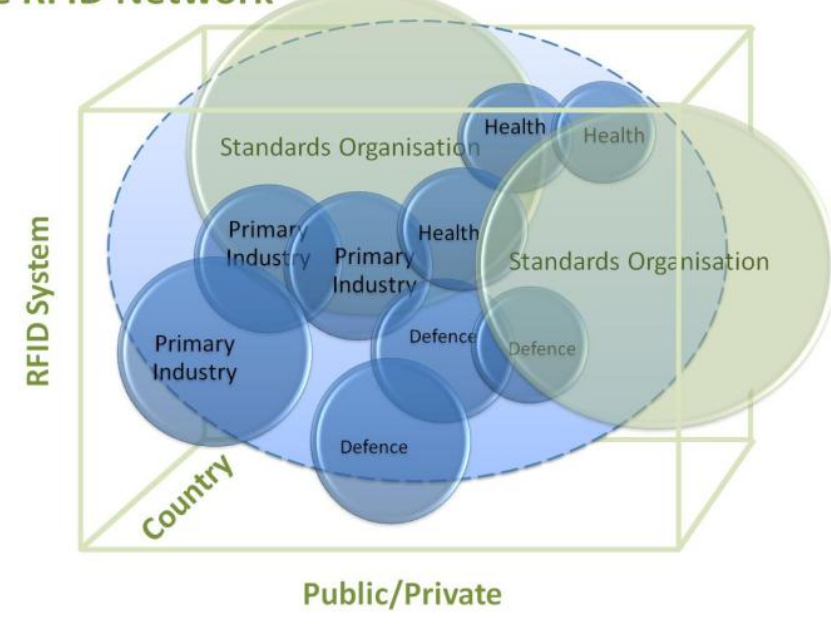

Figure 14: The RFID Network through a complex network of associations, together forming the RFID network and assisting in understanding the multi-faceted nature of the network studied.

This chapter will review these findings in respect of the RFID network and relate them to the theory and concepts outlined in the literature review. The way the RFID network is established and maintained will be discussed through the ANT lens focusing on how the relationships between the various actants contributes to the network formation and maintenance. The chapter will then consider how mediators affect the process of translation by both facilitating and challenging attempts to enrol actants. The role of institutional behaviour in this process will also be discussed along with a brief consideration of the utility of combining ANT with Institutional Theory.

In order to remain true to the ontology of ANT, some parts of this chapter will take the more heroic style of an ANT account. At times it may appear that the non-human actants are given a certain amount of agency, and this is consistent with the ANT approach. 


\subsection{RQa.: Translating the Network - How the Relationship Between the Actants Contributes to Establishing and Maintaining the Network}

In his book Aramis, or, the Love of Technology (2002), Bruno Latour delves deeply into an attempt to introduce the Aramis public transportation technology into Paris in the 1980's. In his account Aramis gains a voice and even comments on events, attempting to gain the sympathy of readers, and relating how allies are acquired to support its use. Unfortunately, Aramis is fragile, eventually succumbing to a myriad of problems relating to finance/cost, inconsistent political support and technological difficulties. However, Latour highlights one problem with the technology that surpasses all others, the treatment of Aramis as "an uncomplicated development project that could unfold in successive phases from the drawing boards to a metro system that would run with 14,000 passengers an hour in the south Paris region every day, twenty-four hours a day" (Latour, 2002, p. 292). There was a clear misunderstanding of the nature and complexity of the Aramis network. Similarly the RFID network, whilst appearing to be a simple collection of technological pieces, is in fact a complex assemblage of technology, human and organisational actants struggling through the process of translation.

This research has been directed at understanding how the RFID network is established and maintained in the public-private context. The language and concepts of ANT, including that of translation, give insight into how this network is formed, and the challenges it faces. But, like Aramis, the RFID network is not fully formed in the publicprivate context. As is shown in the findings, the individual RFID systems are still disparate, and they have not yet merged into a fully interconnected RFID network in the style described by the Internet of Things concept. Nonetheless, the ANT translation of the RFID network in the public-private context, can still be examined by observing Latour's advice to "follow the actors" (Latour, 2005, p. 68), examining how they interact with each other.

The ANT concept of translation suggests that networks are formed through the four stages of translation, these being problematisation, interessement, enrolment and mobilisation. At the beginning of the story of translation in the RFID network studied, 
is the problem of how the network defines what it wants to do, and what informs the problematisation. From the findings it can be seen that there is a focus at first on outcomes, "the benefit that you will derive", costs, and the purpose of the network. In the RFID systems studied the objectives were diverse, from biosecurity to infrastructure protection. Bar-code identification, the major rival to RFID, also appeared early in the problematisation, as the choice of technology (RFID or barcode) had to be dealt with at this stage. Bar code systems tempted actants with promises of cheap product identification, although they could not offer the benefits of item level identification seen in RFID systems. Between problematisation and interessement it was necessary to pass the obligatory passage point (OPP) of business case development, and also of standards (OPPs will be discussed later), before the interessement stage of translation could be reached.

Interessement was characterised by the interplay of the various actants. Here we saw lobbying, consultation, and dissidence. In one instance the initial focal actants went so far as to interest the government in producing legislation which had the effect of requiring their industry members to participate in the network. It's at this stage that the novelty or "buzz" surrounding RFID becomes an advantage, drawing actants into the network. On the challenging side, it's during interessement that a dissident was seen in one instance, attempting to overturn the decisions made in the problematisation. However, this dissident was drawn back into line by the inevitability of legislated participation, and by the desire to be part of the development of the RFID system. The lure of bar coding was still present at interessement, with organisations struggling to decide between the two technologies.

Enrolment was seen to be strengthened by the running of pilot projects as these helped organisations understand the benefits of participating in the network. It was also during enrolment that the various actants reached agreement - producing memoranda of understanding, and aligning themselves with requirements of the RFID system. Training and communication were important parts of mobilisation allowing all members of the network to understand the new system. "Socialising" the change was seen as being effective, and the importance of organisational leadership was continually emphasised. At lower organisational levels, seeing the project come to life 
and succeed helped with mobilisation. At higher organisational levels, partners could speak or delegate for each other.

Throughout the translation stage, RFID technology itself plays a part in shaping the form of the network. Implementation "can be difficult" and this difficulty "is a barrier to present wider adoption". Part of this difficulty can be seen to arise from problems aligning the interests of all actants in the network. As Sidorova and Kappelman (2011) found in their study of enterprise architecture, it is necessary to align the interests of both the organisational actants, and the non-organisational technology actants, such as infrastructure and standards, for a successful translation. The strength of both the standards and infrastructure mediators in the RFID network demonstrates this necessity as they sit outside the organisations and systems concerned, yet must still be integrated within the network, or the network itself will fail. The presence of legislation as an OPP, along with various RFID standards in place for both RFID hardware (infrastructure), and software, assisted in aligning the interests of RFID technology with organisational and human requirements through regulated requirements to operate RFID systems in particular ways. Interestingly, Sidorova and Kappelman (2011) also found that the risk of compromising organisational interests during the process of translation is related to the degree to which these processes become inscribed. Documents such as business cases, for example, can be considered to be inscriptions, and all of the systems studied had produced such business cases. Of course, legislation, policy, standards and mandated requirements, are all strong inscriptions seen in the RFID network studied. The need for actants to be involved in the process of inscription in order to fully represent their organisational interests demonstrates that the dissident seen in one instance resisting interessement was in fact clever to resist while still retaining the ability to contribute to the inscription of the business case and legislation. As the organisation's representative had recognised: "[we] needed to be... angry and do [our] public thing, and [the other members of the network] were cool with that because privately we were still doing the constructive, collaborative, helping shape the thing ${ }^{\prime P R}$. In other instances the inability to align what the technology could provide with the needs of the organisation caused the translation to fail, especially where the organisations involved were resistant to the 
kind of organisational changes required to implement RFID systems. However, a number of non-profit ${ }^{14}$ and non-human ${ }^{15}$ actants worked to assist alignment through the provision of education about RFID systems, technical assistance and standards negotiation.

Law (1992) describes some of the features that help maintain a network making it strong and durable. He suggests that when power is translated through durable materials, such as bricks and mortar, texts and laws, the translation will be more stable. This can be seen in the study network as legislation (a strong and durable inscription) stabilises the network by requiring enrolment according to the legislated regulation. In those systems not stabilised by legislation other methods of encouraging actants to join the translation were seen. In the most successful systems these methods could be considered to be similar to legislation, as they took the form of mandates driven by large corporations, which were enforced by penalties against those not complying with the mandate. Where organisations were not in a position to rely on legislation or mandate to stabilise their networks, they had to rely on weaker factors such as mutual benefit, or business cases to stabilise their translations. This pattern follows that suggested by Law in that the more durable materials led to stronger more lasting translations.

\subsubsection{Inscriptions}

Another important driver of a network is the network's inscriptions, or programs of action, written into the devices (or text) that make up the network. Mähring Holmström and Montealegre (2004) argue that such inscriptions are essential to any network, as they act to stabilise it. At the very basis of the study network, RFID enabled devices are inscribed with product identifiers that drive the data collected by such systems. This data also forms the basis of the benefits derived from RFID systems such as the ability to track and trace individual items, or sensor capabilities, which are directly linked to the data provided by individually numbered (inscribed) RFID tags. The lack of understanding of this data and its management, has already been linked to a disconnect in organisational benefits, and can now be seen to be linked further back

\footnotetext{
${ }^{14}$ Such as standards and industry bodies

${ }^{15}$ Such as industry publications and conferences
} 
to a lack of understanding of how the inscription of RFID devices can be used to derive organisational benefit.

The network itself has a number of higher level inscriptions such as business cases, and legislation (already discussed). The RFID enabled technology artefact itself inscribes a way of behaviour on those organisations using it. This is clearly shown within the study network as organisations and individuals have to change their processes to accommodate the implementation of RFID systems. Once in place, Latour (1992) believes that inscriptions are mostly irreversible, and the strength of the inscription dictates how likely it is to be followed. Legislation is a strong inscription, dictating, and indeed forcing, a course of action on the network. Inscriptions such as business cases, memoranda of agreement and other formal documents also frame the relationships between actants, and dictate to a certain extent the form of the network.

\subsubsection{Obligatory Passage Points, Dissenters and Challenges}

It is a requirement of translation that actants wanting to join the network navigate one or a number of obligatory passage points (OPP). Defined by the focal actant/s, the OPP is essential to the network, and it must be accepted by any actant who wants to join the translation. Actants who wish to join are persuaded that their interests are best served by accepting the OPP proposed by the focal actant/s. In the instances studied, project or business plans can be seen to be an obligatory passage point (OPP), as can legislation or standards.

Legislation, where it is already in place represents an OPP after the problematisation, as it constrains the shape of the network - saying "you must do this in a certain way". Standards also represent an OPP in the network. Even in an RFID system designed to be used exclusively within one supply chain or organisation a basic level of standardisation is necessary, as the RFID tags must be able to talk to the readers, and the readers to the database. However, this is where the story of the network becomes interesting. In the more extensive network studied, the RFID public-private sector network, standards are also necessary for different RFID systems to talk to each other. This is a major challenge that must be met before completely connected RFID systems can be enabled. A number of global standards bodies are interested in providing 
standardised naming services. These would all like to be involved in the network, to not only provide the Internet of Things style connectivity that would allow anyone/anything/anywhere to discover the parts of the network, but to also provide baseline standards for network infrastructure. How is this challenge met? Various systems use a number of standards, and on the international stage both standards and privacy mediators are still disputed, therefore full scale global Internet of Things connectivity is not possible at this time. Further, questions over trust and security are still unsettled, as demonstrated by this research. However, this does not mean that globally interconnected standards will not happen in the future as translation is an ongoing process, and a number of bodies are working towards implementing Internet of Things style systems.

The next challenge to the RFID network in the public-private context comes from another form of standard identification, the classic barcode. Barcode appears a number of times to challenge the network. The use of RFID or barcode technology was seen to be debated at problematisation when the question about which technology is best needs to be decided, with bar coding perceived to be both cheap and ubiquitous. As one actant related: "as a commercial provider, I have a free of charge bar coding system, internationally recognised, now accepted as part of conventional contract packaging. What's the benefit in RFID, and what's the cost of the benefit?". Bar codes use the lure of ubiquity, standardisation and low cost to draw interest away from RFID as a solution. Cost in fact is an on-going mediator in the network, and bar codes can still compete with RFID technology based on this mediator alone. However, RFID is strong, using the additional functionality of RFID systems compared to bar codes to hold off the challenge.

But there are other challenges in the form of dissidents, actants that disagree with the network. In one instance already discussed, an organisation initially accepted the OPP but later, due to a change in internal management, decided to resist the network. This dissident eventually conceded under pressure from legislation. In another instance there was a non-human dissident resisting the system in the form of a number of extensive cross organisation ERP systems, which were considered too costly to integrate. As a result, though the RFID system was implemented, the size and 
complexity of the ERP resisted the integration of data and ERP systems, and the system was weaker because of the inability to share data across all departments of the organisation. Finally dissidence is seen from individual human actants who fear RFID technology on the basis of health, privacy or philosophical grounds. This dissidence was met within the network with education where necessary.

\subsubsection{Micro and Macro-Perspectives and the Internet of Things}

If we look at how RFID works in the systems studied we can see that RFID enabled artefacts move through the individual RFID systems, identifying objects/or transmitting sensor information based on unique identifiers. These identifiers are considered to be inscriptions or immutable mobiles - capable of transmitting meaning, in the case of RFID enabled devices, identity or sensor information. Thus the devices make visible what was otherwise remote and invisible. However, currently the information produced by such systems remains limited to individual systems, and organisations within those linked RFID systems; the "intranets of things" that Slettemeas (2009) proposes, as the widespread, cross organisational, cross system network that would represent the idealised Internet of Things style system is not (yet) in place. However, Callon and Latour (1981) note that micro actors can grow into macro actors "with all due power and influence to speak or act on behalf of another force that comes with the increase in scale" (p. 285). This principle is demonstrated in this study as the most micro of actants - RFID tags and data - can grow into large organisational RFID systems, and may grow further still. However, in the context of this study, particularly with the involvement of the public sector, concerns about privacy and security would present barriers to out of system sharing of data, as seen in this study and described under the data sharing mediator in Section 5.2.4. This lack of willingness to share data would limit the potential growth of a more widespread Internet of Things style network, even if the infrastructure requirements are met. The most this study can do is point to the mediators as indicators of the factors that must be considered before the Internet of Things in the public-private sector could become ubiquitous.

Yet a number of actants discussed the Internet of Things, for them this concept represented the future of the network, something that would eventually occur. So 
what is the place of the Internet of Things within the network? ANT does not accommodate predictions about the future, but it could accommodate a concept appearing as an actant, attempting to shape the network in its own way. The Internet of Things as an actant certainly has representatives within the study network, speaking about it, and on its behalf. It could also be considered to be a dissident within the ANT framework. Like the bar code the Internet of Things drives the network to take a different shape, pressuring the mobilisation and attempting to change the problematisation by offering a more connected view of how the network could (or should) be formed.

What about other emerging computing concepts, the ubiquitous pervasive, disappearing, invisible, and experiential? As with the Internet of Things there are indications of these "working away in the background". According to Ye et al. (2008) the difference between the ubiquitous and pervasive concepts turns on the ubiquitous provision of its infrastructure, and the pervasive provision of computing services. So RFID technology is not completely ubiquitous according to this definition as infrastructure is not ubiquitously available, and cost still limits the provision of the necessary infrastructure to some extent (although these costs are dropping). Nor is RFID pervasive except in the system in which the technology is implemented. So again it can be said that there are signs of these concepts in limited cases, but they are not yet completely realised. These concepts could also offer temptations to the network, attempting to persuade with visions of what might be if only the infrastructure were available to realise their interconnected visions. Similarly, the experiential model proposed by Yoo (2010) would require a far more extensive infrastructure and RFID network than the one currently in existence. But do these computing concepts have representatives within the network, are they actants? The answer would have to be no, none of the study actants mentioned these concepts, and they did not appear to have any influence on the network design, or actions. Unlike the Internet of Things, the disappearing, invisible, pervasive, ubiquitous and experiential concepts are descriptors rather than actants, at least at the moment. 


\subsubsection{Sector Relationships}

Because this research is focused on cross sector RFID systems, the relationship and interaction between different sector organisations is also an important part of the network. At the sector level the relationship was framed to some extent by what could be considered the stereotypical views each sector had of the other, with some public sector actants viewing the private sector as being solely concerned with profit, and some private sector actants levelling accusations of bureaucracy at the public sector. However, beyond the stereotypes there were a few differences apparent between the sectors.

The public sector was seen to be more sensitive to legislation that was already in place. Thus where privacy legislation applied to data collected by an RFID network, the public sector was more considerate of this. Similarly public sector organisations were also more sensitive to the need to secure data collected by networks, which was seen to be related to the nature of the data held by the public sector. Public sector organisations also had more procedures and processes in place, and at times this led to frustration from private sector actants, some of whom saw these procedures as being barriers to interaction. As a result some of the large private sector organisations studied had employees dedicated to dealing with their public sector partners, although no actants discussed the number of staff necessary to deal with private sector partners of those same organisations. In the private sector, frustration was expressed at the political cycle changing government policy. Similarly, the change in private sector leadership also affected the direction of private sector organisations, and their attitude towards their cross sector RFID systems.

The place of legislation was contentious. In some instances the private sector had approached the public sector wanting legislation enacted, and had been successful. Despite the legislation being an industry initiative, others within the industry continued to resist it. In at least one instance of RFID based legislation, it was felt that the public sector should subsidise the involvement of industry, even though industry had originally asked for the legislation to be enacted. In other instances, industry was working hard to demonstrate that legislation would not be necessary, and that industry could self-regulate. 
The two sectors were also seen as being similar in a number of ways, with actants noting that the nature of the individuals they were dealing with was more important than their organisation or sector. This view was expressed in both public and private sectors. Familiarity and time spent working together lessened the feeling that the two sectors were different, instead normalising working relationships. In those systems that were successfully implemented, respondents considered that a cooperative approach was essential, as was good organisational and systems management.

\subsection{5 "Public Sector" as a Multiplicity}

As the network has moved through the OPP, answered dissidents and met challenges on its way to mobilisation - is there more to understand about the network? Like Aramis which exists in both the states of "real" and "unreal," parts of the network have different aspects. The work of Cresswell (2010) and Mol (1999) help here. They suggest that ANT allows multiple realities to co-exist, each reality representing a different view, depending on the perspective of the human or technology actant. This multiplicity (or ability of the same actant to appear and act in a number of different ways) allows us to deal with different performances; different ways actants behave in order to build relationships or networks, depending on their context or the actants they are interacting with. The ability to do this gives us a much more subtle understanding of the network and its struggles.

The most obvious multiple in this study is the public sector (or as it is most commonly referred to by the actants, government). Four different roles are apparent for the public sector/government as:

- a member of the network;

- a provider of legislation or regulation;

- an enforcer of legislation; and

- a funding and service provider.

As a member of the network, the public sector acted in the same way as a private sector member of the supply chain. Goods were received, tags were read and data was recorded. As a provider of legislation, the public sector worked with politicians and the private sector to legislate based on the perception that the legislation was for 
the public good, including setting legislation to favour organisations within their own jurisdiction, amounting to a tariff on other jurisdictions. Any legislation passed had to be enforced, leading to the third role of the public sector/government. Finally, actants also saw the public sector as having a role in providing services such as education on the value of RFID, and on how business might implement RFID technology.

The private sector actants also displayed multiple views of the public sector, with the most common being that of the public sector as 'government' with little distinction made between government and public sector functions. This view was driven by what could be described as a stereotypical view of government such as those seen in [the contrasting public and private Section 4.2.1. However, in other instances the public sector was viewed as a partner - a shareholder in the governance of cross sector RFID systems.

These multiple roles and views are considered to have caused confusion within the network; from the private sector writing off public sector organisations as "just being government", to the difficulty of managing policy that was being developed at the request of the private sector. In one instance, policy development was made more difficult when the industry representatives and policy analysts needed to negotiate issues surrounding policy development, as the industry actant had observed "the policy wonks get involved and it grows a life of its own. So then you've got to go and grab them all, and bring them all back...".

From the private sector side the conflating of the term 'government' with public sector led to difficulties identifying the role the private sector wanted the public sector to play. The most successful cross sector RFID systems displayed a good understanding of the various roles played by the public sector, and targeted their actions accordingly. As one industry actant related, the actants organisation had been "in the odd position of having to talk the government out of being involved in [the system] in terms of being an industry based scheme and then having to talk them back in to being involved in it for the funding". 


\subsection{RQb.: How Mediators Drive the Network}

While the process of translation formed the network, and it was stabilised by durable materials and inscriptions such as legislation, the actions of mediators gave the network shape. Mediators also could cause sudden changes in direction of the translation, or the actants, adding to the complications faced by those wanting to implement RFID systems. To reiterate Latour (2005, p. 39) mediators "transform, translate, distort and modify the meaning or the elements they are supposed to carry". Intermediaries, on the other hand, are unsurprising and their input predicts their output. However, the state of intermediaries and mediators is not always settled; an intermediary can transform into a mediator and vice versa, depending on the actions of actants.

The literature review suggested nine possible mediators of RFID systems in the form of issues most commonly discussed by researchers, either individually or in combination with other mediators, whereas this study identified 12 mediators. Differences in the mediators identified lay in the emergence of organisational knowledge as an important mediator in the public-private RFID network, and the refining of organisational and data management categories from the more general governance category seen in the literature review. It can be seen from this study that the mediators of RFID systems operate in various places within the network, some operating across the entire network, some predominantly within organisations and some between. This is shown in Figure 13 which is repeated here for convenience:

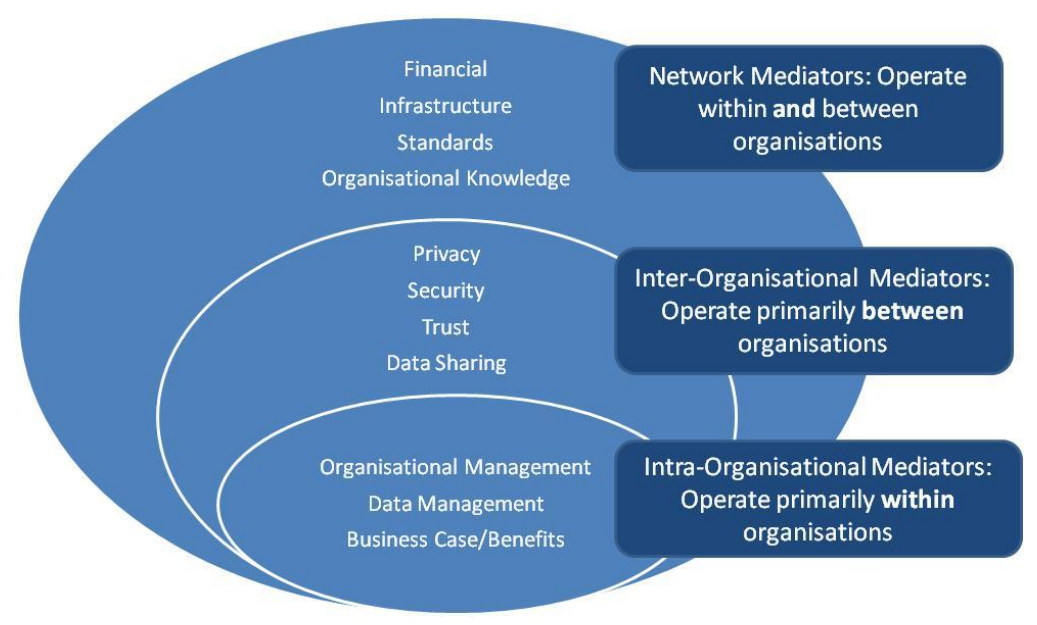

Figure 15: Mediators of the RFID Network 
Although the majority of the mediators were identified by the literature review, it is their strength and how they act within the network that is interesting, and in some cases unexpected. Going over the translation of the network and analysing where the various mediators occur, an interesting pattern emerges in respect to where within the process of translation the various mediators are most active ${ }^{16}$, as demonstrated by the following table:

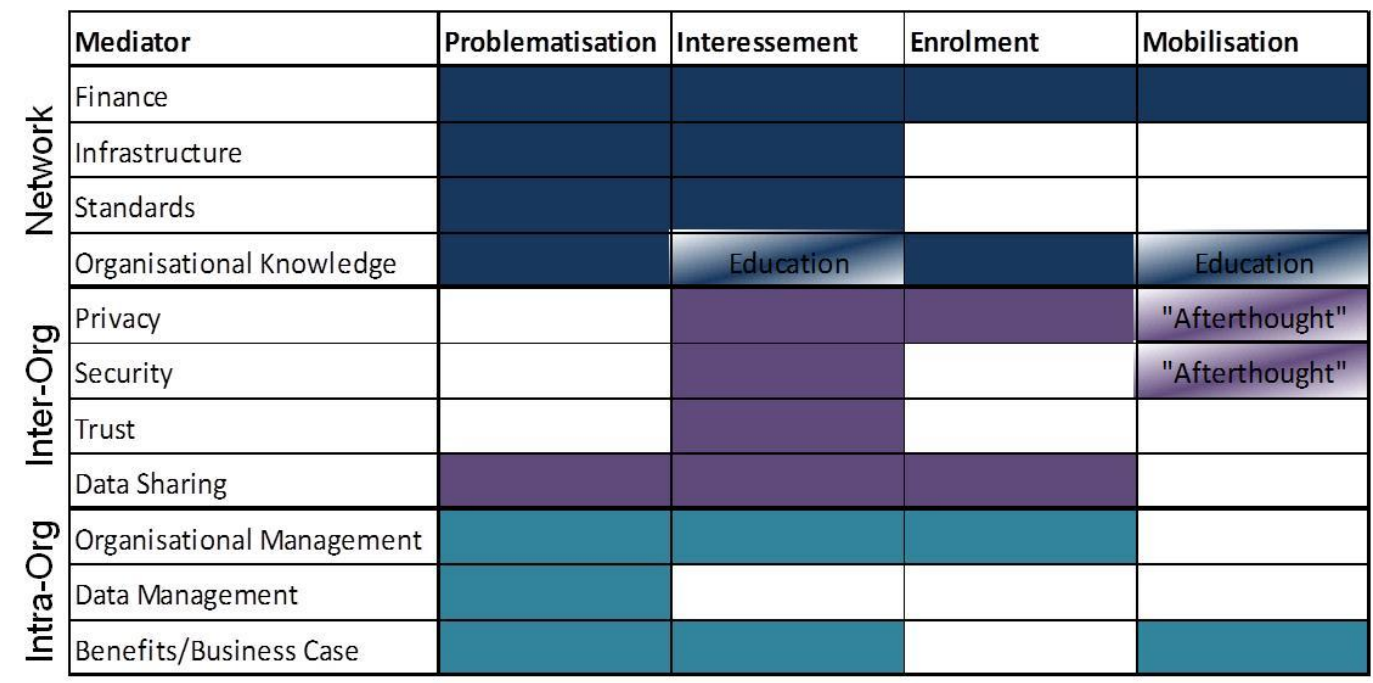

Table 15: The Place of Mediators in the Translation

The stages where mediators are active as such are coloured; where they act as intermediaries, or are not discussed in any appreciable way, the cells are blank.

It can be seen that those mediators considered to be 'inter organisational' are generally not apparent during problematisation. The problematisation is dominated by internal intra-organisational mediators, and by those mediators affecting the entire network. Until the initial focal actants go out and begin attempting to interest others, the inter-organisational mediators are fairly quiet, acting more as intermediaries. This even appears to be true when cross organisational bodies are put together to investigate a particular implementation. For example in one RFID system studied, the committee put together from various bodies to design the RFID system appeared as an actant in and of itself, thus allowing a dissenter to keep a member on this body, while resisting the application externally. This is what would be expected from

\footnotetext{
${ }^{16}$ Where mediators are most active is where the mediators are discussed more often than in other phases of translation. This does not mean that the mediators are not discussed in the other phases of translation (although they may not be), just that they are only occasionally mentioned in these less active phases.
} 
Latour's vision of actants, each actant being made up of loose combinations of other actants, each with their own motivations. It is also apparent that many of the mediators are not discussed at mobilisation. Returning to Latour (2005) we might expect that the nature of these mediators would have changed, now they merely translate action from one point to another rather than being active participants in the network - in other words they have become intermediaries. However, a number of the mediators, especially security and privacy, were found to be afterthoughts in some instances, ready to turn back into mediators from their intermediary state at mobilisation, after RFID systems had been implemented. Although privacy and security did not appear to influence the mobilisation in any of the specific instances related to this study, actants speaking on behalf of these mediators were concerned about their ability to disrupt established RFID systems. These are fragile intermediaries indeed, ready to leap out of their boxes at any moment.

Overall as can be seen in Table 15 the strongest mediator was finance, consistently discussed across every phase of translation. It was lack of finance that caused the failure of one RFID system studied, and financial problems that delayed others. It was on the point of cost that bar-codes presented their strongest challenge. Finance never appeared to settle into intermediary status, it was always there. The mediators of organisational management and data sharing were also strong, either positively through data and organisational management facilitating RFID systems or negatively through organisations struggling just to manage their RFID systems, let alone maximise the use of the data they generated through them. This was best demonstrated in combination with the benefits mediator, as findings indicated that benefits derived from the data gathered by RFID systems were at times disconnected from those expected by organisations. In one example studied data was not able to be shared between the public and private sector organisations due to the use of a secure system on the public sector side. This inability to share led to the need to employ a manual process to exchange data, thus reducing the benefits of the RFID system. Better data sharing and organisational management, and understanding of the benefits attainable from RFID systems would be likely to resolve this disconnect. 
Even though the importance of management, especially leadership, is often discussed in information systems literature (for example in Yoong (2010)), it has only recently begun appearing in RFID based literature. However, management mediators such as organisational management, data management, business case, and organisational knowledge, were strongly expressed in this study, appearing first in the problematisation phase, and continuing throughout the translation. This highlights the need to understand the nature of any RFID systems implementation, and to be able to manage the data (and the organisation) in order to ensure benefits from RFID systems implementation are fully realised.

The presence of organisational knowledge as a mediator was unexpected as it has only been touched upon in previous studies (such as Li, Godon and Visich (2010), or Wamba and Chatfield (2010)), as was the degree to which it was apparent in RFID systems. Organisational knowledge appeared important in problematisation, where the amount of knowledge an organisation (or a particular human actant) had about RFID systems influenced the amount of time the focal actants had to spend educating other actants about RFID systems. The presence of various non-human actants such as published guidelines, books, industry web sites, and conferences was particularly influential here. These non-human actants often provided the first point of contact for organisations curious about RFID systems, as well as being reference sources for those with existing RFID systems. The organisational knowledge mediator reappeared during enrolment, as actants attempting to influence others to join the network first had to educate others as to the benefits of joining the translation. It was here that the loss of trained and knowledgeable staff influenced the translation, in one instance causing the translation to stall as "there [was] no one to champion the cause". During mobilisation it became important to ensure all staff using RFID systems understood their operation, and were comfortable with it, in order to reassure those who may have been fearful of RFID technology on health or privacy grounds.

Standards and infrastructure both dropped from sight after interessement. In both cases this could be expected as questions regarding these mediators needed to be solved early in translation with standards becoming an OPP. Similarly, infrastructure requirements were written into business cases and then treated as a black box for the 
remainder of the translation, at least in the instances studied. Organisational interaction occurred mainly during the interessement and enrolment stages as organisations forged links, decided on processes and agreed the structure of their networks. Related to these mediators, trust occurred primarily in the interessement stage, as it was necessary for the building of organisational relationships. Trust returned to being an intermediary once these connections were established. Privacy persisted as a mediator through both interessement and enrolment, only becoming settled at mobilisation. Like security, privacy appeared as an afterthought in some instances indicating that its settled intermediary state was unlikely to be permanent.

Data sharing is often considered to be a result of trusted relationships, for example in Dawes et al. (2009). However, the link between data sharing and trust was not strongly apparent in this study, possibly because of the presence of legislation in a number of the RFID systems studied. Luhmann (1979) found that the presence of legislation can reduce the effect of trust in data sharing, making it less necessary to form a trusting relationship in order to share data. Although this was not clearly evident in the RFID network studied, teasing out this relationship through further research would prove interesting.

The benefits mediator shows an interesting pattern of activity in the network. It appears in problematisation, advising on the outcome of the network, be it biosecurity, traceability or similar - even though these have been shown to be contested even at this early stage. Benefits then appear to support interessement with the promise of benefits to be gained, attracting other actants to the network. However, on mobilisation the benefits attained sometimes do not match those anticipated by the business case and problematisation. This observation supports the contention by Wamba and Chatfield (2010) that RFID systems seldom realise their full benefit, and may help to explain their observations. This may also explain why RFID applications struggle to define benefits for business cases as the benefits discussed at problematisation are not always those delivered by mobilisation. Finally, associated with the initial expectation of benefits, the business case appeared only during problematisation as might be expected since the production of a business case outlined the problematisation. Despite this brief appearance, this was still an 
influential mediator as business case went on to become an OPP to the remainder of the translation.

The changing of state of mediators to intermediaries at mobilisation shows that they are no longer controversial at this stage, instead they are carriers of meaning, but not active. According to Kaghan and Bowker (2001) , intermediaries assist in interpreting, or negotiating, between black boxes. However, the status of intermediary is not permanent. It is still possible for an intermediary to return to influence the network, rising from its rest to become a mediator again. Gherardi and Nicolini (2005) find that well defined intermediaries are essential to the creation of an actor network - giving the network shape and allowing it to "travel in the world as a recognizable entity" (p. $5)$.

It is also interesting to note the persistence of mediators such as finance, infrastructure, privacy or standards within the network, as these mediators have received considerable academic and industry attention. Their persistence over time shows the issues surrounding them are not yet resolved - possibly due to the speed of technology change, and the necessity for such mediators to keep up with the changing translations required.

\subsection{RQc.: Macro Perspectives, Sectors and Institutional Theory}

This research focuses on the macro view - the larger network of RFID systems shared between the public-private sectors - deconstructing the network and investigating the networks translation in order to understand it better. It is important in the light of the macro view taken by this research, to remember the place of the institutional actant government in the network. Government, however poorly defined (as can be seen from the discussion of the public sector as a multiplicity) is the largest and most complex actant in the network. Made up of a combination of public sector and political actants, government is a leviathan in the sense used by Callon and Latour (1981), able not only to persuade actants to join the network but to force them through legislation. Government is a combination of smaller actants gathered up to create one macro-actant. But as Callon and Latour (1981) point out, there is no need to be frightened of exploring what this Leviathan means, instead this study applied the 
same methodology to the government leviathan as to the smaller actants, in order to discover how it acts within the network, and identifying government as a multiplicity.

While it has been relatively easy to follow the actants through the network, it quickly became apparent that the RFID network, like Aramis, is fragmented and defined more by individual RFID systems than by a cohesive whole. Thus, the discussion so far has taken a high level translation view with an emphasis on the action of mediators, but there are other stories to tell, and a range of actants are involved. These include the stories of individual RFID systems, and larger (more macro) organisational or institutional actants, which Roberts (2012) argues are also translation devices, aligning actants within the network. The small organisations and individuals working within the network also have stories to be told, and have only been briefly mentioned in this research.

In order to account for the presence of the organisational actants, other perspectives were brought into play, as suggested by Cresswell, Worth and Sheikh (2010) who advise combining ANT with other theoretical approaches, especially when analysing data. As discussed in the chapter on methodology and theoretical approach, ANT and Institutional Theory have been combined in a number of studies to successfully interpret the actions of institutional actants, so it is appropriate to utilise Institutional Theory to assist with interpreting the actions of the institutional actants. Institutional theory as outlined by DiMaggio and Powell (1983) recognises three pressures acting on institutions namely; coercive, normative and mimetic pressures.

Coercive pressures are readily apparent within the RFID network as the presence of legislation, or regulation is never far away. In a number of the instances studied, legislation was being sought or was already enacted. Normative pressures are also applied by the various industry bodies and standards organisations wanting (or asking) the other actants to come into alignment with their standards. Mimetic pressures, although less obvious are also present with organisations looking to what others are doing before deciding on the shape of their RFID systems. Mimetic and normative pressures also appear when organisations join RFID systems already in place, as the OPP of business case, and the decisions made by the other actants, require them to 
shape their RFID systems to suit the existing network (or to persuade the others to reform the network).

Aligning the responses to institutional pressure proposed by Oliver $(1991 a)^{17}$, with the three responses to offers of enrolment recognised by Latour $(1987)^{18}$, allows additional insight into the creation of the RFID network as it illuminates the ways actants respond to offers, or coercive requirements to join the RFID network. A

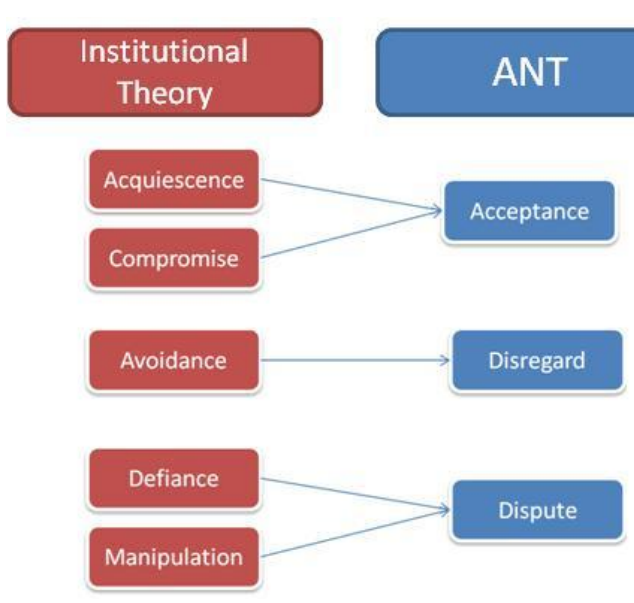

Figure 16: ANT and Institutional Theory Responses summary diagram of this combination is repeated at Figure 17 (from section 3.3) for convenience. These forces/responses are clearly present in the study network. Acceptance was shown by those that joined the network. Some just acquiesced to the problematisation, while others joined in enthusiastically. Yet others compromised by negotiating their involvement. Avoidance was shown by those that chose to use bar code technology instead of RFID, disregarded offers of enrolment, or simply chose not to participate in the network at all (where they had the option in non-legislated systems). Dispute was evident from those actants that openly opposed the translation, usually by resisting legislation. In one instance an organisation openly resisted (defied) the problematisation while still keeping a member in place on the project team ensuring input into the final shape of the translation, thus both defying and manipulating at the same time.

Powell and Colyvas (2008) call for institutional theorists to take more notice of the micro foundations of organisational development. This research shows that ANT can be of assistance in giving insight into these micro foundations, particularly through the process of translation where the construction of the network is laid bare.

\footnotetext{
${ }^{17}$ The responses are acquiescence, compromise, avoidance, defiance and manipulation.

${ }^{18}$ Being accept, dispute or disregard.
} 


\subsection{Summary}

This thesis has taken a journey through the RFID public-private sector network using ANT, and later Institutional Theory, as the means to illuminate this network. But, despite the ANT approach we haven't really heard from our hero - RFID the technology. Just as Latour (2002) provided Aramis with a voice, so too could RFID have a voice. What would it say if it did? Please use me, perhaps. Or maybe there could be advice RFID could offer in the public-private context, advice that can be drawn from this research:

Remember the mediators, make sure you understand what each of them does in the network and account for it. Ensure you know what benefits you want from your RFID systems, and use the data I give you. Talk to each other, and me, through the use of standards. Remember each sector has slightly different needs, and that the public sector comes in many different forms.

This advice can be translated into a more formal outline for practice. The mediators identified in this research highlight issues that organisations wishing to engage in cross sector RFID systems need to consider. Some of these mediators have been discussed many times in this research and in literature yet still remain important, particularly finance. Other mediators are not so commonly discussed, especially the importance of knowledge of RFID within organisations, and the need to educate both higher level managers and workers as to the nature of RFID systems. The speed of technology change makes it difficult to keep up with the organisational knowledge mediator (as it does with standards and infrastructure) because the knowledge required to understand and implement RFID systems also changes rapidly. This indicates to industry the need to be aware that those they talk to about RFID systems may not have the same level of knowledge they do.

The importance of benefits within the RFID network has also been under reported. The need to align benefits with the obligatory passage point of business case is emphasised by this research. It is the business case that spells out benefits expected, and these benefits draw other organisations into the network through interessement. The importance of good organisational and data management in achieving the 
benefits of RFID systems has also been highlighted, through the identification of a disconnect between benefits expected and attained in some RFID systems. While this might not be an unsurprising finding, this study makes it explicit.

The obligatory passage points of standards and legislation point to the need to understand how these will operate in any cross sector RFID system. It is important to note that these mediators often lag behind technology developments, especially legislation which takes time to enact. Organisations need to be aware of this, both in planning for legislation which may be enacted in the future, and in realising the importance of establishing trust as a mechanism for enhancing data sharing, as legislation cannot always be enacted rapidly enough to take the place of trust. As has already been discussed, data sharing is necessary for attaining the hoped for benefits from RFID systems.

The multiple nature of the public sector has also been demonstrated in this research, emphasising how public organisations can have more than one role within an RFID system. This is something that was not apparently considered within the study network, and again is something that organisations both public and private need to consider when working with RFID technology. The role the public sector is taking in a particular system is important, and easily confused. Keeping focused on the role required is important as it assists to clarify how the other mediators (such as finance and legislation) need to interact with the translation, and to reduce uncertainty in the RFID public-private network.

So finally, is the public-private sector RFID network like Aramis? Is it fragile and unstable or is there strength in its current translation? The findings make it clear that there is no widespread Internet of Things style RFID network between the public and private sectors with separate systems able to interact seamlessly. Instead, each RFID system exists within its own individual silo, not interacting with other systems, even if it may be technically possible. There are also examples of failed systems, like Aramis too fragile to survive translation. However, the pieces that can be seen (the individual systems), like the fragments of Aramis, can be studied, and conclusions can be drawn based on them. The RFID network that does exist allows this study to paint a rich 
picture of what currently is - and comment on what might become the public-private sector RFID network. 



\section{Conclusion}

This study has investigated the state of RFID technology in the context of RFID systems that cross the boundary between the public and private sectors. The aim of the study was to examine how the RFID network comes to be established and maintained in systems that cross the boundary between the public and private sectors; discuss how the relationship between the various actants involved contributes to establishing and maintaining the network; identify the mediators that influence it, and understand how ANT and Institutional Theory can assist in understanding such networks. This study has explored the relationships between the organisations involved in these public-private RFID networks. It has revealed network mediators and intermediaries that serve to drive the relationships between the various actants, as well as dictating the networks stability of the network. The combination of ANT and Institutional Theory provides an insight as to the complexity of the construction of the network, and to the struggle for RFID to become established in a broader public-private context.

This conclusion will reflect on the use of ANT, and discuss how Institutional Theory adds additional insight into the results. It will summarise the network mediators, outline how the various parts of the network work together, and detail the challenges faced by the network especially at the organisational level. Finally, the future of the network is discussed, along with the contribution of this study, and suggestions for future research.

\subsection{ANT and the Network}

The use of ANT in this study has allowed RFID technology to take centre stage. The ANT model of translation uncovers the interactions that caused the RFID network to be created, and maintained, and could lead to it being destroyed, or reformed. Driving these interactions and relationships were mediators/intermediaries that stabilised (or destabilised) the network translation, along with various obligatory passage points and inscriptions. These concepts, based on the language of ANT, gave a framework with which to describe the interactions observed between the various human, technological and organisational actants. 
Methodologically ANT steps through the network from actant to actant without regard for the actant's nature, or its place in reality. A technological actant is allowed to speak through representatives, either human or non-human. Thus subject matter experts (such as RFID engineers) could be consulted as representatives of RFID technology. Similarly documents such as business cases or legislation could also be consulted in a role as representatives for the organisation's RFID systems. Not only does this approach avoid the problem of technological determinism, it also means that technology can participate in its own network. The view allowed by this approach, combined with the language provided by ANT, gave a much richer view of the RFID network than that which would be found using other more conservative approaches.

\subsubsection{Network Mediators}

In total twelve mediators were identified by this study, acting within or between organisations, or across the whole RFID network. Varying in activity they moved between mediating interactions and being intermediaries - carrying meaning but not influencing the translation. Some of the mediators were familiar from information systems literature, such as finance, infrastructure, standards, data management and sharing, security, privacy and trust. That these familiar mediators continue to appear in technology networks, despite the on-going academic focus on them, shows that issues surrounding them are not yet settled. But, would we expect these issues to ever be settled? Technology is constantly changing, as are organisations, the environment, and the expectations of individuals. This rate of change, combined with the complexity of human/technology networks such as the RFID network studied here, means that these mediators will have little opportunity to settle into an intermediary state

Other mediators were less familiar within the RFID in the public-private sector context, such as organisational knowledge, benefits, business case, and organisational management. These more organisationally focused mediators were made apparent partly through the ANT process of translation, where they occur in relation to the interactions surrounding the implementation and management of the RFID network.

While the combination of mediators uncovered could be considered unconventional, in that some are conceptual rather than technological, these are the mediators that 
were apparent in the RFID network. Their unearthing highlights one of the strengths of the ANT approach, allowing both technology based, and sociological or organisational interactions to become evident in the study network, and allowing them to act in its formation, as suggested by Latour (1985).

\subsubsection{Network Translation}

The influence of the mediators in driving relationships between the actants was clear as the various actants moved through the process of translation. During the problematisation phase the mediators were focused primarily on the internal management of the organisation (intra-organisational mediators), or on the whole network. However, where mediators were intra organisational they predominantly occurred in the interessement phase, where organisations wanted to recruit other actants to their networks. Many mediators were settled, becoming intermediaries by the mobilisation phase. This is expected in the ANT model of translation where mobilisation is characterised by a certain amount of stability in the network. However, it is particularly interesting to note that this observation applies to interactions occurring between organisational as well as human actants.

While most mediators moved to intermediary status, others took different paths within the translation. Legislation, once made, becomes an obligatory passage point and inscription, able to dictate meaning throughout the network over time and distance. Durable and lasting, legislation anchored the RFID systems in which it was relevant, forcing compliance on other actants. Legislation obliged the translation to occur in a particular way. Hanseth and Monterio (1997) found that alignment of networks with their inscriptions dictated its strength. Where networks were anchored by legislation they were indeed strong, as participation in the network was required and the inscription of legislation framed the RFID system. Business cases, once written also became obligatory passage points (and inscriptions), providing guidance as to how the translation should progress. But they did not have the strength of legislation in dictating the translation process. Standards also attempted to become an OPP. At the technology level (in the various instances) it was successful as technology standards were required for the components of the various RFID systems to interact. However at the public-private sector level the question of the place of standards is still 
unsettled with a number of global standards available, and no agreement as to which, if any, to follow.

The use of ANT has allowed this study to expose the interactions of technology with humans and organisations without becoming deterministic, as well as complying with Hanseth and Monterio's (1998) call to better understand the detail behind the formation of technology networks. ANT allows the technology to have a voice, important in a network which so strongly relies on the connectivity of technology components (the RFID tags, readers and databases). However, the forces acting on organisations are not easily deciphered by using ANT. Through the course of this research it became apparent that institutional forces were better explained by including a second theoretical framework namely Institutional Theory. As noted by Orlikowski and Barley (2001):

"Technologies are simultaneously social and physical artefacts. Consequently, neither a strictly constructionist nor a strictly materialist stance are adequate for studying technologies in the work place. Elements of both perspectives are required" (p 149)

\subsubsection{ANT and Institutional Theory}

Orlikowski and Barley (2001) recommend combining Institutional Theory with other theories, specifically recommending theoretical approaches from Information Technology and Organisational Sciences in order to integrate an understanding of how the social and technical interact, "building a bridge" (p. 149) between the two. They speculated this would allow for the avoidance of technological determinism as well as avoiding an excess of social constructionism in the description of technology/social systems. Despite Institutional Theory being constructivist in nature (while ANT is not), this study has shown that the two work well together as lenses into a network which contains both technology and organisational actants. ANT describes how RFID systems come into being and how are they performed; how they become established, stabilised and maintained. Institutional Theory describes how organisations act or change when influenced by various forces, operating on an institutional or macro level. In the context of an organisational approach these two theories are complementary, 
able to observe both the nature of technology and the organisation to expose the relationships between the actants. Further, the symmetrical view adopted by ANT (where all things human or non-human are considered to be able to act or have agency) struggles with complex institutional or organisational actants as it theoretically requires extensive investigation of each individual element of the organisation, as macro actants are made up of micro actants. Such an in depth investigation is not practicable in the case of large institutional actants. Instead, the addition of Institutional Theory allowed for the behaviour of organisational actants to be further explained without the need to examine each actant in micro-detail. Although it is acknowledged that the Institutional Theory concepts could themselves be considered to be black boxes.

From an Institutional Theory viewpoint, coercive, normative and mimetic pressures are clearly apparent in the RFID network. For example, legislation represented a strong coercive pressure requiring compliance, and matching with its ANT role as an inscription or OPP. Similarly the drive for standardisation was a normative pressure in the institutional sense and an inscriptive one in the ANT sense. Mimetic pressure while less obvious was still present, partly shown through the need to align standards regimes, and also through organisations falling into alignment with what other organisations were doing in the RFID network. At a more macro level, the action of the Internet of Things (treated as an actant in this research) might also be considered to be Institutional in nature, if the Internet of Things itself is considered to be an institution. This would be unconventional but still acceptable under the definition of institutions proposed by Jepperson (1991, p. 145), in that the Internet of Things is indeed a "pattern that has attained a certain state or property". As an actant the Internet of Things tempts the network with a vision of complete connectivity. As an institutional actor the Internet of Things could be considered to exert either a normative pressure, through the action of various professional bodies influencing RFID systems owners to comply with Internet of Things standards, or a mimetic pressure as organisations wanting to join the Internet of Things copy the actions of other organisations. If indeed the Internet of Things could be considered an institution, could other complex socio-technical networks be thought of this way? Such a 
discussion is outside the scope of this thesis but does suggest an area where further research might prove interesting.

The complexity of modern information systems, which include numerous technological as well as human and organisational actants, leaves us asking how best to understand them. The use of ANT at an organisational level is unusual compared to the majority of ANT studies where a far more micro (case based) perspective is taken. However, in this study the macro view has allowed for a rich picture of the forces/mediators that act on the network to be discovered. In combination with Institutional Theory this has allowed the actions of larger organisational actants to be exposed and understood, along with those of smaller micro actants. Thus a multidimensional view was presented that would not have been possible with the use of a single theory alone. The ability to map the types of pressures exerted in an Institutional situation, with the responses to the offer of translation suggested by Latour (1987) further demonstrates the compatibility of the two theories. In short, while ANT can open up the black box of institutions, Institutional Theory can help explain it.

\subsection{The RFID Network in the Public-Private Sector Context}

The story of the network, and the influence of the mediators described how the various actants constructed the network. However, this study was also interested in the higher level issue of how the sectors acted together. Framed by the perceptions that actants in each sector had of the other sector, this story became more mundane the longer the sectors worked together. As the actants became familiar with each other they appeared to forget the differences between their sectors and behaved simply as organisations working together, with the relationships focused on the individuals. Often criticisms or compliments that could be directed at one sector, where many mediators were concerned, could be directed at both. Interestingly, this observation is also a reflection of what might be expected by Institutional Theory; with its focus on isomorphism suggesting that organisations are driven to become more similar over time through institutional pressure. However, there were still differences between the two sectors notably in the way privacy and security were handled. This was seen to be related to the nature of data being held by the public sector which 
meant that this sector was more sensitive to considerations around security and privacy. These differences showed the importance of understanding the data held by RFID systems, and putting in place appropriate protections, as the private sector particularly were less concerned about matters of security and privacy. It is important to take note of these differences when considering cross sector RFID systems as the mixing of the sectors changes translation by strengthening the effects of the privacy and security mediators. So, while there was some evidence of public-private isomorphism, it was clear that there were still considerable and significant differences between the two sectors.

The appearance of the public sector as a multiplicity, with at least four different performances of the public sector apparent, added to the complexity of the network. In particular the difficulty some actants had distinguishing the public sector from government, and problems around public sector actants being clear on what role they should be performing in relation to the network, led to confusion. There is no question that the roles of the public sector are multiple, and an understanding of which role is being enacted is essential to a smooth translation/mobilisation. In other words, when operating in a particular network it is important for public sector actants to understand whether they are operating as a regulator producing legislation to frame the network; an enforcer of such legislation; a member of the network participating in the RFID system; or a funder or provider of services to network members. Where acting as a regulator this study has shown it is also necessary to understand the strength of legislation and how this might affect the operation of the various networks.

But the question still remains at the higher level RFID network in the public-private sector - is the network cohesive and complete or is it fragmented? As Latour (2002, p. 291) finds with Aramis "the demand for it [Aramis] is undefined, the feasibility of the vehicle is uncertain, its costs are variable, its operating conditions are chancy, its political support - like all political support - is inconsistent." These are the very problems seen within the RFID network studied. Some systems studied are complete and well maintained, supported by politicians, and with strong inscriptions such as legislation and standards in place. Others are not well supported; they suffer from financial problems, the mediators act unpredictably, and the network does not appear 
to be particularly feasible. Overall the individual RFID systems do not, and due to a lack of an agreed standard often cannot, interconnect with each other. The sensitive nature of data collected by some public sector organisations was also an issue. It is unlikely that this data would ever be available for sharing, nor would it be appropriate to do so. However, a nuanced understanding of the nature of data collected was seen as being central to the ability to share it. A more open approach by some public sector organisations, based on this understanding, offers hope of greater public-private sector integration around RFID networks. Further questions arising around the problematisations themselves, whether the technology being used is appropriate to the problem, or even whether the correct questions are being asked, are also challenges that need to be addressed.

This conclusion has so far focused on what was observable within the RFID network studied. However, the stability of the network translation itself has not been addressed. If the network is not stable, something that might be implied from the actions of the mediators changing between mediator and intermediary state, the question can be asked is there a future state (or translation) for the network? Although the ANT paradigm does not allow for more than a description of what is (and what has been), it does offer some assistance here. ANT suggests that micro networks can join together to form macro networks, especially in the presence of strong inscriptions such as standards or legislation. If we lift the context of our discussion for a moment from "RFID used in applications that cross the border between public and private sectors" to all RFID applications, we can see that the translation we are investigating is by no means the only translation that has been undertaken by the network. The already discussed IFF system was an initial translation of the RFID network, it was followed by others, influenced by various technology changes, leading to the network translation studied here. There will be more translations, occurring at the speed of technology change, stabilised in part by standards and legislation, where necessary. These may eventually lead to a widely available, fully connected Internet of Things within the public-private context. 


\subsection{Contribution to Theory}

This study makes a number of contributions to theory, research and practice. First, this study makes a theoretical contribution by offering a possible method by which to study complex technology systems. The combination of ANT and Institutional Theory suggests that at the organisational/institutional level it is possible to understand both the formation of networks through the ANT translation, and the pressures put upon organisations and institutions to join (or reject) the network through the Institutional Theory lens. The way organisations respond to institutional pressures, and offers to enrol in the network translation, were seen to be related, and this relationship was invaluable in understanding organisational behaviour, answering a weakness in ANT which struggles to understand organisational behaviour. Further, ANT also offers Institutional Theory a way to understand the micro-foundations of Institutional behaviour, which have been difficult to locate using just the Institutional Theory framework. The combination of ANT and Institutional Theory answers the call by Bardaki et al. (2010) to provide a framework to assist in understanding the complexity of modern organisational systems and points towards a combined theoretical framework through which complex socio-technological systems can be understood.

\subsection{Contribution to Research}

This study also addresses the gap in literature outlined in the introduction by expanding understanding of how RFID systems that cross the boundary between the public and the private sector are established and maintained. Specifically the finding that a combination of mediators influences the RFID network has not been previously reported. Some of these were identified in the literature, either individually or in combination, but the importance of prior organisational knowledge has been underreported. Also, the disconnect between benefits expected from RFID systems, and those realised, has not been comprehensively investigated. This research was able to determine that poor understanding of data gathered by RFID systems may explain this observation, as shown in Section 5.3.3, Benefits and Business Case.

The theoretical nature of the mediators model also contributes to research by offering a framework that could be used as a guide in studying other similar technology systems, either quantitatively or qualitatively. Further, The use of ANT, with its lack of 
constraints on the form the actants take, allowed for the identification of the public sector as a multiplicity. This would have been difficult if a more restrictive technology implementation or adoption framework was used. The use of ANT in this way contributes to research as it suggests a method by which complexity in large distributed technology systems can be understood.

\subsection{Contribution/Implications for Practice}

The mediator's framework contributes to practice by pointing towards issues that need to be considered, when implementing and managing RFID systems in the publicprivate sector context. The nature of mediators, and their ability to change between mediator and intermediary states assists organisations in understanding the issues on which their RFID systems can falter. Some of the mediators identified were unexpected, especially the need for understanding of the benefits derived from RFID systems, and the need for organisations to understand and appropriately manage such systems. The mediators identified present a road-map to practice, highlighting the factors that should be considered for successful RFID systems. Further, combined with the understanding of RFID systems derived from ANT, it can be seen that those implementing cross border RFID systems need to ensure they address all the mediators in problematisation. This is especially true of the inter-organisational mediators which currently appear as intermediaries in problematisation stage of the ANT translation.

This study also contributes to understanding the interaction of the public and private sectors around complex technology systems. The uncovering of the multiplicity of the public sector is important for practitioners as it alerts them to the different aspects of the public sector that need to be taken into account when participating in publicprivate RFID systems. Further, the understanding that the public sector is multiple, should reduce confusion, as practitioners will be able to highlight which aspect of the public sector they need to interact with and focus on that aspect thus increasing efficiency of interaction. For researchers this finding offers a possible reason for some of the confusion surrounding public-private sector technology systems, and suggests research directions for determining the effects of this multiplicity. 
Finally, this study adds to the understanding of the place of RFID technology within the range of technology concepts, suggesting that while RFID technology definitely contributes to the pervasive/ubiquitous/invisible concepts, it does not yet approach the experiential model. Nor can RFID systems in the public-private context be considered to be part of the Internet of Things as they still exist within individual silos, although the possibility still exists that Internet of Things style systems could be implemented in the future.

\subsection{Limitations}

This research is partially limited by the descriptive nature of ANT. ANT is interested in what is and what has been, and thus is not able to predict outcomes. This prevents any speculation on the future of the network and also limits any generalisation to that which is observed within the network, although this limitation is also common to qualitative interpretivist research. However, sound methodology allows for a certain amount of trustworthiness in the results. The methodology adopted by this study (outlined in the Methodology chapter), includes rigorous design based on explicit theory. Attention was paid to coding reliability and sampling techniques in order to address this concern. Sound research design also addresses concerns around the researcher's place in the construction of reality by ensuring the researcher recognises any bias or misinterpretation that might arise from this. Further, Hardy and Williams (2008) in an ANT study of e-government procurement, suggest that while ANT translations within a similar context vary according to local practices, the framework remained similar. They also found that broader government/institutional processes were similar - or isomorphic. This may allow for some higher level generalisation, and suggests that the mediators/intermediaries might be able to be applied to similar contextual networks.

Another limitation of this study is its focus on the macro organisational and sector actants. Hanseth (1997) accuses ANT of manageralism, focusing on strong actants, and therefore making it difficult to locate those that refuse to be involved in the network. Institutional theory could also be accused of this as it focuses on pressures affecting organisations much more than individuals. As this study has also focused at the organisational level it is likely that the voice of the weaker actants (members of the 
public for example) have not been fully represented. However, it would never have been possible to capture all the actants in the network because of time and distance constraints. Likewise, cultural differences may have been apparent in a larger more geographically distributed sample, but were not clearly observed in the network as studied.

A further limitation arises from the maturity of the network. As the RFID network becomes more mature, and assuming issues such as infrastructure and standards are resolved, the mediators within the network may be expressed differently. There is no real way within the limitations of the ANT framework to anticipate what these differences may be.

\subsection{Future Study}

A number of aspects of this research could be interesting to investigate further. Theoretically, the utility of the combination of ANT, and Institutional Theory, has been demonstrated by this research. Given the number of complex technology systems where human and non-human actants interact on a daily basis, it would be valuable to further test this combined theoretical approach as it shows promise as a method to understand such human/technology networks. Further, the ability to deconstruct multi-organisational networks in order to determine their mediators would be of assistance in understanding both the networks and the nature of their interactions.

Avenues for future research are also apparent from the uncovering of the mediators. The mediator model produced can be tested quantitatively in order to confirm the relationship of the various mediators, their relative strengths in different situations, and whether the grouping is appropriate. It may also be interesting to apply the model to other technologically distributed systems like those related to cloud computing or big data systems. This would test the applicability of the mediators' model to other complex human/technology systems. The nature of the relationship between some of the mediators such as privacy, trust, and the type of the data being shared could also be further explored. Similarly, the question of the differences in treatment of privacy between the two sectors could be examined. The issue of the nature of benefits, and the disconnect between benefits anticipated and those actually realised is intriguing 
and could be studied further. This disconnect in benefits might also be seen in other IT systems. Additionally, the effect of the uneven distribution of benefit and cost between actants in the network, is an important one especially for practice. This study has only briefly touched upon this issue and it warrants further investigation, especially given the strength of the finance mediator.

The multiplicity of roles for the public sector, and the resulting confusion within the network, was only highlighted by this study, and might prove fruitful for public sector researchers. The effects of the different multiples could be further described, especially in relation to their influence on the network mediators. The private sector may also display multiple roles, and it could be worthwhile to explore this. The apparent lack of information systems focused research in respect of the multiplicity of roles in the public sector, suggests that this could be a rich area for researchers. Again it might be valuable to compare the situation seen within the RFID network with other networks that cross the boundary between the public and the private sector.

From the institutional theory perspective, it may be interesting to explore the place of Institutional forces in driving public-private networks towards isomorphism, and whether or not this drive is changing the way the public-private sectors are defined. The possibility that technology systems may also act as institutions is one that was not explored in this research, but that may also provide a rich area for research, not only in the understanding of technology systems themselves but also in challenging the definition of an institution.

All of the areas for future research suggested above provide good grounds for study, both in order to contribute to understanding how RFID enabled artefacts and the Internet of Things act in society, but also to understand more broadly the role of complex technological systems. The utility of the combination of ANT and Institutional Theory in understanding such systems is only just being explored and the power of this combination to unpick the complexities of socio-technical networks has not yet been realised. Future research will determine the usefulness of this combination and in doing so expand understanding of how technology systems interact with society in networks that cross the boundary between public and private sectors. 


\section{References}

Aanestad, M. (2003). The camera as an actor: Design-in-use of telemedicine infrastructure in surgery. Computer Supported Cooperative Work, 12(1), 1-20. ABI Research. (2012). The RFID market will be worth over $\$ 70$ billion across the next five years. Retrieved August 22, 2013, from https://www.abiresearch.com/press/the-rfid-market-will-be-worth-over-70billion-acro

Agha, G. (2008). Computing in pervasive cyberspace. Communications of the ACM, 51(1), 68-70. doi:10.1145/1327452.1327484

Akrich, M. (1992). The de-scription of technical objects. In W. Bijker \& J. Law (Eds.), Shaping technology building society: Studies in socio-technical change (pp. 205-224). Cambridge, Mass. : MIT Press.

Akrich, M., \& Latour, B. (1992). A summary of a convenient vocabulary for the semiotics of human and nonhuman assemblies. In W. Bijker (Ed.), Shaping technology building society: Studies in socio-technical change (pp. 259-264). Cambridge Mass.: MIT Press.

Albrecht, K., \& McIntyre, L. (2006). Spychips: How major corporations and government plan to track your every purchase and watch your every move. New York: Plume.

Albright, B. (2005). Retailers wrestle with the data end of RFID. Frontline Solutions, 6(5), 18-22.

Alcadipani, R., \& Hassard, J. (2009). Critical management studies and actor network theory: Towards a political ontology of organising. The Academy of Management Proceedings, 1-6.

Alvarez, G. (2004). What's missing from RFID tests. Information Week. Retrieved from http://www.informationweek.com/news/globalcio/showArticle.jhtml?articleID $=52500193$

Alvesson, M., \& Sköldberg, K. (2009). Reflexive methodology: New vistas for qualitative research (2nd ed.). Los Angeles: SAGE.

Anttiroiko, A.-V. (2005). Towards ubiquitous government: The case of Finland. EService Journal, 4(1), 65-99.

Anttiroiko, A.-V. (2012). The role of new technologies in reshaping governance platforms. International Journal of Information Communication Technologies and Human Development, 4(3), 1-13.

Archer, N. (2010). m-Government and e-government. In E-government information, technology, and transformation (pp. 106-122). Armonk N.Y.: M. E. Sharpe.

Ashton, K. (2009). That "internet of things" thing. RFID Journal. Retrieved from http://www.rfidjournal.com/article/articleview/4986/1/82/

Atzori, L., lera, A., \& Morabito, G. (2010). The internet of things: A survey. Computer Networks, 54(15), 2787-2805. doi:10.1016/j.comnet.2010.05.010 
Bacheldor, B. (2005). RFID pain now, rewards to come. Information Week, (1032), 51.

Backhouse, J., Hus, C., \& Silva, L. (2006). Circuits of power in creating de jure standards: Shaping an international information systems security standard. MIS Quarterly, 413-438.

Bailey, C. A. (2007). A guide to qualitative field research (2nd ed.). Thousand Oaks, Calif: Pine Forge Press.

Bandyopadhyay, D., \& Sen, J. (2011). Internet of things: Applications and challenges in technology and standardization. Wireless Personal Communications, 58(1), 4969.

Banks, J., Pachano, M., Thompson, L., \& Hanny, D. (2007). RFID applied. Hoboken, NJ, USA: John Wiley \& Sons, Inc.

Barbour, R. S. (2008). Introducing qualitative research: A student guide to the craft of doing qualitative research. Los Angeles: London.

Bardaki, C., Kourouthanassis, P., \& Pramatari, K. (2010). Exploring the deployment and adoption of RFID-enabled retail promotions management. International Journal of RF Technologies: Research and Applications, 2(2), 91-115.

Barratt, M., \& Choi, T. (2007). Mandated RFID and institutional responses: Cases of decentralized business units. Production and Operations Management, 16(5), 569-585.

Belanger, F., Carter, L. D., \& Schaupp, L. C. (2005). U-government: A framework for the evolution of e-government. Electronic Government, an International Journal, 2(4), 426-445.

Bendavid, Y., \& Cassivi, L. (2010). Bridging the gap between RFID/EPC concepts, technological requirements and supply chain e-business processes. Journal of Theoretical and Applied Electronic Commerce Research, 5(3), 1.

Bhon, J., Gartner, F., \& Vogt, H. (2003). Dependability issues of pervasive computing in a healthcare environment. In International Conference on Security in Pervasive Computing (pp. 53-70). Boppard, Germany. Retrieved from http://www.vs.inf.ethz.ch/publ/papers/bohn_pervasivehospital_spc_2003_fin al.pdf

Bijker, W. E. (1993). Do not despair: There is life after constructivism. Science, Technology, \& Human Values, 18(1), 113-138.

Blomqvist, K. (2005). Trust in a dynamic environment: Fast trust as a threshold condition for asymmetric technology partnership formation in the technology sector. In K. Bijlsma-Frankema \& R. K. Woolthuis (Eds.), Trust under pressure: Empirical investigations of trust and trust building in uncertain circumstances (pp. 127-147). Edward Elgar Publishing.

Blomqvist, K., Hurmelinna-Laukkanen, P., Nummela, N., \& Saarenketo, S. (2008). The role of trust and contracts in the internationalization of technology-intensive Born Globals. Journal of Engineering and Technology Management, 25(1), 123135. 
Bødker, M., Gimpel, G., \& Hedman, J. (2012). Time-out/time-in: The dynamics of everyday experiential computing devices. Information Systems Journal. doi:10.1111/isj.12002

Bonner, B., Chiasson, M., \& Gopal, A. (2009). Restoring balance: How history tilts the scales against privacy. An actor-network theory investigation. Information and Organization, 19(2), 84-102. doi:10.1016/j.infoandorg.2008.12.001

Bonner, W., \& Chiasson, M. (2005). If fair information principles are the answer, what was the question? An actor-network theory investigation of the modern constitution of privacy. Information and Organization, 15(4), 267-293. doi:10.1016/j.infoandorg.2005.03.001

Borgman, C. (2003). From Gutenberg to the global information infrastructure: Access to information in the networked world (1st MIT Press pbk. ed.). Cambridge Mass.: MIT Press. Retrieved from http://books.google.co.nz/books?hl=en\&lr=\&id=xeQnNI0GNqIC\&oi=fnd\&pg=P $R 7 \& d q=$ definition+information+infrastructure \&ots $=5 s 4 d 9 Q v-$ RN\&sig=TLwfpEP_vEcWeXDtnybYkPEUF30\#v=onepage\&q=definition\%20infor mation\%20infrastructure $\& \mathrm{f}=$ false

Borgman, C. (2007). Scholarship in the digital age: Information, infrastructure, and the internet. Cambridge Mass.: MIT Press. Retrieved from http://books.google.co.nz/books?hl=en\&lr=\&id=ZDDu3CuzDdMC\&oi=fnd\&pg= $P R 7 \& d q=$ definition+information+infrastructure\&ots=Es05sb14LE\&sig=yQze9qg ap8nGXqMf65ALNwae7lk\#v=onepage\&q=definition\%20information\%20infrast ructure $\& \mathrm{f}=$ false

Bose, I., Ngai, E. W. T., Teo, T. S. H., \& Spiekermann, S. (2009). Managing RFID projects in organizations. European Journal of Information Systems, 18(6), 534-540.

Boxenbaum, E., \& Strandgaard Pedersen, J. (2009). Scandinavian institutionalism-a case of institutional work. Institutional Work: Actors and Agency in Institutional Studies of Organization, 178-204.

Brady, M., Fellenz, M. R., \& Armstrong, C. (2007). Too much data, too little information: The challenges of RFID implementation. SSRN eLibrary. Retrieved from http://papers.ssrn.com/sol3/papers.cfm?abstract_id=989303

Bretschneider, S. (1990). Management information systems in public and private organizations: An empirical test. Public Administration Review, 50(5), 536-545.

Brodie, C., Karat, C.-M., Karat, J., \& Feng, J. (2005). Usable security and privacy: A case study of developing privacy management tools. In Proceedings of the 2005 Symposium on Usable Privacy and Security (pp. 35-43). ACM.

Brown, S. (1997). Revolution at the checkout counter. Cambridge Mass.: Harvard University Press.

Bryman, A. (2012). Social research methods (4th ed.). Oxford: Oxford University Press.

Bryson, J. M., Crosby, B. C., \& Bryson, J. K. (2009). Understanding strategic planning and the formulation and implementation of strategic plans as a way of 
knowing: The contributions of actor-network theory. International Public Management Journal, 12(2), 172-207. doi:10.1080/10967490902873473

Bunduchi, R., Weisshaar, C., \& Smart, A. U. (2011). Mapping the benefits and costs associated with process innovation: The case of RFID adoption. Technovation, 31(9), 505-521. doi:10.1016/j.technovation.2011.04.001

Busch, L. (2010). Can fairy tales come true? The surprising story of neoliberalism and world agriculture. Sociologia Ruralis, 50(4), 331-351. doi:10.1111/j.14679523.2010.00511.x

Callon, M. (1986). Some elements of a sociology of translation: Domestication of the scallops and the fishermen of St Brieuc Bay. In J. Law (Ed.), Power, action and belief: A new sociology of knowledge? (pp. 196-233). London; Boston: Routledge and Kegan Paul.

Callon, M. (1987). Society in the making: The study of technology as a tool for sociological analysis. In The social construction of technological systems: New directions in the sociology and history of technology (pp. 83-105). Cambridge, Mass: MIT Press.

Callon, M, \& Latour, B. (1981). Unscrewing the big leviathan: How actors macrostructure reality and how sociologists help them to do so. In K. Knorr-Cetina \& A. V. Cicourel (Eds.), Advances in social theory and methodology: Toward an integration of micro- and macro-sociologies (pp. 276-303). Boston: Routledge \& Kegan Paul.

Callon, Michel. (1991). Techno-economic networks and irreversibility. A Sociology of Monsters: Essays on Power, Technology and Domination, 38, 132-161.

Carr, A. S., Zhang, M., Klopping, I., \& Min, H. (2010). RFID technology: Implications for healthcare organizations. American Journal of Business, 25(2), 25-41.

Cas, J. (2005). Privacy in pervasive computing environments - a contradiction in terms? IEEE Technology and Society Magazine, 24(1), 24-33. doi:10.1109/MTAS.2005.1407744

Chalmers, D., Chalmers, M., Crowcroft, J., Kwaitkowska, M., Milner, R., O’Neill, E., ... Sloman, M. (2006). Ubiquitous computing: Experience, design and science. Retrieved from http://www-dse. doc. ic. ac. uk/Projects/UbiNet/GC/Manifesto/manifesto. pdf

Chatfield, A. T., Wamba, S. F., \& Tatano, H. (2010). E-government challenge in disaster evacuation response: The role of RFID technology in building safe and secure local communities. In 2010 43rd Hawaii International Conference on System Sciences (pp. 1-10). Honolulu, Hawaii, USA. doi:10.1109/HICSS.2010.164

Cheek, J. (2005). The practice and politics of funded qualitative research. In N. Denzin (Ed.), The SAGE handbook of qualitative research (3rd ed., pp. 387-409). Thousand Oaks: Sage Publications. 
Choi, T., \& Bhakoo, V. (2013). The iron cage exposed: Institutional pressures and heterogeneity across the healthcare supply chain. Journal of Operations Management, 31(6), 432-449.

Chopra, S., \& White, L. (2007). Privacy and artificial agents, or, is Google reading my email? In Proceedings of the 20th International Joint Conference on Artificial Intelligence (pp. 1245-1250).

Chow, R., Golle, P., Jakobsson, M., Shi, E., Staddon, J., Masuoka, R., \& Molina, J. (2009). Controlling data in the cloud: Outsourcing computation without outsourcing control. In Proceedings of the 2009 ACM Workshop on Cloud Computing Security (pp. 85-90). Chicago, Illinois, USA: ACM. doi:10.1145/1655008.1655020

Chui, M., Löffler, M., \& Roberts, R. (2010). The internet of things. McKinsey Quarterly, (2), 70-79.

Clegg, S. (2010). The state, power, and agency: Missing in action in institutional theory? Journal of Management Inquiry, 19(1), 4-13. doi:10.1177/1056492609347562

Coleman, S. (2008). Foundations of digital government. In H. Chen, L. Brandt, V. Gregg, R. Traunmüller, S. Dawes, E. Hovy, ... C. A. Larson (Eds.), Digital government (pp. 3-19). Springer US. Retrieved from http://dx.doi.org/10.1007/978-0-38771611-4_1

Corbin, J. M., \& Strauss, A. L. (2008). Basics of qualitative research: Techniques and procedures for developing grounded theory. Los Angeles, Calif.: Sage Publications.

Cordella, A., \& Shaikh, M. (2003). Actor network theory and after: What's new for IS research? In European Conference of Information Systems. Naples, Italy. doi:10.1111/j.1467-629X.1980.tb00220.x

Cresswell, K. M., Worth, A., \& Sheikh, A. (2010). Actor-Network Theory and its role in understanding the implementation of information technology developments in healthcare. BMC Medical Informatics and Decision Making, 10(1), 67. doi:10.1186/1472-6947-10-67

Creswell, J. (2009). Research design: Qualitative, quantitative, and mixed method approaches (3th ed.). Thousand Oaks: Sage Publications.

Currie, W. L., \& Swanson, E. B. (2009). Special issue on institutional theory in information systems research: Contextualizing the IT artefact. Journal of Information Technology, 24(4), 283-285. doi:10.1057/jit.2009.17

Curtin, J., Kauffman, R., \& Riggins, F. J. (2007). Making the "MOST" out of RFID technology: A research agenda for the study of the adoption, usage and impact of RFID. Information Technology and Management, 8(2), 87-110. doi:10.1007/s10799-007-0010-1

Czarniawska-Joerges, B., \& Hernes, T. (2005). Constructing macro actors according to ANT. In Actor-network theory and organizing (pp. 7-14). Malmö; Copenhagen: Liber; Copenhagen Business School Press. 
Davis Jr, F. D. (1986). A technology acceptance model for empirically testing new enduser information systems: Theory and results (PhD dissertation). Massachusetts Institute of Technology.

Dawes, S. S. (1996). Interagency information sharing: Expected benefits, manageable risks. Journal of Policy Analysis and Management, 15(3), 377-394.

Dawes, S. S. (2008). Introduction to digital government research in public policy and management. In Digital Government (Vol. 17, pp. 103-125). Springer US. Retrieved from http://dx.doi.org/10.1007/978-0-387-71611-4_1

Dawes, S. S., Cresswell, A. M., \& Pardo, T. A. (2009). From "need to know" to "need to share": Tangled problems, information boundaries, and the building of public sector knowledge networks. Public Administration Review, 69(3), 392-402.

De Hert, P. (2008). Identity management of e-ID, privacy and security in Europe. A human rights view. Information Security Technical Report, 13(2), 71-75. doi:16/j.istr.2008.07.001

Denscombe, M. (2007). The good research guide for small-scale social research projects (3. ed.). Maidenhead: Open University Press.

Denzin, N. K., \& Lincoln, Y. S. (2005). The discipline and practice of qualitative research. In N. K. Denzin (Ed.), The SAGE handbook of qualitative research (3rd ed., pp. 1-32). Thousand Oaks: Sage Publications.

DiMaggio, P. J., \& Powell, W. W. (1983). The iron cage revisited: Institutional isomorphism and collective rationality in organizational fields. American Sociological Review, 48(2), 147-160.

DiMaggio, P. J., \& Powell, W. W. (1991). Introduction. In W. W. Powell \& P. J. DiMaggio (Eds.), The new institutionalism in organizational analysis (1st ed., pp. 1-38). University Of Chicago Press.

Dobkin, D. M. (2013). The RF in RFID: UHF RFID in practice (2nd ed.). Newnes.

Doganova, L. (2013). Transfer and exploration: Two models of science-industry intermediation. Science and Public Policy, 40(4), 442-452.

Doolin, B., \& Lowe, A. (2001). To reveal is to critique: Actor-network theory and critical information systems research. Journal of Information Technology, 17(2), 69. doi:10.1080/02683960210145986

Dutta, A., Lee, H. L., \& Whang, S. (2007). RFID and operations management: Technology, value, and incentives. Production and Operations Management, 16(5), 646-656.

Elbanna, A. (2009). Actor network theory and IS research. In Y. Dwivedi (Ed.), Handbook of Research on Contemporary Theoretical Models in Information Systems (pp. 403-419). Hershey PA: Information Science Reference.

Elbanna, A. (2011). The theoretical and analytical inclusion of actor network theory and its implication. In A. Tatnall (Ed.), Actor-network theory and technology innovation: Advancements and new concepts (pp. 130-142). United States of America: Information Science Reference. 
EPCglobal. (2010). About Us. Retrieved November 19, 2010, from http://www.epcglobalinc.org/about/

Eurich, M., Oertel, N., \& Boutellier, R. (2010). The impact of perceived privacy risks on organizations' willingness to share item-level event data across the supply chain. Electronic Commerce Research, 10(3-4), 423-440. doi:10.1007/s10660010-9062-0

European Commission. (2012). Digital agenda: Commission consults on rules for wirelessly connected devices - the "Internet of Things" (No. IP/12/360). The European Commission.

European Commission. (2013). Report on the public consultation on loT governance. European Commission. Retrieved from https://ec.europa.eu/digitalagenda/en/news/conclusions-internet-things-public-consultation European Union. (2009). Internet of things - an action plan for Europe (No. 278). Brussels: Commission of the European Communities. Retrieved from http://ec.europa.eu/information_society/policy/rfid/documents/commiot2009 .pdf

Eze, S., Duan, Y., \& Chen, H. (2012). Factors affecting emerging ICT adoption in SMEs: An actor network theory analysis. In Contemporary research on e-business technology and strategy (pp. 361-377). Springer.

Feldman, M., \& Pentland. (2005). Organizational routines and the macro-actor. In B. Czarniawska-Joerges \& T. Hernes (Eds.), Actor-network theory and organizing (pp. 91-111). Malmö ;Copenhagen: Liber ;;Copenhagen Business School Press.

Fredriksson, M., Pallas, J., \& Wehmeier, S. (2013). Public relations and neoinstitutional theory. Public Relations Inquiry, 2(2), 183-203.

Friedewald, M., \& Raabe, O. (2011). Ubiquitous computing: An overview of technology impacts. Telematics and Informatics, 28(2), 55-65. doi:10.1016/j.tele.2010.09.001

Gad, C., \& Jensen, C. B. (2010). On the consequences of post-ANT. Science, Technology \& Human Values, 35(1), 55 -80. doi:10.1177/0162243908329567

Gao, P. (2005). Using actor-network theory to analyse strategy formulation. Information Systems Journal, 15(3), 255-275. doi:10.1111/j.13652575.2005.00197.x

Garon, J. (2010). The implications of informatics on data policy. Media Law Review, Forthcoming. Retrieved from http://papers.ssrn.com/sol3/papers.cfm?abstract_id=1658908

Gershenfeld, N., Krikorian, R., \& Cohen, D. (2004). The internet of things. Scientific American, 291(4), 76.

Gherardi, S., \& Nicolini, D. (2005). Actor-networks: Ecology and entrepreneurs. In Actor-network theory and organizing (pp. 285-306). Malmö;Copenhagen: Liber ; Copenhagen Business School Press. 
Giddens, A. (1979). Central problems in social theory: Action, structure and contradictions in social analysis (Vol. 241). University of California Pr.

Gil-Garcia, J. R., Pardo, T. A., Burke, G. B., \& Guler, A. (2010). Trust in government cross-boundary information sharing initiatives: Identifying the determinants. In System Sciences (HICSS), 2010 43rd Hawaii International Conference on System Sciences (pp. 1-10). Hawaii. Retrieved from

http://ieeexplore.ieee.org.helicon.vuw.ac.nz/stamp/stamp.jsp?tp=\&arnumber $=5428341$

Glover, B., \& Bhatt, H. (2006). RFID essentials. Sebastopol CA: O'Reilly.

Gogan, J. L., Williams, C. B., \& Fedorowicz, J. (2007). RFID and interorganisational collaboration: Political and administrative challenges. Electronic Government, an International Journal, 4(4), 423-435.

Greenhalgh, T., \& Stones, R. (2010). Theorising big IT programmes in healthcare: Strong structuration theory meets actor-network theory. Social Science \& Medicine, 70(9), 1285-1294. doi:10.1016/j.socscimed.2009.12.034

Grönlund, A., \& Horan, T. A. (2005). Introducing e-gov: History, definitions, and issues. Communications of the Association for Information Systems, 39(15). Retrieved from http://aisel.aisnet.org/cais/vol15/iss1/39

Guba, E. G., \& Lincoln, Y. S. (2005). Paradigmatic controversies, contradictions, and emerging confluences. In N. Denzin (Ed.), The SAGE handbook of qualitative research (3rd ed., pp. 191-215). Thousand Oaks: Sage Publications.

Hanseth, O., \& Lyytinen, K. (2010). Design theory for dynamic complexity in information infrastructures: The case of building internet. Journal of Information Technology, 25(1), 1-19.

Hanseth, O, Aanestad, M., \& Berg, M. (2004). Guest editors' introduction: Actornetwork theory and information systems. What's so special? Information Technology \& People, 17(2), 116-123. doi:10.1108/09593840410542466

Hanseth, Ole, \& Monteiro, E. (1997). Inscribing behaviour in information infrastructure standards. Accounting, Management and Information Technologies, 7(4), 183211. doi:10.1016/S0959-8022(97)00008-8

Hanseth, Ole, \& Monteiro, E. (1998). Understanding information infrastructure. Unpublished Book, Http://heim. Ifi. Uio. No/ oleha/Publications/bok. Html.

Hanseth, Ole, Monteiro, E., \& Hatling, M. (1996). Developing information infrastructure: The tension between standardization and flexibility. Science, Technology \& Human Values, 21(4), $407-426$. doi:10.1177/016224399602100402

Hardy, C. A., \& Williams, S. P. (2008). E-government policy and practice: A theoretical and empirical exploration of public e-procurement. Government Information Quarterly, 25(2), 155-180. doi:10.1016/j.giq.2007.02.003

Harrison, M., \& Parlikad, A. K. (2006). Lifecycle ID and lifecycle data management AUTO-ID labs at MIT (Auto-ID Labs White Paper No. WP-BIZAPP-032). Auto-ID 
Labs. Retrieved from

http://autoid.mit.edu/CS/files/folders/whitepapers/entry3030.aspx

Harrop, P., \& Das, R. (2013). RFID forecasts, players and opportunities 2012-2022.

IDTechEx. Retrieved from http://www.idtechex.com/research/reports/rfid-

forecasts-players-and-opportunities-2012-2022-000322.asp

Hatch, M. J. (2012). Organization theory: Modern, symbolic and postmodern

perspectives. Oxford University press.

Holmes, D. (2001). eGov: eBusiness strategies for government. Naperville III.: Nicholas Brealey Pub.

Hossain, M. A., \& Quaddus, M. (2011). The adoption and continued usage intention of RFID: An integrated framework. Information Technology \& People, 24, 236-256. doi:10.1108/09593841111158365

Hovy, E. (2008). An outline for the foundation of digital government research. In Digital Government (Vol. 17). Springer US. Retrieved from http://dx.doi.org/10.1007/978-0-387-71611-4_1

Hudson, B., Hardy, B., Henwood, M., \& Wistow, G. (1999). In pursuit of inter-agency collaboration in the public sector - what is the contribution of theory and research? Public Management: An International Journal of Research and Theory, 1(2), 235. doi:10.1080/14719039900000005

Ifrah, G. (2001). The universal history of computing: From the abacus to the quantum computer. New York: John Wiley.

Ilie-Zudor, E., Kemény, Z., van Blommestein, F., Monostori, L., \& van der Meulen, A. (2011). A survey of applications and requirements of unique identification systems and RFID techniques. Computers in Industry, 62(3), 227. doi:10.1016/j.compind.2010.10.004

Irani, Z., Gunasekaran, A., \& Dwivedi, Y. K. (2010). Radio frequency identification (RFID): Research trends and framework. International Journal of Production Research, 48(9), 2485. doi:10.1080/00207540903564900

Iyamu, T., \& Tatnall, A. (2011). The impact of network of actors on the information technology. In A. Tatnall (Ed.), Actor-network theory and technology innovation: Advancements and new concepts (pp. 234-258). United States of America: Information Science Reference.

Jansen, A. (2011). E-government - just a matter of technology? In Proceedings of the 44th Hawaii International Conference on System Sciences.

Jepperson, R. L. (1991). Institutions, institutional effects, and institutionalism. In P. J. DiMaggio \& W. W. Powell (Eds.), The new institutionalism in organizational analysis (Vol. 6, pp. 143-163). Chicago: University Of Chicago Press.

Justesen, L., \& Mouritsen, J. (2011). Effects of actor-network theory in accounting research. Accounting, Auditing \& Accountability Journal, 24(2), 161-193.

Kaghan, W. N., \& Bowker, G. C. (2001). Out of machine age?: Complexity, sociotechnical systems and actor network theory. Journal of Engineering and 
Technology Management, 18(3-4), 253-269. doi:10.1016/S0923-

4748(01)00037-6

King, N. J., \& Jessen, P. W. (2010). Profiling the mobile customer - is industry self-

regulation adequate to protect consumer privacy when behavioural advertisers target mobile phones? - Part II. Computer Law \& Security Review, 26(6), 595612. doi:10.1016/j.clsr.2010.09.007

Klein, H. K., \& Myers, M. D. (1999). A set of principles for conducting and evaluating interpretive field studies in information systems. MIS Quarterly, 23(1), 67-93.

Konomi, S., \& Roussos, G. (2007). Ubiquitous computing in the real world: Lessons learnt from large scale RFID deployments. Personal Ubiquitous Computing, 11(7), 507-521.

Kopalchick III, J., \& Monk, C. (2005). RFID risk management. Internal Auditor, 62(2), 66-73.

Kourouthanassis, P. E., Giaglis, G. M., \& Karaiskos, D. C. (2010). Delineating "pervasiveness" in pervasive information systems: A taxonomical framework and design implications. Journal of Information Technology, 25(3), 273-287. doi:10.1057/jit.2009.6

Kros, J. F., Richey Jr., R. G., Chen, H., \& Nadler, S. S. (2011). Technology emergence between mandate and acceptance: An exploratory examination of RFID. International Journal of Physical Distribution \& Logistics Management, 41(7), 697-716. doi:10.1108/09600031111154143

Krotov, V., \& Junglas, I. (2008). RFID as a disruptive innovation. Journal of Theoretical and Applied Electronic Commerce Research, 3(2), 44.

Laeequddin, M., Sahay, B., Sahay, V., \& Waheed, K. A. (2012). Trust building in supply chain partners relationship: An integrated conceptual model. Journal of Management Development, 31(6), 550-564.

Lahiri, S. (2006). RFID sourcebook. Upper Saddle River NJ: IBM Press.

Langheinrich, M. (2001). Privacy by design - principles of privacy-aware ubiquitous systems. In Proceedings of the 3rd International Conference on Ubiquitous Computing (pp. 273-291). Atlanta, Georgia, USA: Springer-Verlag. Retrieved from

http://portal.acm.org.helicon.vuw.ac.nz/citation.cfm?id=741336\&dl=GUIDE\&c oll=GUIDE\&CFID=105735479\&CFTOKEN=72288629

Latour, B. (1987). Science in action: How to follow scientists and engineers through society. Cambridge, Mass.: Harvard University Press.

Latour, B. (1988). The pasteurization of France. Harvard University Press.

Latour, B. (1991). Technology is society made durable. In J. Law (Ed.), A Sociology of monsters: Essays on power, technology, and domination. Routledge.

Latour, B. (1992). Where are the missing masses, sociology of a few mundane artefacts. In W. Bijker \& J. Law (Eds.), Shaping technology building society: Studies in socio-technical change (pp. 225-259). 
Latour, B. (1993). We have never been modern. Cambridge Mass.: Harvard University Press.

Latour, B. (1999a). On recalling ANT. In J. Law \& J. Hassard (Eds.), Actor network theory and after (pp. 93-95). Oxford [England]; Malden MA: Blackwell/Sociological Review.

Latour, B. (1999b). Pandora's hope: Essays on the reality of science studies. Harvard University Press.

Latour, B. (2002). Aramis, or, the Love of Technology (4th ed.). Cambridge Mass.: Harvard University Press.

Latour, B. (2005). Reassembling the social: An introduction to actor-network theory. Oxford; New York: Oxford University Press.

Law, J. (1992). Notes on the theory of the actor-network: Ordering, strategy, and heterogeneity. Systems Practice, 5(4), 379-393. doi:10.1007/BF01059830

Law, J. (1999). After ANT: Complexity, naming and topology. In J. Hassard \& J. Law (Eds.), Actor network theory and after (pp. 1-14). Oxford [England]; Malden MA: Blackwell/Sociological Review.

Law, J. (2007). Actor network theory and material semiotics. Centre for Science Studies, Lancaster University, Disponible En Web:< Http://www. Heterogeneities. net/publications/Law-ANTandMaterialSemiotics. Pdf.

Law, J., \& Singleton, V. (2005). Object lessons. Organization, 12(3), 331 -355. doi:10.1177/1350508405051270

Lee, C.-P., \& Shim, J. P. (2007). An exploratory study of Radio Frequency Identification (RFID) adoption in the healthcare industry. European Journal of Information Systems, 16(6), 712-724. doi:10.1057/palgrave.ejis.3000716

Lee, S. M., Park, S.-H., Yoon, S. N., \& Yeon, S.-J. (2007). RFID based ubiquitous commerce and consumer trust. Industrial Management \& Data Systems, 107(5), 605-617. doi:10.1108/02635570710750381

Levinson, M. (2003). The RFID imperative; the adoption of RFID technology is inevitable. Its transformational promise, huge. But the success of RFID in your business depends on your infrastructure. Here's what you need to add to your holiday to-do list. $\mathrm{ClO}, 17(5), 1$.

Lewis, P. (2007). Using ANT ideas in the managing of systemic action research. Systems Research \& Behavioural Science, 24(6), 589-598.

Li, S., Godon, D., \& Visich, J. K. (2010). An exploratory study of RFID implementation in the supply chain. Management Research Review, 33(10), 1005-1015. doi:http://dx.doi.org.helicon.vuw.ac.nz/10.1108/01409171011084003

Li, S., Visich, J. K., Khumawala, B. M., \& Zhang, C. (2006). Radio frequency identification technology: Applications, technical challenges and strategies. Sensor Review, 26(3), 193-202.

Lincoln, Y. S., \& Guba, E. G. (1985). Naturalistic Inquiry (Vol. 75). Sage. 
Lindgren, I., \& Jansson, G. (2013). Electronic services in the public sector: A conceptual framework. Government Information Quarterly, 30(2), 163-172. doi:10.1016/j.giq.2012.10.005

Lounsbury, M. (2008). Institutional rationality and practice variation: New directions in the institutional analysis of practice. Accounting, Organizations and Society, 33(4-5), 349-361. doi:10.1016/j.aos.2007.04.001

Luhmann, N. (1979). Trust; and, power. Wiley Chichester.

Lyytinen, K., \& Yoo, Y. (2002). Introduction: Issues and challenges in ubiquitous computing. Communications of the ACM, 45(12), 62-65. doi:10.1145/585597.585616

Mahinderjit-Singh, M., \& Li, X. (2010). Trust in RFID-enabled supply-chain management. International Journal of Security and Networks, 5(2), 96-105.

Marche, S., \& McNiven, J. D. (2003). E-government and e-governance: The future isn't what it used to be. Canadian Journal of Administrative Sciences / Revue Canadienne Des Sciences de l'Administration, 20(1), 74-86.

Markus, M. L., Steinfield, C. W., Wigand, R. T., \& Minton, G. (2006). Industry-wide information systems standardization as collective action: The case of the U.S. residential mortgage industry. MIS Quarterly, 30, 439-465.

McKnight, W. (2007). The four pillars of RFID. DM Review, 17(10), 18.

McMillen, D. (2004). Privacy, confidentiality, and data sharing: Issues and distinctions. Government Information Quarterly, 21(3), 359-382. doi:10.1016/j.giq.2004.05.001

Meyer, J. W., \& Rowan, B. (1977). Institutionalized organizations: Formal structure as myth and ceremony. American Journal of Sociology, 340-363.

Michelfelder, D. P. (2010). Philosophy, privacy, and pervasive computing. Al \& Society: Knowledge, Culture and Communication, 25(1), 61-70. doi:10.1007/s00146009-0233-2

Mignerat, M., \& Rivard, S. (2009). Positioning the institutional perspective in information systems research. Journal of Information Technology, 24(4), 369391.

Miles, M. B., \& Huberman, A. M. (1994). Qualitative data analysis: An expanded sourcebook. Sage.

Miles, M. B., Huberman, A. M., \& Saldana, J. (2013). Qualitative data analysis: An expanded sourcebook (3rd ed.). Thousand Oaks: Sage Publications.

Miorandi, D., Sicari, S., De Pellegrini, F., \& Chlamtac, I. (2012). Internet of things: Vision, applications and research challenges. Ad Hoc Networks, 10(7), 1497-1516. doi:10.1016/j.adhoc.2012.02.016

Mol, A. (1999). Ontological politics. A word and some questions. In J. Law \& J. Hassard (Eds.), Actor network theory and after (pp. 74-89). Oxford [England]; Malden MA: Blackwell/Sociological Review. 
Monteiro, E., \& Ciborra, C. (2000). Actor-network theory and information infrastructure. In From control to drift: The dynamics of corporate information infrastructure (pp. 71-83). Oxford University Press. Retrieved from http://www.idi.ntnu.no/ ericm/ant.FINAL.htm

Mukerji, B., \& Palanisamy, R. (2011). The RFID technology adoption in e-Government: Issues and challenges. International Journal of Electronic Government Research, 7(1), 89-101. doi:10.4018/jegr.2011010106

Murakami, T. (2003). Establishing the ubiquitous network environment in Japan - from e-Japan to u-Japan (No. 66). NRI. Retrieved from http://www.nri.co.jp/english/opinion/papers/2003/np200366.html

Murphy, G. B., \& Blessinger, A. A. (2003). Perceptions of no-name recognition business to consumer e-commerce trustworthiness: The effectiveness of potential influence tactics. The Journal of High Technology Management Research, 14(1), 71-92. doi:10.1016/S1047-8310(03)00005-1

Myers, M. D. (2009). Qualitative research in business and management. Los Angeles: SAGE.

Navarrete, A. C., Mellouli, S., Pardo, T. A., \& Gil-Garcia, J. R. (2009). Information sharing at national borders: Extending the utility of border theory. In System Sciences, 2009. HICSS '09. 42nd Hawaii International Conference on (pp. 1-10).

Neuby, B. L., \& Rudin, E. (2008). Radio frequency identification: A panacea for governments? Public Organization Review, 8(4), 329-345.

New Zealand Government. Privacy Act (1993). Retrieved from http://www.legislation.govt.nz/act/public/1993/0028/latest/DLM296639.html

Ngai, E. W. T., Moon, K. K. L., Riggins, F. J., \& Yi, C. Y. (2008). RFID research: An academic literature review (1995-2005) and future research directions. International Journal of Production Economics, 112(2), 510-520. doi:10.1016/j.ijpe.2007.05.004

OECD. (1980). OECD Guidelines on the Protection of Privacy and Transborder Flows of Personal Data. Retrieved from http://www.oecd.org/internet/ieconomy/oecdguidelinesontheprotectionofpri vacyandtransborderflowsofpersonaldata.htm

Ohkubo, M., Suzuki, K., \& Kinoshita, S. (2005). RFID privacy issues and technical challenges. Communications of the ACM, 48(9), 66. doi:10.1145/1081992.1082022

Okhuysen, G., \& Bonardi, J.-P. (2011). The challenges of building theory by combining lenses. Academy of Management Review, 36(1), 6-11.

Oliver, C. (1991a). Strategic responses to institutional processes. Academy of Management Review, 16(1), 145-179. doi:10.2307/258610

Oliver, C. (1991b). Strategic Responses to Institutional Processes. The Academy of Management Review, 16(1), 145. doi:10.2307/258610 
Orlikowski, W. J., \& Barley, S. R. (2001). Technology and institutions: What can research on information technology and research on organizations learn from each other? MIS Quarterly, 25(2), 145-165.

Orlikowski, W. J., \& Baroudi, J. J. (1991). Studying information technology in organizations: Research approaches and assumptions. Information Systems Research, 2(1), 1-28. doi:10.1287/isre.2.1.1

Ostrom, E. (2005). Understanding institutional diversity. Princeton University Press.

Osyk, B. A., Vijayaraman, B. S., Srinivasan, M., \& Dey, A. (2012). RFID adoption and implementation in warehousing. Management Research Review, 35(10), 904926. doi:10.1108/01409171211272651

Oxford Dictionary. (2013). Oxford dictionary. Retrieved from https://www.oxforddictionaries.com/us/definition/american_english/publicsector

Parsons, D. W. (1995). Public policy: An introduction to the theory and practice of policy analysis. Aldershot, UK ; Brookfield, Vt., US: Edward Elgar.

Pelletier, M.-P., Trépanier, M., \& Morency, C. (2011). Smart card data use in public transit: A literature review. Transportation Research Part C: Emerging Technologies, In Press, Corrected Proof. doi:10.1016/j.trc.2010.12.003

Pindyck, R. S., \& Rubinfeld, D. L. (2009). Microeconomics (7th ed.). Upper Saddle River, N.J.: Pearson/Prentice Hall.

Pollack, J., Costello, K., \& Sankaran, S. (2013). Applying Actor-Network Theory as a sensemaking framework for complex organisational change programs. International Journal of Project Management. doi:10.1016/j.ijproman.2012.12.007

Powell, W. W., \& Colyvas, J. (2008). Microfoundations of institutional theory. In R. Greenwood, C. Oliver, R. Suddaby, \& K. Sahlin-Andersson (Eds.), The SAGE Handbook of Organizational Institutionalism (pp. 276-298). SAGE Publications Ltd.

Ramanathan, R., Ramanathan, U., \& Ko, L. W. L. (2013). Adoption of RFID technologies in UK logistics: Moderating roles of size, barcode experience and government support. Expert Systems with Applications.

RFID Institute. (2013a). About us | International RFID Institute. Retrieved October 21, 2013, from http://rfidinstitute.org/about-us/

RFID Institute. (2013b). Types of certifications | International RFID Institute. Retrieved October 21, 2013, from http://rfidinstitute.org/rfid-certifications/types-ofcertifications/?utm_medium=email\&utm_source=rfid+journal\&utm_campaign =3178916_RFIDInstituteSurvey_10-10-13\&dm_i=1JOI,1W4V8,9AWF09,6SCE3,1

Richards, L., \& Morse, J. M. (2007). Readme first for a user's guide to qualitative methods (2nd ed.). Thousand Oaks Calif.: Sage Publications.

Riggins, F. J., \& Slaughter, K. T. (2006). The role of collective mental models in IOS adoption: Opening the black box of rationality in RFID deployment. In 
Proceedings of the 39th Annual Hawaii International Conference on System Sciences (HICSS'06) (pp. 1-10). Kauia, HI, USA. doi:10.1109/HICSS.2006.479 Roberts, C. M. (2006). Radio frequency identification (RFID). Computers \& Security, 25(1), 18-26. doi:10.1016/j.cose.2005.12.003

Roberts, J. M. (2012). Poststructuralism against poststructuralism: Actor-network theory, organizations and economic markets. European Journal of Social Theory, 15(1), 35-53. doi:10.1177/1368431011423573

Rocheleau, B., \& Wu, L. (2002). Public versus private information systems. The American Review of Public Administration, 32(4), 379 -397. doi:10.1177/027507402237866

Rogers, E. M. (2003). Diffusion of innovations, $5^{\text {th }}$ edition. Simon and Schuster. Rosenberg, R. (2004). The social impact of computers (3rd ed.). Amsterdam; Boston: Elsevier Academic Press.

Rothfeder, J. (2004). What's wrong with RFID? All the promises made for RFID technology will eventually come true. But it will take longer than you think. $\mathrm{ClO}$ Insight, 1(42), 45.

Rousseau, D. M., Sitkin, S. B., Burt, R. S., \& Camerer, C. (1998). Not so different after all: A cross-discipline view of trust. The Academy of Management Review, 23(3), 393-404.

Roussos, G. (2006). Enabling RFID in retail. Computer, 39(3), 25-30. doi:10.1109/MC.2006.88

Rubin, H., \& Rubin, I. (2012). Qualitative interviewing: The art of hearing data (3rd ed.). Los Angeles, [Calif.]; London: Sage Publications.

Saha, D., \& Mukherjee, A. (2003). Pervasive computing: A paradigm for the 21st century. Computer, 36(3), 25-31. doi:10.1109/MC.2003.1185214

Santucci, G. (2010). The internet of things: Between the revolution of the internet and the metamorphosis of objects. European Commission. Retrieved from http://www.theinternetofthings.eu/content/g\%C3\%A9rald-santucci-internetthings-window-our-future

Sarma, S. (2004). Integrating RFID. Queue, 2(7), 50-57. doi:10.1145/1035594.1035620

Schindler, R. (2009). The disappearing computer. Brussels, Belgium: European Commission. Retrieved from http://www.ercim.eu/EU-NSF/DC.pdf

Scott, W. R. (2001). Institutions and organizations (2nd ed.). Thousand Oaks, Calif: Sage Publications.

Shah, R. C., \& Kesan, J. P. (2010). Software as governance. In E-government information, technology, and transformation (Vol. 17, pp. 125-140). Armonk N.Y.: M. E. Sharpe.

Sharma, S. K., \& Gupta, J. N. D. (2004). Web services architecture for m-government: Issues and challenges. Electronic Government, an International Journal, 1(4), 462-474. 
Shaw, R., \& Eichbaum, C. (2011). Public policy in New Zealand: institutions, processes and outcomes. Auckland, N.Z.: Pearson Education New Zealand.

Shin, D.-H., \& Lee, C.-W. (2011). Disruptive innovation for social change: How technology innovation can be best managed in social context. Telematics and Informatics, 28(2), 86-100. doi:10.1016/j.tele.2010.08.002

Sidorova, A., \& Kappelman, L. (2011). Better business-IT alignment through enterprise architecture: An actor-network theory perspective. Journal of Enterprise Architecture, 7(1), 39-47.

Slettemeas, D. (2009). RFID - the "next step" in consumer - product relations or Orwellian nightmare? Challenges for research and policy. Journal of Consumer Policy, 32(3), 219-244.

Smith, L. S. (2006). RFID and other embedded technologies: Who owns the data? Santa Clara Computer and High Technology Law Journal, 22, 695-755.

Spekman, R. E., \& Sweeney II, P. J. (2006). RFID: From concept to implementation. International Journal of Physical Distribution \& Logistics Management, 36(10), 736.

Sponge count. (2006). Communications of the ACM, 49(10), 10.

Sprague, C. (2008). Fulfilling the promise of e-government. KM World, S6.

Stake, R. E. (2005). Qualitative case studies. In N. Denzin (Ed.), The SAGE Handbook of Qualitative Research (3rd ed., pp. 443-466). Thousand Oaks: Sage Publications.

Stanford, V. (2003). Pervasive computing goes the last hundred feet with RFID systems. IEEE Pervasive Computing, 2(2), 9-14. doi:10.1109/MPRV.2003.1203746

Streitz, N. A. (2008). From cognitive compatibility to the disappearing computer: Experience design for smart environments. In Proceedings of the 15th European Conference on Cognitive Ergonomics: The Ergonomics of Cool Interaction (pp. 1-2). Funchal, Portugal: ACM. doi:10.1145/1473018.1473020

Streitz, N. A., \& Nixon, P. (2005). The disappearing computer. Communications of the ACM , 48(3), 32-35. doi:10.1145/1047671.1047700

Streitz, N. A., Rocker, C., Prante, T., van Alphen, D., Stenzel, R., \& Magerkurth, C. (2005). Designing Smart Artifacts for Smart Environments. Computer, 38(3), 41-49. doi:10.1109/MC.2005.92

Swedberg, C. (2011). RFID helps scientists study honey bees' homing behaviour. RFID Journal. Retrieved September 14, 2011, from http://www.rfidjournal.com/article/view/8466/

Tang, J. (2013). Designing an anti-swindle Mahjong leisure prototype system using RFID and Ontology Theory. Journal of Network and Computer Applications. doi:10.1016/j.jnca.2013.07.012

Taylor, D. (2009). The great "global crisis of maturity" and the new world order. Retrieved September 17, 2010, from http://www.oldthinkernews.com/Articles/oldthinker\%20news/global_crisis_of _maturity.htm 
Tejpal, G., Garg, R. K., \& Sachdeva, A. (2013). Trust among supply chain partners: A review. Measuring Business Excellence, 17(1), 51-71.

The European Commission. (2006). Your voice on RFID: Background document for public consultation on radio frequency identification (RFID). European Commission. Retrieved from http://www.rfidconsultation.eu/

The RFID Reader. (2006). RFID enabled passports. RFID Reader. Retrieved October 11, 2013, from http://www.therfidreader.com/2005/12/rfid_enabled_pa.html

Thiesse, F., Al-Kassab, J., \& Fleisch, E. (2009). Understanding the value of integrated RFID systems: A case study from apparel retail. European Journal of Information Systems, 18(6), 592-614. doi:10.1057/ejis.2009.33

Thiesse, F., Floerkemeier, C., Harrison, M., Michahelles, F., \& Roduner, C. (2009). Technology, standards, and real-world deployments of the EPC network. IEEE Internet Computing, 13(2), 36.

Thomas, D. R. (2006). A general inductive approach for analyzing qualitative evaluation data. American Journal of Evaluation, 27(2), 237 -246. doi:10.1177/1098214005283748

Tilson, D. A. (2008). The interrelationships between technical standards and industry structures: Actor-network based case studies of the mobile wireless and television industries in the US and the UK (PhD dissertation). Caase Western Reserve University.

Ting, S. L., Kwok, S. K., Tsang, A. H. C., \& Lee, W. B. (2011). Critical elements and lessons learnt from the implementation of an RFID-enabled healthcare management system in a medical organization. Journal of Medical Systems, 35(4), 657-669. doi:10.1007/s10916-009-9403-5

Treglia, J. V., \& Park, J. S. (2009). Towards trusted intelligence information sharing. In Proceedings of the ACM SIGKDD Workshop on Cyber Security and Intelligence Informatics (pp. 45-52). Paris, France: ACM. doi:10.1145/1599272.1599283

United Nations. (2006). Legal issues of RFID technology. United Nations. Retrieved from

http://www.rfidconsultation.eu/docs/ficheiros/Legal_issues_of_RFID_technolo gy_LEGAL_IST.pdf

United Nations. (2007). Managing knowledge to build trust in government. United Nations Department of Economic and Social Affairs. Retrieved from http://unpan1.un.org/intradoc/groups/public/documents/un/unpan028460.pd $f$

Van de Ven, A. H. (2005). Running in packs to develop knowledge-intensive technologies. MIS Quarterly, 29(2), 365.

Van Lieshout, M., \& Kool, L. (2007). RFID technologies: Emerging issues and challenges. In Expanding the knowledge economy: Issues, applications, case studies. IOS Press. 
Venkatraman, N. (1994). IT-enabled business transformation: from automation to business scope redefinition. Sloan Management Review, 35, 73-73.

Vidgen, R., \& McMaster, T. (1996). Black boxes, non-human stakeholders and the translation of IT through mediation. In W. Orlikowski, G. Walsham, M. R. Jones, \& J. I. DeGross (Eds.), Information Technology and Changes in Organizational Work: Proceedings of the IFIP WG8.2 Working Conference on Information Technology and Changes in Organizational Work, December 1995 (pp. 250271). London: Chapman \& Hall on behalf of the International Federation for Information Processing (IFIP).

Vlad, M., Parvulet, R. A., Vlad, M. S., \& Pivoda, C. A. (2012). A survey of livestock identification systems (pp. 165-170). Presented at the Proceedings of the 13th WSEAS International Conference on Automation and Information,(ICAI12). Iasi, Romania: WSEAS Press.

Vosselman, E. (2012). Approaching control in interfirm transactional relationships: Contrasting and connecting a transaction cost economics perspective with an actor-network theory perspective. Qualitative Research in Accounting \& Management, 9(1), 4-20. doi:10.1108/11766091211216088

Waldorff, S. B. (2013). Accounting for organizational innovations: Mobilizing institutional logics in translation. Scandinavian Journal of Management, 29(3), 219-234. doi:10.1016/j.scaman.2013.03.010

Walsham, G. (1997). Actor-network theory and IS research: Current status and future prospects. In A. S. Lee, J. Liebenau, \& J. I. DeGross (Eds.), Information systems and qualitative research : proceedings of the IFIP TC8 WG 8.2 International Conference on Information Systems and Qualitative Research, 31st May-3rd June 1997, Philadelphia,. London: Chapman \& Hall.

Wamba, S. F. (2012). RFID-enabled healthcare applications, issues and benefits: An archival analysis (1997-2011). Journal of Medical Systems, 36(6), 3393-8. doi:http://dx.doi.org.helicon.vuw.ac.nz/10.1007/s10916-011-9807-x

Wamba, S. F., \& Chatfield, A. T. (2009). A contingency model for creating value from RFID supply chain network projects in logistics and manufacturing environments. European Journal of Information Systems, 18(6), 615-636. doi:10.1057/ejis.2009.44

Wamba, S. F., \& Chatfield, A. T. (2010). The impact of RFID technology on warehouse process innovation: A pilot project in the TPL industry. Information Systems Frontiers, 13(5), 693-706. doi:10.1007/s10796-010-9246-0

Warkentin, M., Gefen, D., Pavlou, P. A., \& Rose, G. M. (2001). Encouraging citizen adoption of e-government by building trust. Electronic Markets, 12(3), 157. doi:10.1080/101967802320245929

Warren, S. D., \& Brandeis, L. D. (1890). The right to privacy. Harvard Law Review, 4(5), 193-220. 
Weiser, M. (1991). The computer for the 21st century. Scientific American, 265(3), 94. Welbourne, E., Battle, L., Cole, G., Gould, K., Rector, K., Raymer, S., ... Borriello, G. (2009). Building the internet of things using RFID: The RFID ecosystem experience. IEEE Internet Computing, 13(3), 48-55.

Whitaker, J., Mithas, S., \& Krishnan, M. (2009). A field study of RFID deployment and return expectations. Production and Operations Management, 16(5), 599.

Wilson, M. W. (2012). Location-based services, conspicuous mobility, and the locationaware future. Geoforum, 43(6), 1266-1275. doi:10.1016/j.geoforum.2012.03.014

World Bank. (2004). Building blocks of e-government: lessons from developing countries (No. 91). Retrieved from http://www1.worldbank.org/prem/PREMNotes/premnote91.pdf

Wu, N. C., Nystrom, M. A., Lin, T. R., \& Yu, H. C. (2006). Challenges to global RFID adoption. Technovation, 26(12), 1317-1323. doi:10.1016/j.technovation.2005.08.012

Wyld, D. C. (2005). RFID: The right frequency for government. IBM Center for The Business of Government. Retrieved from http://www.businessofgovernment.org/report/rfid-right-frequencygovernment

Xiao, Y., Yu, S., Wu, K., Ni, Q., Janecek, C., \& Nordstad, J. (2007). Radio frequency identification: Technologies, applications, and research issues. Wireless Communications and Mobile Computing, 7(4), 457-472.

Yang, T.-M., \& Pardo, T. A. (2011). How is information shared across boundaries? In Proceedings of the 44th Hawaii International Conference on System Sciences (pp. 1-10).

Yao, W., Chu, C. H., \& Li, Z. (2011). The adoption and implementation of RFID technologies in healthcare: A literature review. J Med Syst. Retrieved from http://www.springerlink.com/index/pdf/10.1007/s10916-011-9789-8

Ye, J., Dobson, S., \& Nixon, P. (2008). An overview of pervasive computing systems. In Augmented materials and smart objects: Building ambient intelligence with microsystems (pp. 3-17). Springer-Verlag. Retrieved from http://dx.doi.org.helicon.vuw.ac.nz/10.1007/978-0-387-46264-6_1

Yin, R. (2009). Case study research: Design and methods (4th ed.). Los Angeles Calif.: Sage Publications.

Yoo, Y. (2010). Computing in everyday life: A call for research on experiential computing. MIS Quarterly, 34(2), 213-231.

Yoong, P. (2010). Leadership in the Digital Enterprise: Issues and Challenges. Business Science Reference.

Yu, C. C., \& Hu, P. J. . (2007). Rethinking the relationship between ubiquitous government and electronic government. Presented at the 11th Pacific-Asia Conference on Information System. 
Zhou, W., \& Piramuthu, S. (2010). Framework, strategy and evaluation health care processes with RFID. Decision Support Systems, 50(1), 222-233. doi:10.1016/j.dss.2010.08.003

Zorzi, M., Gluhak, A., Lange, S., \& Bassi, A. (2010). From today's intranet of things to a future internet of things: A wireless-and mobility-related view. Wireless Communications, IEEE, 17(6), 44-51. 


\section{Appendix A - Inductive Coding Table}

\begin{tabular}{|c|c|}
\hline Code & Description \\
\hline \multicolumn{2}{|l|}{ Sector Interaction } \\
\hline Sector Interaction & $\begin{array}{l}\text { Observations about the interaction of organisations in } \\
\text { the RFID network. }\end{array}$ \\
\hline $\begin{array}{l}\text { Sector Interaction - Getting } \\
\text { Agreement }\end{array}$ & Organisations work together to get agreement. \\
\hline $\begin{array}{l}\text { Sector Interaction - Individual } \\
\text { Based }\end{array}$ & $\begin{array}{l}\text { Where individuals are seen to represent } \\
\text { organisations. }\end{array}$ \\
\hline $\begin{array}{l}\text { Sector Interaction - Perception } \\
\text { of Public Sector }\end{array}$ & $\begin{array}{l}\text { How the public sector is seen or perceived, either by } \\
\text { the private sector, or within the public sector. }\end{array}$ \\
\hline $\begin{array}{l}\text { Sector Interaction - Perception } \\
\text { of Private Sector }\end{array}$ & $\begin{array}{l}\text { How the private sector is seen or perceived, either by } \\
\text { the public sector, or within the private sector. }\end{array}$ \\
\hline $\begin{array}{l}\text { Sector Interaction - Public } \\
\text { Funding }\end{array}$ & $\begin{array}{l}\text { How organisations pursue or obtain public sector } \\
\text { funding for RFID implementations. }\end{array}$ \\
\hline $\begin{array}{l}\text { Sector Interaction - Public- } \\
\text { Private Comparison }\end{array}$ & $\begin{array}{l}\text { Comparison of public and private sector } \\
\text { organisations. }\end{array}$ \\
\hline $\begin{array}{l}\text { Sector Interaction - Public- } \\
\text { Private the Same }\end{array}$ & $\begin{array}{l}\text { Where public and private sector organisations act or } \\
\text { are perceived to act in the same way. }\end{array}$ \\
\hline $\begin{array}{l}\text { Sector Interaction - Role of } \\
\text { Government }\end{array}$ & $\begin{array}{l}\text { The perceived or stated role of government within the } \\
\text { RFID network. }\end{array}$ \\
\hline $\begin{array}{l}\text { Sector Interaction - Third } \\
\text { Parties }\end{array}$ & $\begin{array}{l}\text { How the implementations or systems work with third } \\
\text { parties (parties that might not normally be involved } \\
\text { with the network). }\end{array}$ \\
\hline $\begin{array}{l}\text { Sector Interaction - Working } \\
\text { Together }\end{array}$ & How the organisations work together. \\
\hline
\end{tabular}

\begin{tabular}{|l|l|}
\hline \multicolumn{2}{|l|}{ Network Mediators } \\
\hline Finance & Cost associated with the RFID network. \\
\hline Finance - Cost & Comparison of the cost of RFID and Barcode systems. \\
\hline Comparison & How cost is imposed on one sector or organisation by \\
Finance - Cost Imposition & $\begin{array}{l}\text { Cost of RFID systems and willingness to pay, related to } \\
\text { the criticality or otherwise of the system. }\end{array}$ \\
\hline Finance - Criticality & Funding/financing of RFID systems. \\
\hline Finance - Funding & $\begin{array}{l}\text { Cost of RFID related infrastructure including tags, } \\
\text { readers, data storage etc. }\end{array}$ \\
\hline Finance - Cost Infrastructure &
\end{tabular}




\begin{tabular}{|c|c|}
\hline Finance - Cost Sharing & $\begin{array}{l}\text { Sharing and/or allocation of costs between members } \\
\text { of the RFID system. }\end{array}$ \\
\hline \multicolumn{2}{|l|}{ Infrastructure } \\
\hline Infrastructure & Infrastructure associated with the RFID network. \\
\hline Infrastructure - Design & $\begin{array}{l}\text { Covers the design of the RFID system infrastructure, } \\
\text { placement of equipment and simplicity. }\end{array}$ \\
\hline Infrastructure - Environment & $\begin{array}{l}\text { Environment in which the RFID infrastructure is } \\
\text { operating, includes humidity, presence of metals, } \\
\text { location etc. }\end{array}$ \\
\hline Infrastructure - Health Concerns & $\begin{array}{l}\text { Health concerns associated with human exposure to } \\
\text { RFID systems. }\end{array}$ \\
\hline Infrastructure - Standards & $\begin{array}{l}\text { Standards related specifically to RFID infrastructure } \\
\text { tags, readers, transmission spectrum. Does not } \\
\text { include data. }\end{array}$ \\
\hline Infrastructure - Tag & $\begin{array}{l}\text { Infrastructure comments related specifically to RFID } \\
\text { tags. }\end{array}$ \\
\hline \multicolumn{2}{|l|}{ Organisational Knowledge } \\
\hline Organisational Knowledge & $\begin{array}{l}\text { The amount of knowledge an organisation has related } \\
\text { to RFID. }\end{array}$ \\
\hline $\begin{array}{l}\text { Organisational Knowledge - } \\
\text { Public Perception }\end{array}$ & $\begin{array}{l}\text { Perception the public has of RFID systems, and how } \\
\text { organisations respond to that perception. Includes } \\
\text { negative perceptions. }\end{array}$ \\
\hline $\begin{array}{l}\text { Organisational Knowledge - } \\
\text { Training }\end{array}$ & $\begin{array}{l}\text { Training provide to, or needed by, organisations in } \\
\text { order to understand or use their RFID systems. }\end{array}$ \\
\hline \multicolumn{2}{|l|}{ Standards } \\
\hline Standards - Compliance & $\begin{array}{l}\text { Why and how organisations comply or decide to } \\
\text { comply with standards. }\end{array}$ \\
\hline Standards - Cost & Cost of implementing standards specifically. \\
\hline Standards - Criticality & $\begin{array}{l}\text { The need for standards related to the criticality of the } \\
\text { application. }\end{array}$ \\
\hline Standards - Hardware & $\begin{array}{l}\text { Standards, standards setting etc related to RFID } \\
\text { systems hardware. }\end{array}$ \\
\hline Standards - International & $\begin{array}{l}\text { Standards at the international level, including } \\
\text { international organisations. }\end{array}$ \\
\hline Standards - Proprietary & $\begin{array}{l}\text { Standards specific to a particular implementation, not } \\
\text { designed or intended to be shared outside that } \\
\text { system. }\end{array}$ \\
\hline Standards - Private Sector & $\begin{array}{l}\text { Standards related specifically to private sector } \\
\text { attitudes, implementation and knowledge }\end{array}$ \\
\hline Standards - Public Sector & $\begin{array}{l}\text { Standards related specifically to public sector } \\
\text { attitudes, implementation and knowledge }\end{array}$ \\
\hline
\end{tabular}




\begin{tabular}{|c|c|}
\hline Standards - Setting & $\begin{array}{l}\text { Setting of standards, including those shared between } \\
\text { public and private sectors. }\end{array}$ \\
\hline \multicolumn{2}{|l|}{ Intra-Organisational Mediators } \\
\hline \multicolumn{2}{|l|}{ Data Sharing } \\
\hline Data Sharing & Data sharing associated with the RFID network. \\
\hline Data Sharing - Anonymisation & $\begin{array}{l}\text { Anonymisation of data could lead to increased data } \\
\text { sharing. }\end{array}$ \\
\hline Data Sharing - Cross Sector & Data sharing across sectors. \\
\hline Data Sharing - Privacy & $\begin{array}{l}\text { Privacy issues related specifically to the sharing of } \\
\text { data and information. }\end{array}$ \\
\hline $\begin{array}{l}\text { Data Sharing - Secure to Non } \\
\text { Secure }\end{array}$ & $\begin{array}{l}\text { Sharing of data and information between secure and } \\
\text { non secure environments. }\end{array}$ \\
\hline Data Sharing - Cross Jurisdiction & Privacy Legislation, development and application. \\
\hline \multicolumn{2}{|l|}{ Privacy } \\
\hline Privacy & $\begin{array}{l}\text { General discussion of privacy associated with the RFID } \\
\text { network. }\end{array}$ \\
\hline Privacy-Access & Access to information or data, in the privacy context. \\
\hline Privacy - Data Sharing & $\begin{array}{l}\text { Relates to the privacy issues surrounding the sharing } \\
\text { of data and information between organisations or } \\
\text { individuals. }\end{array}$ \\
\hline Privacy - International & International privacy related issues. \\
\hline Privacy - Data Storage & $\begin{array}{l}\text { Privacy issues surrounding the storage of data, } \\
\text { including jurisdiction. }\end{array}$ \\
\hline Privacy - Legislation & Privacy Legislation, development and application. \\
\hline Privacy - Nature of Data & $\begin{array}{l}\text { The nature of data being collected or stored in RFID } \\
\text { systems. Its origin and sensitivity. }\end{array}$ \\
\hline Privacy - Private Sector & Privacy in the private sector context. \\
\hline Privacy - Public Sector & Privacy in the public sector context. \\
\hline Privacy-Purpose of Collection & $\begin{array}{l}\text { The purpose for which data was collected, or about } \\
\text { the relevance of purpose of collection. }\end{array}$ \\
\hline Privacy - Sector Differences & $\begin{array}{l}\text { Highlights the differences between sectors in their } \\
\text { treatment of privacy related issues. }\end{array}$ \\
\hline Privacy - Self Regulation & $\begin{array}{l}\text { Self regulation of privacy matters, as opposed to } \\
\text { legislated regulation. }\end{array}$ \\
\hline Privacy - Voluntariness & $\begin{array}{l}\text { Covers the voluntariness of interaction with the public } \\
\text { sector. }\end{array}$ \\
\hline
\end{tabular}




\begin{tabular}{|c|c|}
\hline \multicolumn{2}{|l|}{ Security } \\
\hline Security & Security of or associated with the RFID network. \\
\hline Security - Internet of Things & $\begin{array}{l}\text { Security related specifically to the RFID in the Internet } \\
\text { of Things context. }\end{array}$ \\
\hline Security - Necessity & The necessity of security in particular RFID systems. \\
\hline Security - Private Sector & Security in the private sector context. \\
\hline Security - Public Sector & Security in the public sector context. \\
\hline \multicolumn{2}{|l|}{ Trust } \\
\hline Trust & $\begin{array}{l}\text { General discussion of trust associated with the RFID } \\
\text { network. }\end{array}$ \\
\hline Trust - Between Sectors & Trust between public and private sector entities. \\
\hline Trust - Building & $\begin{array}{l}\text { The building of trust between organisations and } \\
\text { individuals. }\end{array}$ \\
\hline Trust - Internet of Things & Trust in the context of the Internet of Things. \\
\hline Trust - Loss & Loss of trust between organisations and individuals. \\
\hline \multicolumn{2}{|l|}{ Intra-Organisational Mediators } \\
\hline \multicolumn{2}{|l|}{ Benefits } \\
\hline Benefits & $\begin{array}{l}\text { Description of actual benefit derived from } \\
\text { implementation of RFID system. }\end{array}$ \\
\hline Business Case & $\begin{array}{l}\text { Case written to support the implementation of RFID } \\
\text { system. }\end{array}$ \\
\hline Benefits - Discovery/Realisation & $\begin{array}{l}\text { How the organisation found the benefits, or how } \\
\text { benefits arose, as a result of RFID implementation. }\end{array}$ \\
\hline \multicolumn{2}{|l|}{ Data Management } \\
\hline Data Management & Data management associated with the RFID network. \\
\hline $\begin{array}{l}\text { Data Management - Data } \\
\text { Appropriateness }\end{array}$ & $\begin{array}{l}\text { How the nature of the data being gathered and its } \\
\text { appropriateness to the task for which it is being used. }\end{array}$ \\
\hline $\begin{array}{l}\text { Data Management - Negative } \\
\text { Data }\end{array}$ & $\begin{array}{l}\text { How data that is perceived to be negative is received } \\
\text { by the organisation. }\end{array}$ \\
\hline Data Management - Using Data & The specifics of using data generated by RFID systems. \\
\hline
\end{tabular}




\begin{tabular}{|l|l|}
\hline \multicolumn{2}{|l|}{ Organisational Management } \\
\hline Organisational Management & $\begin{array}{l}\text { Organisational management associated with the RFID } \\
\text { network. }\end{array}$ \\
\hline $\begin{array}{l}\text { Organisational Management - } \\
\text { Agreement }\end{array}$ & $\begin{array}{l}\text { Organisational management involved in getting } \\
\text { agreement. }\end{array}$ \\
\hline $\begin{array}{l}\text { Organisational Management - } \\
\text { Change }\end{array}$ & $\begin{array}{l}\text { How organisations deal with the issues and } \\
\text { complexities surrounding the changes required by } \\
\text { RFID implementation. }\end{array}$ \\
\hline $\begin{array}{l}\text { Organisational Management - } \\
\text { Governance }\end{array}$ & How governance affects RFID systems. \\
\hline $\begin{array}{l}\text { Organisational Management - } \\
\text { Management Support }\end{array}$ & $\begin{array}{l}\text { How support from various management layers affects } \\
\text { RFID implementation and system. }\end{array}$ \\
\hline $\begin{array}{l}\text { Organisational Management - } \\
\text { Staff }\end{array}$ & $\begin{array}{l}\text { How the treatment and attitudes of staff affect RFID } \\
\text { networks. }\end{array}$ \\
\hline
\end{tabular}





\section{Appendix B - Deductive Coding Table}

\begin{tabular}{|c|c|}
\hline Code & Description \\
\hline \multicolumn{2}{|l|}{ Actor-Network Theory } \\
\hline Black Box & $\begin{array}{l}\text { Where an actant, object, organisation is accepted as it } \\
\text { stands and thought to be unchanging. }\end{array}$ \\
\hline Focal Actant & $\begin{array}{l}\text { The initial actant within a network, which organises } \\
\text { and runs the translation. }\end{array}$ \\
\hline Inscription & $\begin{array}{l}\text { A program or action written into a technology or } \\
\text { artefact. }\end{array}$ \\
\hline Intermediary & A predictable element of the network. \\
\hline Mediator & $\begin{array}{l}\text { Something of which the input is not a good predictor } \\
\text { of the output, can cause unexpected results. }\end{array}$ \\
\hline Multiplicity & Indicates more than one aspect of an actant. \\
\hline Obligatory Passage Point & $\begin{array}{l}\text { A point through that must be passed in order for the } \\
\text { translation to progress. }\end{array}$ \\
\hline Punctualisation & $\begin{array}{l}\text { Part of the network is simplified and assumed to act } \\
\text { in the same way. }\end{array}$ \\
\hline Offer Response - Acceptance & $\begin{array}{l}\text { Where an actant accepts the offer of enrolment } \\
\text { during translation. }\end{array}$ \\
\hline Offer Response - Disregard & $\begin{array}{l}\text { Where an actant disregards or ignores the offer of } \\
\text { enrolment during translation. }\end{array}$ \\
\hline Offer Response - Dispute & $\begin{array}{l}\text { Where an actant disputes the offer of enrolment } \\
\text { during translation. }\end{array}$ \\
\hline Translation - Problematisation & $\begin{array}{l}\text { The stage of translation where the focal actant } \\
\text { describes the problem. }\end{array}$ \\
\hline Translation - Interessement & $\begin{array}{l}\text { The stage of translation where the focal actant } \\
\text { attempts to interest others. }\end{array}$ \\
\hline Translation - Enrolment & The stage of translation where roles are defined. \\
\hline Translation - Mobilisation & $\begin{array}{l}\text { The stage of translation where the focal actant works } \\
\text { to ensure that others remain enrolled. }\end{array}$ \\
\hline \multicolumn{2}{|l|}{ Institutional Theory } \\
\hline Coercion & $\begin{array}{l}\text { Pressure from formal or informal requirements, } \\
\text { regulation. }\end{array}$ \\
\hline Mimetic & Pressure to conform to what others are doing. \\
\hline Normative & $\begin{array}{l}\text { Pressure to follow the dictates of standards or } \\
\text { professional bodies. }\end{array}$ \\
\hline
\end{tabular}




\begin{tabular}{|l|l|}
\hline $\begin{array}{l}\text { Pressure Response - } \\
\text { Acquiescence }\end{array}$ & Compliance with pressures for perceived good. \\
\hline $\begin{array}{l}\text { Pressure Response - } \\
\text { Compromise }\end{array}$ & $\begin{array}{l}\text { Compliance with institutional pressures through } \\
\text { compromise. }\end{array}$ \\
\hline Pressure Response - Avoidance & $\begin{array}{l}\text { Action taken to avoid complying with institutional } \\
\text { pressures. }\end{array}$ \\
\hline Pressure Response - Defiance & $\begin{array}{l}\text { Defiance of, ignoring, or dismissing institutional } \\
\text { pressures. }\end{array}$ \\
\hline $\begin{array}{l}\text { Pressure Response - } \\
\text { Manipulation }\end{array}$ & $\begin{array}{l}\text { Attempting to deflect institutional pressures through } \\
\text { attempting to control or manipulate. }\end{array}$ \\
\hline RFID Codes & $\begin{array}{l}\text { Older form of identification technology based on a } \\
\text { printed bar code. Identifies to product type. }\end{array}$ \\
\hline Bar Code & $\begin{array}{l}\text { Abbreviation for Electronic Product Code, a individual } \\
\text { item level identification code. }\end{array}$ \\
\hline EPC & $\begin{array}{l}\text { Abbreviation for Electronic Product Code Information } \\
\text { System, a middleware system carrying details } \\
\text { associated with each EPC. }\end{array}$ \\
\hline EPCIS & $\begin{array}{l}\text { Other numbering schemes used to individually } \\
\text { identify RFID enabled items. }\end{array}$ \\
\hline Other Numbering Scheme & Device to read RFID tags. \\
\hline Reader & RFID tag. \\
\hline Tag &
\end{tabular}




\title{
11 Appendix C - Contact Summary Sheet
}

\author{
Summary \\ Contact Type: \\ Contact Date: $\quad$ Today's Date: \\ Contact Name: Contact Location: \\ Contact Organisation:
}

1. Main issues or themes in this contact:

2. Summary of information gained (or not gained) in each target area:

a. Demographics

b. How the organisation became involved with RFID?

c. How RFID is used?

d. How RFID interacts with other organisations?

e. How will it be used in the future?

f. Other contacts

3. Anything else salient, interesting, illuminating or important in this contact?

4. Follow up required or new (or remaining) target questions in considering the next contact with this site?

5. Thoughts generated by coding 



\section{Appendix D - Consent to Participate}

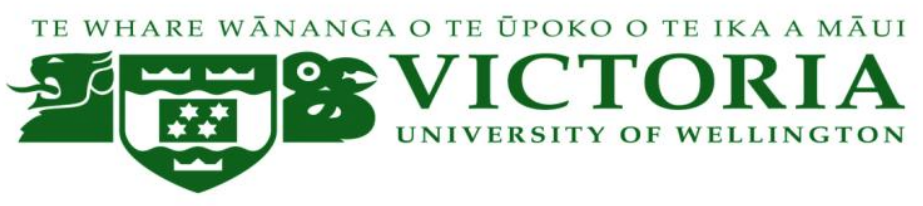

Consent to Participation in Research

I have been given, and understood, an explanation of this research project.

I have had an opportunity to ask questions and I am satisfied with the answers I received.

I understand that I can withdraw myself (or any information I provide) from this project before $1^{\text {st }}$ August 2012, by contacting the researcher. In this case all the information I provided will be excluded from the study.

I understand that this research is funded by, but independent of, GS1 New Zealand.

] I understand that any information I provide will only be accessed by the researcher and her supervisors.

$\square \quad$ I am aware that the published results will not use my name; however my position title may be used unless otherwise requested.

$\square$ I understand that the digital recording and transcriptions of interviews will be kept secure at all times, as will any documents I give to the researcher.

$\square \quad$ I understand that I may review the transcript of my interview and will be able to make clarifications and corrections if necessary.

$\square \quad$ I understand that the data I provide will not be used for any other purpose or released to others, including GS1 New Zealand.

I understand that I will receive a summary of findings on completion of the project.

I consent to participate in this research project.

Signed:

Date:

Name: 



\section{Appendix E - Glossary}

\begin{tabular}{|l|l|}
\hline Term & Definition \\
\hline Actor-Network Theory (ANT) & $\begin{array}{l}\text { Theory developed primarily by Bruno Latour, John Law and } \\
\text { Michael Callon, which believes everything (human and non- } \\
\text { human alike) has agency and can act in a social network. }\end{array}$ \\
\hline AIDC & $\begin{array}{l}\text { Abbreviation for Automatic Identification and Data Capture } \\
\text { - technology used to automatically identify items, for } \\
\text { example RFID technology. }\end{array}$ \\
\hline EPC & $\begin{array}{l}\text { Abbreviation for Electronic Product Code - the unique code } \\
\text { by which items can be identified using RFID technology. }\end{array}$ \\
\hline ERP & $\begin{array}{l}\text { Abbreviation for Enterprise Resource Planning - the process } \\
\text { by which organisations electronically manage their } \\
\text { business. }\end{array}$ \\
\hline IFF & $\begin{array}{l}\text { Abbreviation for Identify Friend or Foe, a very early RFID } \\
\text { type technology in which aircraft were identified as friendly } \\
\text { or not during World War 2. }\end{array}$ \\
\hline Internet of Things & $\begin{array}{l}\text { Theory that describes how various pressures act on } \\
\text { institutions in order to modify their behaviours. }\end{array}$ \\
\hline Performativity & $\begin{array}{l}\text { The network of uniquely and automatically identified } \\
\text { artefacts, joined together through the internet. }\end{array}$ \\
\hline RFID & $\begin{array}{l}\text { The actions taken in order to establish (or perform) an } \\
\text { identity or thing. }\end{array}$ \\
\hline Supply Chain & $\begin{array}{l}\text { Abbreviation for Radio Frequency Identification, a } \\
\text { technology for uniquely and automatically identifying } \\
\text { artefacts or objects. }\end{array}$ \\
\hline $\begin{array}{l}\text { The flow of products, materials and items from their raw } \\
\text { components, through manufacture and sale. }\end{array}$ \\
\hline
\end{tabular}

${ }^{19}$ Note that ANT and Institutional Theory are defined in the Deductive Coding table in Appendix B 